\title{
POST-OCCUPANCY EVALUATION OF SEVERAL U.S. GOVERNMENT BUILDINGS
}

\section{Belinda L. Collins Gary L. Gillette Mubarak S. Dahir Peter J. Goodin}

\section{U.S. DEPARTMENT OF COMMERCE National institute of Standards and Technology National Englneering Laboratory Center for Building Technology Gaithersburg, MD 20899}


WATIONAL INSTITUTE OF STANDARDS \&

TECHNOLOGY

Research Information Center

Gaithersburg, MD 20899

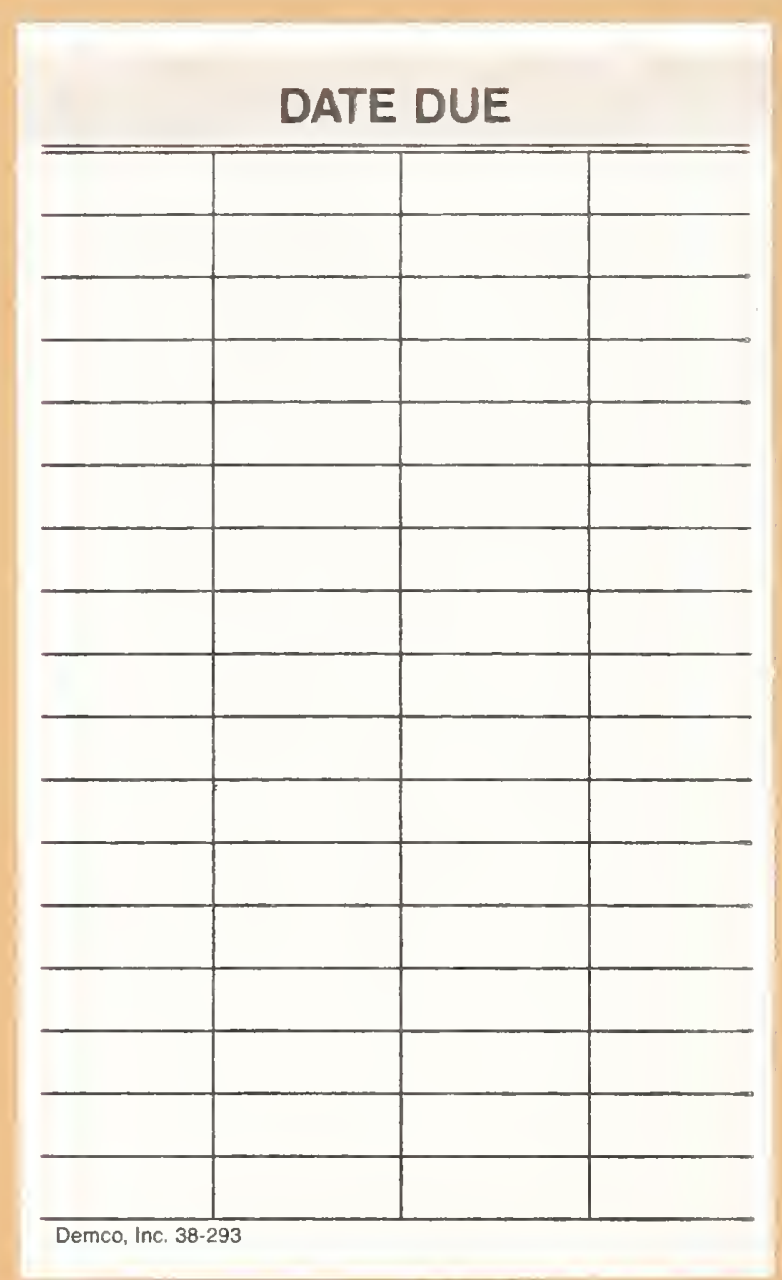




\section{Belinda L. Collins}

Gary L. Gillette

Mubarak S. Dahir

Peter J. Goodin

U.S. DEPARTMENT OF COMMERCE National Institute of Standards and Tochnology

National Engineering Laboratory Center for Building Tochnology

Gaithersburg, MD 20899

Prepared for.

U.S. Army Communications -

Electronles Support Facillty

Vint HIII Farms Station

Warrenton, VA 22186-5141

September 1989

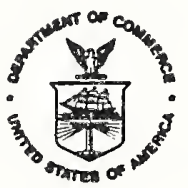

U.S. DEPARTMENT OF COMMERCE Robert A. Mosbacher, Secrotary NATIONAL INSTITUTE OF STANDARDS AND TECHMOLOGY

Raymond C. Kammer, Acting Director 
. 


\section{ABSTRACT}

A post-occupancy evaluation was performed on five small, low-rise U.S. government office buildings at a site south of Washington, D.C. The study recorded occupant response to indoor environmental conditions including lighting, space, noise, and indoor air quality; and provided recommendations for improvements to the facilities. In addition, a comparison was made of environmental conditions before and after renovation of one of the buildings. The study employed a questionnaire about the environmental conditions, physical measures of the space (lighting, space, noise, temperature, etc.), and interviews with personnel at the site. A total of 308 people participated (including measures before and after the renovation) and physical measures were taken at 92 work stations. Analysis of the physical measurement data indicated problems with limited space, lack of adjustable task lighting, and perceptions of poor indoor air quality in two of the buildings. The renovation was perceived to have improved the appearance of one building substantially, however. Suggestions for improvements to the buildings at the site were also made.

\section{KEYWORDS :}

Automation, contrast, environmental assessment, indoor air quality, lighting, luminance, noise, post-occupancy evaluation, temperature, VDT's. 
This report summarizes research conducted from September 1987 to June 1989, under contract Number WF 3HYC7237-7-164.

\section{ACKNOWLEDGEMENTS}

The authors wish to thank Ms. Belinda kuo for her efforts in the data transcription and initial analysis, Dr. Arthur Rubin for his assistance in the initial phases of the study and detailed review of the first draft, and Dr. Francis Ventre for his insights and critique of the final draft. The authors also wish to thank all the people at the site who cooperated with us in the course of this research. Without their willing and enthusiastic help and support, this report would not have been possible.

DISCLAIMER

Any commercial products or trade names mentioned in this report are included for informational purposes only, and do not constitute an endorsement or recommendation by the National Institute of Standards and Technology or the U.S. Army. 
1. Introduction ....................... 1

1.1 Background . . . . . . . . . . . . . . . . . 1

1.2 Technical Approach . . . . . . . . . . . . . . . . . 2

1.2.1 Questionnaire Survey . . . . . . . . . . . . 2

1.2.2 Physical Measurements ............ . 3

2. Questionnaire Results . . . . . . . . . . . . . . . 4

2.1 Approach . . . . . . . . . . . . . . . . . 4

2.2 Air Quality and Temperature . . . . . . . . . . . . 5

2.3 Lighting and VDT's.................. . . . 9

2.4 Noise and Privacy . . . . . . . . . . . . . . . . . 15

2.5 Space and Windows . . . . . . . . . . . . . . 20

2.6 Appearance and Furnishings . . . . . . . . . . . . . . 20

2.7 Health Issues . . . . . . . . . . . . . . . . . 25

2.8 Job Attitudes . . . . . . . . . . . . . . . . . . . . . 30

2.9 General Feelings about Facility . . . . . . . . . . . . 32

2.10 Comparison of Rating Differences . . . . . . . . . . . . . . 35

3. Choices for Improvements to the Facility . . . . . . . . . . . . . 40

3.1 Choices Selected as Improvements . . . . . . . . . . . . . . . 40

3.2 Reasons for Choices . . . . . . . . . . . . . . . . . . . . . 40

3.3 Changes Suggested by the Occupants . . . . . . . . . . . . . 46

4. Measurement Data . . . . . . . . . . . . . . . 52

4.1 Lighting Measurements . . . . . . . . . . . . . . . . 52

4.2 Physical Conditions . . . . . . . . . . . . . . . . 60

5. Recommendations . . . . . . . . . . . . . . . . 70

5.1 Source for Suggestions . . . . . . . . . . . . . . . . . 70

5.1.1 Indoor Air Quality . . . . . . . . . . . . . 70

5.1.2 Space and Privacy . . . . . . . . . . . . . 72

5.1.3 Noise and Privacy .. . . . . . . . . . . 72

5.1.4 Windows and Break Areas ............ . 73

5.1.5 Lighting . . . . . . . . . . . . . . . . . . 74

5.1.6 Safety and Training . . . . . . . . . . . . 75

5.1.7 Building 235 ............... . . 76

5.2 Conclusions . . . . . . . . . . . . . 76

6. References .................... 77

Appendix A . . . . . . . . . . . . . . . . . . . . 79

Appendix B . . . . . . . . . . . . . . . . . . . . . . 94

Appendix C . . . . . . . . . . . . . . . . 112 
Figure 1. Percentage of people rating ventilation and air circulation on a scale of poor to excellent. . . . . . . . . . . . . . . . 7

Figure 2. Percentage of respondents rating air quality on a scale of poor to excellent. . . . . . . . . . . . . . . . . 7

Figure 3. Ratings of heating in the work space on a 5-point scale of poor to excellent. ................... 8

Figure 4. Ratings of cooling in the work space on a 5-point scale of poor to excellent. . . . . . . . . . . . . . . . . . . 8

Figure 5. Percentage of respondents rating their satisfaction with the amount of light at their work station.

Figure 6. Percentage of respondents rating the amount of light at their work station on a scale of "too bright" and "too dim".

Figure 7. Percentage of respondents rating the bothersomeness of reflected glare from their work surfaces. . . . . . . . . . . 14

Figure 8. Percentage of respondents rating their ability to adjust the light in their work station.

Figure 9. Percentage of respondents rating the truth of the statement that they are frequently overheard by coworkers.

Figure 10. Percentage of respondents rating the bothersomeness of ringing telephones in their office on a 4-point scale.

Figure 11. Percentage of respondents rating conversational privacy in their offices on a 5-point scale of poor to excellent.

Figure 12. Percentage of respondents rating the amount of storage space in their work stations on a 5-point scale.

Figure 13. Percentage of respondents rating the amount of surface area for doing their work on a 5-point scale.

Figure 14. Percentage of respondents rating the truth of the statement "I miss having a view out" on a 4-point scale.

Figure 15. Percentage of respondents rating the appearance of their work station on a 5 -point scale of poor to excellent.

Figure 16. Percentage of respondents rating the condition of their furniture on a 5-point scale of poor to excellent.

Figure 17. Percentage of respondents rating the ease of adjusting their chair back.

Figure 18. Percentage of people rating the color of their furniture on a 5-point scale of poor to excellent: . . . . . . . . . . . . .

Figure 19. Percentage of people rating the frequency of headaches on a 5 point scale from rare to very frequent. . . . . . . . . . . .

Figure 20. Percentage of respondents rating the truth that their job is important on a 4 -point scale. . . . . . . . . . . . . . . . .

Figure 21. Percentage of respondents rating their satisfaction with their job. Percentage of respondents rating their building as pleasant on

Figure 22. Percentage of respondents rating their building as pleasant on
a 5-point scale of "not very" to "very". . . . . . . . . . .

Figure 23. Percentage of respondents rating their building as spacious on

Figure 23. Percentage of respondents rating their building as spacious on
a 5-point scale of "not very" to "very". . . . . . . . . .

Figure 24. Distribution of illuminances with body shadow at the primary work station. 
Figure 25. Distribution of luminances of the white paper task measured at the primary work station. . . . . . . . . . . . . . . . . 57

Figure 26. Distribution of contrasts for the luminances of the white paper and black image measured at the primary work location. 58

Figure 27. Distribution of average luminances (including luminance straight ahead, to the left, to the right, the ceiling, darkest object, and the luminaire) as seen from the primary work station. . . . . . . . . . . . . . . . . . . . . . . . .

Figure 28. Distribution of contrasts between screen and character as calculated for VDT's in the different buildings. . . . . . . 61 
Table 1. Mean Ratings of Reaction to the Environmental Conditions in the Buildings Studied. . . . . . . . . . . . . . . . . . . . . . .

Table 2. Mean Ratings of Reaction to the Lighting Conditions in the Buildings Studied. . . . . . . . . . . . . . . . . . . 10

Table 3. Mean Ratings of Reaction to Noise, Space and Privacy Conditions in the Buildings Studied. . . . . . . . . . . . . . . 16

Table 4. Mean Ratings of General Appearance and Furniture Condition in the Buildings Studied. . . . . . . . . . . . . . . . . . 23

Table 5. Health Related Responses to the Environment . . . . . . . . . 26

Table 6. Mean Ratings of Building Appearance from the Environmental Conditions in the Buildings Studied. . . . . . . . . . . . . . 33

Table 7. Rating scheme applied to the results from the questionnaire for the different buildings. . . . . . . . . . . . . . . . . . . . 36

Table 8. Improvements to the working environment selected by respondents in the different buildings. . . . . . . . . . . . . . . . . . 41

Table 9. Reasons Given for Desired Changes to Work Stations . . . . . . 42

Table 10. Suggestions for Changes to the Working Environment. . . . . . 48

Table 11. Summary Lighting Measurement Data for the Four Buildings . . . 53

Table 12. Additional Lighting and Physical Characteristics of the Work Stations. . . . . . . . . . . . . . . . . . . 62

Table 13. Average Temperature, Humidity and Noise in the Four Buildings

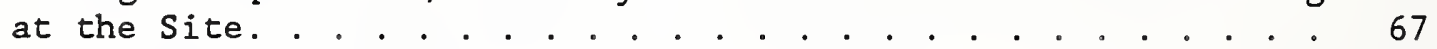

Table 14. Measurements of Space in the Four Buildings . . . . . . . . . 69 


\subsection{Background}

The use of post-occupancy evaluation techniques provides a means for evaluating occupant response to an existing environment and suggesting areas for improvement. Post occupancy evaluations use a battery of tests to assess environmental conditions in the facility, including questionnaire surveys of the occupants, physical measures, personal observations, and individual interviews. The post-occupancy evaluation technique is thus designed to provide information about the occupants' reaction to their work spaces and document the physical conditions to which they are responding.

Dillon and Vischer (1987a, b) used post-occupancy evaluation techniques to study four office buildings in Canada and develop response norms. Rubin and Collins (1987, 1988) and Collins and Rubin (1988) used this technique to evaluate environmental conditions in three U.S. Army field stations. Marans (1987), Marans and Brown (1987), Gillette (1988), Gillette and Brown (1986), and Collins, Fisher, Gillette and Marans (1989) applied post-occupancy evaluation techniques in a study of lighting, energy use, and other environmental conditions in thirteen office buildings in the United States. These studies identified the importance of lighting, thermal comfort, indoor air quality and privacy as major factors in influencing people's response to their environments.

Other studies have used only questionnaire or laboratory techniques to determine people's response to the environment. Thus, when Louis Harris and Associates for Steelcase (1987) questioned workers in the U.S. and Canada, using a telephone survey, they found that respondents placed a great deal of emphasis on office layout, furniture, improved lighting, and chairs as the key to increasing productivity. Respondents also placed considerable importance on privacy, improved temperatures, and reduced distractions or noise as well as reductions of glare on VDT screens. Laboratory studies of the response to lighting systems have identified the importance of lighting distributions in influencing occupant response to the space. For example, Flynn, Spencer, Martyniuk, and Hendrick (1973) found that ratings of perceptual clarity were closely correlated with the "bright/dim" dimensions, while ratings of pleasantness were closely correlated with the "overhead/ peripheral" and "uniform/non-uniform" dimensions. Lighting installations identified as pleasant scored higher on the peripheral and non-uniform ends of the scales, while spaciousness appeared to be predicted best by a combination of the three dimensions. Hawkes, Loe, and Rowlands (1979), determined that subjective brightness and interest were important factors in influencing the evaluation of lighting systems. In addition, the pattern of illuminance was important, with designs in which only one wall was lit judged as dim, and designs using only diffuse sources rated as less interesting than situations which used focused sources. Hawkes, et al. suggested that situations that are judged as being brighter and more interesting (or complex) are also preferred. Finally, Ulrich (1987) determined that windows provide important benefits, including speeding the recovery from illness, to people in confined spaces, such as hospitals and even offices. 
Other studies have focused on issues such as thermal comfort, including temperature and humidity. For example the ASHRAE Standard (55-1981) states that: "80\% of all adults dressed for winter indoor conditions find temperatures acceptable between $68^{\circ} \mathrm{F}$ and $74.5^{\circ} \mathrm{F}\left(20-23.5^{\circ} \mathrm{C}\right)$, a relative humidity of 30-608, and the air velocity at $0.15-.-0.25 \mathrm{~m} / \mathrm{sec}$. Acceptable summer indoor temperature is between 73 and $79^{\circ} \mathrm{F}\left(20-26.5^{\circ} \mathrm{C}\right)$." Meyer (1983, p.27) pointed out the "extensive experimentation has shown that for an average, sedentary, lightly clothed person this [thermal comfort] occurs most readily when the air in a standard room has a temperature of $24.5{ }^{\circ} \mathrm{C}$ $\left(76.1^{\circ} \mathrm{F}\right)$, a relative humidity of $40 \%$, and an air velocity of $0.25 \mathrm{~m} / \mathrm{sec} . "$

\subsection{Technical Approach}

The present study used post-occupancy evaluation techniques including questionnaires and physical measurements to evaluate a number of concerns about a specific set of five small U.S. government buildings. In addition, during the course of the study, one building was renovated with new, "systems" furniture replacing older, more conventional office furniture. A secondary goal of the present research was thus to determine if the changes made during the renovation improved physical conditions and occupant response to their environment. Environmental conditions of concern included lighting, air quality, temperature, space, color, and lack of windows. The occupant questionnaire addressed each of these areas, as well as reports of personal health and well-being. The physical measures concentrated on lighting, VDT's, noise, temperatures, and space.

\subsubsection{Questionnaire Survey}

The study was performed over about a six-month period from July 1988 to January 1989, before and after the renovation of one building. A detailed environmental questionnaire was administered in August to the occupants of the five buildings, and then again in January following the renovation to the occupants of the renovated building. The questionnaire was based on that used by Rubin and Collins (1988) for an evaluation of U.S. Army field stations but modified as appropriate for the present study. Individuals were assured of anonymity and encouraged to participate, with about 40-50\% responding for a total of 308 (including both surveys).

The questionnaire generally covered attitudes toward air quality, temperature, lighting, VDT's, space, noise, privacy, windows, facility appearance, furniture, health, and job satisfaction, as well as length of time at the facility and general demographic information. A copy of the questionnaire is provided in Appendix A.

The participants were distributed as follows, with conditions before the renovation in building 268 referred to as 268-1; and those following it as 268-2:

Building 235 - 24 respondents; referred to as $A$ in the figures,

Building 260 - 69 respondents; referred to as B in the figures; Building 293/98 - 19 respondents; referred to as $C$ in the figures; Building 268-1 - 114 respondents; referred to as D1 in the figures; Building 268-2 - 82 respondents; referred to as D2 in the figures. 
All the buildings were relatively small (about 60,000 to $80,000 \mathrm{ft}^{2}$ ), onestory, windowless facilities, although buildings 293 and 298 were substantially smaller, between 2400 and $6000 \mathrm{ft}^{2}$. Building 268 also had a substantial shops area where equipment repair and maintenance were done. The majority of the occupants performed office-type tasks including routine use of VDT's, although some (about 10-15\%) performed equipment maintenance and repair. A few also did warehouse storage and shipping (in building 235).

\subsubsection{Physical Measurements}

In addition to the questionnaire, detailed physical measurements were also taken in the course of the study. Physical measurements were taken in July and August of 1988 and then again in January, 1989. The physical data collection included lighting measures (both illuminance and luminance), noise, temperature, humidity, air flow, and the physical dimensions of the work station. Other assessments included calculations of contrast, estimations of color, sound intrusiveness, distractions, chair quality, furnishing type and condition, carpet, use of fans and space heaters, personalization of individual spaces, and general environmental quality. The protocol used in collecting these data is also presented in Appendix A.

Physical measurements were taken at a total of 92 individual work stations. Forty-nine work stations were measured in building 268 before the renovation, while 26 were measured after. The remaining 17 work stations were located in building 260 (12) and 235 (5). Because many of the work stations were virtually identical, measurements in only one or two areas characterized the physical conditions in the whole room. 


\subsection{Approach}

The tables in section 3 present a summary of the questionnaire results, in terms of mean ratings and number of respondents for selected questions. Appendix $B$ contains the complete data from the questionnaire in terms of percentage frequency for each element of each question, along with the mean and standard deviation for each question for each building. It also contains the mean for all respondents for each question.

Background demographic information was obtained about the respondents who participated in the study. Most respondents were male -- between 568 and $82 \%$ depending on the building, with building 260 having the most females - 448 . Most (62 - 75\%) were civilians, with the rest being military. According to the classifications given by the respondents, about 35 - 458 classified themselves as managers, $10-25 \%$ as clerical, $5-15 \%$ as equipment maintenance, 1-68 as ADP, and 20 - 50\% as "other" depending on the building.

In the tables summarizing the mean ratings in the text, responses are categorized according to major environnental classifications, such as air quality, lighting, temperature, noise, and the like. Results are listed by building number with 268-1 representing the findings before renovation and 268-2 after. The scale for the responses is given above each grouping-either a 5 or a 4 point rating scale. The mean for each building is given for each question, identified by a unique identifier such as "AIRCIRC" or "COOLING". The identifier code appears on the questionnaire in appendix A. Where several questions pertained to the same environmental area, and the same rating scale was used ( 4 point or 5 point), the data were averaged for each building ( $A V G$ ) and then for the whole data set (Site Mean). (The standard deviations for individual ratings are presented in appendix B.)

Several questions were examined in the data analysis. The first question is whether the ratings from any particular building were noticeably different from the others. The second is whether the ratings in 268 changed following the renovations. The third is whether the mean ratings differed from an expected value. Two values were used for this comparison. The first was simply the scale midpoint or theoretical mean of the scale -- 3 for a 5 point scale and 2.5 for a 4 point scale. (The scale midpoint is the value most likely to be neutral.) Statistical comparisons with the scale midpoint were made. The second comparison was with a set of normative scores developed for Public Works Canada by Dillon and Vischer (1987 a,b). The Canadian scores are based on field data -- ratings given by people in four Canadian office buildings, and so may be a good reflection of typical ratings for government office buildings (at least in Canada). Since these scores were based on five point rather than four point scales, they do not apply to all the present data, but provide a useful reference point where applicable. In addition, frequency distribution data for each individual rating scale are presented in Appendix $B$ and in selected graphs throughout the text. This particular presentation allows detailed comparison of the pattern of responses of people from different buildings to a particular question. 


\subsection{Air Quality and Temperature}

The first three ratings to be discussed pertain to air circulation (AIRCIRC), air quality satisfaction (AIRQSAT), and the presence of fumes. For these scales, a "1" meant poor, while a "5" meant excellent. Table 1 indicates that all the mean ratings were below 3.0, with ratings for air quality satisfaction and air circulation being close to 2.0. Mean ratings for AIRCIRC and AIRQSAT were below 2.0 for buildings 260 and 268, indicating a very serious problem with the perceptions of air quality and circulation in these two buildings. In fact, 758-80\% of these occupants rated their air circulation and air quality satisfaction as only poor to fair as can be seen in figures 1 and 2. In addition, the renovation in 268 improved the ratings for air quality only slightly. (No modifications were made to the air handling system). The perception of fumes appeared to be less of a problem to the occupants of the four buildings with mean ratings around 2.6. The mean site rating of 2.19 was slightly lower than the Canadian rating of 2.3, as can be seen in Table 1 and well below the scale midpoint of 3.0 .

The next portion of Table 1 presents several 4-point scales related to air quality. In this set of data, a "l" represented "not at all bothersome" 1 while a "4" represented "Very bothersome". Here a rating of "2.5" was considered neutral, although the question had no obvious neutral point. Again, the ratings suggest that perceptions of stuffy air and indoor air quality were particularly bothersome ${ }^{1}$ in buildings 260 and 268 , with ratings of 2.9 to 3.0 , above the scale midpoint of 2.5 . The ratings of 2.3 to 2.4 for smells and smoke suggest that these were less bothersome. (Many of these offices had a "no-smoking" policy; smoking was permitted only if everyone in the office agreed to it.) The data indicate, however, that conditions in 268 worsened somewhat, particularly for smoke, following the renovation. Examining all the data for indoor air quality ratings suggests that fumes, smells, and smoke were not as bothersome as general air quality, circulation and stuffy air. The majority of the offices had a no smoking policy, or the ratings of "smells" etc. might have been substantially more negative. Examination of the comment data reveals, however, that many respondents were dissatisfied with the enforcement of the no smoking policy. The slight increase in ratings of stuffiness and smoke following the renovation in 268 suggests that the new work stations may have blocked some air movement. Furthermore, the comment data suggest that fumes from the shop area continued to be a problem for this building.

The next questions dealt with the thermal environment, with ratings of both heating and cooling on a 5 point scale. Table 1 demonstrates that the site mean for all four buildings was quite low -- 2.24 -- indicating considerable dissatisfaction with temperature. Although there was substantial variation between buildings, ratings for both heating and cooling were quite low (around 2.2) in buildings 260 and 268, whereas cooling was rated more positively in the other buildings. Figures 3 and 4, which present the

1 The word "bothersome" is used because respondents were questioned about "how bothersome" a particular condition was. A colloquial word was selected as being more communicative to those completing the questionnaire. 
Table 1. Mean Ratings of Reaction to the Environmental Conditions in the Buildings Studied.

$\begin{array}{rrrlllc}\text { BLDG } & \text { BLDG } & \text { BLDG } & \text { BLDG } & \text { BLDG } & \text { SITE } & \text { TOTAL } \\ 235 & 260 & 293 / 98 & 268-1 & 268-2 & \text { MEAN } & \text { N }\end{array}$

\section{Air Quality}

\begin{tabular}{|c|c|c|c|c|c|c|}
\hline AIRCIRC & 2.46 & 1.88 & 2.89 & 1.59 & 1.96 & 1.90 \\
\hline AIRQSAT & 2.74 & 1.77 & 2.79 & 1.84 & 2.04 & 2.00 \\
\hline FUMES & 2.55 & 2.63 & 3.00 & 2.66 & 2.67 & 2.67 \\
\hline avg & 2.58 & 2.09 & 2.89 & 2.03 & 2.22 & 2.19 \\
\hline STUFYAIR & 2.38 & 2.97 & 2.28 & 2.95 & 2.91 & 2.86 \\
\hline SMELIS & 2.14 & 2.31 & 2.33 & 2.43 & 2.23 & 2.32 \\
\hline SMOKE & 2.24 & 2.27 & 2.16 & 2.47 & 2.63 & 2.43 \\
\hline AIRQUAL & 2.27 & 3.01 & 2.26 & 2.89 & 2.90 & 2.83 \\
\hline avg & 2.26 & 2.64 & 2.26 & 2.69 & $2: 67$ & 2.61 \\
\hline
\end{tabular}

Canadian Rating for Air Quality Mean $=2.3+/-1.1$

\section{Thermal Environment}

$\begin{array}{llllllll}\text { COOLING } & 3.04 & 2.17 & 3.32 & 1.81 & 2.10 & 2.16 & 307 \\ \text { HEATING } & 2.91 & 2.29 & 2.78 & 2.21 & 2.22 & 2.32 & 299 \\ \text { avg } & 2.98 & 2.23 & 2.03 & 2.01 & 2.16 & 2.24 & \end{array}$

Canadian Rating for Thermal Comfort Mean $=2.8+/-1.0$

$\begin{array}{llllllll}\text { DRAFTS } & 2.00 & 2.22 & 2.22 & 2.18 & 2.06 & 2.15 & 289 \\ \text { HOTSUMR } & 2.00 & 2.22 & 2.42 & 3.05 & 2.71 & 2.66 & 294 \\ \text { TEMPSWN } & 2.10 & 2.70 & 2.47 & 2.72 & 2.63 & 2.63 & 291 \\ \text { COLDWTR } & 2.20 & 2.39 & 2.50 & 2.69 & 2.58 & 2.55 & 291 \\ \text { avg } & 2.08 & 2.38 & 2.40 & 2.66 & 2.50 & 2.50 & \end{array}$




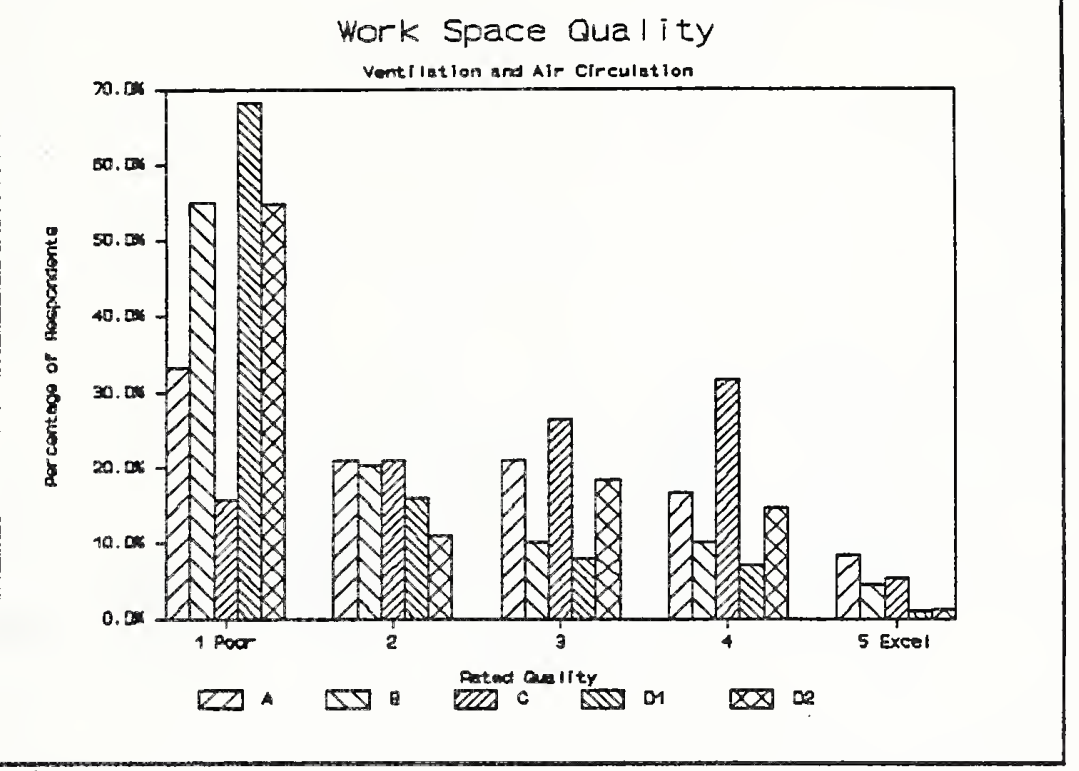

Figure 1. $A=235 ; \quad B=260 ; C=293 / 8 ; \quad D 1=268-$ 1; $\mathrm{D} 2=268-2$.

Figure 1. Percentage of people rating ventilation and air circulation on a scale of poor to excellent.

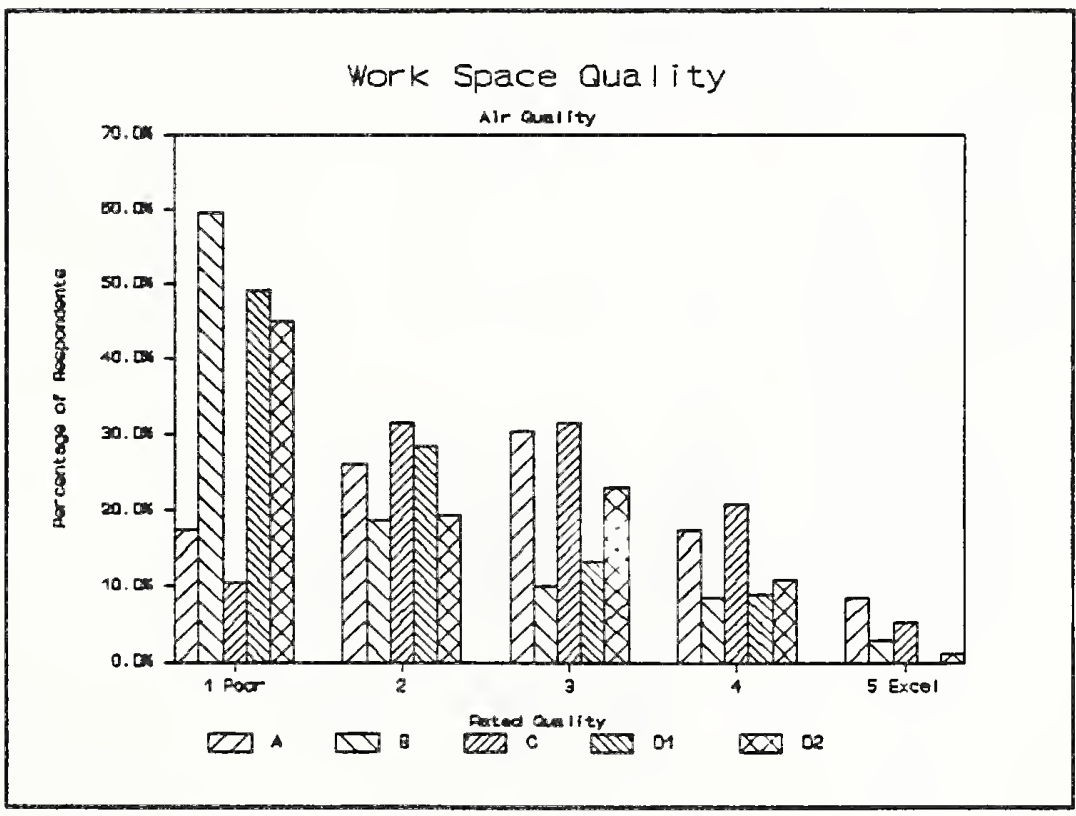

Figure 2. Percentage of respondents rating air quality on a scale of poor to excellent. 


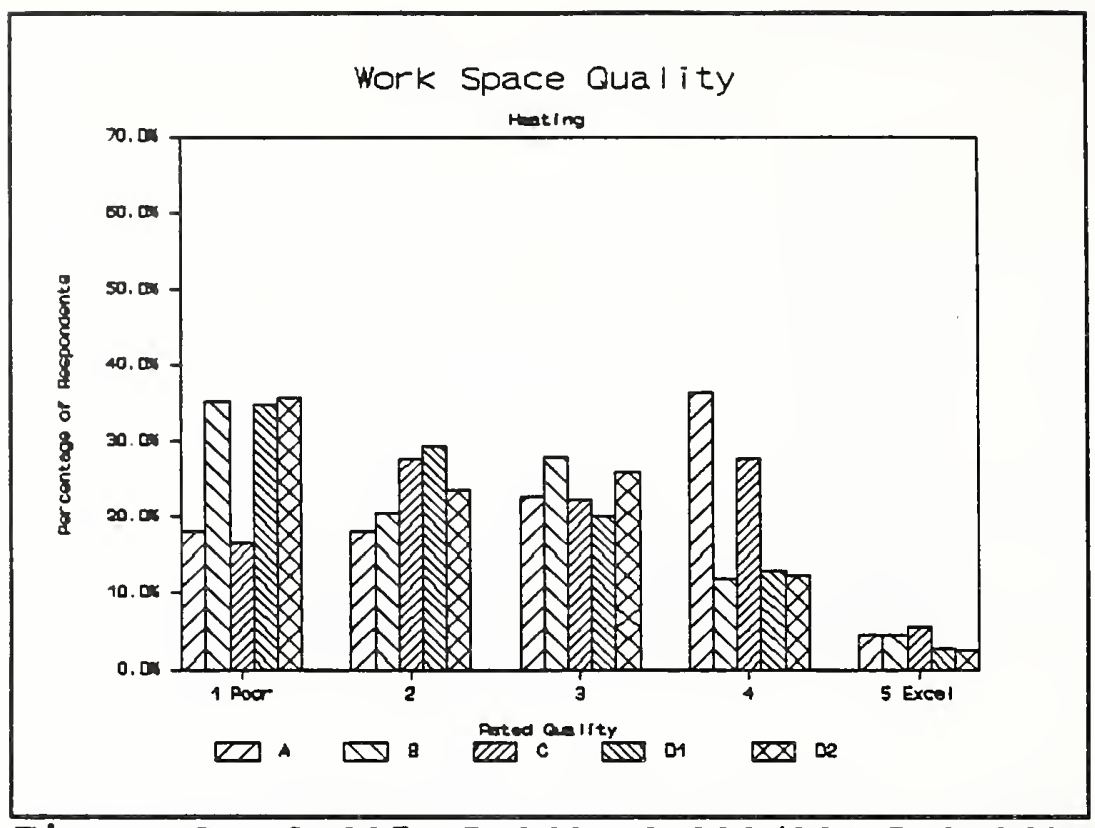

Figure 3. $A=235 ; B=260 ; C=293 / 98 ; D-1=268-$ 1 ; and $D-2=268-2$.

Figure 3. Ratings of heating in the work space on a 5-point scale of poor to excellent.

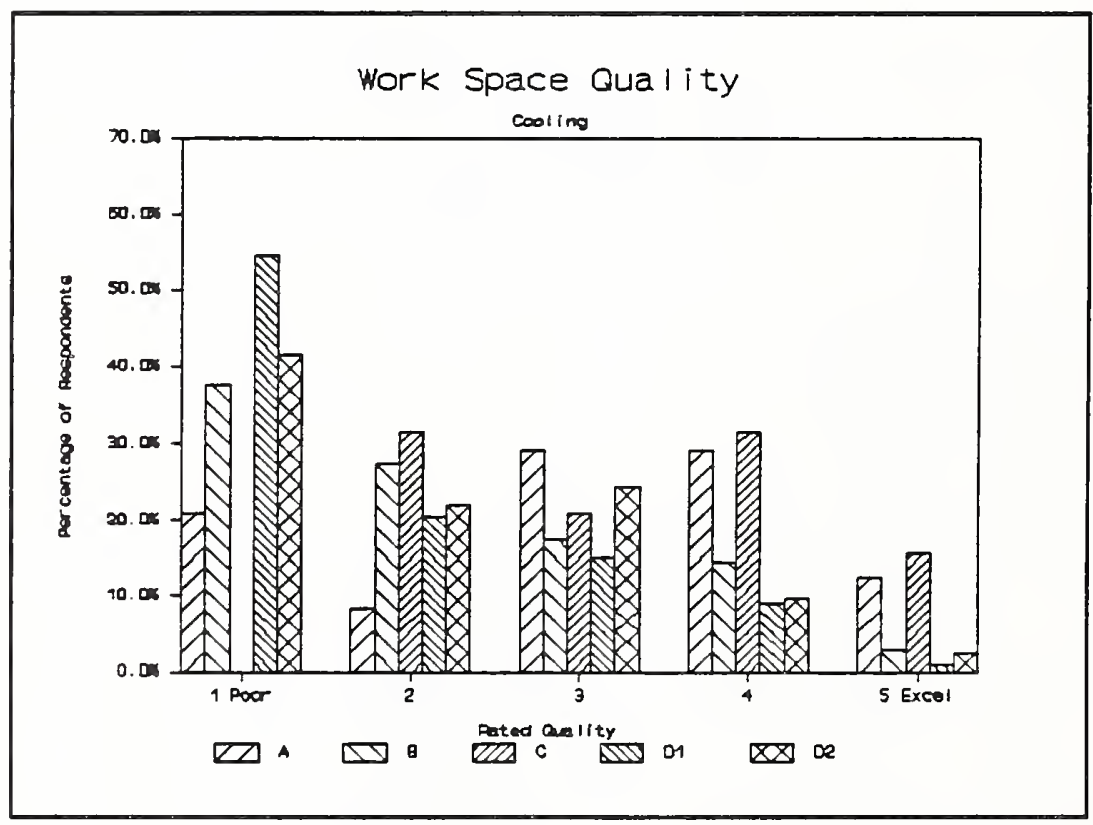

Figure 4. Ratings of cooling in the work space on a 5-point scale of poor to excelient. 
distribution of ratings for heating and cooling, demonstrate that the renovation in 268 improved the ratings for cooling slightly, but had little impact on heating. (Since the post-renovation questionnaire was administered in January, heating, not cooling was likely to have been more of a problem.) The mean site rating and the ratings for 260 and 268 were substantially below the Canadian rating of 2.8 , as well as below the scale midpoint of 3.0 . It should be noted, however, that satisfaction with both indoor air quality and temperature was higher in 293/298, although only 19 people participated in the questionnaire for these two buildings.

Examination of the mean data for the four point scales related to the "bothersomeness" of building temperatures reveals high ratings, indicating problems for occupants of building 268 with hot summer temperatures, temperature swings, and cold winter temperatures. Ratings improved somewhat following the renovation, although occupants had not yet experienced summer conditions. Drafts did not seem to be a problem in any building (which makes sense given the number of complaints about stuffy air). Buildings 235 and 293/8 performed below the scale midpoint of 2.5 on all 4 rating scales, as did building 260 (except for the question about temperature swings).

\subsection{Lighting and VDT's}

Table 2 presents data on the reaction to lighting -- the amount of light for working, the brightness of the light, and overall lighting satisfaction. These ratings were much more positive than those for air quality, with a group mean of 3.14 , which was slightly lower than the Canadian rating of 3.3 . There was also less variation among the buildings, although ratings for 260 and 268-1 tended to be lower. The data suggest that the renovation may have generally improved lighting conditions in building 268 , with increases in mean lighting satisfaction from 2.96 to 3.46 and rated amount of light for work from 2.88 to 3.39. For example, the percentage of those rating the amount of light as "good" or "excellent" increased from 358 to 558 . Figure 5 indicates that the number who expressed satisfaction with the lighting in 268 (rated it as good or excellent) increased from 268 to 528 after the renovation. This figure also indicates, however, that about 428 of those in building 260 were dissatisfied with their lighting (rating it poor or fair). Figure 6 demonstrates that all buildings except 293/8 were rated as dimmer, rather than brighter.

When the ratings of the quality of light for specific areas and tasks are examined, it is clear that the ratings for building 268 improved for each scale following the renovation. These data support the conclusion that the renovation in 268 with its repainted walls, new furniture, and more task lighting etc. improved the response to the lighting. Although low ratings were given for lighting for break areas, this may have occurred because many of the buildings had inadequate or no break areas, particularly 268, rather than because the lighting was bad. Excluding break areas, the overall site mean for the quality of light in specific areas was 3.16 - - above the scale midpoint of 3.0. The renovation in 268 was particularly important in improving the mean rating for the site. The mean ratings of the lighting for 
Table 2. Mean Ratings of Reaction to the Lighting Conditions in the Buildings Studied.

\section{Lighting}

$\begin{array}{rrclllc}\text { BLDG } & \text { BLDG } & \text { BLDG } & \text { BLDG } & \text { BLDG } & \text { SITE } & \text { TOTAL } \\ 235 & 260 & 293 / 98 & 268-1 & 268-2 & \text { MEAN } & \text { N }\end{array}$

$\begin{array}{llllllll}\text { AMTLTWRK } & 2.83 & 3.09 & 3.79 & 2.96 & 3.46 & 3.16 & 307 \\ \text { WSLITSAT } & 3.38 & 2.91 & 3.68 & 2.88 & 3.39 & 3.11 & 308 \\ \text { avg } & 3.10 & 3.00 & 2.49 & 2.92 & 3.43 & 3.14 & \end{array}$

Canadian Rating Mean $=2.3+/-1.0$

\begin{tabular}{|c|c|c|c|c|c|c|c|}
\hline RTLTSPAC & 3.13 & 3.01 & 3.53 & 2.79 & 3.33 & 3.06 & 307 \\
\hline RTLTRSTM & 2.96 & 3.10 & 3.42 & 3.25 & 3.63 & 3.31 & 308 \\
\hline RTLTHALL & 3.46 & 3.39 & 2.41 & 3.08 & 3.51 & 3.26 & 306 \\
\hline RTLTCONF & 1.95 & 3.22 & 2.28 & 3.05 & 3.33 & 3.04 & 302 \\
\hline RTLTBRK & 2.75 & 2.87 & 3.58 & 1.60 & 1.87 & 2.18 & 298 \\
\hline avg & 2.85 & 3.12 & 3.04 & 2.76 & 3.14 & 2.97 & \\
\hline \multicolumn{8}{|c|}{ Lighting for Tasks } \\
\hline LTVDT & 3.14 & 2.70 & 3.65 & 2.65 & 2.90 & 2.83 & 247 \\
\hline LTREAD & 3.64 & 2.96 & 3.74 & 3.05 & 3.49 & 3.23 & 292 \\
\hline LTOTHER & 2.60 & 1.89 & 2.33 & 2.45 & 2.97 & 2.51 & 90 \\
\hline LTFILE & 3.31 & 3.00 & 3.94 & 2.84 & 3.22 & 3.09 & 219 \\
\hline LTDRAFT & 2.42 & 2.32 & 2.69 & 2.47 & 2.57 & 2.48 & 219 \\
\hline LOCCLNLT & 2.79 & 2.99 & 3.63 & 2.92 & 3.32 & 3.07 & 308 \\
\hline avg & 2.98 & 2.64 & 3.33 & 2.73 & 3.08 & 2.87 & \\
\hline GLRCLNLT & 2.10 & 2.25 & 2.05 & 2.39 & 2.15 & 2.25 & 291 \\
\hline GLRWKSF & 2.23 & 2.18 & 2.11 & 2.35 & 2.07 & 2.21 & 291 \\
\hline DIMLIT & 2.14 & 2.39 & 1.72 & 2.21 & 2.25 & 2.23 & 286 \\
\hline avg & 2.15 & 2.28 & 1.96 & 2.32 & 2.15 & 2.23 & \\
\hline LTGHINDR & 3.10 & 3.03 & 3.63 & 2.68 & 3.09 & 2.96 & 293 \\
\hline AMTLTBRT & 3.57 & 3.46 & 2.84 & 3.35 & 3.24 & 3.33 & 300 \\
\hline ADJAMTLT & 2.39 & 1.75 & 2.11 & 1.91 & 2.52 & 2.09 & 302 \\
\hline NOTSKLT & 2.30 & 2.75 & 2.16 & 2.71 & 2.49 & 2.6 & 284 \\
\hline $\operatorname{avg}$ & 2.84 & 2.75 & 2.69 & 2.66 & 2.84 & 2.75 & \\
\hline
\end{tabular}


Table 2 Continued.

\section{Lighting and VDT's}

$\begin{array}{rrclllc}\text { BLDG } & \text { BLDG } & \text { BLDG } & \text { BLDG } & \text { BLDG } & \text { SITE } & \text { TOTAL } \\ 235 & 260 & 293 / 98 & 268-1 & 268-2 & \text { MEAN } & \text { N }\end{array}$

$\begin{array}{llllllll}\text { VDTADJLT } & 2.91 & 2.54 & 1.93 & 2.85 & 2.54 & 2.62 & 206 \\ \text { VDTBRTLT } & 2.55 & 2.20 & 1.64 & 2.56 & 2.24 & 2.32 & 209 \\ \text { VDTREFSC } & 2.55 & 2.43 & 2.00 & 2.76 & 2.54 & 2.55 & 216 \\ \text { VDTADJSC } & 2.30 & 1.93 & 1.93 & 2.31 & 2.04 & 2.11 & 209 \\ & & & & & & & \\ \text { VDTGLARE } & 2.45 & 2.57 & 1.94 & 2.90 & 2.57 & 2.63 & 216 \\ \text { VDTREAD } & 1.90 & 1.93 & 1.56 & 2.06 & 2.13 & 2.00 & 209 \\ \text { VDTSPACE } & 2.60 & 2.51 & 1.93 & 2.59 & 2.54 & 2.51 & 207 \\ \text { VDTANGSC } & 1.82 & 1.64 & 1.63 & 1.99 & 1.81 & 1.81 & 209 \\ & & & & & & & \\ \text { VDTDSTSC } & 1.91 & 1.68 & 1.56 & 1.74 & 1.62 & 1.69 & 211 \\ \text { VDTSEAT } & 2.18 & 1.58 & 1.69 & 1.91 & 2.07 & 1.86 & 211 \\ \text { VDTFLICK } & 2.36 & 1.93 & 2.19 & 2.20 & 1.89 & 2.05 & 211 \\ \text { VDTANGKB } & 2.27 & 1.92 & 1.67 & 1.90 & 1.93 & 1.91 & 211 \\ \text { VDTDSKHT } & 2.09 & 1.73 & 1.60 & 2.06 & 1.98 & 1.91 & 211 \\ & & & & & & & \end{array}$




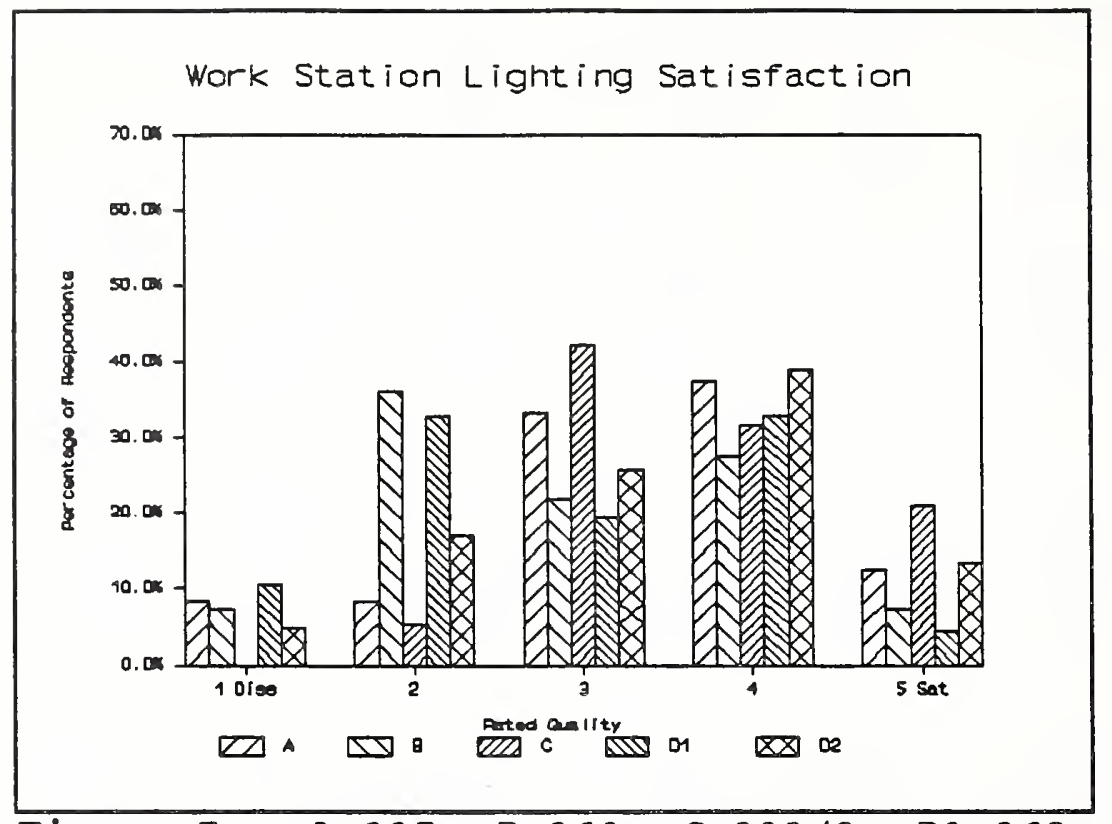

Figure 5. $A=235 ; \quad B=260 ; C=293 / 8 ; \quad D 1=268-$ 1 ; and $\mathrm{D} 2=268-2$.

Figure 5. Percentage of respondents rating their satisfaction with the amount of light at their work station.

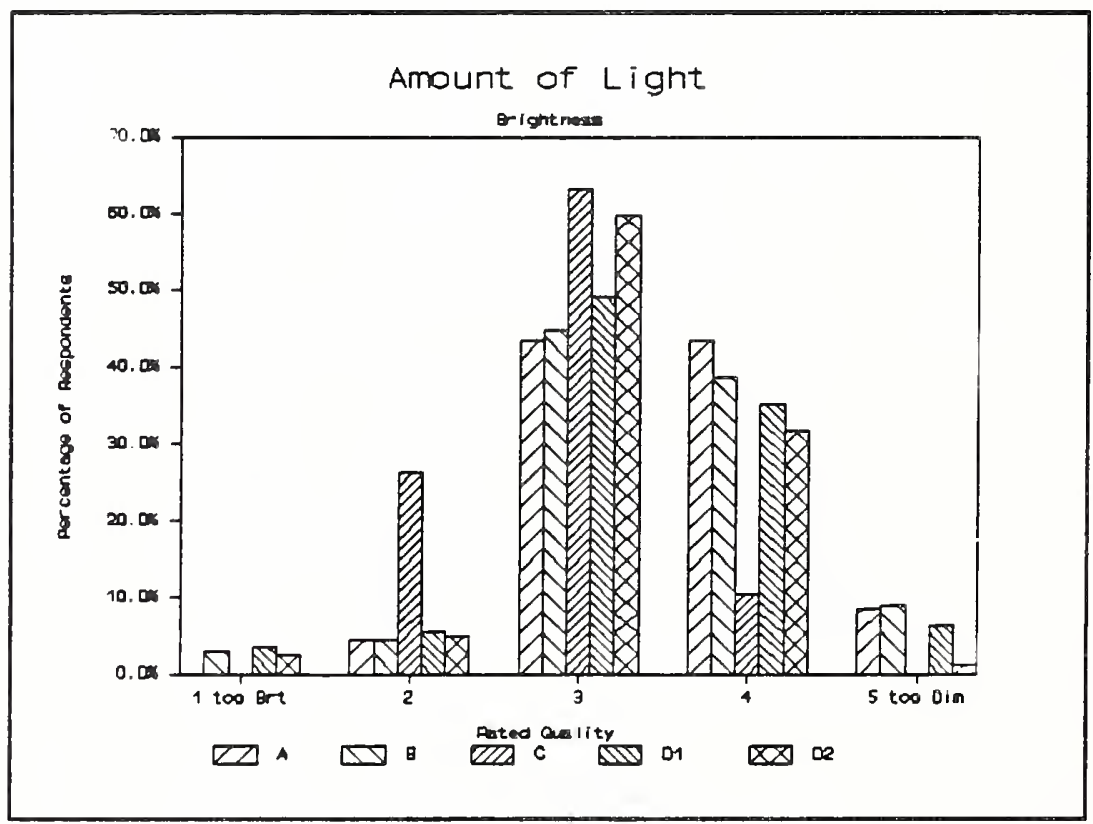

Figure 6. Percentage of respondents rating the amount of light at their work station on a scale of "too bright" and "too dim". 
tasks also improved by about 0.4 following the renovation in 268 . The rating for lighting for tasks was lowest for 260 with a mean of 2.64 .

In all buildings, the lowest ratings for lighting were for drafting and "other"; and highest for reading, and filing. Lighting for VDT's appeared to cause problems in 260 and 268 particularly before the renovation. The next three scales dealt with the perception of the "bothersomeness" of several aspects of lighting; namely, glare from ceiling lights and work surfaces, and dim lighting. On this scale a rating of (4) meant very "bothersome". All four buildings were quite similar -- with a site mean of 2.23 , below the scale midpoint (2.5) -. indicating that glare and dim lighting were not particularly bothersome. Again, conditions in 293/8 were least bothersome, while they improved following the renovation in 268. Figure 7 demonstrates that relatively few people rated glare from the work surface as "fairly" or "very" bothersome, with only about $30 \%$ being bothered by this type of glare.

Ratings of light as a hindrance to doing the job (where "4" meant that light did not hinder getting the job done), shown in the next portion of Table 2 , indicated that this was also not a problem. Issues related to control include the ability to adjust a light for the task as well as the actual presence of a task light. On the first scale (a 5 point scale) respondents clearly felt that they did not have much ability to adjust their light; those in 260 and 268 were the most bothered with mean ratings below 2.6. Figure 8 demonstrates that $35-55 \%$ felt that their ability to adjust their light was poor. The renovation in 268 successfully increased the perceived ability to adjust the light, although still not to the scale midpoint of 3.0 . Finally the absence of a task light was bothersome to many, as shown by the relatively low site rating of 2.6 .

An important issue in lighting is the need to light offices for both paper and "VDT" tasks. The next set of data present the bothersomeness of lighting for VDT's where 4 equaled "very bothersome". Very few problems occurred in building 293/8 where all ratings were below 2. More problems arose in the other buildings where mean ratings were between 2.5 and 2.9. The lack of ability to adjust the light emerged as a particular problem in 260 . As with other lighting situations, the renovation in 268 improved the lighting for VDT's.

The next questions dealt with the bothersomeness of various environmental conditions for using VDT's. Again, a higher number implies greater bothersomeness. Table 2 indicates that most conditions associated with VDT's were not particularly bothersome with mean ratings below 2.0, with some important exceptions. "Space for printed material" was rated as particularly bothersome in all buildings except 293/98. (Yet, about 508 of the respondents in $293 / 8$ and 235 indicated that they spent less than 2 hours using a VDT -- as compared with 508 in 260 and 268 who spent 2-6 hours/day at a VDT). The mean rating for the bothersomeness of space for printed material was 2.51 with between 20 and 50 f finding it to be fairly or very bothersome.

The renovation in 268 decreased dissatisfaction on this scale only slightly. The flickering of VDT's was a slight problem for those in 235 and 268 before the renovation. VDT characteristics that were not bothersome included screen 


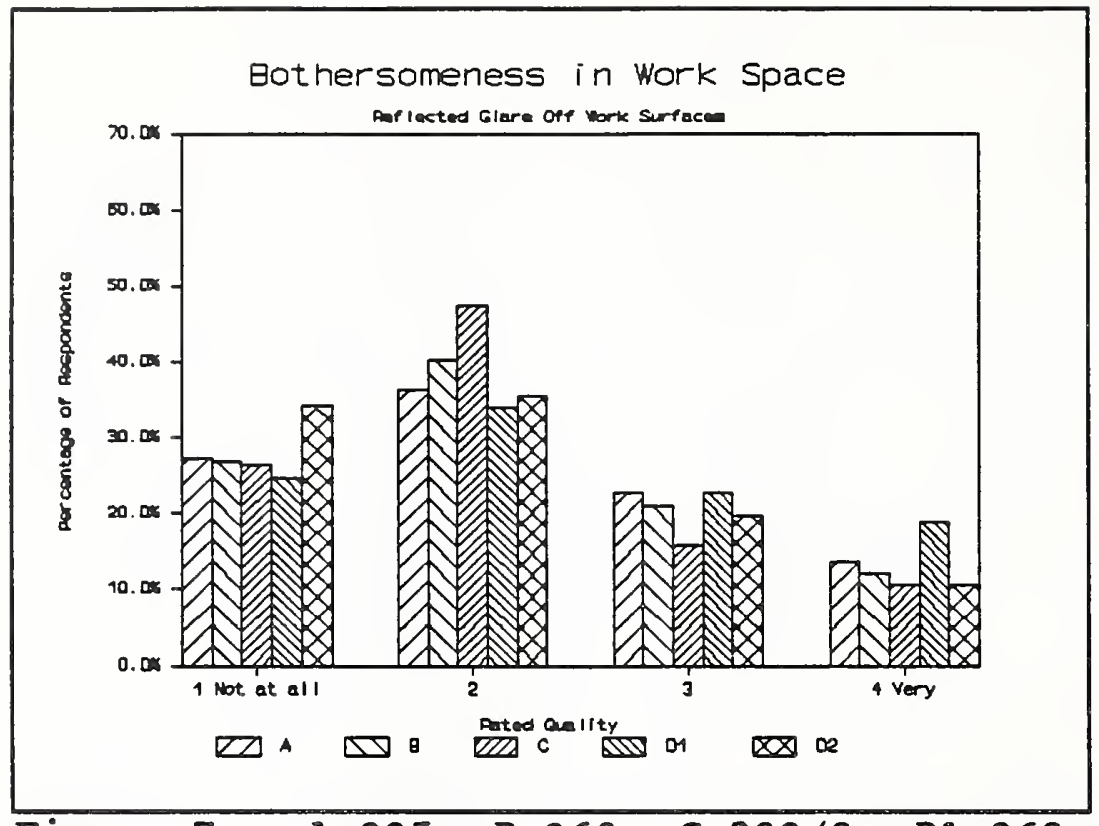

Figure 7. $A=235 ; \quad B=260 ; \quad C=293 / 8 ; \quad D 1=268-$ 1; $D 2=268-2$.

Figure 7. Percentage of respondents rating the bothersomeness of reflected glare from their work surfaces.

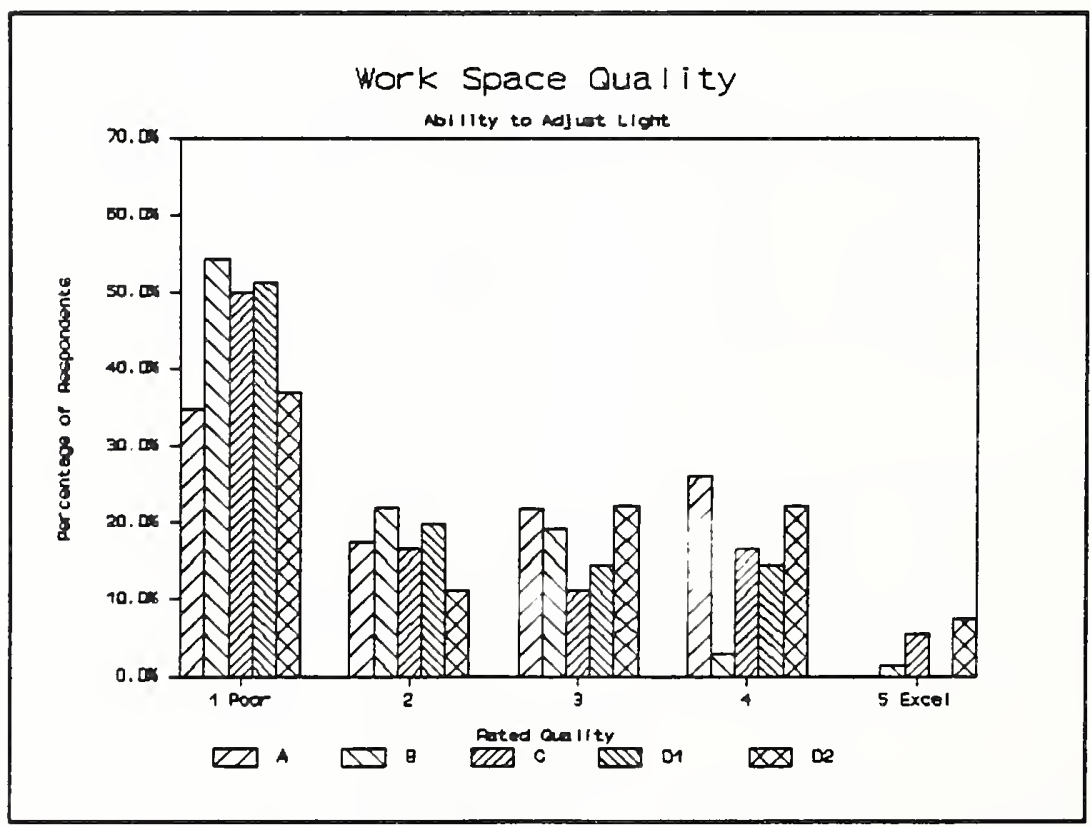

Figure 8. Percentage of respondents rating their ability to adjust the light in their work station. 
angle, distance to the screen, seat, keyboard angle and desk height, although the last three were rated as somewhat more bothersome in building 235 . Clearly, though, lack of space for paper tasks was considered the most troublesome aspect of VDT's at the site.

\subsection{Noise and Privacy}

Table 3 indicates that a major concern for respondents in all work stations was noise and privacy. The first set of ratings refers to the bothersomeness of noise from coworkers using a 4-point scale. The low ratings for the first entry indicate that "it is very true" that one can be overheard by coworkers. On this scale, the buildings had very low and similar ratings -- between 1.38 and 1.79 -- indicating that being overheard was a very real concern. Only about $10 \%$ of those in any building considered that it was not a problem. Figure 9 presents a distribution of the ratings for this question. The second entry in table 3, indicated that hearing people talk was also a problem, with a mean of 2.53 , but not as bothersome as the feelings of being overheard. The ratings on both scales improved slightly following the renovation in 268, although $90 \%$ still found that being overheard was bothersome. Nevertheless the site mean was 2.01, below the Canadian Rating of 2.9 (derived from a 5 point scale) and below the theoretical scale midpoint of 2.5 .

Another area of concern was that of environmental noises - from the hall, equipment, phones, ventilating systems, and printers. Because a high rating meant "very bothersome," the relatively low ratings for these noise sources indicate that environmental noises were less bothersome than noise from people or concerns about being overheard. Again, the renovation improved the ratings slightly, although no building was rated as being particularly bothersome. Figure 10 reveals a fairly even distribution of ratings-except in building 235 where 40 \% were very bothered by ringing telephones. The overall site mean for environmental noise was fairly low, 2.14 , and better than the scale midpoint of 2.5 .

The next series of entries in Table 3 present data on the bothersomeness of people walking around and being too close. Ratings for all buildings were low for these scales, with a site mean of 2.2. This suggests that these two issues were not particularly bothersome (since "4" meant "very bothersome"). On the other hand, ratings of conversational privacy on a five-point scale where 5 meant "excellent" were quite low, indicating that this was a concern to all the occupants. Figure 11 reveals that 58-788 of the respondents considered their conversational privacy to be "poor" to "fair". The renovation improved the situation in 268 -- but $58 \%$ of the respondents still found it unacceptable. Ratings of visual privacy were somewhat more positive, with a marked improvement in the ratings for 268 following the renovation. Here 108 rated their visual privacy as good before the renovation, whereas 358 rated it as "good" (or "excellent") after the renovation. Nevertheless, the site mean for privacy in general, 2.11, was somewhat below the Canadian rating of 2.3 . Both the site mean and the Canadian rating for privacy were well below the scale midpoint of 3 for these scales, indicating potential problems in this area. 
Table 3. Mean Ratings of Reaction to Noise, Space and Privacy Conditions in the Buildings Studied.

$\begin{array}{rrrlllc}\text { BLDG } & \text { BLDG } & \text { BLDG } & \text { BLDG } & \text { BLDG } & \text { SITE } & \text { TOTAL } \\ 235 & 260 & 293 / 98 & 268-1 & 268-2 & \text { MEAN } & \text { N }\end{array}$

\section{Office Noise}

$\begin{array}{llllllll}\text { COWRKHR } & 1.57 & 1.48 & 1.79 & 1.38 & 1.54 & 1.49 & 297 \\ \text { PEPTALK } & 2.05 & 2.41 & 2.53 & 2.68 & 2.56 & 2.53 & 294 \\ \text { avg } & 1.81 & 1.95 & 1.44 & 2.03 & 2.05 & 2.01 & \end{array}$

Canadian Rating for Office Noise Mean $=2.9+/-0.9$

\section{Building Noise}

$\begin{array}{llllllll}\text { NOISEHAL } & 1.90 & 1.85 & 1.88 & 1.91 & 1.79 & 1.86 & 288 \\ \text { NOISEEQP } & 2.00 & 2.27 & 2.22 & 2.29 & 2.04 & 2.19 & 291 \\ \text { NOISEPHN } & 2.14 & 2.33 & 3.00 & 2.49 & 2.42 & 2.44 & 293 \\ \text { NOISEVNT } & 1.86 & 2.08 & 1.83 & 2.03 & 1.82 & 1.96 & 289 \\ \text { NOISEPRT } & 2.06 & 2.30 & 2.11 & 2.27 & 2.19 & 2.23 & 287 \\ \text { avg } & 1.99 & 2.17 & 2.21 & 2.20 & 2.05 & 2.14 & \end{array}$

Canadian Rating for Building Noise Mean $=4.4+/-0.7$

$\begin{array}{llllllll}\text { WRKNOISE } & 3.24 & 2.82 & 2.79 & 2.53 & 2.50 & 2.65 & 295\end{array}$

\section{$\underline{\text { Privacy }}$}

$\begin{array}{llllllll}\text { PEPLCLOS } & 1.95 & 2.14 & 2.33 & 2.43 & 2.30 & 2.29 & 290 \\ \text { PEPLWALK } & 2.00 & 1.90 & 2.39 & 2.15 & 2.18 & 2.10 & 290 \\ \text { avg } & 1.98 & 2.02 & 1.57 & 2.29 & 2.24 & 2.20 & \\ & & & & & & & \\ \text { VISPRIV } & 2.61 & 2.24 & 2.84 & 1.88 & 2.74 & 2.31 & 301 \\ \text { CONVPRIV } & 1.79 & 1.80 & 1.95 & 1.70 & 2.29 & 1.90 & 307 \\ \text { avg } & 2.20 & 2.02 & 2.39 & 1.79 & 2.51 & 2.11 & \end{array}$

Canadian Rating for Privacy Mean $=2.3+/-1.0$ 
Table 3 Continued.

\begin{tabular}{rrrlllc}
\multicolumn{9}{c}{ Space } \\
BLDG & BLDG & BLDG & BLDG & BLDG & SITE & TOTAL \\
235 & 260 & $293 / 98$ & $268-1$ & $268-2$ & MEAN & N
\end{tabular}

$\begin{array}{llllllll}\text { WSSPCAMT } & 3.33 & 2.97 & 2.84 & 2.85 & 3.17 & 3.00 & 309 \\ \text { STORAGE } & 2.41 & 1.99 & 2.37 & 2.03 & 2.57 & 2.21 & 305 \\ \text { WRKSPACE } & 2.78 & 2.50 & 2.58 & 2.55 & 2.77 & 2.62 & 305 \\ \text { WALLSPC } & 3.00 & 2.64 & 2.74 & 2.27 & 2.63 & 2.54 & 306 \\ \text { ARGMTWS } & 3.30 & 3.04 & 2.89 & 2.82 & 3.09 & 2.98 & 303 \\ \text { avg } & 2.97 & 2.63 & 2.68 & 2.50 & 2.85 & 2.67 & \end{array}$

Canadian Rating for Spatial Comfort Mean $=3.3+/-1.0$

Windows

$\begin{array}{llllllll}\text { NOVIEW } & 2.33 & 3.05 & 2.12 & 2.57 & 2.38 & 2.58 & 276 \\ \text { WEATHER } & 2.41 & 1.42 & 1.95 & 1.97 & 2.07 & 1.91 & 297 \\ \text { MISSVIEW } & 2.24 & 1.42 & 3.06 & 1.92 & 2.11 & 1.95 & 296 \\ \text { avg } & 2.33 & 1.96 & 1.78 & 2.15 & 2.19 & 2.15 & \end{array}$




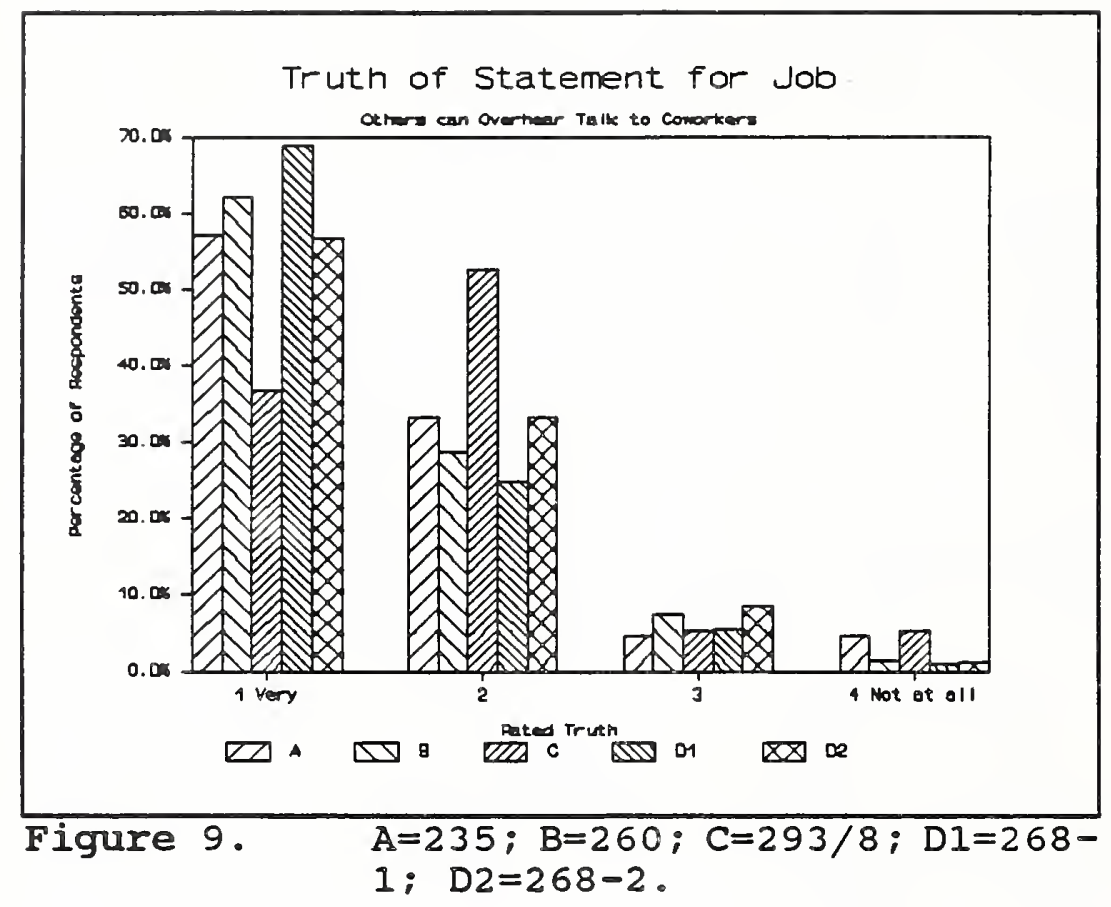

Figure 9. Percentage of respondents rating the truth of the statement that they are frequently overheard by coworkers. 


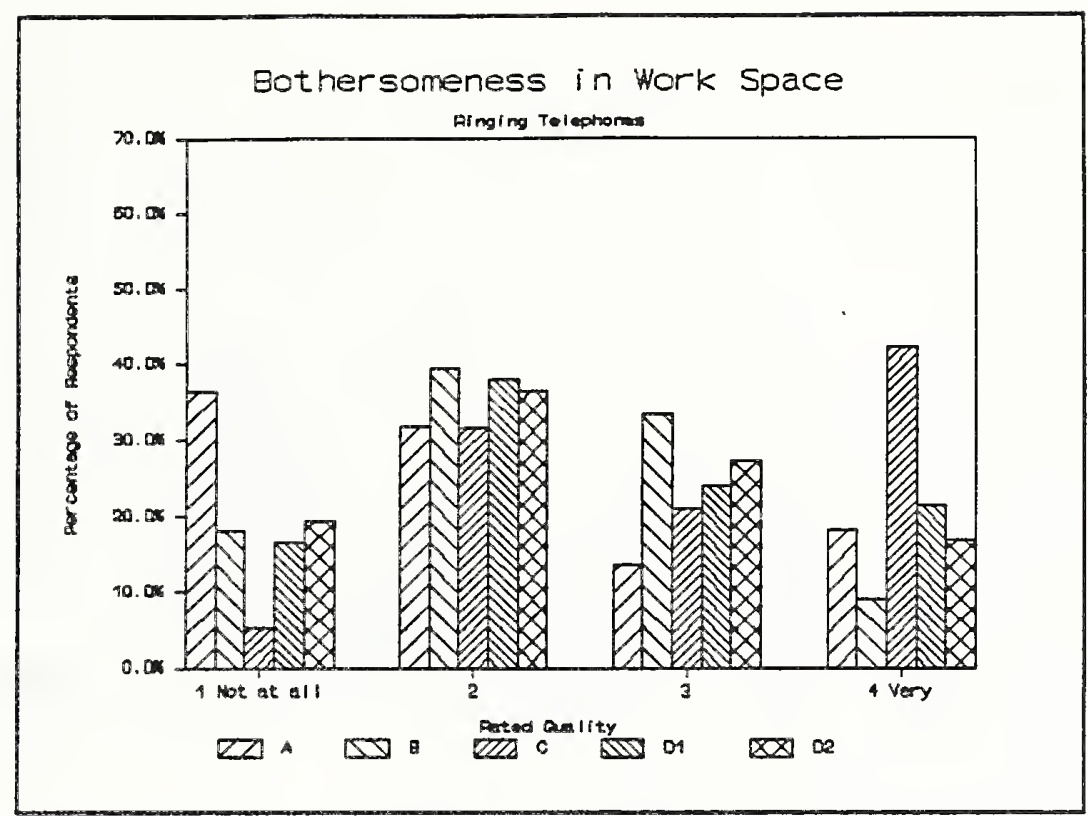

Figure 10. $A=235 ; B=260 ; C=293 / 8 ; D I=268-$

1 ; and $\mathrm{D} 2=268-2$.

Figure 10. Percentage of respondents rating the bothersomeness of ringing telephones in their office on a 4 -point scale.

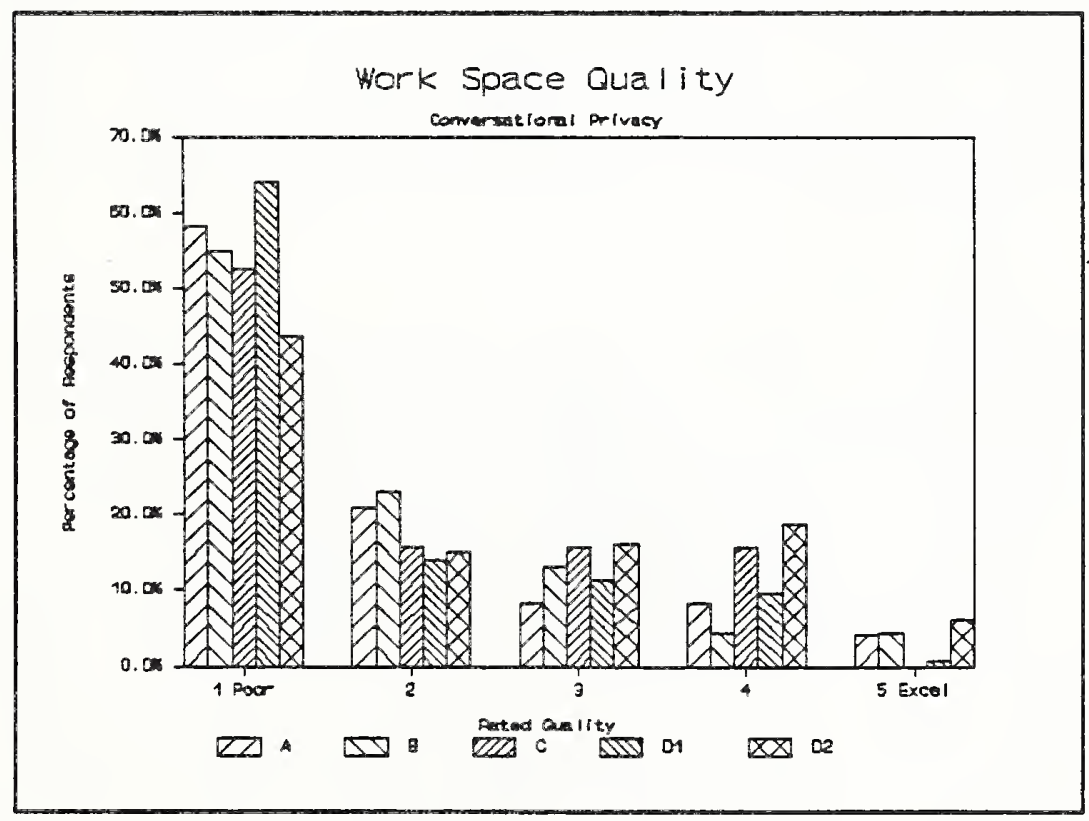

Figure 11. Percentage of respondents rating conversational privacy in their offices on a 5-point scale of poor to excellent. 


\subsection{Space and Windows}

A major issue was the amount of space in the work station, including space for work, storage, surface area, personal items, and general arrangement for doing work. Table 3 demonstrates that the mean ratings were relatively low (below the scale midpoint), particularly for storage space, surface area, and wall space. Figure 12 reveals that between 50 and 708 of the respondents rated their storage space as "poor" to "fair", with less than 108 in any building considering it to be "excellent". Figure 13 demonstrates that about 408 in all buildings felt that they did not have enough surface area to do their jobs properly. Although conditions for storage and space in 268 improved following the renovation, $50 \%$ of the respondents remained dissatisfied. Ratings for the amount of space and arrangement of the space- more general questions -- were somewhat higher. Yet, the overall mean for the five questions was markedly below the Canadian rating of 3.3 , as well as below the scale midpoint of 3.0. While the renovation in 268 increased the ratings, especially for storage, they remained below the Canadian rating. These data suggest that lack of storage space and surface area for work continued to be problem areas in all buildings.

Since all the buildings were vixtually windowless, a series of questions dealt with the reaction to the absence of windows. Responses to a question about a view out during break or at lunch were overwhelmingly positive with 678 answering it as "yes". Answers to a question about the lack of a view out indicated that this was particularly bothersome to those in 260 and 268 (mean ratings of 2.12 to 2.57 ) on a 4 point scale. Figure 14 indicates that $75 \%$ of the respondents in 260 missed having a view out, while only 10-30\% of those in 293/8 and 235 were similarly bothered. The desire to know about the weather and being bothered by the lack of a view out was very strong for those in 260 (mean was 1.42) and 268 (mean was about 2.0). These findings reinforce the desirability of providing a separate windowed area for breaks and lunch, and allowing people to go outside during lunch.

\subsection{Appearance and Furnishings}

Another important concern, particularly following the renovation in 268, was the general appearance of the work station and materials, as well as overall satisfaction with the furniture, equipment, and chairs. Ratings presented in Table 4 were generally positive and above 3 on the 5 point scale, with the exception of a general question about how the offices looked. Ratings for this question tended to be low (below 2.8) particularly in 260 and 268 before the renovation. As figure 15 demonstrates, however, the renovation had a dramatic impact on the answers to this question, increasing the mean rating from 2.5 to 3.45 , and the frequency of those rating it as "pretty good" or "excellent" from about 238 to 638 . Figure 16 demonstrates a similar improvement in the ratings for the condition of desks and chairs, which went from a mean of 2.96 (the lowest of any building) before the renovation to 3.98 after. Ratings for furniture satisfaction and chair comfort were similar and reasonably positive across buildings, particularly following the renovation in 268 . 


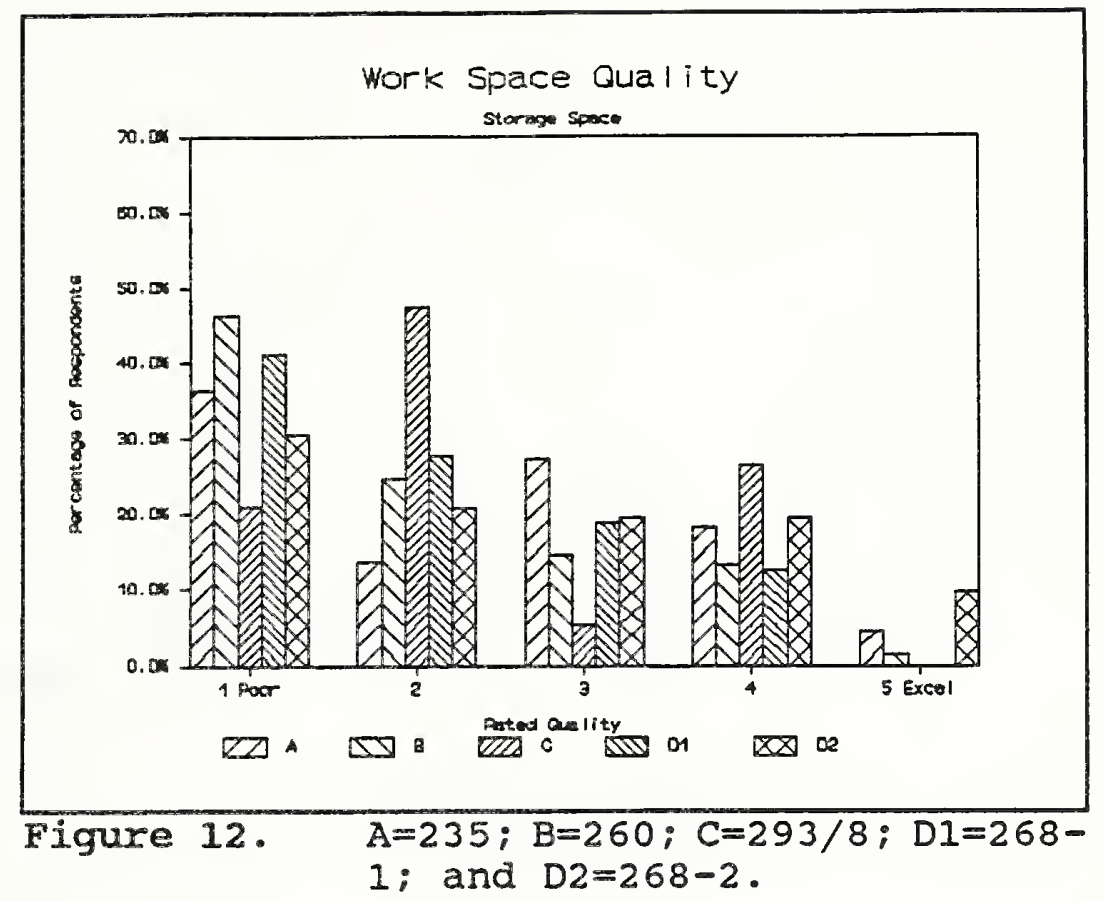

Figure 12. Percentage of respondents rating the amount of storage space in their work stations on a 5-point scale.

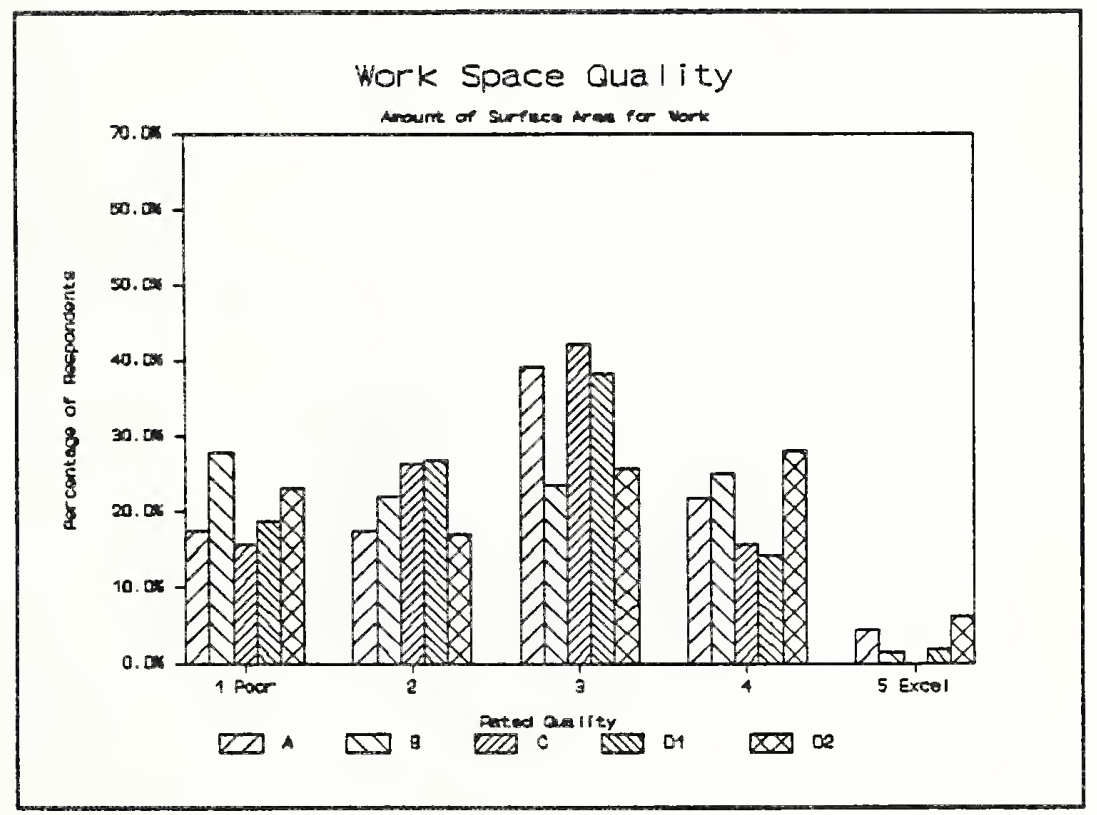

Figure 13. Percentage of respondents rating the amount of surface area for doing their work on a 5-point scale. 


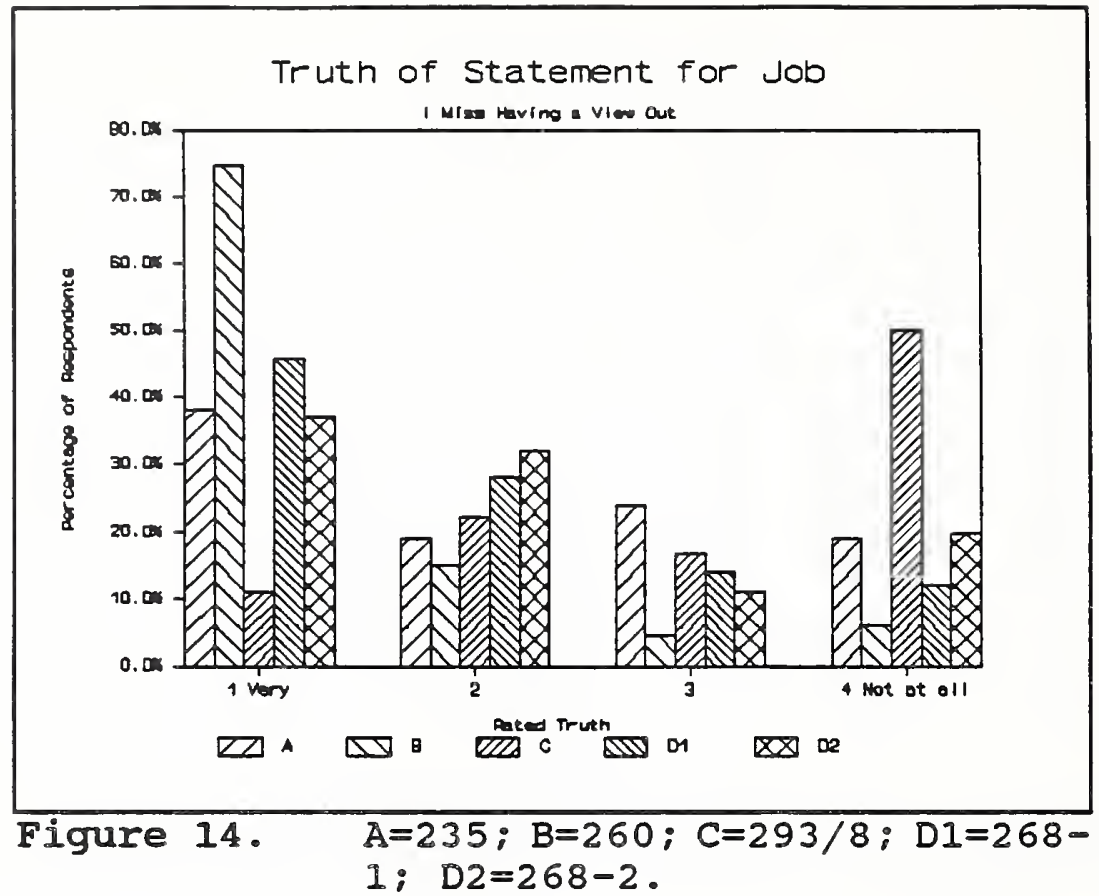

Figure 14. Percentage of respondents rating the truth of the statment "I miss having a view out" on a 4-point scale.

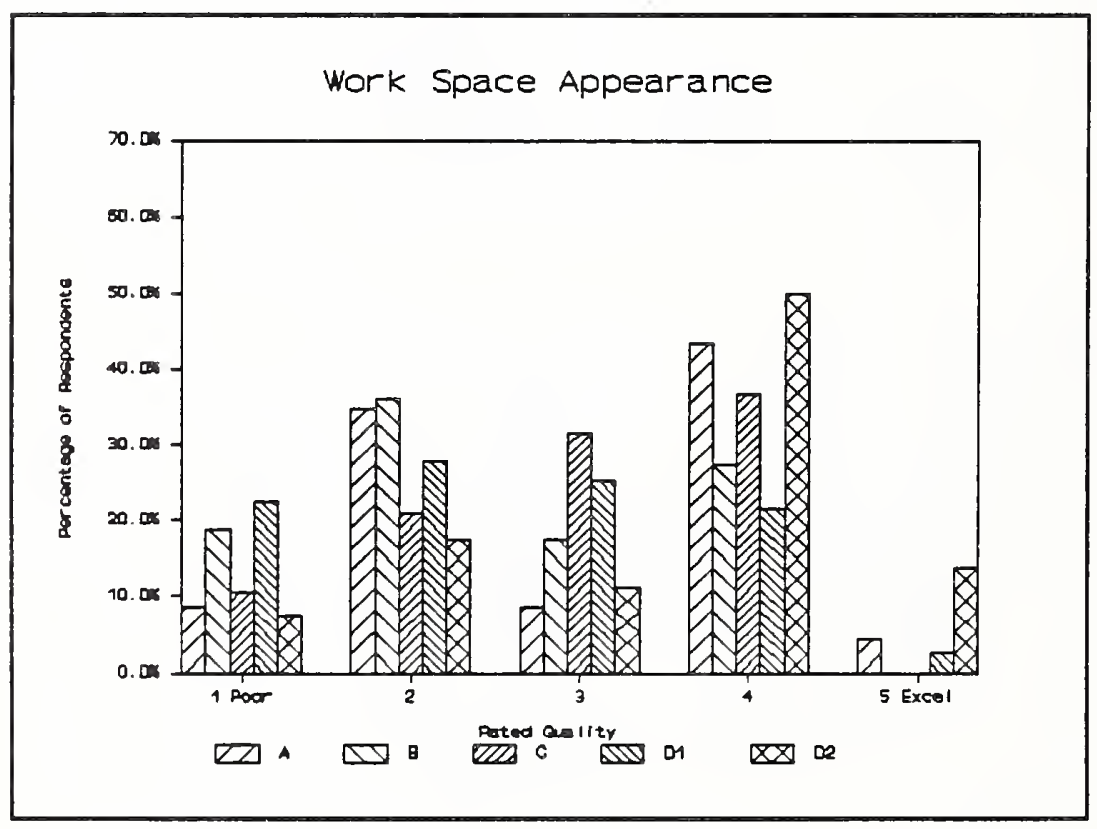

Figure 15. Percentage of respondents rating the appearance of their work station on a 5-point scale of poor to excellent. 
Table 4. Mean Ratings of General Appearance and Furniture Condition in the Buildings Studied.

\section{Appearance}

$\begin{array}{rrcllcc}\text { BLDG } & \text { BLDG } & \text { BLDG } & \text { BLDG } & \text { BLDG } & \text { SITE } & \text { TOTAL } \\ 235 & 260 & 293 / 98 & 268-1 & 268-2 & \text { MEAN } & \text { N }\end{array}$

$\begin{array}{llllllll}\text { LOOKWS } & 3.00 & 2.54 & 2.95 & 2.55 & 3.45 & 2.84 & 303 \\ \text { WSMATL } & 3.38 & 3.68 & 3.53 & 2.96 & 3.98 & 3.46 & 307 \\ \text { EQUIPSAT } & 3.75 & 3.20 & 2.74 & 3.05 & 3.30 & 3.19 & 305 \\ \text { FURNSAT } & 3.38 & 3.14 & 3.21 & 2.78 & 3.32 & 3.08 & 305 \\ \text { CHRCMFT } & 3.08 & 3.57 & 3.26 & 3.15 & 3.26 & 3.27 & 307 \\ & & & & & & & \\ \text { avg } & 3.32 & 3.23 & 3.14 & 2.90 & 3.46 & 3.17\end{array}$

\section{Chair Condition}

$\begin{array}{llllllll}\text { CHAIRMOV } & 2.71 & 2.93 & 2.74 & 2.61 & 2.67 & 2.72 & 277 \\ \text { CHRHGT } & 2.43 & 2.77 & 2.32 & 2.39 & 2.49 & 2.50 & 299 \\ \text { CHRBACK } & 2.35 & 2.57 & 2.05 & 2.33 & 2.23 & 2.34 & 288 \\ \text { CHAIRCON } & 2.63 & 3.04 & 2.74 & 2.73 & 2.73 & 2.79 & 303 \\ \text { CHRADJT } & 2.39 & 2.83 & 2.53 & 2.57 & 2.54 & 2.60 & 295 \\ & & & & & & & \\ \text { avg } & 2.50 & 2.83 & 2.47 & 2.52 & 2.53 & 2.59\end{array}$

Color of Furnishings

$\begin{array}{llllllll}\text { FURNCOLR } & 2.83 & 3.15 & 3.16 & 2.73 & 3.68 & 3.11 & 299 \\ \text { WALLCOLR } & 3.04 & 2.51 & 3.58 & 3.06 & 3.48 & 3.08 & 307 \\ & & & & & & & \\ \operatorname{avg} & 2.94 & 2.83 & 3.37 & 2.90 & 3.58 & 3.10\end{array}$

\section{Maintenance}

$\begin{array}{llllllll}\text { FURNDUST } & 2.88 & 2.24 & 2.74 & 2.77 & 2.95 & 2.70 & 293 \\ \text { CARPET } & 2.65 & 2.88 & 2.68 & 3.56 & 3.22 & 3.17 & 270 \\ & & & & & & & \\ \text { avg } & 2.76 & 2.56 & 2.71 & 3.17 & 3.09 & 2.94\end{array}$




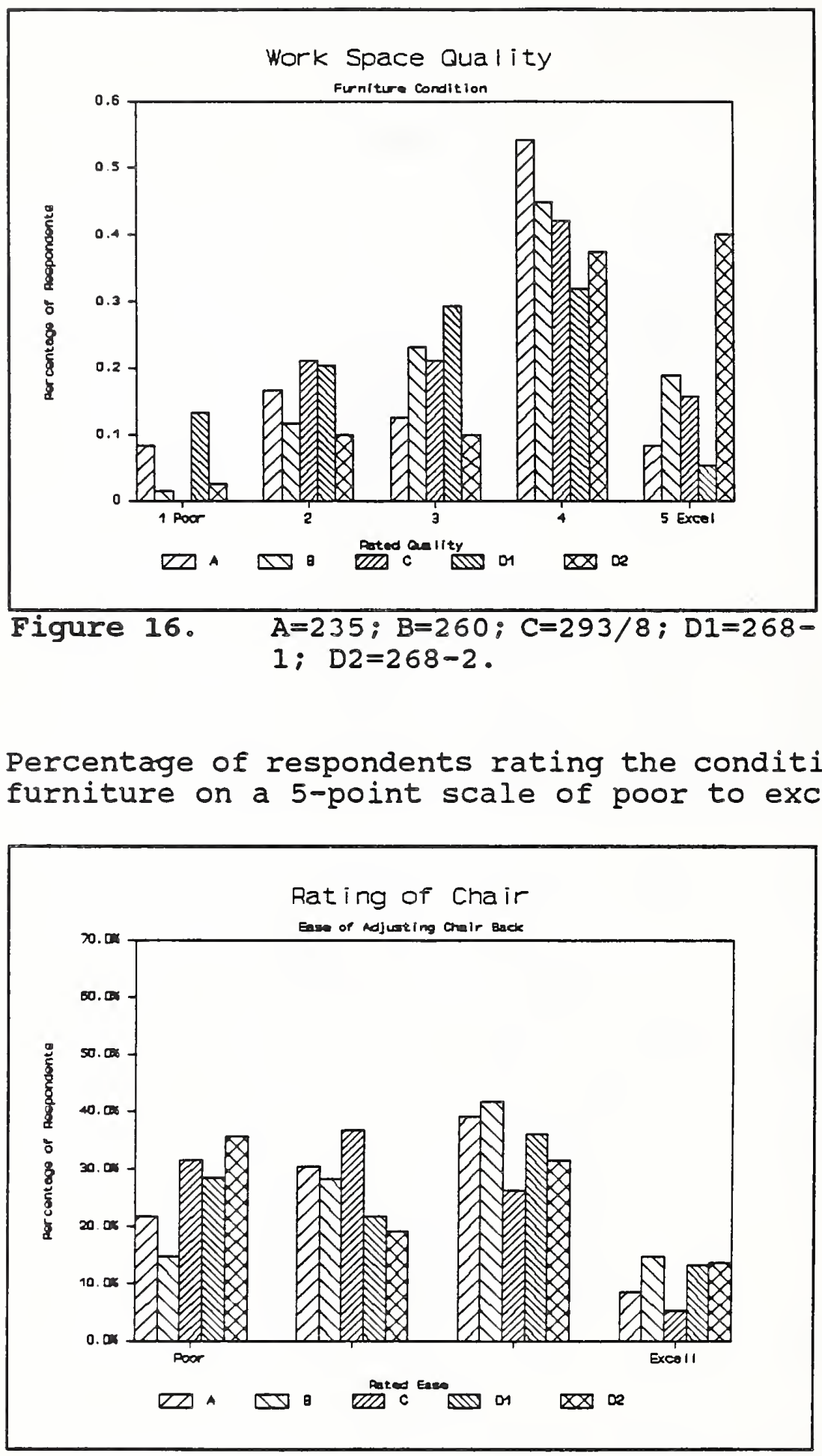

Figure 16. Percentage of respondents rating the condition of their furniture on a 5-point scale of poor to excellent.

Figure 17. Percentage of respondents rating the ease of adjusting their chair back. 
Satisfaction with equipment varied quite a bit with those in $293 / 8$ being most dissatisfied. Here $41 \%$ expressed dissatisfaction as compared with $15 \%$ in 235. Specific suggestions for improving equipment are discussed at greater length in section 3 . The mean site rating of 3.19 was fairly high, however.

The next entries in table 4 present responses to chair characteristics using a four point scale of poor to excellent. Ratings were generally slightly above the theoretical scale midpoint of 2.5. The lowest ratings occurred for a question about the chair back, where between 15 and $35 \%$ indicated that the ease of adjustment was poor. This was particularly true for building 293/8 and 268 as shown in figure 17. Unlike the findings reported by Rubin and Collins (1988), chair performance did not appear to be a major problem, with 40-55\% considering chair condition to be "good".

Ratings for questions about the color of the furniture and walls varied quite a bit between buildings. Although the overall mean was about 3.0 , the mean for wall color in 260 was substantially below that at 2.51 . Here $48 \%$ rated wall color as "poor" to "fair". The greatest improvement occurred in 268 where the mean rating improved from 2.7 to 3.7 following the renovation. Figure 18 illustrates the marked shift in ratings in 268 where 228 judged furniture color as "good" to "excellent" before the renovation and 628 gave such ratings after. Ratings for maintenance were not as positive with about 628 of those in building 260 considering dust to be a problem. Similarly ratings for carpet condition were relatively low in buildings 235,260 and $293 / 8$, with 35-458 considering it to be "fair" to "poor". Interestingly, ratings of carpet condition dropped in 268 following the renovation with $15 \%$ fewer people giving it an "excellent" rating. Yet its condition was still rated as better (mean 3.22) than in the other buildings (with means of 2.65 to 2.88 ).

\subsection{Health Issues}

The next questions dealt with the reported health of the occupants in terms of symptoms that they believed to be related to their office environment. Here a high rating meant frequent occurrence of the symptoms. Although all symptoms had a mean rating below 3 , indicating relatively infrequent occurrence, it is instructive to look at the distribution of ratings. Table 5 presents the frequency of occurrence of different symptoms in terms of "never", "rare", "sometimes", "frequently", and "most of the time". The mean ratings tended to be lowest in 235 and highest in 260 and 268 with little change following the renovation in 268 .

Table 5 indicates that occupants did not consider dizziness and ear infections to be a frequent occurrence. Conversely, as many as $75 \%$ in 260 and 65-708 in 268 experienced headaches, at least some of the time, as figure 19 indicates. Sleepiness occurred at least some of the time to about $75 \%$ in 260 and about 608 in 268, whereas sore throats occurred frequently to only about 9 to $18 \%$ of the occupants, (although the incidence was greater in 260 and 268). Although runny noses and trouble focusing eyes were reported primarily in 260, they did not occur as frequently as irritated eyes, reported by 30-35\% of those in 260 and 268. Occasional to frequent difficulties in concentrating were reported by about 70-75\% of those in 260 
Table 5. Health Related Responses to the Environment

\begin{tabular}{|c|c|c|c|c|c|c|c|c|c|c|}
\hline & & Never & $\underline{\text { Rarely }}$ & Some & Freq & $\underline{\text { Most }}$ & $\underline{N}$ & Mean & $\underline{\text { Std }}$ & $\frac{\text { Site }}{\text { Mean }}$ \\
\hline 235 & HEADACHE & 22.78 & 50.08 & 9.18 & 13.68 & 4.58 & 22 & 2.27 & 1.09 & 2.82 \\
\hline 260 & HEADACHE & 5.98 & 19.18 & 42.68 & 27.98 & 4.48 & 68 & 3.06 & 0.94 & \\
\hline $293 / 8$ & HEADACHE & 15.88 & 26.38 & 31.68 & 15.88 & $10.5 \%$ & 19 & 2.79 & 1.20 & \\
\hline $268-1$ & HEADACHE & 14.88 & 19.18 & 40.98 & 19.18 & 6.18 & 115 & 2.83 & 1.09 & \\
\hline $268-2$ & HEADACHE & 17.18 & 12.28 & 48.88 & 19.58 & 2.48 & 82 & 2.78 & 1.02 & \\
\hline 235 & DIZZY & 54.58 & 27.38 & 13.68 & 0.08 & 4.58 & 22 & 1.73 & 1.01 & 1.78 \\
\hline 260 & DIZZY & 50.08 & 22.1 왕 & 17.68 & 5.98 & 4.48 & 68 & 1.93 & 1.14 & \\
\hline $293 / 8$ & DIZZY & 47.48 & 36.88 & 10.58 & 0.08 & 5.38 & 19 & 1.79 & 1.00 & \\
\hline $268-1$ & DIZZY & 54.98 & 20.48 & 18.68 & 4.48 & $1.8 \%$ & 113 & 1.78 & 1.01 & \\
\hline $268-2$ & DIZZY & 55.68 & 29.68 & 11.18 & 1.28 & 2.58 & 81 & 1.65 & 0.90 & \\
\hline 235 & SLEEPY & 36.48 & 36.48 & 22.78 & 0.08 & 4.58 & 22 & 2.00 & 1.00 & 2.66 \\
\hline 260 & SLEEPY & 13.48 & 11.98 & $47.8 \%$ & 17.98 & 9.08 & 67 & 2.97 & 1.09 & \\
\hline $293 / 8$ & SLEEPY & 31.68 & 36.88 & 21.18 & 10.58 & 0.08 & 19 & 2.11 & 0.97 & \\
\hline $268-1$ & SLEEPY & 21.28 & 18.68 & 31.08 & 23.08 & 6.28 & 113 & 2.74 & 1.20 & \\
\hline $268-2$ & SLEEPY & $20.7 \%$ & 22.08 & 37.88 & 17.18 & 2.48 & 82 & 2.59 & 1.07 & \\
\hline 235 & SORTHROT & 54.58 & 36.48 & 0.08 & 4.58 & 4.58 & 22 & 1.68 & 1.02 & 2.20 \\
\hline 260 & SORTHROT & 34.38 & 17.98 & 34.38 & 9.08 & 4.58 & 67 & 2.31 & 1.16 & \\
\hline $293 / 8$ & SORTHROT & 42.18 & 31.68 & $15.8 \%$ & 5.38 & 5.38 & 19 & 2.00 & 1.12 & \\
\hline $268-1$ & SORTHROT & 38.18 & 24.88 & 19.58 & 15.98 & $1.8 \%$ & 113 & 2.19 & 1.16 & \\
\hline $268-2$ & SORTHROT & 28.88 & 27.58 & 31.38 & 8.88 & 3.88 & 80 & 2.31 & 1.09 & \\
\hline 235 & RUNN & 52.28 & 21.78 & 17.48 & 4.38 & 4.38 & 23 & 1.87 & 1.12 & 2.38 \\
\hline 260 & RUNNOSE & 34.38 & 11.98 & 40.38 & 7.58 & 6.08 & 67 & 2.39 & 1.20 & \\
\hline $293 / 8$ & RUNNOSE & 31.68 & 21.18 & 26.38 & 10.58 & $10.5 \%$ & 19 & 2.47 & 1.31 & \\
\hline $268-1$ & RUNNOSE & $33.6 \%$ & $18.6 \%$ & 29.28 & 15.08 & 3.58 & 113 & 2.36 & 1.19 & \\
\hline $268-2$ & RUNNOSE & 24.78 & 27.28 & 25.98 & 17.38 & 4.98 & 81 & 2.51 & 1.18 & \\
\hline 235 & IRR & 39 & 21.78 & 21.78 & 8.78 & 8.78 & 23 & 2.26 & 1.29 & 2.76 \\
\hline 260 & IRRITEYE & 17.98 & 11.98 & 34.38 & 28.48 & 7.58 & 67 & 2.96 & 1.19 & \\
\hline $293 / 8$ & IRRITEYE & 26.38 & 26.38 & 26.38 & 15.88 & 5.38 & 19 & 2.47 & 1.19 & \\
\hline $268-1$ & IRRITEYE & 25.28 & 13.08 & 30.48 & 26.18 & 5.28 & 115 & 2.73 & 1.24 & \\
\hline $268-2$ & IRRITEYE & 22.28 & $9.9 \%$ & $35.8 \%$ & 24.78 & 7.48 & 81 & 2.85 & 1.23 & \\
\hline 235 & FOCUSEYE & 27.38 & 40.98 & 9.18 & 13.68 & 9.18 & 22 & 2.36 & 1.26 & 2.43 \\
\hline 260 & FOCUSEYE & 19.48 & 25.48 & 25.48 & 26.98 & 3.08 & 67 & 2.69 & 1.15 & \\
\hline $293 / 8$ & FOCUSEYE & 36.88 & 31.68 & 15.88 & 10.58 & 5.38 & 19 & 2.16 & 1.18 & \\
\hline $268-1$ & FOCUSEYE & 32.78 & 19.58 & 24.88 & 16.88 & 6.28 & 113 & 2.42 & 1.28 & \\
\hline $268-2$ & FOCUSEYE & 27.28 & 32.18 & 25.98 & 11.18 & 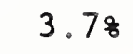 & 81 & 2.32 & 1.10 & \\
\hline 235 & DIFFCONC & 36.48 & 22.78 & 22.78 & 13.68 & 4.58 & 22 & 2.27 & 1.21 & 2.84 \\
\hline 260 & DIFFCONC & 4.58 & 27.38 & 54.58 & 12.18 & 1.58 & 66 & 2.79 & 0.77 & \\
\hline $293 / 8$ & DIFFCONC & 15.88 & 31.68 & 36.88 & 10.58 & 5.38 & 19 & 2.58 & 1.04 & \\
\hline $268-1$ & DIFFCONC & 7.88 & 19.18 & 49.68 & 19.18 & 4.38 & 115 & 2.93 & 0.93 & \\
\hline $268-2$ & DIFFCONC & 8.88 & 15.0 용 & 50.08 & $23.8 \%$ & 2.58 & 80 & 2.96 & 0.91 & \\
\hline
\end{tabular}




\begin{tabular}{|c|c|c|c|c|c|c|c|c|c|c|}
\hline & & Never & Rarely & $\underline{\text { Some }}$ & Freq & Most & $\underline{\mathrm{N}}$ & Mean & $\underline{\text { Std }}$ & $\frac{\text { Site }}{\text { Mean }}$ \\
\hline 235 & FATIGUE & 36.48 & 36.48 & 13.68 & 9.18 & 4.58 & 22 & 2.09 & 1.12 & 2.69 \\
\hline 260 & FATIGUE & 9.18 & 15.28 & 47.08 & 27.38 & 1.58 & 66 & 2.97 & 0.92 & \\
\hline $293 / 8$ & FATIGUE & 21.18 & 26.38 & 36.88 & 15.88 & 0.08 & 19 & 2.47 & 0.99 & \\
\hline $268-1$ & FATIGUE & 17.48 & 18.38 & 45.08 & 15.68 & 3.78 & 109 & 2.70 & 1.04 & \\
\hline $268-2$ & FATIGUE & 7.48 & 33.38 & 46.98 & 9.98 & 2.58 & 81 & 2.67 & 0.85 & \\
\hline 235 & EAR INF. & 65.28 & 26.18 & 4.38 & 0.08 & $4.3 \%$ & 23 & 1.52 & 0.93 & 1.46 \\
\hline 260 & EAR & 73.88 & 16.98 & 6.28 & 3.18 & 0.08 & 65 & 1.38 & 0.74 & \\
\hline $293 / 8$ & EAR & $73.7 \%$ & 21.18 & 5.38 & 0.08 & 0.08 & 19 & 1.32 & 0.57 & \\
\hline $268-1$ & EAR & 68.28 & 16.48 & 8.28 & 4.58 & 2.78 & 110 & 1.57 & 1.00 & \\
\hline $268-2$ & EAR & 73.48 & 17.78 & 6.38 & 1.38 & 1.38 & 79 & 1.39 & 0.77 & \\
\hline 235 & COLDS & 52.28 & 39.18 & 0.08 & 4.38 & 4.38 & 23 & 1.70 & 1.00 & 2.10 \\
\hline 260 & COLDS & 40.98 & 33.38 & 16.78 & 7.68 & 1.58 & 66 & 1.95 & 1.01 & \\
\hline $293 / 8$ & COLDS & 31.68 & 26.38 & 31.68 & 10.58 & 0.08 & 19 & 2.21 & 1.00 & \\
\hline $268-1$ & COLDS & $38.7 \%$ & 23.48 & 21.68 & 12.68 & 3.68 & 111 & 2.19 & 1.18 & \\
\hline $268-2$ & COLDS & 30.08 & 33.88 & 25.08 & 8.88 & 2.58 & 80 & 2.20 & 1.04 & \\
\hline 235 & SINUS & 52.28 & 21.78 & 4.38 & 13.08 & 8.78 & 23 & 2.04 & 1.37 & 2.48 \\
\hline 260 & SINUS & 40.98 & 12.18 & 21.28 & 12.18 & 13.68 & 66 & 2.45 & 1.46 & \\
\hline $293 / 8$ & SINUS & 31.68 & 21.18 & 31.68 & 5.38 & 10.58 & 19 & 2.42 & 1.27 & \\
\hline $268-1$ & SINUS & 35.78 & 15.28 & 26.88 & 13.48 & 8.98 & 112 & 2.45 & 1.33 & \\
\hline $268-2$ & SINUS & 27.58 & 15.08 & 30.08 & 16.38 & 11.38 & 80 & 2.69 & 1.33 & \\
\hline 235 & ALLERGY & 52.28 & 30.48 & 4.38 & 4.38 & $8.7 \%$ & 23 & 1.87 & 1.23 & 2.14 \\
\hline 260 & ALLERGY & $56.1 \%$ & 15.28 & 10.68 & 9.18 & 9.18 & 66 & 2.00 & 1.36 & \\
\hline $293 / 8$ & ALLERGY & 42.18 & 21.18 & 21.18 & 5.38 & 10.58 & 19 & 2.21 & 1.32 & \\
\hline $268-1$ & ALLERGY & 45.48 & 17.68 & 19.48 & 10.28 & 7.48 & 108 & 2.17 & 1.30 & \\
\hline $268-2$ & ALLERGY & 40.58 & 17.78 & 24.18 & 10.18 & 7.68 & 79 & 2.27 & 1.29 & \\
\hline & & None & $1-2 d a$ & $\underline{3-5 d a}$ & $6-12$ & $12+$ & $\mathrm{N}$ & & & \\
\hline 235 & LONGSICK & $\overline{47.88}$ & $\overline{47.88}$ & 0.08 & $\overline{4.38}$ & 0.08 & 23 & & & \\
\hline 260 & LONGSICK & 33.38 & 34.88 & 15.98 & 11.68 & 4.38 & 69 & & & \\
\hline $293 / 8$ & LONGS ICK & $36.8 \%$ & 15.88 & 21.18 & 26.38 & 0.088 & 19 & & & \\
\hline $268-1$ & LONGSICK & 40.08 & 26.48 & 17.38 & 10.08 & 6.48 & 110 & & & \\
\hline $268-2$ & LONGS ICK & $26.8 \frac{8}{8}$ & $30.5 \%$ & 30.58 & 6.18 & 4.98 & 82 & & & \\
\hline & & \multicolumn{2}{|c|}{ Very True } & Not at & all True & $\underline{\mathrm{N}}$ & Mean & $\underline{\text { std }}$ & \multicolumn{2}{|c|}{ Site Mean } \\
\hline 235 & TIREDEYE & 4.88 & 33.38 & 33.38 & 28.68 & 21 & 2.86 & $\overline{0.89}$ & & 45 \\
\hline 260 & TIREDEYE & 13.68 & 43.98 & 28.88 & 13.68 & 66 & 2.42 & 0.89 & & \\
\hline $293 / 8$ & TIREDEYE & 21.18 & 42.18 & 26.38 & 10.58 & 19 & 2.26 & 0.91 & & \\
\hline $268-1$ & TIREDEYE & 19.38 & 36.78 & 31.28 & 12.88 & 109 & 2.38 & 0.94 & & \\
\hline $268-2$ & TIREDEYE & 12.38 & 40.78 & 30.98 & 16.08 & 81 & 2.51 & 0.90 & & \\
\hline 235 & WORKSAT & 47.68 & 47.68 & 0.08 & 4.88 & 21 & 1.62 & 0.72 & & 77 \\
\hline 260 & WORKSAT & 43.98 & 50.08 & 3.08 & 3.08 & 66 & 1.65 & 0.69 & & \\
\hline $293 / 8$ & WORKSAT & 26.38 & 52.68 & 21.18 & 0.08 & 19 & 1.95 & 0.69 & & \\
\hline $268-1$ & WORKSAT & 28.28 & 60.98 & 10.08 & 0.98 & 110 & 1.84 & 0.63 & & \\
\hline $268-2$ & WORKSAT & 35.48 & 54.98 & 7.38 & 2.48 & 82 & 1.77 & 0.69 & & \\
\hline
\end{tabular}


Very True

$\begin{array}{ll}235 & \text { WRKACR } \\ 260 & \text { WRKACR } \\ 293 / 8 & \text { WRKACR } \\ 268-1 & \text { WRKACR } \\ 268-2 & \text { WRKACR }\end{array}$

235 WRKIMPT

260 WRKIMPT

293/8 WRKIMPT

268-1 WRKIMPT

268-2 WRKIMPT

1.58

2.88

0.08

$\begin{array}{ll}76.28 & 19.08 \\ 70.18 & 28.48 \\ 47.48 & 36.88 \\ 68.88 & 29.48 \\ 62.28 & 32.98\end{array}$

Not at all True

N

$\begin{array}{rrrrrr}4.88 & 0.08 & 21 & 1.29 & 0.55 & 1.38 \\ 1.58 & 0.08 & 67 & 1.31 & 0.50 & \\ 5.38 & 10.58 & 19 & 1.79 & 0.95 & \\ 1.88 & 0.08 & 109 & 1.33 & 0.51 & \\ 4.98 & 0.08 & 82 & 1.43 & 0.58 & \end{array}$

$\frac{\text { Not at all True }}{0.08 \quad 4.88}$

Very True

3.08

4.8890 .58

18.28

77.38

21.18

52.68

15.8 용

24.18

67.68

20.7 \%

70.78

$\frac{\mathrm{N}}{21}$

Mean

3.86

Std Site Mean

66

19

3.71

0.47

0.60

108

3. 16

1.04

82

$\begin{array}{rr}0.08 & 9.18 \\ 0.08 & 6.18 \\ 5.38 & 15.88 \\ 1.88 & 7.38 \\ 3.78 & 4.98\end{array}$

$50.08 \quad 40.98$

$39.48 \quad 54.58$

21.18

57.98

49.18

41.88

52.48

39.08

$\begin{array}{rr}22 & 3.32 \\ 66 & 3.48 \\ 19 & 3.32 \\ 110 & 3.31 \\ 82 & 3.27\end{array}$

0.72

0.64

$\begin{array}{rr}4.88 & 9.58 \\ 4.68 & 13.88 \\ 22.28 & 33.38 \\ 6.48 & 11.98 \\ 6.18 & 13.48\end{array}$

66.78

$19.0 \%$

46.28

35.48

27.88

16.78

52.38

29.48

37.88

21

3.00

$\begin{array}{ll}65 & 3.12\end{array}$

0.63

0.61

0.92

0.68

0.72

3.34

$42.7 \%$

18

2.39

0.69

3.04

109

3.05

0.81

1.01

0.82

82

3.12

0.86

\begin{tabular}{|c|c|c|}
\hline No & Yes & $\underline{\mathrm{N}}$ \\
\hline 68.28 & 31.88 & 22 \\
\hline 72.78 & 27.38 & 66 \\
\hline 73.78 & 26.38 & 19 \\
\hline 62.08 & 36.08 & 100 \\
\hline 74.48 & 25.68 & 82 \\
\hline
\end{tabular}

CIVILIAN
CIVILIAN
CIVILIAN
CIVILIAN
CIVILIAN

No Yes N

$27.38 \quad 72.78 \quad 66$

$\begin{array}{lll}22.28 & 77.88 & 18\end{array}$

$\begin{array}{lll}26.08 & 74.08 & 96\end{array}$

268-1 MILITARY

268-2 MILITARY

$\begin{array}{ll}235 & \text { SEX } \\ 260 & \text { SEX } \\ 293 / 8 & \text { SEX }\end{array}$

$\frac{\text { Female }}{18.28} \quad \frac{\text { Male }}{81.88} \quad \frac{\mathrm{N}}{22}$

43.98

26.38

56.18

73.78

24.48

$74.48 \quad 82$

$\frac{\text { Yes }}{54.28}$

50.78

47.48

33.68

32.98 $\frac{\text { No }}{45.88} \quad \frac{N}{24}$

$49.38 \quad 69$

$52.68 \quad 19$

$66.48 \quad 110$

$67.18 \quad 82$
Female Male $\quad \frac{N}{107}$

268-1 SEX 25.28 74.88 107

268-2 SEX 20.78 $79.38 \quad 82$

268-1 GLASSES

268-2 GLASSES

235 AGE

260 AGE

293/8 AGE

268-1 AGE

268-2 AGE

$\begin{array}{lllllr}\frac{20-29}{0.08} & \frac{30-39}{31.88} & \frac{40-49}{31.88} & \frac{50-59}{22.78} & \frac{60+}{13.68} & \frac{\mathrm{N}}{22} \\ 1.58 & 36.88 & 29.48 & 23.58 & 8.88 & 68 \\ 0.08 & 36.88 & 26.38 & 21.18 & 15.88 & 19 \\ 0.08 & 22.98 & 29.48 & 28.48 & 19.38 & 109 \\ 0.08 & 16.78 & 30.88 & 30.88 & 21.88 & 78\end{array}$

$$
\begin{array}{lrrr}
\text { Yes } & \text { No } & \text { N } \\
\hline 95.78 & & 4.38 & 23 \\
95.78 & & 4.38 & 69 \\
84.28 & & 15.88 & 19 \\
63.98 & 36.18 & 97 \\
74.48 & 25.68 & 82
\end{array}
$$




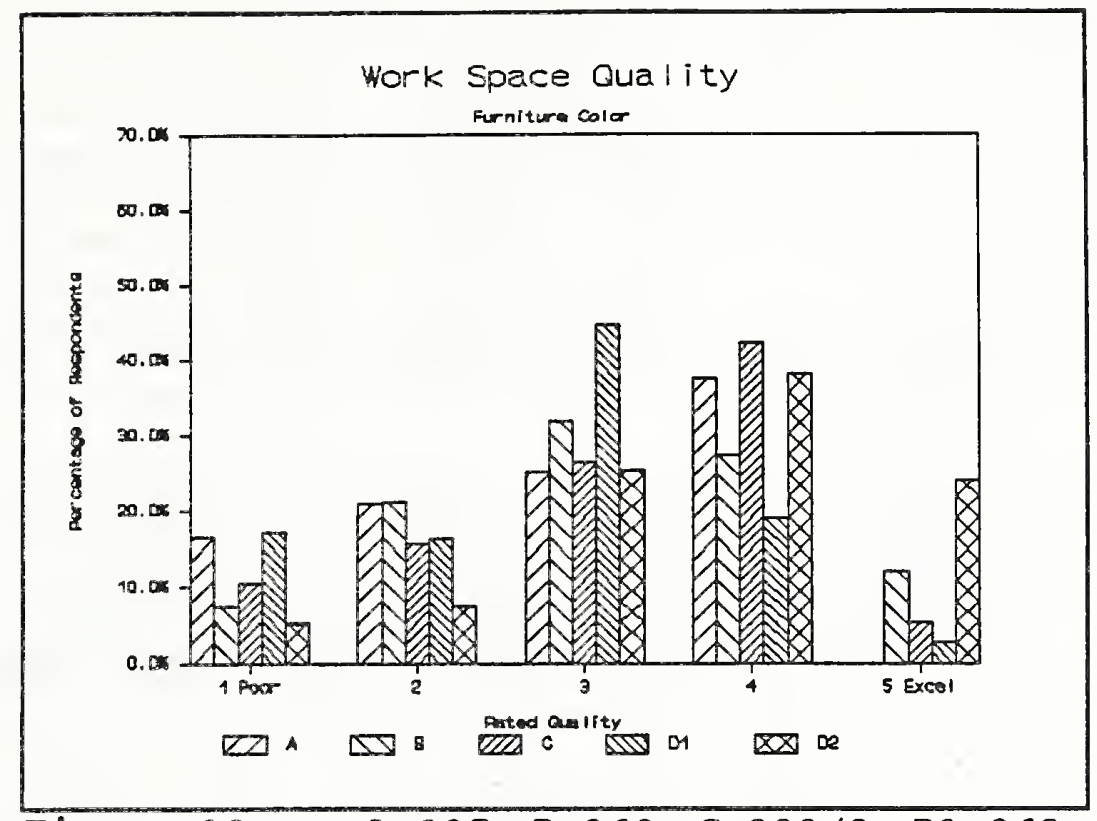

Figure 18. $A=235 ; B=260 ; C=293 / 8 ; D 1=268-$ 1: $\mathrm{D} 2=268-2$.

Figure 18. Percentage of people rating the color of their furniture on a 5-point scale of poor to excellent.

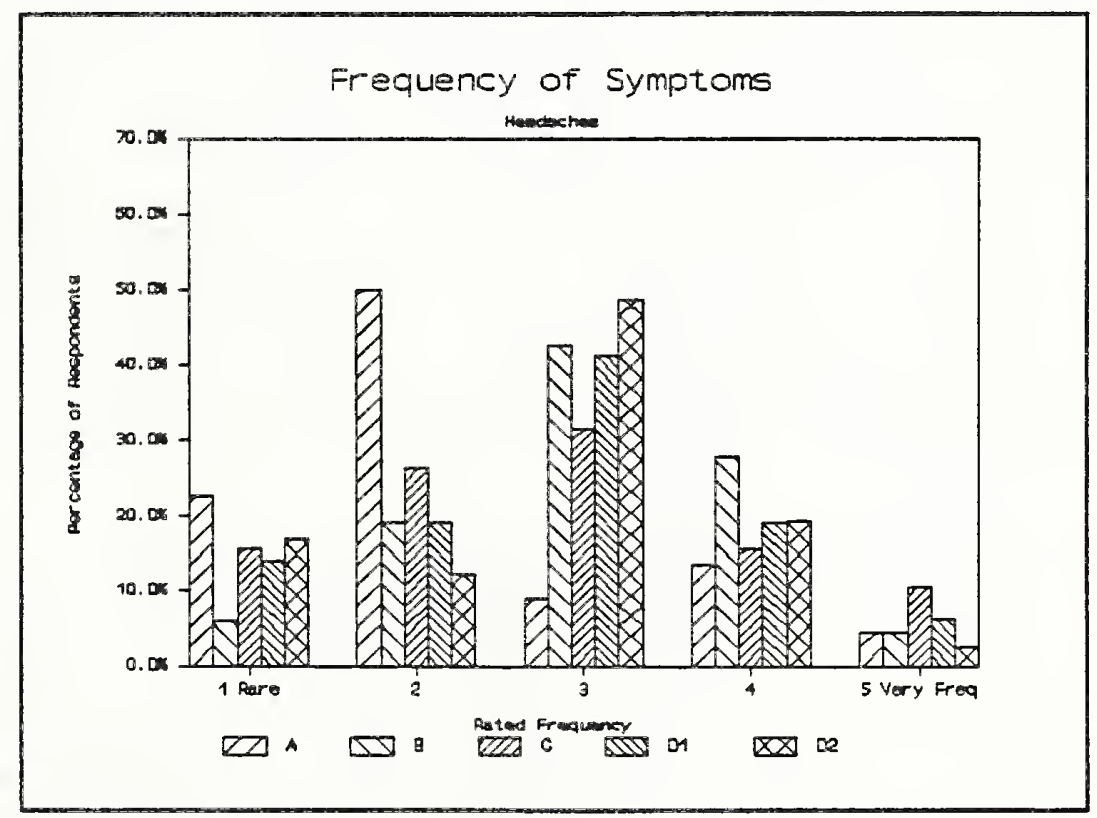

Figure 19. Percentage of people rating the frequency of headaches on a 5-point scale of rare to very frequent. 
and 268, while problems with fatigue were mentioned by $60-758$ of those in these two buildings. Finally, difficulties with sinuses were more prevalent than colds or allergies, again most frequently in 260 and 268 . Inspection of table 5 makes it very clear that problems with headaches, sleepiness, irritated eyes, difficulty in concentration, and fatigue were reported as occurring at least sometimes to 608 of those in buildings 260 and 268 . Such a high frequency of health-related symptoms suggests possible problems specific to the two buildings - especially since these buildings also had the lowest ratings for air quality satisfaction. It would seem prudent to investigate this relationship further, particularly since some 308 of the respondents in these two buildings reported frequent headaches.

The air quality problems in 260 and 268 are partially borne out by the number of days reported being sick (LONGSICK) in the last six months - - with between 4-6\% being ill for more than 12 days. Yet the data for sick leave reveals that a high percentage (26\% -- or about 5 people) in building $293 / 8$ reported being sick 6-12 days -- more than in any other building. People in 293/8 had reported frequent runny noses, colds, and headaches as well. These findings make the health-related effects of the buildings very difficult to determine - although the problems in 260 and 268 may relate to air quality. Certainly a high incidence of headaches, irritated eyes, sleepiness, and difficulties in concentrating was reported for these two buildings. These conditions may have been annoying, but not serious enough to take sick leave.

\subsection{Job Attitudes}

The next entries in Table 5 present attitudes toward people's jobs, including job satisfaction, work accuracy, and work importance. Here a high rating indicated a positive attitude for these 4 point scales. The overall mean was 3.0 -- indicating a very positive reaction. The mean for work importance was one of the highest at the site-- 3.61 on a 4 point scale. As figure 20 indicates, more than $70 \%$ of those in 235, 260 and 268 felt that their jobs were very important. The lowest mean rating, 3.0, was given by those in building 293/8. Their ratings for overall job satisfaction shown in figure 21 were also the lowest at the site, with a mean of 2.39 as compared with ratings around 3 for the other buildings. As many as $85 \%$ in 260 and 269 expressed high levels of job satisfaction. In fact, the data suggest that the majority of the people at the site, particularly those in 260 and 268, took pride in their work and were satisfied with their performance.

Answers to questions about the accuracy and quality of people's work indicated that people felt that their work must be accurate (mean of 1.38 - a low rating meant a positive response) and that they were satisfied with the quality of their work (mean of 1.76). These ratings suggest that only about 58 felt dissatisfled with the accuracy and quality of their work. Those in 293/8 were again least positive, particularly for the accuracy of their work, although the mean ratings were very similar for the five groups. As noted in section 2.1 and shown in table 5, the work force was largely male, civilian, and between 30 and 49 , with 45 to $67 \%$ wearing glasses, bifocals, or contacts. 


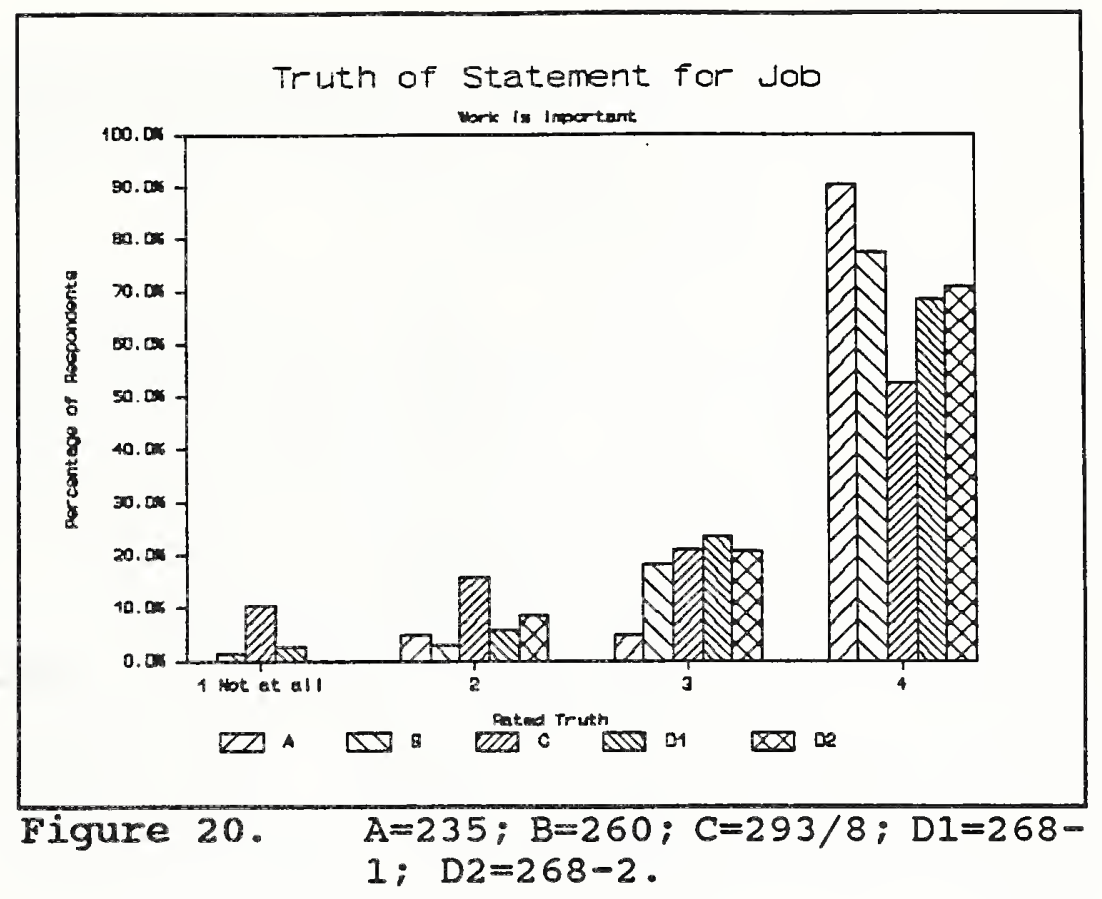

Figure 20. Percentage of respondents rating the truth that their job is important on a 4 -point scale.

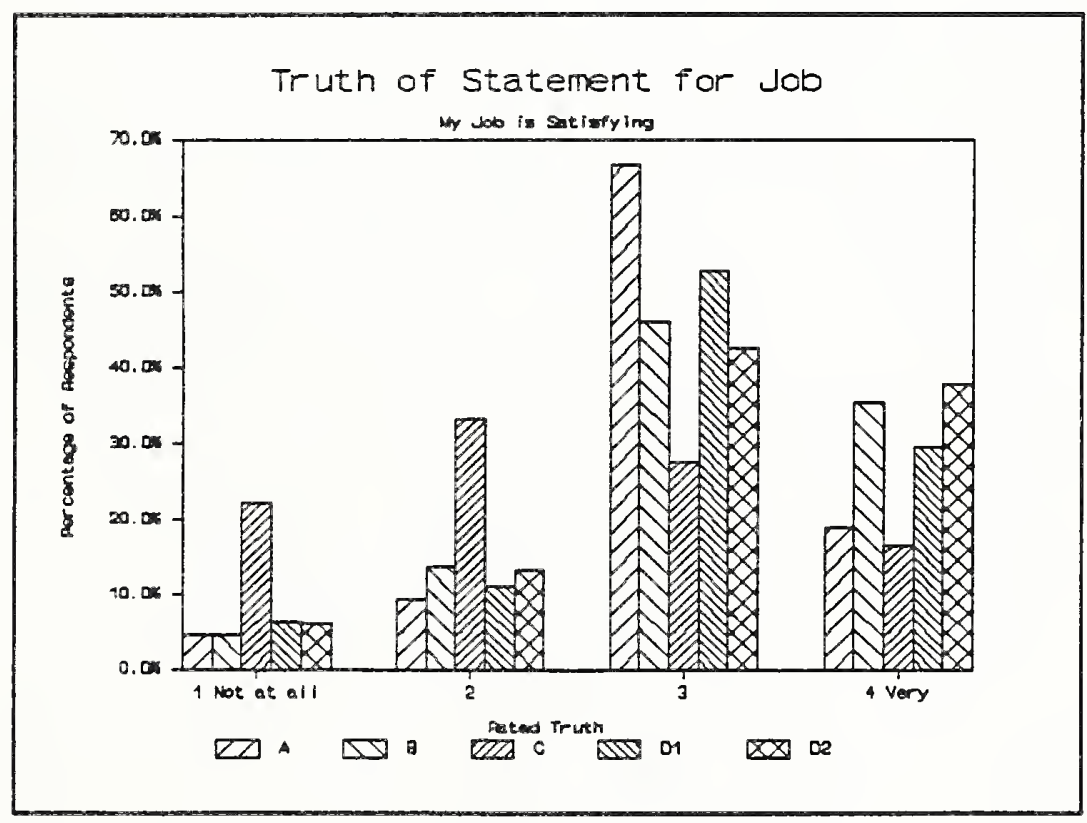

Figure 21. Percentage of respondents rating their satisfaction with their job. 


\subsection{General Feelings about Facility}

Table 6 presents bipolar scale data on the feelings toward the buildings. On a bipolar scale, feelings about a particular attribute of a space are rated on a 5 point scale ranging from positive to negative -- such as pleasant to unpleasant. For these scales, a rating of "3" was neutral -- meaning that a building was neither pleasant nor unpleasant.

The mean ratings for the scale of "smelly-not smelly" (where a high rating meant "not smelly") indicated that building 235 was considered to be the least smelly, while 260 was the most. Building 268 was rated as somewhat more smelly following the renovation - - perhaps because of the new furniture. Ratings of "interesting-boring" indicated that all the buildings were more "boring" than "interesting", with 260 receiving the lowest mean rating (most boring). Scores for 268 improved following the renovation. Ratings for "stimulating-unstimulating" indicated that the buildings were not seen as stimulating. Ratings of "pleasantness" showed the greatest variation among buildings with those in $293 / 8$ being highest and those in 260 being lowest. The ratings of building pleasantness shown in Figure 22 demonstrate that $20 \%$ of those in 260 rated it as "not very pleasant". The renovation in 268 , however, increased its pleasantness. Although no building was rated as particularly colorful, 260 was judged as least colorful, with 42 rating it as drab. Building 268 was rated as somewhat more colorful following the renovation. Although responses to two questions about lighting, "well lit" and "bright", were more positive, examination of the responses reveals that 25-35\% of those in 260 and 268 felt that their spaces were poorly lit and dim.

The mean ratings for questions about building maintenance and cleanliness were positive and similar for all buildings except 260 , which was perceived as clean but poorly maintained. Maintenance in Building 268 improved following the renovation. Ratings of "confined-spacious" revealed that the buildings were all perceived to be confined, with $55 \%$ of those in 260 rating it as "confined" as shown in figure 23. Building 268 was also thought to be more confined following the renovation. Yet, the buildings were generally considered to be adequate for the job with mean ratings slightly above 3 . Responses to a question about noise revealed that respondents rated their buildings as "noisier" rather than quiet. In particular, 458 of those in 268 (before and after the renovation) rated it as noisy, as did 39\% in 260. All buildings were rated as more "humid" than "dry", except 293/8 which was seen as neutral by $72 \%$ of the respondents. Responses for temperature varied, with 235 and 268-1 receiving higher mean ratings (indicating that they were "hot"). About $13 \%$ felt that building 260 was cold, while $18 \%$ thought that 268 was too warm before the renovation, but only 58 thought that it was too warm after. (The change in outside temperature from August to January may be more responsible for this shift in attitudes than the renovation itself). The ratings shown in table 5 suggest that respondents were somewhat more negative than positive about their buildings. People were most negative about spaciousness and colorfulness and most positive about cleanliness and adequacy for their jobs. Furthermore, respondents were most positive about building 235 and least positive about 260, with the renovation in 268 improving peoples' attitudes about its appearance. 
Table 6. Mean Ratings of Building Appearance from the Environmental Conditions in the Buildings Studied.

\section{Building Appearance}

$\begin{array}{llllllc}\text { BLDG } & \text { BLDG } & \text { BLDG } & \text { BLDG } & \text { BLDG } & \text { Site } & \text { Total } \\ 235 & 260 & 293 / 8 & 268-1 & 268-2 & \text { Mean } & \text { N }\end{array}$

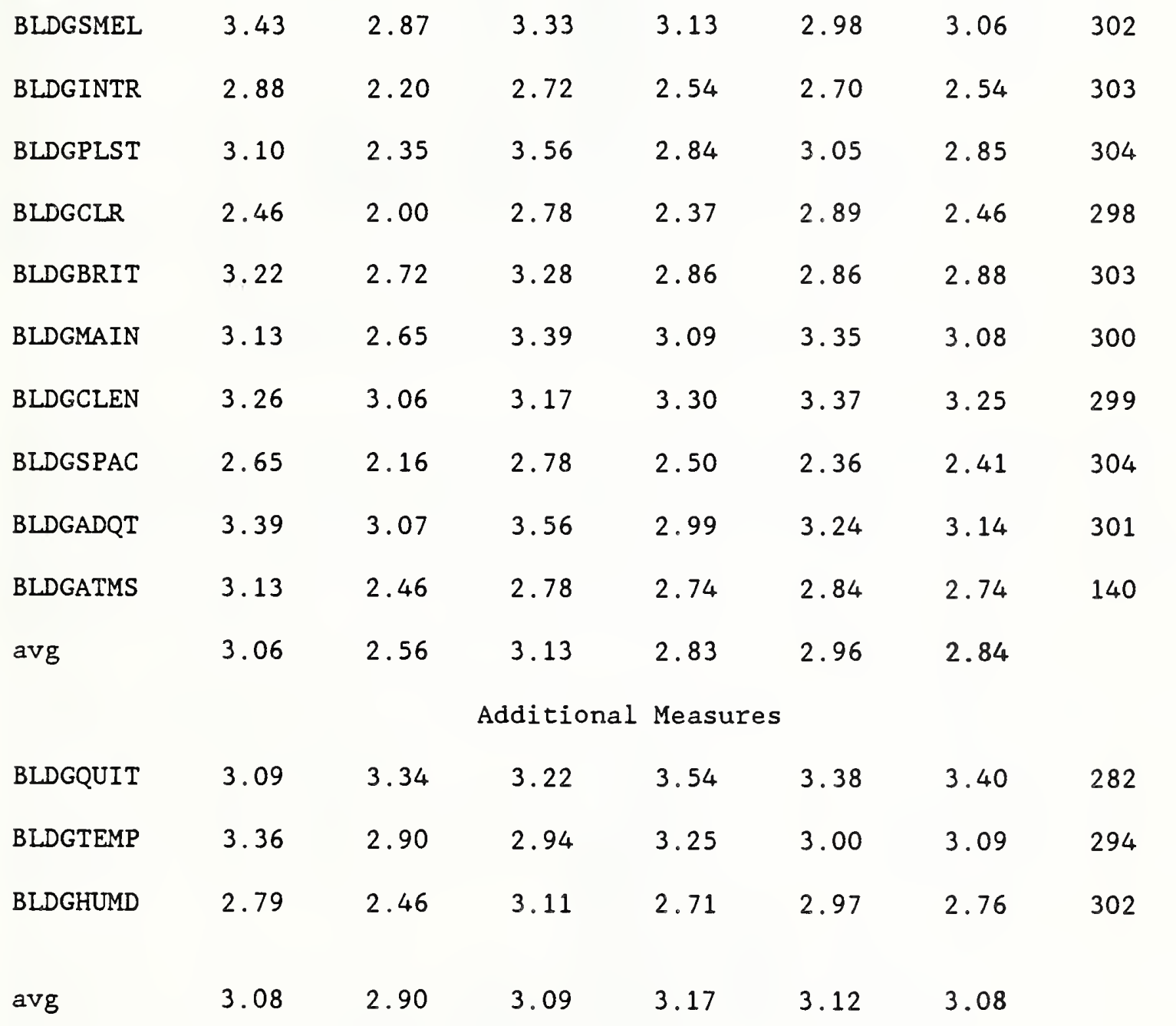




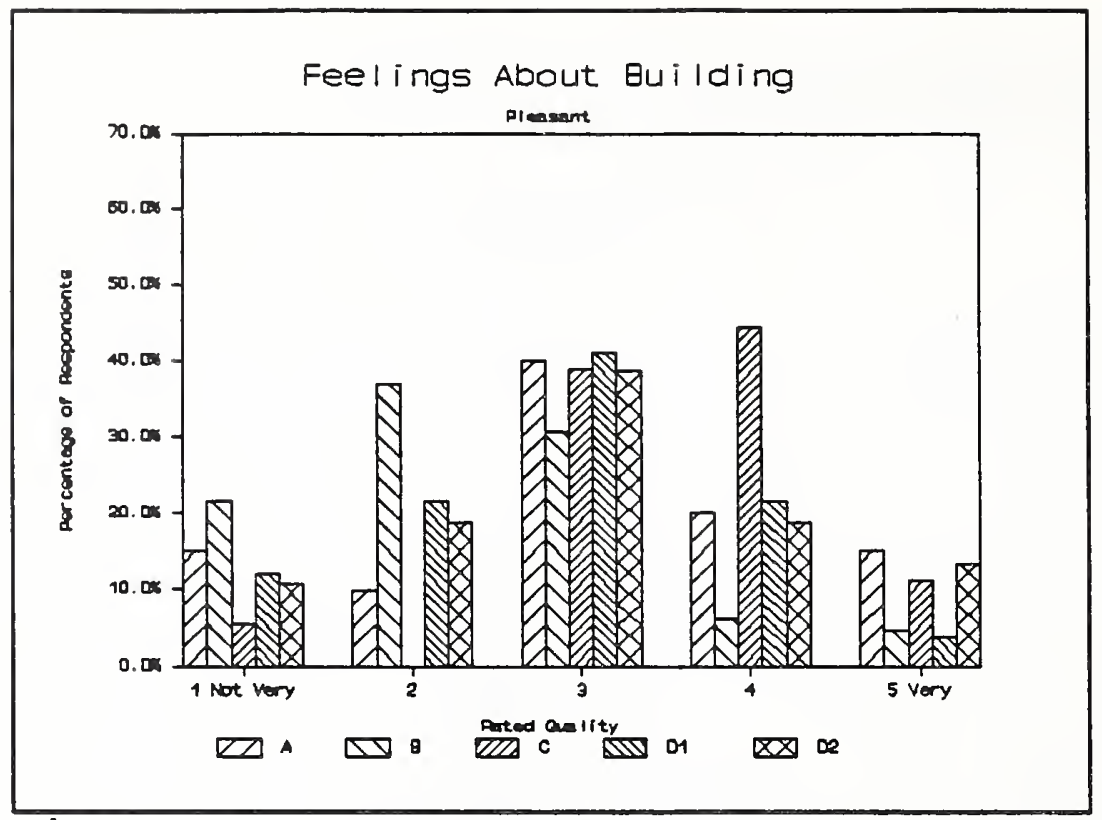

Figure 22. $A=235 ; B=260 ; C=293 / 8 ; D 1=268-$ 1: $\mathrm{D} 2=268-2$.

Figure 22. Percentage of respondents rating their building as pleasant on a 5-point scale of "not very" to "very".

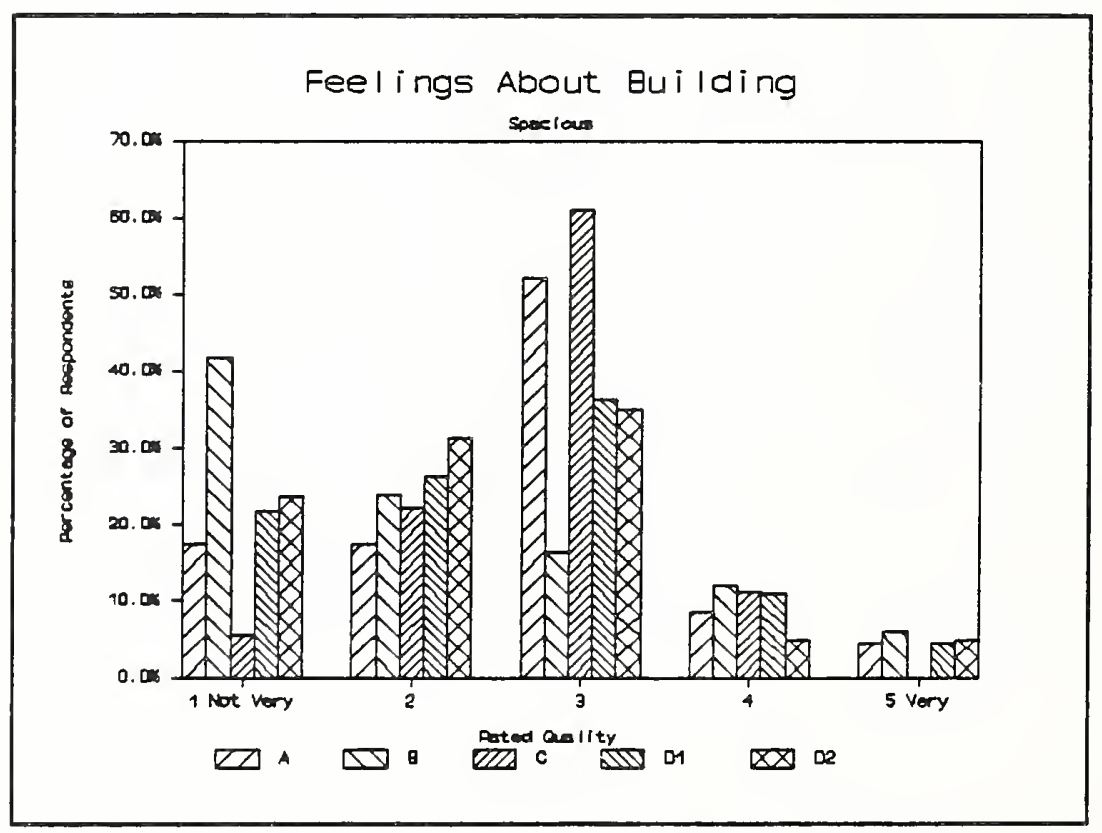

Figure 23. Percentage of respondents rating their building as spacious on a 5-point scale of "not very" to "very". 


\section{2,10 Comparison of Rating Differences}

Several different procedures were used to make meaningful comparisons of the rating data obtained for the site. A coding scheme was developed to compare the differences from the scale midpoint for each rating for the five buildings. In this scheme, the direction of differences from the scale midpoint was coded by "+", "0", or "-", depending on the relationship to the mean. In addition, an attempt was made to determine the size of the difference. For this comparison, a difference of 0.5 was considered to be meaningful; differences of 1.0 were considered to be important. An indication of the size of the difference is given by the number of "+' $s$ " or "-'s". Thus, for a five-point scale, the following scheme was used:

$$
\begin{aligned}
& 1.90 \rightarrow 2.39=--; 2.40 \rightarrow 2.89=-; \\
& 2.90 \rightarrow 3.09=0 ; \\
& 3.10 \rightarrow 3.59=+; \text { and } 3.60 \rightarrow 4.10=++ \text {. }
\end{aligned}
$$

For a four-point scale, the following scheme was used:

$$
\begin{aligned}
& 1.40 \rightarrow 1.89=--; 1.90 \rightarrow 2.39=-; \\
& 2.40 \rightarrow 2.59=0 ; \\
& 2.60 \rightarrow 3.09=+; \text { and } 3.10 \rightarrow 3.60=++ \text {. }
\end{aligned}
$$

This scheme thus allows one to compare differences in scales as well as in buildings, and provides an overview of the magnitude of the difference from the scale midpoint of the rating scale. The codings are such that a "-" always means a negative rating; "+" always means a positive one. Thus, for the scales of "bothersomeness", ratings above 2.5 were treated as negative since they indicated "more bothersomeness". Table 7 presents the coding scheme for each of the questions rated.

Table 7 also presents information on the statistical significance of the ratings. An asterisk (*) indicates differences from the scale midpoint that were significant according to a t-test with a significance level of $p<.01$. Because these differences were also lower than expected, they may well indicate problem areas. Significant differences in which performance was better than expected are identified by a double asterisk (**). In the statistical comparisons, the mean for all buildings combined was compared against the scale midpoint.

Use of the coding system and statistical comparisons allowed several areas of potential concern to be identified along with the buildings in which these concerns arose. Entries had to have at least a double minus rating (- -) to and be statistically below the scale midpoint to be included as a problem area. According to this technique, at least six broad areas of concern were identified. These include:

a. Problems related to the HVAC system

1. Air Circulation (AirCirc)

2. Heating

3. Cooling

4. Air Quality Satisfaction (AirQSat) 
Table 7. Rating scheme applied to the results from the questionnaire for the different buildings.

\section{Item}

WS SPCAMT

WSMATL**

AMTLTWK***

LOCCLNLT

WALLCOLR

FURNCOLR

*STORAGE

*CONVPRIV

COWORKER

*WALLSPC

*ADJAMTLT

*VISPRV

*WRKSPC

CHRCOMFT**

*AIRCIRC

*HEATING

*COOLING

*AIRQSAT

CARPET

*FUMES

*FURNDUST

ARGMTWS

LOOKWS

$\star$ RTLTBRK

RTLTHALL**

RTLTRSTM**

RTLTSPAC

*RTLTCONF

LTREAD**

LTVDT

LTFILE

*LTDRAFT

* LTOTHER

*AMTLTBRT

WSLITSAT

VDTFLICK**

VDTSTSC $* *$

VDTANGSC $* *$

VDTGLARE

VDTANGKB**

VDTDSKHGT $* *$

VDTSEAT**
Bldg 235

Bldg $260 \quad$ Bldg $293 / 8$

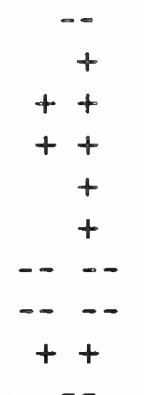

Bldg 268-1 Bldg 268-2
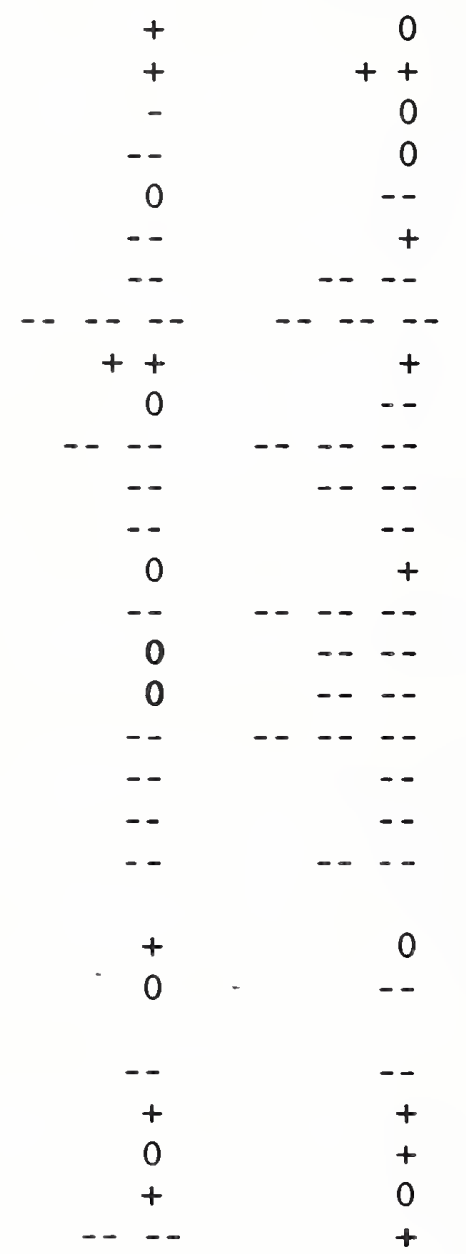

$++$

\section{$+$}

$+$

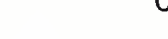

-

$--$

+
++
++
0
+
++
++

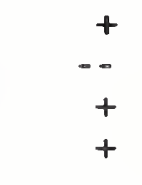

$++$

$++$

$++$

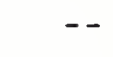

$--$

$\begin{array}{rr}+ & + \\ + & ++ \\ ++ & + \\ 0 & + \\ + & ++ \\ + & ++\end{array}$
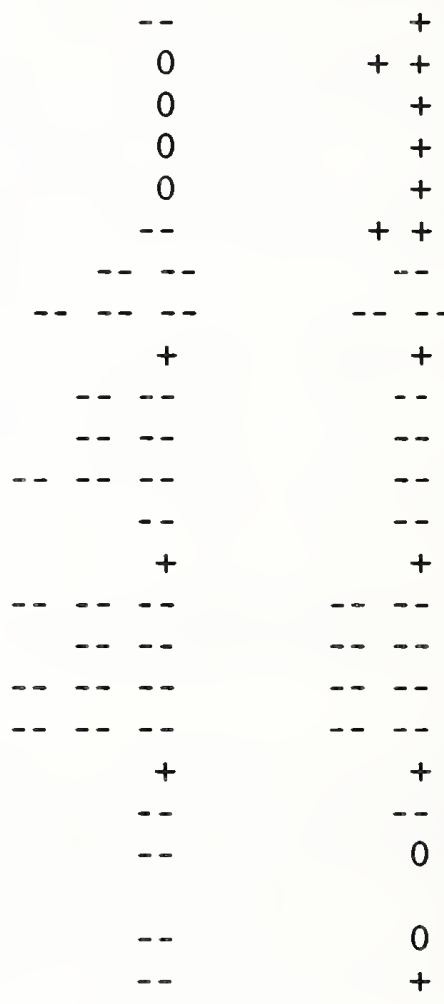

$+-$
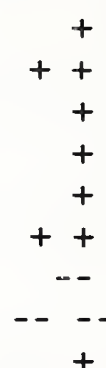

0

0

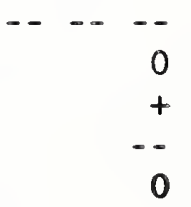

0

- 0

- $\quad+$

$--$

$--$

0

$-$

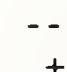

+
++
++
+
++
++
++

++
++
++
0
+
+
+ 
Table 7 Continued.

Item

VDTREFSC VDTREAD** VDTBRTLT** VDTADJSC $* *$ VDTSPACE VDTADJLT

NOISEPHN PEPTALK NOISEPRT ** NOISEEQP** NOISEVNT** NOISEHAL ** GLRWKSF** GLRCLNLT*** DIMLT** NOVIEW HOTSUMR COLDWTR DRAFTS ** *STUFYAIR PEPLWALK** PEPLCOS ** SMELLS** SMOKE TEMPSWN *AIRQUAL NOTSKLT

*BLDGPLST

BLDGADQT

BLDGMA IN *BLDGSPAC *STIMUL

*WELLIT

*BLDGHUMD

BLDGCLEN

*BLDGQUIT

*BLDGCLR

*BLDGINTR

BLDGTEMP

*BLDGATMS

BLDGSML

BLDGBRT

FURNSAT EQUIPSAT
Bldg 235

$\begin{array}{cc}0 & 0 \\ + & + \\ 0 & + \\ + & + \\ -- & 0 \\ -- & 0\end{array}$

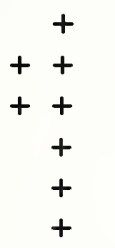

Bldg 268-1

Bldg 268-2
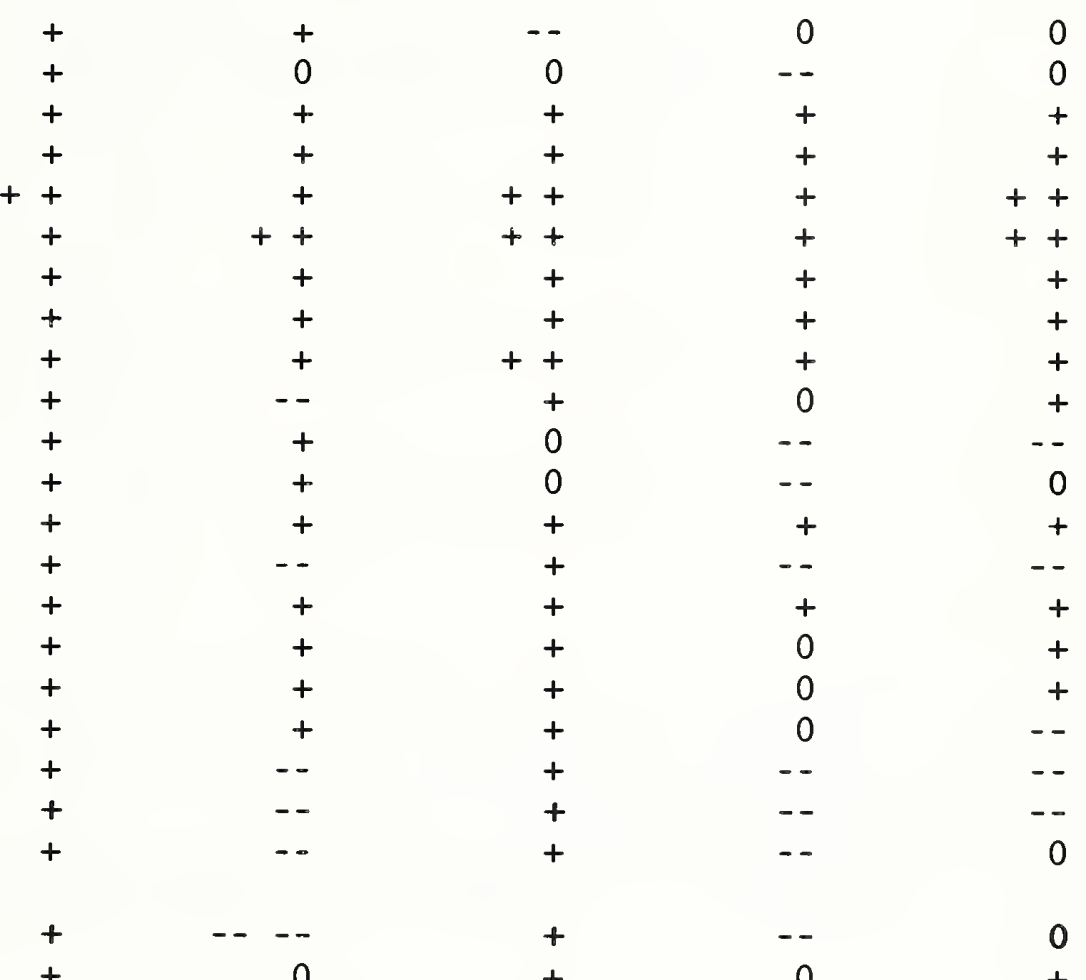

0

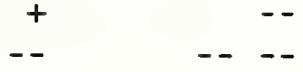

$-$

0

- -

$+$

$\begin{array}{lll}-- & -- & - \\ -- & -- & --\end{array}$

- 0

0

$--$

$+$

$+$

+
++

Bldg 293/8

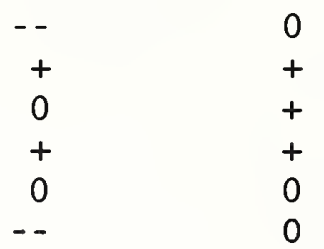

$+$

$+$

$+$

$--$

$+$

$+$

$+$

$+$

-

0

$--$

$+$

$+$ $\begin{array}{ll}-- & 0 \\ + & 0\end{array}$

$+$

$+$

$+$

0

0

(

$-$

0

0

$+$

$+$

$--$

0

$+$

$+$

$-$

$\begin{array}{ll}-- & - \\ - & -\end{array}$

$--$

0 
Table 7 Continued.

\begin{tabular}{|c|c|c|c|c|c|}
\hline Item & Bldg 235 & Bldg 260 & Bldg $293 / 8$ & Bldg 268-1 & Bldg 26 \\
\hline CHAIRMOV $* *$ & + & + & + & + & + \\
\hline CHRHGT & 0 & + & - - & - & 0 \\
\hline *CHRBACK & - & 0 & $\ldots$ & - & -- \\
\hline CHAIRADJ & - & + & 0 & 0 & 0 \\
\hline CHAIRCON** & + & + & + & + & + \\
\hline 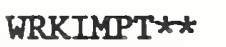 & $+t+$ & $+t+$ & ++ & ++ & +++ \\
\hline *COWRKHR & --- & --- & -- -- & -. - - & --- \\
\hline JOBSAT & + & ++ & - & + & ++ \\
\hline WRKACR ** & $+t+$ & +++ & ++ & $+t+$ & +++ \\
\hline EQUIP & ++ & + & 0 & + & + \\
\hline TIREDEYE & + & 0 & - & -- & 0 \\
\hline NOMOVFWS & + & 0 & + & 0 & + \\
\hline CONCNTRT** & $+t$ & $+t$ & + & ++ & ++ \\
\hline WORKTIME & ++ & 0 & 0 & + & + \\
\hline LTGHINDR ** & $+t$ & + & $+t$ & + & ++ \\
\hline WRKABILIT & + & 0 & 0 & 0 & + \\
\hline WORKSAT** & ++ & ++ & + & ++ & ++ \\
\hline *MISSVIEW & -- & ---- & + & - & -- \\
\hline WRKNOISE & ++ & + & + & 0 & 0 \\
\hline WORKFAST & + & ++ & + & + & + \\
\hline *WEATHER & 0 & $\ldots$ & $\ldots$ & -- & -- \\
\hline
\end{tabular}

* Indicates statistically significant, and below the scale midpoint; hence a potential problem.

* Indicates statistically significant, and above the scale midpoint; hence not a problem. 
b. Problems related to privacy

1. Conversational Privacy (Convpriv)

2. Visual Privacy (Vispriv)

3. Coworkers Overhearing Conversations (Cowrkhr)

c. Problems related to lighting

1. Inability to adjust amount of light (Adjamtlt) - All buildings

2. Right Light for Break (Rtltbrk) - 268-1; 268-2

3. Right Light for Conference Rooms (Rtltconf) - 235; 293/8

4. Light for Drafting (Ltdraft) - 260

5. Light for Other (Ltother) - 260;293/8

d. Problems related to the interior spaces

1. Storage - all buildings

2. Spaciousness (Bldgspac) - 260;268-2

3. Stimulating spaces (Stimul) - 260

4. Color - 260

5. Interesting - 260

6. Miss view out (MissView) -260

7. Want to know weather (Weather) -260

8. Furndust - 260

Three broad areas stand out as being particularly troublesome in almost all the buildings. These include problems with the HVAC systems (especially the air circulation portion), privacy, and lack of storage. Without doubt, building 260 was plagued with more complaints than the other buildings, although building 268 also experienced numerous problems. While some of these were corrected by the renovation, the concerns with indoor air quality, HVAC operation, and lack of space (and privacy) continued.

At the same time, the coding scheme allowed the identification of areas which did not cause problems, and which were coded positively $(++$, or +++$)$. These included:

1. Work Importance, Work Accuracy, Ability to Concentrate, and Work Satisfaction for all buildings.

2. Most all areas related to VDT operation in all buildings.

3. Questions related to lighting in buildings $293 / 8$.

In fact, work importance, accuracy, satisfaction, and the ability to concentrate received very positive (and statistically significant) ratings in all buildings (although they were lower in buildings 293/8). This suggests that people took real pride in their work despite their concerns with the physical environment in which the work was performed. 


\section{Choices for Improvements to the Facility}

\subsection{Choices Selected as Improvements}

Respondents were given a list of 17 possible changes that could be made to improve their work station. These ranged from more comfortable temperature, better lighting, and air quality, to access to the outside, and are listed in question 18 of the questionnaire (see Appendix A). Respondents were asked to select four of the possible choices and indicate the reasons for their selection.

Table 8 presents the percentage of times that each choice was selected by the occupants of each building. Choices are listed in order of the frequency of occurrence for each building. This table indicates that improvement in air circulation was among the first four choices in all buildings but that there was considerable variation in the other selections for the different buildings.

In building 235, improved lighting led the list, followed by improved air circulation. Greater privacy and change in color of walls, furnishings, and carpet tied for third and fourth place. In building 260, the first choices were improved air circulation and greater privacy followed by view out/daylight and improved air quality. Improvements in air circulation and quality were among the most frequent selections. For building 293/298, greater surface area was the first choice followed by less noise and more comfortable temperatures. Air quality and privacy were tied for fourth. For building 268, the choices included improvements in temperature, air circulation, privacy, and air quality before and after the renovation, although the order varied. The renovation in 268 decreased the number of selections for lighting and task lighting but increased the number of choices for greater surface area, decreased noise, and more daylight. Across all buildings, cleaning, moving further from co-workers, and greater access to the outside during breaks were the least frequently selected choices.

\subsection{Reasons for Choices}

Table B-2 in Appendix B lists the reasons given for the choices by choice type, beginning with air quality and air circulation. The rank of the choice ( $1,2,3$ or 4) is listed first followed by the comment. Table 9 summarizes the reasons for the choices. The comments were reviewed and categorized according to the primary content, with the number of times each category occurred given in Table 9. Since not all people gave reasons for their choices, the totals are different from those given in the previous table. Yet, the frequency counts provide insight into the reasons for each choice. For more complete findings, the table in Appendix B should be studied.

Table 9 demonstrates that many people mentioned stuffy air with poor circulation and resulting health problems as the reasons for selecting improved air circulation. In 260, other complaints concerned the lack of windows for ventilation and fresh air, dirty vents, as well as the smoke. In 268, problems with stale, stuffy stagnant air and health problems were noted, as well as the lack of filtering of fumes from the maintenance shop and Table 
8. Improvements to the working environment selected by respondents in the different buildings.

Choice 235 Choice 260 Choice 293 Choice 268-1 Choice 268-2

\begin{tabular}{|c|c|c|c|c|c|c|c|c|c|}
\hline Litng & $16^{\frac{8}{6}} .98$ & AirCirc & $12^{\frac{8}{6}} .4 \frac{8}{3}$ & Surface & $15^{\frac{8}{6}} .98$ & Temp. & $14^{\frac{8}{6}} .68$ & AirCirc & $13^{\frac{8}{6}} .28$ \\
\hline AirCirc & 12.8 & Privacy & 12.48 & Noise & 12.78 & AirCirc & $12.8 \%$ & AirQual & 12.68 \\
\hline Privacy & 9.68 & Daylt & 11.68 & Temp. & $11.1 \%$ & Privacy & 11.38 & Temp. & 12.38 \\
\hline olor & 9.68 & AirQual & 10.78 & AirQual & 7.98 & AirQual & 11.38 & Privacy & 9.38 \\
\hline emp & 7.28 & Surface & 9.58 & Privacy & 7.98 & Litng & $8.8 \%$ & Surface & 8.68 \\
\hline ayit & 7.28 & Temp & $9.1 \%$ & AirCirc & 6.38 & Surface & 6.38 & Noise & 7.08 \\
\hline urface & 7.28 & Litng & 7.08 & Break & 6.38 & Noise & 6.08 & Daylt & $6.6 \%$ \\
\hline i rQual & 6.08 & Color & 6.68 & Chairs & 6.38 & Daylt & 5.58 & Break & $5.6 \%$ \\
\hline TaskLt & 6.08 & Noise & $4.1 \%$ & Furn. & $4.8 \%$ & Break & $5.5 \%$ & Litng & 5.68 \\
\hline urn. & 4.88 & Break & 3.78 & TaskLt & 4.88 & TaskLt & $4.8 \%$ & TaskLt & 3.68 \\
\hline Noise & 3.68 & TaskLt & 3.78 & Daylt & $4.8 \%$ & Furn. & 3.08 & Furn. & $3.3 \%$ \\
\hline Other & 3.68 & Furn. & 2.58 & Locat. & 3.28 & Locat. & 2.88 & Other & 3.38 \\
\hline hairs & 2.48 & Outside & $2.5 \%$ & Litng & 3.28 & Color & 2.88 & Chairs & 3.08 \\
\hline reak & 2.48 & Clean & 2.18 & Clean & 3.28 & Chairs & 2.38 & Outside & 2.08 \\
\hline ocat. & 1.28 & Locat. & 1.78 & Color & $1.6 \%$ & Outside & $1.5 \%$ & Locat. & 1.78 \\
\hline atside & 0 & Chair & 0.48 & Outside & 0 & Clean & $1.5 \%$ & Color & $1.7 \%$ \\
\hline Clean & 0 & Other & 0 & Other & 0 & Other & 0.58 & Clean & 0.78 \\
\hline
\end{tabular}

$\begin{array}{llllllll}\text { Choice N } 83 & \text { Choice N } 242 & \text { Choice N } 63 & \text { Choice N } 398 & \text { Choice N } 302\end{array}$ $\begin{array}{lllllllll}\text { Total N } 23 & \text { Total N } 69 & \text { Total N } 19 & \text { Total N } 115 & \text { Total N } & 82\end{array}$ 
Table 9. Reasons Given for Desired Changes to Work Stations

\section{Air Quality}

Category

Stuffy air

Health problems

Poor filtering, venting

Smoking irritating

Smells, fumes

Need window for fresh air

Dirty vents

Extremes - hot summer, cold winter
Swings in temperature

$235260293 / 8 \quad 268-1 \quad 268-2$ Total

column totals

$\begin{array}{rrrrrr}3 & 12 & 2 & 13 & 15 & 45 \\ 3 & 6 & 2 & 5 & 11 & 27 \\ 2 & 3 & 1 & 4 & 4 & 14 \\ 0 & 3 & 2 & 1 & 5 & 11 \\ 0 & 1 & 0 & 1 & 4 & 6 \\ 1 & 3 & 0 & 0 & 1 & 5 \\ 0 & 3 & 0 & 0 & 2 & 5 \\ 0 & 1 & 0 & 1 & 2 & 4 \\ 0 & 0 & 0 & 1 & 3 & 4 \\ 9 & 32 & 7 & 26 & 47 & 121\end{array}$

\section{Temperature}

\section{Category $235 \quad 260 \quad 293 / 8 \quad 268-1 \quad 268-2$ Total}

$\begin{array}{lllllll}\text { Swings in temperature } & 0 & 11 & 0 & 11 & 10 & 32\end{array}$

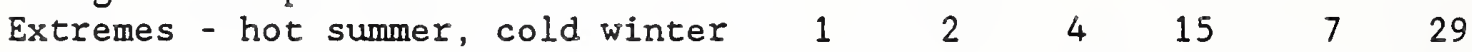

Too hot

$\begin{array}{llllll}2 & 1 & 1 & 7 & 4 & 15\end{array}$

Too cold

Stuffy air

Health problems

Break down of HVAC system

$\begin{array}{llllll}0 & 4 & 1 & 2 & 4 & 11\end{array}$

$3 \quad 2 \quad 0013$

$\begin{array}{llllll}0 & 0 & 0 & 5 & 2 & 7\end{array}$

column totals:

$\begin{array}{llllll}6 & 20 & 6 & 46 & 28 & 106\end{array}$

\section{Lighting and Task Lighting}

\section{Category}

Need adjustable light

Glare, glare on VDT screen

Better visual performance

Light task area

Too dim

Health problems

Extreme variation in brightness

Replace bulbs

column totals:

\section{$235260293 / 8 \quad 268-1 \quad 268-2$ Total}

$\begin{array}{rrrrrr}0 & 6 & 0 & 5 & 9 & 20 \\ 0 & 4 & 1 & 11 & 1 & 17 \\ 4 & 1 & 0 & 9 & 1 & 15 \\ 3 & 1 & 2 & 4 & 5 & 15 \\ 3 & 4 & 0 & 3 & 3 & 13 \\ 0 & 1 & 1 & 3 & 0 & 5 \\ 3 & 0 & 0 & 1 & 2 & 6 \\ 0 & 2 & 0 & 0 & 0 & 2 \\ 13 & 19 & 4 & 36 & 21 & 93\end{array}$


Table 9 Continued.

\section{Noise}

\section{Category}

Need quiet to concentrate Conversations distracting Interruptions, distractions Equipment noise bothersome Health

column totals:

\section{$235260293 / 8 \quad 268-1 \quad 268-2$ Total}

$\begin{array}{rrrrrr}1 & 2 & 2 & 9 & 7 & 21 \\ 1 & 3 & 0 & 1 & 5 & 10 \\ 0 & 2 & 0 & 2 & 3 & 7 \\ 1 & 1 & 1 & 2 & 2 & 7 \\ 0 & 0 & 0 & 1 & 0 & 1 \\ 3 & 8 & 3 & 15 & 17 & 46\end{array}$

Color, Break areas, Cleaning

\section{Category}

Need break area, place to eat Change colors

Dirty

Smoke is irritating

Paint walls

Confined, health

Need place to eat

Drab

Need view out

column totals:

\section{$235260293 / 8$ 268-1 268-2 Total}

$\begin{array}{rrrrrr}1 & 6 & 3 & 7 & 7 & 24 \\ 1 & 4 & 1 & 5 & 0 & 11 \\ 0 & 5 & 2 & 1 & 2 & 10 \\ 0 & 2 & 1 & 2 & 2 & 7 \\ 2 & 3 & 1 & 1 & 0 & 7 \\ 0 & 1 & 0 & 2 & 2 & 5 \\ 0 & 1 & 0 & 4 & 0 & 5 \\ 0 & 1 & 0 & 1 & 2 & 4 \\ 0 & 0 & 0 & 0 & 3 & 3 \\ 4 & 23 & 8 & 23 & 18 & 76\end{array}$

Chairs and Furnishings

$$
\text { Category }
$$

Chairs are uncomfortable

Chairs do not adjust

Furniture, chairs, too old

Need more storage, chairs, space
$235260293 / 8 \quad 268-1 \quad 268-2$ Total

$\begin{array}{rrrrrr}0 & 0 & 2 & 2 & 7 & 11 \\ 0 & 0 & 1 & 3 & 2 & 6 \\ 0 & 3 & 0 & 3 & 2 & 8 \\ 1 & 0 & 0 & 0 & 2 & 3 \\ 1 & 3 & 3 & 8 & 13 & 28\end{array}$

Soace and Furnishings

column totals:

$235260293 / 8 \quad 268-1 \quad 268-2$ Total

\section{Category}

Need more surface, storage area

Need more space in the office

Conversations are distracting

column totals: $\begin{array}{llllll}2 & 10 & 2 & 15 & 14 & 43\end{array}$

$\begin{array}{llllll}1 & 7 & 5 & 7 & 6 & 26\end{array}$

$\begin{array}{rrrrrr}1 & 2 & 0 & 2 & 4 & 9\end{array}$

$\begin{array}{llllll}4 & 19 & 7 & 24 & 24 & 78\end{array}$ 
Table 9 Continued.

\section{Privacy}

$\begin{array}{lrrrrrr}\quad \text { Category } & 235 & 260 & 293 / 8 & 268-1 & 268-2 & \text { Total } \\ \text { Open area is very distracting } & 0 & 5 & 0 & 9 & 7 & 21 \\ \text { Need private area for counseling } & 1 & 8 & 1 & 5 & 4 & 19 \\ \text { Too many interruptions, distractions } & 0 & 4 & 0 & 5 & 3 & 12 \\ \text { Conversations are distracting } & 3 & 3 & 0 & 2 & 4 & 12 \\ \text { Need more space in the office } & 1 & 2 & 1 & 5 & 2 & 11 \\ \text { Need quiet for concentration } & 0 & 0 & 3 & 3 & 3 & 9 \\ \text { Need partitions, indiv. offices } & 1 & 3 & 0 & 1 & 1 & 6 \\ \text { Health } & 0 & 0 & 0 & 2 & 0 & 2 \\ \text { column totals: } & 6 & 25 & 5 & 32 & 24 & 92\end{array}$

Window and Access to Outside

Category

Need windows

Improve mood, productivity, health office is too confined

Need view out, know weather

Need daylight, sunshine

Need break area, outside

Need window for fresh air

Need more variety, spaciousness

column totals:

\section{Category}

Management issues

Smoke is irritating

Need more storage area

Need more space

Improve phone service

Health

Need more surface area to work

Need window for fresh air

Interruptions, distractions

Glare is annoying

Improve floor

column totals:

\section{$235260293 / 8 \quad 268-1$}

268-2 Total

$\begin{array}{llllll}2 & 6 & 1 & 6 & 3 & 18\end{array}$

$\begin{array}{llllll}1 & 6 & 0 & 4 & 6 & 17\end{array}$

$\begin{array}{llllll}1 & 8 & 0 & 3 & 1 & 13\end{array}$

$\begin{array}{llllll}0 & 2 & 1 & 3 & 6 & 12\end{array}$

$\begin{array}{rrrrrr}1 & 2 & 0 & 2 & 2 & 7\end{array}$

$\begin{array}{llllll}0 & 0 & 1 & 3 & 2 & 6\end{array}$

$\begin{array}{llllll}1 & 2 & 0 & 2 & 1 & 6\end{array}$

$\begin{array}{llllll}0 & 0 & 1 & 3 & 1 & 5\end{array}$

$\begin{array}{llllll}6 & 26 & 4 & 26 & 22 & 84\end{array}$

\section{Other}

\section{$235260293 / 8 \quad 268-1 \quad 268-2$ Total}

$\begin{array}{rrrrrr}1 & 2 & 3 & 3 & 1 & 10 \\ 2 & 0 & 0 & 1 & 3 & 6 \\ 0 & 0 & 0 & 3 & 1 & 4 \\ 0 & 0 & 0 & 1 & 3 & 4 \\ 0 & 0 & 1 & 2 & 0 & 3 \\ 0 & 1 & 0 & 1 & 0 & 2 \\ 0 & 0 & 0 & 1 & 0 & 1 \\ 0 & 0 & 0 & 1 & 0 & 1 \\ 0 & 0 & 0 & 0 & 1 & 1 \\ 0 & 0 & 0 & 1 & 0 & 1 \\ 0 & 0 & 1 & 0 & 0 & 1 \\ 3 & 3 & 5 & 14 & 9 & 34\end{array}$


smoking, both before and after the renovation. In addition, people claimed that the new furniture blocked ventilation even more. They also noted that the problems with dirty vents and ducts continued, and mentioned failures to enforce the "no smoking" policy. Comments in 293 related to general air quality, while those in 298 concerned smoking.

Most of the reasons for selecting improved temperature involved excessive swings and/or extremes in temperatures from day to day for all buildings. Those in 268 also complained of being too hot and needing air conditioning, while those in 260 complained of extreme fluctuations from too hot to too cold from day to day. Similar comments were made in 268 , although there were also many statements that the air conditioning was not effective. In addition, many people mentioned being too cold in winter and too hot in summer. There was little change in these comments after the renovation. Similar complaints were made in building 293/298.

In general, the comments about lighting involved the need to light the task better, by using adjustable or directional lighting, as well as the need to improve the overall quality of the lighting. In 235, many comments indicated that the light was too bright in some areas, but not bright enough in others. In 260, people mentioned both the dimness of the overall lighting and problems with glare. Many suggested that adjustable task lighting could be used to solve these problems. In 268, frequent comments included glare and position of the overhead lighting. The systems furniture was moderately successful in that complaints about glare dropped noticeably following the renovation in 268. Nevertheless, many people commented that they needed more adjustable task lighting to direct the lighting where they needed it most, and away from computer and VDT screens. The comments in 293/298 concerned light source position and glare on computer screens.

Reasons for selecting improvements to noise, location near co-workers, and surface area included the need for more surface area, work space, and fewer distractions. In 235, people mentioned the need for more surface space for reviewing drawings and fewer distractions from conversations in the office. In 260, comments involved the need for more space for privacy and freedom from interruptions and distractions as well as to review printouts and drawings. Comments in 268 concerned distracting noises, conversations, crowding (people too close), and lack of space to review large documents. The number of observations about noise from distracting conversations, phones, and equipment increased after the renovation, with little change in the comments about lack of space. Similar statements about noise, distractions and lack of space were made in 293/298. Although privacy was treated separately from noise, the comments made it clear that excessive noise and interruptions were major reasons for wanting greater privacy.

In 235, privacy selections related to noise, overhearing conversations, and lack of space for private discussions. Similar comments were made in 260 , together with the desire for a private area for individual discussions and counseling. Respondents noted that the openness of the space caused interruptions and distractions, which resulted in reduced productivity. In 268, problems with distractions and interruptions in open areas were mentioned, along with overhearing conversations and being overheard. There 
was . Iittle change after the renovation. Relatively few comments about greater privacy were made in $293 / 298$.

Many respondents mentioned the desirability of windows for their buildings. In 235, most comments addressed the beneficial impact of windows on mood, ventilation, and light. In 260, many people reported a sense of confinement due to lack of windows, need to know the weather, and have sunshine and fresh air in the office. In 268, the beneficial aspects of windows on mood and stimulation were noted, along with a desire for sunshine, daylight, and view out. Comments about the beneficial aspects of windows on mood and productivity increased after the renovation. In 293/8, people mentioned the desirable view outside -- which they could not see since they had no window.

The next topics covered were improved colors, break area, and more frequent cleaning. Suggestions for color included painting the walls in 235; decreasing drabness, improving variety, and painting the walls more frequently in 260; and adding variety and more cheerful colors in 268. The need for a separate break area was noted repeatedly in 268 , particularly a place to eat besides one's desk and a separate place for smokers. The need for a non-smoking break area was mentioned repeatedly for 260 and 268 . Lack of a break area continued to be an irritant in 268 , even after the renovation. The few comments about cleaning were concentrated in 260 . Most comments about improvements to the chairs and furnishings noted their age and worn-out condition. Requests for more adjustable chairs with better back support were common with many comments about uncomfortable chairs in 268 after the renovation. Finally, other comments included problems with smoking in 235, need for better management and attention to management's problems in 260, and problems with storage, working conditions, and telephones in both 268 and 298.

Review of the comments thus provides some insight into the areas that caused major concerns to the people at the site. Examination of their comments supports the data obtained with the questionnaire and provides additional insights into areas that troubled them. This list is headed by problems related to indoor air quality, including stuffy air, air circulation, and health. While the renovation was successful in improving the appearance of the space in 268, the comments indicate that people still perceived continuing problems with the indoor air quality after the renovation.

\subsection{Changes Suggested by the Occupants}

Occupants were also asked to give recommendations for improvements to their work stations and buildings. The questionnaire contained four items which asked respondents to suggest specific changes for equipment, lighting, work space, and the general environment to improve working conditions. Although some suggestions were noted in the "reasons for the choices selected as improvements" presented in 4.3, these four specific questions elicited a broader range of comments.

As in 3.2, the responses were reviewed, condensed, and tabulated to indicate the desired changes and the frequency with which particular suggestions were made. The suggestions derived from this procedure are listed in Table 10 
with the complete comments given in Appendix $C$.

The first portion of Table 10 contains suggestions for changes to equipment. The general theme for equipment improvements involved modernization and increased reliability. In addition, numerous comments referred to the need for more reliable, faster $\mathrm{PC}$ 's and $\mathrm{ADP}$ equipment. In addition, Table 10 indicates that the need for "new equipment" that was not computer-related was mentioned frequently. Although requests for new equipment were generally non-specific -- usually mentioning newer, more reliable equipment, specific requests were made for new forklifts, soldering, and test equipment. The need for newer, more reliable computers, was also mentioned frequently, particularly in 260. Related improvements included newer, more functional software and ready access to a computer for everyone. Other equipment improvements included a better phone system, more adequate supplies, more frequent repairs, and better training. Improvements to procurement procedures were also noted. Many "equipment" comments referred to the work space itself and included comments about better, less glaring lighting, better furniture, more office space, more surface space, use/non-use of systems furniture, better HVAC equipment, and windows.

The second portion of table 10 contains suggestions for improving the lighting. The common thread in these recommendations was the need for better positioning of the light for the task. Most people stated that the lighting should be more flexible, with controls to adjust the light where needed. Such control would minimize glare on VDT screens while providing light for paper tasks. Table 10 indicates that the most common requests were for more task lighting and adjustable lighting. A frequent comment was that the lighting was not in the best place to illuminate the task. Individually controlled lighting would allow people to light their task, yet decrease glare on VDT screens. Other suggestions for redesigning lighting included improvement of the uneven distributions of light. Such comments were most common in 268 before the renovation. After, the most frequent comment was to replace burned out or missing lamps. Other suggestions included changing lamp type from fluorescent (to incandescent or halogen), repairing and maintaining luminaires (often somewhat yellowed and dingy), making a particular area brighter or dimmer, and adding windows.

Recommendations for improving the indoor air quality included adding windows for fresh air, replacing the HVAC system, and enforcing the no-smoking policy. Other suggestions included improving the appearance of the work space, by adding new and better furniture, chairs and carpets, as well as repainting, changing colors, and cleaning.

As table 10 indicates, numerous suggestions were made for improvements to the work space. In fact the total number of suggestions was about 2.5 times the number made for improving the lighting system. The most frequent suggestion (by about $1 / 3$ of those responding) was for more office space to increase privacy and quiet for concentration, reduce distractions and interruptions, and enhance productivity. Other suggestions included more storage space, more surface space, and more effective use of space. Some respondents wished 
Table 10. Suggestions for Changes to the Working Environment

$$
\text { Suggested Changes to Equipment }
$$

Suggested Changes

Improve / Add computers

New/more software

More computers per person

More training, better procurement

New equipment

Improve phones

More forklifts

More equipment (non-computer)

Use systems furniture

Improve furniture, chairs

More adequate supplies, repairs

Don't use systems furniture

Redesign lighting, reduce glare

Add task, adjustable lighting

More storage space

More office space, privacy

More surface space

Use space better, get window

Replace HVAC

Column totals:

Suggested Changes to Lighting

Suggested Changes

More light, make brighter

Add task, adjustable lighting

Redesign lighting

Reduce glare

Replace, repair bulbs

Change bulb type

Fix luminaires

Light specific area

Make dimmer

Need window

Column totals
235260

$0 \quad 19$

20

03

$0 \quad 2$

87

26

10

02

$0 \quad 6$

$0 \quad 2$

$0 \quad 0$

$0 \quad 0$

$\begin{array}{ll}1 & 3 \\ 0 & 0\end{array}$

$0 \quad 0$

$0 \quad 1$

11

00

01

$15 \quad 53$

235

$\begin{array}{ll}3 & 5 \\ 0 & 3 \\ 1 & 5 \\ 1 & 4\end{array}$

$\begin{array}{ll}0 & 9 \\ 0 & 1 \\ 0 & 1\end{array}$

22

$293 / 8$

268-1 268-2 Total

$\begin{array}{rrrr}8 & 13 & 8 & 48 \\ 1 & 7 & 2 & 12 \\ 1 & 2 & 3 & 9 \\ 0 & 1 & 0 & 3\end{array}$

$\begin{array}{llll}1 & 24 & 18 & 58\end{array}$

$\begin{array}{llll}3 & 2 & 3 & 16\end{array}$

$\begin{array}{llll}5 & 0 & 0 & 6\end{array}$

$\begin{array}{llll}0 & 1 & 1 & 4\end{array}$

$\begin{array}{llll}1 & 4 & 0 & 11\end{array}$

$\begin{array}{llll}1 & 2 & 1 & 6\end{array}$

$\begin{array}{llll}0 & 4 & 1 & 5\end{array}$

$\begin{array}{llll}0 & 1 & 2 & 3\end{array}$

$\begin{array}{llll}0 & 3 & 0 & 7 \\ 0 & 2 & 0 & 2\end{array}$

$\begin{array}{llll}0 & 5 & 3 & 8\end{array}$

$\begin{array}{llll}0 & 1 & 3 & 5\end{array}$

$\begin{array}{llll}1 & 2 & 0 & 5\end{array}$

$\begin{array}{llll}0 & 1 & 1 & 2\end{array}$

$\begin{array}{llll}0 & 0 & 1 & 2\end{array}$

212 
Table 10 continued.

Suggested Changes to the Work Space

Suggested Changes

More office space

Greater privacy

Add more storage space

Add more surface space

Utilize space better

Need quiet for concentration

Add partitions

Remove partitions

Redesign lighting

Add task, adjustable lighting

Reduce glare

Need windows, windows for fresh air

Replace HVAC system, improve temps.

Provide better air quality

Enforce no smoking

Get new, better furniture

Get better chairs, carpet

Repaint

Use systems furniture

Change colors

Clean offices

Don't use systems furniture

Modernize, get new equipment, supplies

Improve phones, phone service

Improve / add computers

Get new bldg / remodel

Management

Want music

Column totals:
$235260293 / 8 \quad 268-1268-2$ Total

$\begin{array}{rrrrrr}6 & 16 & 6 & 22 & 27 & 77 \\ 1 & 7 & 0 & 9 & 6 & 23 \\ 2 & 3 & 3 & 7 & 7 & 22 \\ 0 & 7 & 0 & 6 & 6 & 19 \\ 0 & 1 & 1 & 9 & 7 & 18 \\ 0 & 3 & 0 & 6 & 3 & 12 \\ 0 & 1 & 0 & 5 & 0 & 6 \\ 0 & 2 & 0 & 0 & 1 & 3\end{array}$

$\begin{array}{rrrrrr}0 & 7 & 0 & 11 & 8 & 26 \\ 2 & 1 & 0 & 3 & 2 & 8 \\ 0 & 2 & 0 & 0 & 0 & 2\end{array}$

$\begin{array}{rrrrrr}0 & 8 & 0 & 7 & 1 & 16 \\ 0 & 5 & 1 & 6 & 4 & 16 \\ 0 & 1 & 0 & 4 & 0 & 5 \\ 0 & 0 & 1 & 3 & 0 & 4\end{array}$

$\begin{array}{llllll}0 & 2 & 1 & 5 & 0 & 8\end{array}$

$\begin{array}{llllll}2 & 0 & 1 & 2 & 2 & 7\end{array}$

$\begin{array}{llllll}3 & 0 & 0 & 3 & 0 & 6\end{array}$

$\begin{array}{llllll}0 & 2 & 1 & 2 & 0 & 5\end{array}$

$\begin{array}{llllll}0 & 1 & 0 & 0 & 1 & 2\end{array}$

$\begin{array}{llllll}0 & 0 & 0 & 2 & 0 & 2\end{array}$

$\begin{array}{llllll}0 & 0 & 0 & 1 & 1 & 2\end{array}$

$\begin{array}{llllll}1 & 2 & 1 & 0 & 0 & 4\end{array}$

$\begin{array}{llllll}0 & 0 & 1 & 1 & 1 & 3\end{array}$

$\begin{array}{llllll}0 & 0 & 1 & 1 & 0 & 2\end{array}$

$\begin{array}{llllll}1 & 2 & 2 & 9 & 2 & 16\end{array}$

$\begin{array}{llllll}0 & 1 & 0 & 0 & 0 & 1\end{array}$

$\begin{array}{llllll}0 & 0 & 0 & 1 & 0 & 1\end{array}$

$\begin{array}{llllll}18 & 74 & 20 & 125 & 79 & 316\end{array}$ 
Suggested Changes to the General Environment

Suggested Changes

Replace HVAC system

Better air quality, less fumes

Enforce no smoking

Improve phones, add lines

Get new equipment

Improve power

More training

More forklifts

Improve, add computers

Get better chairs

Better colors, redecorate, repaint

Need break area

Add conference area

Improve furniture, use systems furn

Repair roof, carpet

Better lighting

Add task, adjustable lighting

More office space

Greater privacy

Need quiet

More storage space

Utilize space better

More individual offices

Need window

Need windows for fresh air, view out

Get new bldg or remodel

Management

Improve safety, exits, access

Get more people

Improve cafeteria

Need better working conditions

Want music

Column totals:

\section{0}

$293 / 8$

$268-1$

$268-2$

Total

$\begin{array}{ll}2 & 4 \\ 1 & 8 \\ 0 & 2\end{array}$

4

$\begin{array}{rrr}22 & 14 & 46 \\ 8 & 16 & 33 \\ 4 & 1 & 9\end{array}$

04

21

$0 \quad 0$

$0 \quad 0$

10

$0 \quad 1$

2

0

0

1

2

$$
4
$$

$4 \quad 11$

1

1

1

$$
\begin{aligned}
& 1 \\
& 0
\end{aligned}
$$$$
0
$$

1

0

0

$$
\begin{aligned}
& 0 \\
& 0
\end{aligned}
$$

\section{6}

\section{1}


to add partitions; others wished to remove them. Respondents again mentioned the need to redesign lighting, add task lighting, and reduce glare. Some commented in favor of systems furniture, while others were against it. More general recommendations included a completely new building or extensive remodeling; new equipment, including phones and computers, and improving management procedures. The renovation in 268 decreased the number of suggestions for improving office appearance, but not the number of spacerelated suggestions.

The fourth set of suggestions presented in table 10 dealt with improving the building to make the job easier. About 258 of the comments referred to air quality with suggestions for replacing the HVAC system, reducing fumes, reducing swings in temperature, and enforcing the no-smoking regulations. Such comments were prevalent in 260 and 268 before and after renovation.

Space issues were the next most frequently mentioned category for change. Respondents again requested more space, privacy, quiet, storage area, better use of space, and individual offices. Many suggestions involved improving the appearance and functioning of the work space. These included new chairs and furniture, better colors, repainting, redecorating, and repairs to the carpet and roof. Adding a separate break area in 268 so that people could eat lunch away from their desks and see outside was a particular concern. A separate break area for smokers was another request, as was a conference area. Many people suggested improving the general lighting and adding task lighting. Adding windows for fresh air, daylight, and view out was another frequent request.

Other recommendations involved improvements to the phone and electrical power service, as well as new equipment, more and better computers, more materials handling equipment such as forklifts, and more training. Other suggestions included improved safety and emergency access/egress. A number of people suggested ways for improving the flow of work; including, hiring more people to solve staffing problems; soliciting and listening to input from personnel; and providing management training. People also requested a better cafeteria (or break area with wider selection from vending machines) and generally better working conditions. Finally, there were recommendations for totally remodeling the building or building an entirely new building to solve the problems of air quality, lighting, and space mentioned throughout the questionnaire. 


\subsection{Lighting Measurements}

Table 11 presents the measurement data for lighting. A total of 92 work stations were examined using the procedure given in Appendix A-2. These included 49 in 268 before the renovation, 26 in 268 after, 12 in 260 , and 5 in 235. Illuminance was measured using a hand-held Minolta ${ }^{2}$ photometer with a cosine-corrected diffuser and a photopic response filter. Measurements were made in the primary work station at the center of the work surface about 12 in from the edge of the desk, about 18 in from the edge to the right of the center, and about 18 in from the edge to the left.

Table 11 presents the means and standard deviations for the primary illuminance ${ }^{3}$ followed by that to the right and to the left for work stations in buildings 260,235, 268-1 and 268-2. Figure 24 presents the distribution of illuminance at the primary work station for the different buildings. As table 11 indicates, illuminance in 235 tended to be high with large variability (as evidenced by the high standard deviations). Only five work stations were measured in this building, which functioned largely as a warehouse. Comparisons between 260 and 268 , which were more conventional office buildings, are therefore more meaningful. In 260 , the mean illuminance was 624 lux with about 150 lux less to the immediate left and right. In 268, there was less variation in illuminance from left to right across the task location both before and after the renovation, although. the mean illuminance dropped by about 260-300 lux following the renovation. This drop was most likely due to the systems furniture blocking the overhead lighting.

The next entry in table 11 , is the average for the three measurement locations (left, center, and right) which confirms that the renovation in 268 lowered the overall light levels at the primary work station from a mean of 685 lux to 391 lux. Yet, as shown by the next series of entries, the renovation had less impact on the illuminances at the secondary work station. In 268 before the renovation, the secondary illuminances were only slightly lower than at the primary work station, while after the renovation they were actually 100-150 lux higher with a mean of 531 lux (although the variability was also greater). There were, however, many more secondary work stations because of the system furniture configuration. Illuminance was lower by 200800 lux at the secondary work station in building 260 and 235 .

2 Brand names are provided for identification purposes only, and do not constitute endorsement by the National Institute of Standards and Technology or the U.S. Army.

3 Illuminance may be defined as "the density of the luminous flux incident on a surface; it is the quotient of the luminous flux by the area of the surface when the latter is uniformly illuminated" (IESNA, 1984, p.1-16). In lay terms, illuminance is the amount of light falling on a surface. 
Table 11. Summary Lighting Measurement Data for the Four Buildings

\begin{tabular}{|c|c|c|c|c|c|c|c|c|}
\hline \multirow[t]{2}{*}{ Building } & \multicolumn{2}{|c|}{260} & \multicolumn{2}{|c|}{235} & \multicolumn{2}{|c|}{$268-1$} & \multicolumn{2}{|c|}{$268-2$} \\
\hline & Mean & Std & Mean & std & Mean & std & Mean & Std \\
\hline & \multicolumn{8}{|c|}{ Illuminance in Lux } \\
\hline Primary & 624.3 & 256.4 & 1536 & 589 & 685.4 & 262.7 & 391.3 & 234.9 \\
\hline Right & 477.5 & 243.4 & 1082 & 275.3 & 665 & 239.5 & 399 & 251.4 \\
\hline Left & 485.8 & 274.8 & 952 & 236.1 & 688 & 266.7 & 413.4 & 252.2 \\
\hline Primary & & & & & & & & \\
\hline Average & 481.7 & 248.9 & 1017 & 242.1 & 662.7 & 245 & 406.2 & 244.3 \\
\hline Secondary & 343.4 & 299.1 & 706.2 & 181.6 & 572.5 & 298.3 & 531.2 & 342.1 \\
\hline Right & 384.6 & 219.5 & 744.6 & 226 & 463.7 & 204.7 & .472 .1 & 277.4 \\
\hline Left & 335.8 & 222.4 & 759.3 & 216.5 & 523 & 193.7 & 573.5 & 288.5 \\
\hline Secondary & & & & & & & & \\
\hline Average & 360.2 & 222.3 & 728.8 & 193.8 & 513.4 & 197.1 & 522.8 & 270.8 \\
\hline
\end{tabular}

Luminance in $\mathrm{cd} / \mathrm{m} 2$ for Primary Task Area

$\begin{array}{lrrrrrrrr}\text { White Task } & 156.7 & 65.1 & 408.7 & 151 & 164.2 & 66.2 & 239 & 70.7 \\ \text { Black Task } & 27.7 & 16.6 & 72.1 & 33.5 & 18.5 & 15 & 21.4 & 16.3 \\ & & & & & & & & \\ \text { Contrast } & 0.84 & 0.13 & 0.83 & 0.02 & 0.89 & 0.06 & 0.9 & 0.13\end{array}$

Luminance in $\mathrm{cd} / \mathrm{m}^{2}$ of surroundings

\begin{tabular}{|c|c|c|c|c|c|c|c|c|}
\hline Ceiling & 27.2 & 18.6 & 45.6 & 6.3 & 41.3 & 19 & 34 & 0 \\
\hline Luminaire & 2585.4 & 1691 & 3672 & 843.9 & 4041. & 1616.4 & 2595.6 & 1382.3 \\
\hline Darkest & 3.7 & 4.2 & 9.5 & 4 & 6.1 & 4.3 & 5.6 & 2.5 \\
\hline Ahead & 17.5 & 48.6 & 59.2 & 45.7 & 60.9 & 48.5 & 116.8 & 90.1 \\
\hline Left & 35.7 & 41.7 & 20.6 & 17.7 & 57 & 43.6 & 56.7 & 56.8 \\
\hline Right & 30.4 & 49.9 & 104.2 & 42 & 62.4 & 52.6 & 26.3 & 21 \\
\hline $\begin{array}{l}\text { Average All } \\
\text { Average }\end{array}$ & 453.3 & 277.6 & 656.7 & 141.4 & 716.8 & 271.7 & 473.7 & 235.6 \\
\hline Lft, Rt, Ahd & 27.9 & 33.7 & 61.4 & 18.9 & 60.3 & 33.6 & 66.9 & 32 \\
\hline \multicolumn{9}{|c|}{ VDT Characteristics } \\
\hline Distance (in) & ) 15.8 & 5.8 & 12 & 0 & 21.7 & 2.4 & 25.8 & 3.1 \\
\hline \multicolumn{9}{|c|}{ Illuminance in lux } \\
\hline Keyboard & 438.9 & 259.4 & 903.3 & 199.7 & 592.7 & 256.3 & 424.8 & 250.2 \\
\hline Screen & 335 & 193.6 & 488 & 98.5 & 433.5 & 191.7 & 347.9 & 141.5 \\
\hline
\end{tabular}

Luminance of VDT Paper Task

$\begin{array}{lrrrrrrrr}\text { White } & 122 & 62.6 & 218.4 & 75.4 & 116.8 & 58.7 & 135.9 & 74.7 \\ \text { Black } & 21.4 & 15.3 & 31 & 10 & 15.7 & 8.3 & 20.9 & 15.2\end{array}$ 
Table 11 continued.

\section{Luminance in $\mathrm{cd} / \mathrm{m}^{2}$ of Screen}

\begin{tabular}{|c|c|c|c|c|c|c|c|c|}
\hline Center & 7.3 & 18.1 & 4.7 & 3.3 & 19.2 & 22.2 & 17.1 & 22.4 \\
\hline Left & 6.8 & 8.5 & 9.9 & 12.3 & 10.7 & 10.5 & 11.6 & 14.1 \\
\hline Right & 6.6 & 22.9 & 5.1 & 3.3 & 17.4 & 29.2 & 16 & 21.4 \\
\hline Top & 5.8 & 27.1 & 13.5 & 13.9 & 22.3 & 34.4 & 13.3 & 16.8 \\
\hline Bottom & 6.2 & 12.2 & 4.6 & 0.5 & 10.7 & 15.9 & 17.3 & 22.1 \\
\hline Char 1 & 1 & 17.2 & 13.6 & 13.4 & 7.9 & 38.2 & 29.4 & 23.9 \\
\hline Char2 & 2 & 6.2 & 24.1 & 0 & 0 & 36.1 & 22.9 & 21.4 \\
\hline \multicolumn{9}{|c|}{ Average Luminance for Screen and Character } \\
\hline Screen & 7.6 & 2.3 & 9.4 & 4.6 & 15.5 & 19.2 & 16.9 & 17.8 \\
\hline Char & 17.4 & 13.4 & 13.4 & 7.9 & 37 & 25.7 & 25.4 & 18.4 \\
\hline Screen & & & & & & & & \\
\hline Contrast & 0.36 & 0.32 & 0.28 & 0.12 & 0.59 & 0.3 & 0.5 & 0.27 \\
\hline
\end{tabular}

\section{Task Lighting}

\section{Illuminance}

\begin{tabular}{lrrrrrrrr} 
Primary & 710.4 & 630.9 & 1873.3 & 514.1 & 1127. & 730.8 & 833.1 & 267.1 \\
\cline { 3 - 6 } & & \multicolumn{7}{c}{ Luminance of Paper Task } \\
White & 183 & 133.6 & 523 & 74.2 & 238.4 & 157.6 & 68.5 & 6.9 \\
Black & 34.9 & 23.7 & 98.2 & 15.4 & 22.2 & 22.1 & 3.4 & 0 \\
Height (in) & 13 & 7.8 & 11 & 0.8 & 19 & 8 & 14.5 & 3.5
\end{tabular}




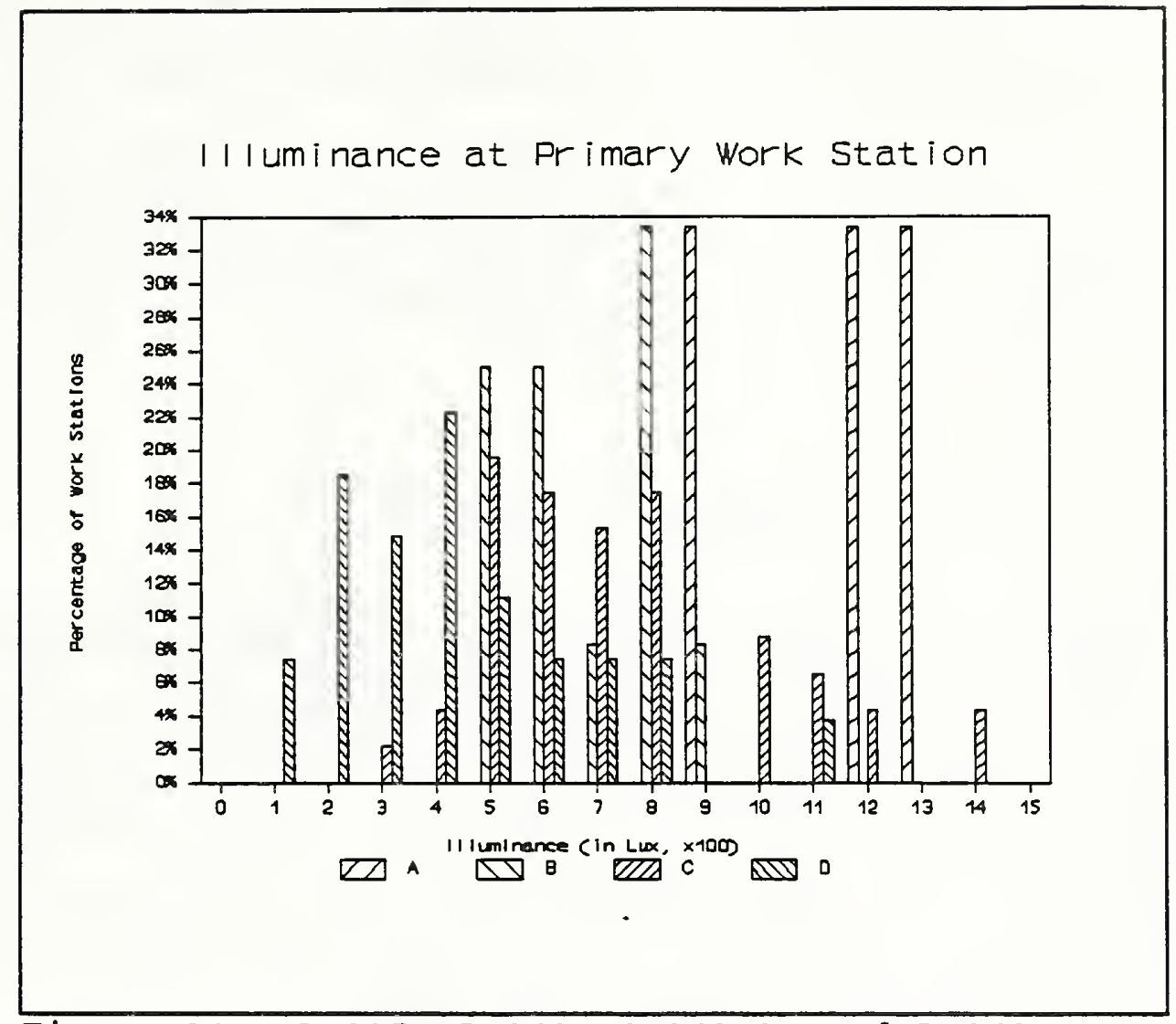

Figure 24. $A=235 ; B=260 ; C=268-1 ;$ and $D=268-2$.

Figure 24. Distribution of illuminances with body shadow at the primary work station. 
The illuminances for the primary and secondary work stations are generally in line with the recommendations for office lighting, including both paper and VDT tasks, given by the Illuminating Engineering Society (IESNA, 1987).

The next entries in Table 11 are the luminance (or brightness) of a paper task. Using a portable Minolta ${ }^{2}$ luminance meter with a one-degree spot size, the luminance ${ }^{4}$ of a white piece of paper with a very black letterhead was measured, again in the center of the working surface about 12 in from the edge of the desk. The contrast for this "standard" piece of paper was then calculated according to the following formula:

$$
\begin{aligned}
& C=\mathrm{L}_{\mathrm{B}}-\mathrm{L}_{\mathrm{T}} / \mathrm{L}_{\mathrm{B}} \\
& \text { where } \mathrm{L}_{\mathrm{B}}=\text { luminance of the background } \\
& \text { and } \mathrm{L}_{\mathrm{T}}=\text { luminance of the target. }
\end{aligned}
$$

Task contrast is one measure of the effect of lighting on task visibility. The scale ranges from 0 to 1 with higher values indicating a potentially more "visible" task with "brighter" whites and "darker" blacks. (Rea, 1986 presents a full discussion of the role of task contrast in visibility.) Table 11 demonstrates that the luminance of the white target was highest for Building 235 (as would be expected from the higher overall illuminance) but that the average contrast was low (probably because veiling reflections from the overhead luminaires reduced the blackness of the task). Figure 25 presents a distribution of the luminances of the white task, while figure 26 shows a distribution of contrasts at the primary task location. Both the luminance of the white target and overall contrast were lower in 260 but higher in 268, particularly following the renovation.

The next entries in table 11 present the luminance of different surfaces in the rooms - ceiling, luminaire, darkest object in the field of view, and vertical surfaces immediately ahead, to the left, and to the right. These measures provide an indication of the brightness of different surfaces, as the observer would perceive them. In table 11, all the luminances were averaged together to provide an indication of the overall brightness in the space. As shown in figure 27, the average luminance was highest in 268 before the renovation and lowest in 260. The luminances of the vertical surfaces to the left, right and ahead, when averaged, were highest in 268 following the renovation.

The following entries in table 11 present the illuminance and luminance of VDT tasks. Illuminance was measured at the center of the screen and keyboard. As might be expected, mean keyboard illuminance was lowest in building 260 and 268 following the renovation, highest in 235, and

4 Luminance may be defined as the quotient of the luminous flux at an element of the surface surround the point and propagated in directions defined by an elementary cone containing the given direction; by the product of the solid angle of the cone and the area of the orthogonal projection of the element of the surface on a plane perpendicular to the given direction (IESNA, 1984). In lay terms, it is the amount of light reflected from a surface. 


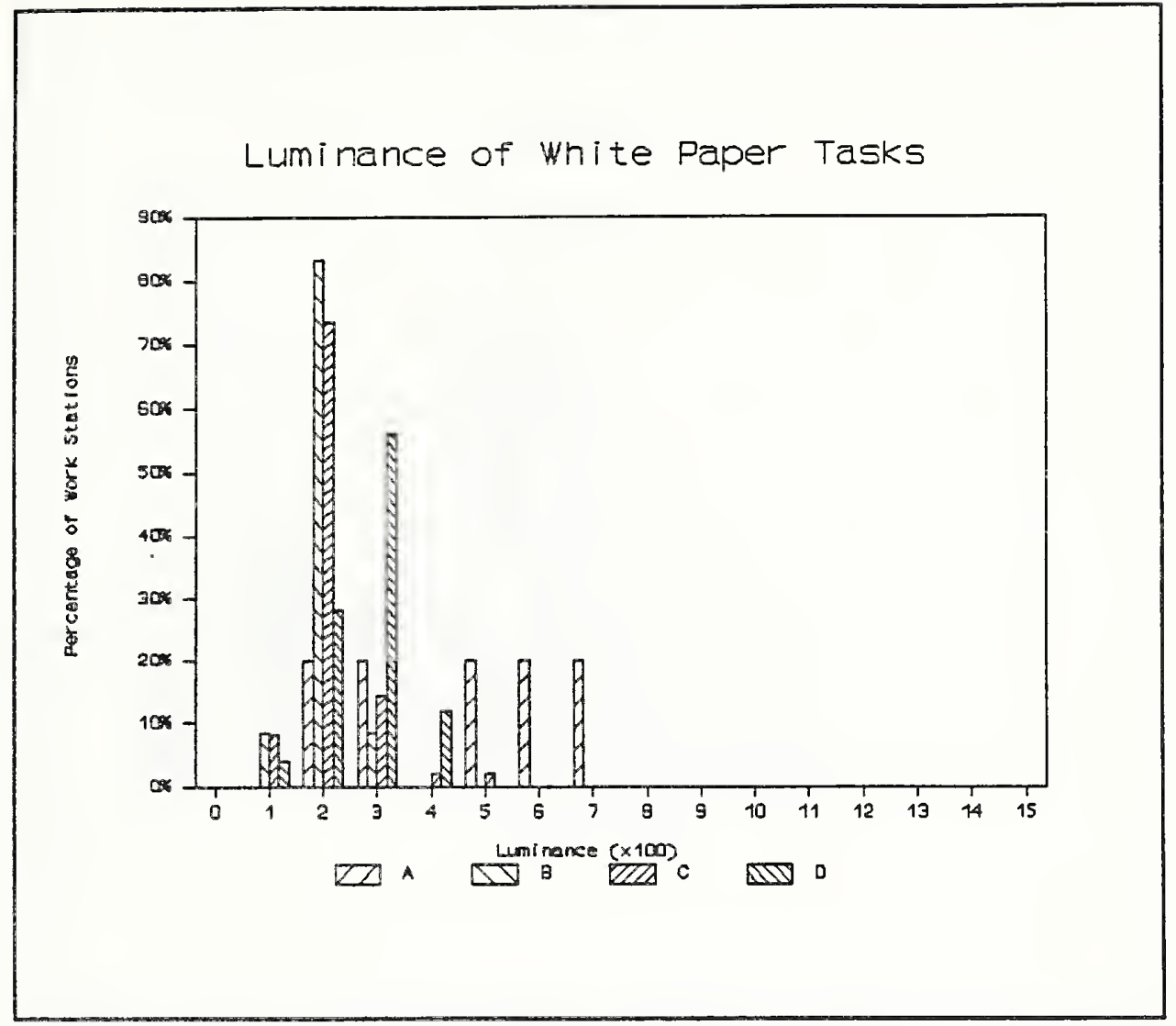

Figure 25. $\mathrm{A}=235 ; \mathrm{B}=260 ; \mathrm{C}=268-1 ;$ and $\mathrm{D}=268-2$.

Figure 25. Distribution of Iuminances of the white paper task measured at the primary work station. 
Task contrast

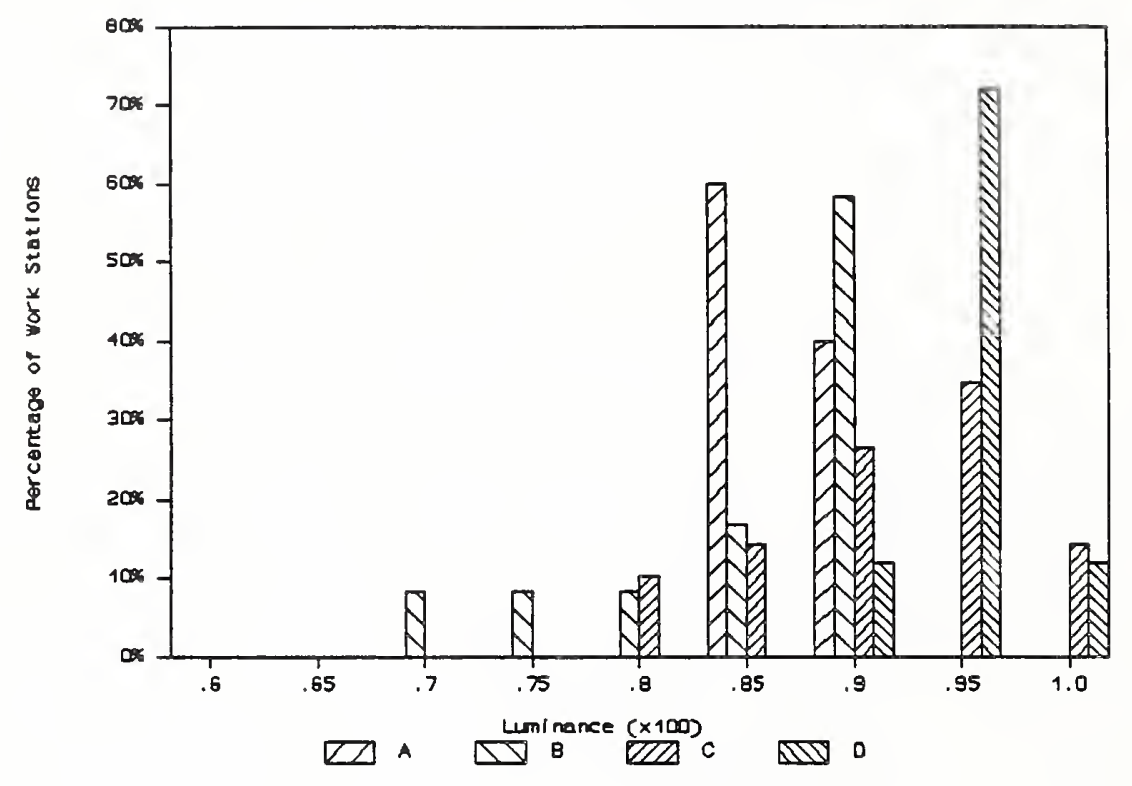

Figure 26. $\mathrm{A}=235 ; \mathrm{B}=260 ; \mathrm{C}=268-1 ; \mathrm{D}=268-2$.

Figure 26. Distribution of contrasts for the luminances of the white paper and black image measured at the primary work location. 


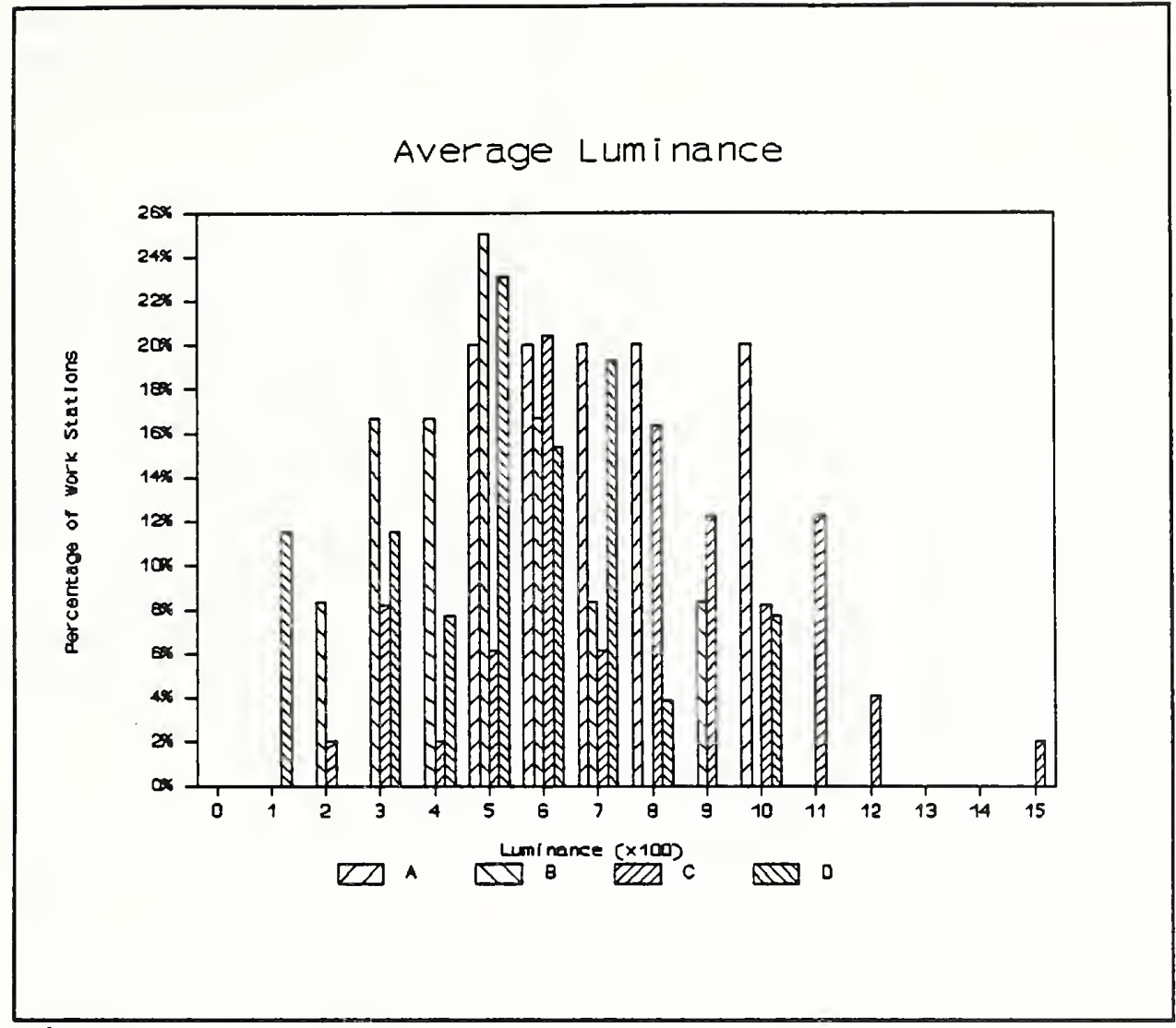

Figure 27. $A=235 ; \quad B=260 ; C=268-1 ; \quad D=268-2$.

Figure 27. Distribution of average luminances (including luminance straight ahead, to the left, to the right, the ceiling, darkest object, and the luminaire) as seen from the primary work station. 
intermediate in 268 before the renovation. As is desirable, mean screen illuminance was lower than keyboard illuminance in all buildings, and ranged from 335 lux in 268-1 to 488 lux in 235. The renovation had little impact on mean keyboard and screen illuminance in 268.

The luminance of six areas on the VDT screen was also measured, again using the Minolta ${ }^{2}$ luminance meter. Five measurements of the screen luminance as set by the work station user were made - at the top, bottom, center, right, and left of the screen. In addition, the luminance of two characters was also measured ${ }^{5}$. The five screen luminances were averaged, and then combined with the average of the luminances of the two characters to create a measure of screen contrast. The data for different screen luminances suggest that bright spots -- most likely due to reflections from the overhead luminaires- occurred at the top of the VDT screens in 235, while dark spots occurred at the bottom of the screen in 268-1. The distribution of mean contrasts was fairly even with a range of 0.1 to 1.0 , as shown in figure 28 . The low contrasts (below 0.5 ) obtained at a number of work stations indicates that people with these VDT's may have had trouble seeing all the characters on their screens. The low contrast was likely due to reflections in the screen from overhead luminaires.

In addition to the measurements of the illuminance of the ambient lighting, the illuminance of the task lamp was measured using the Minolta ${ }^{2}$ hand-held photometer, again in the center of the primary work surface. Illuminance for the task lights was quite high but with large variability among work stations. Means ranged from 710 to 1873 lux with standard deviations as high as 730 lux. Illuminance of the task light decreased by about 300 lux following the renovation in 268 but was still reasonably high (with a mean of 830 lux).

\subsection{Physical Conditions}

Table 12 describes the physical conditions in the work stations as recorded by the experimenter during the physical measurement phase using the form given in Appendix A. This table itemizes the number of surfaces used by a work station occupant, control over lighting, task lighting, and some characteristics of the VDT's.

Table 12 makes it very clear that the way that occupants used their work stations changed dramatically following the renovation in 268 . Before, $70 \%$ had used only one surface -- after, $70 \%$ used two surfaces. (Measurements of the area of the work station and surfaces will be discussed in the next section). In 260, $73 \%$ used two surfaces, while 40\% did in 235, (although only 5 work stations were assessed in 235.)

5 Measurement of character luminance includes some screen luminance in the very immediate surround of the character. As such, it is a biased, but useful estimate of character luminance. 


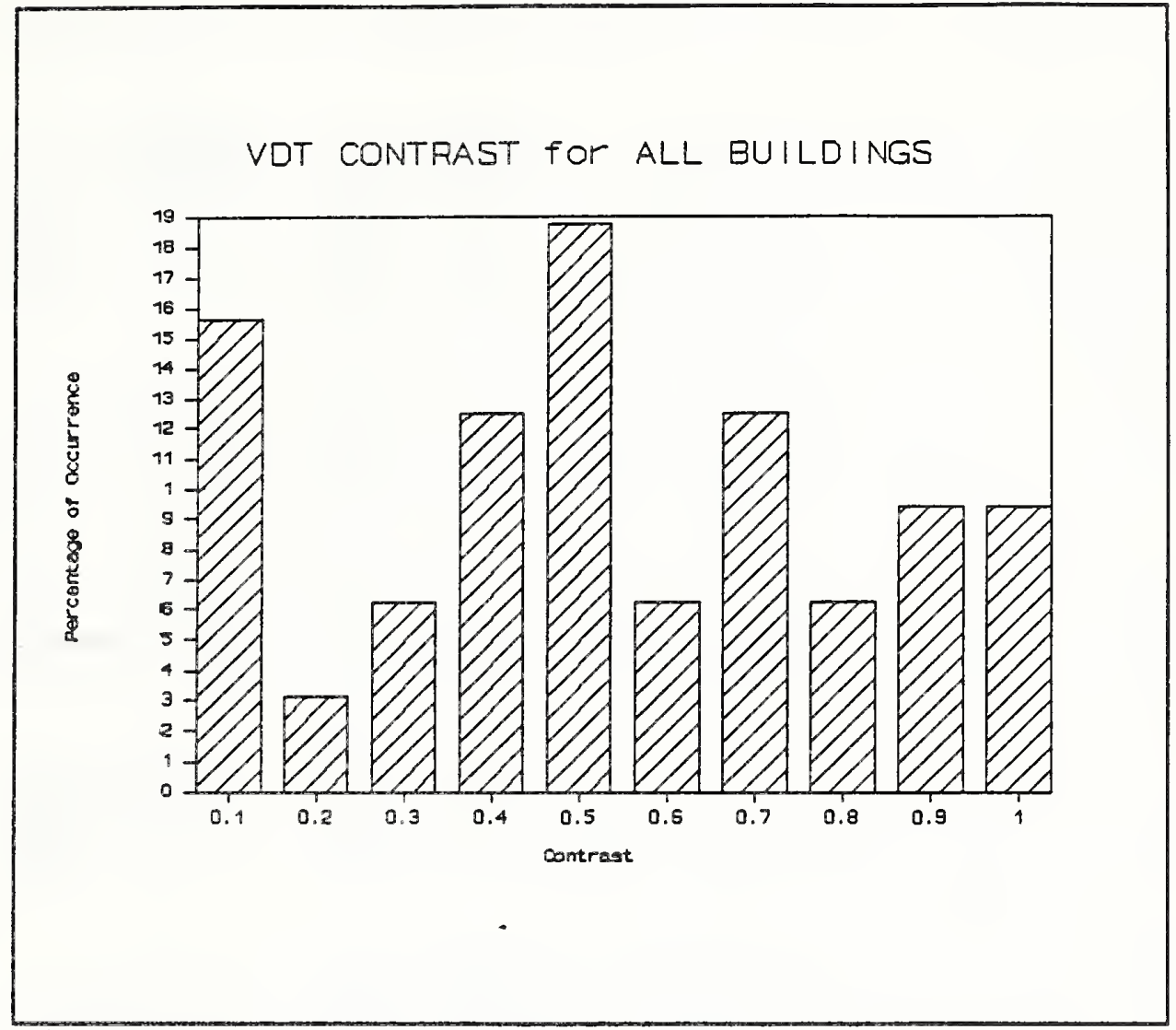

Figure 28. $A=235 ; \quad B=260 ; D=268-1 ;$ and $D=268-2$.

Figure 28. Distribution of contrasts between screen and character as calculated for VDT's in the different buildings. 
Table 12. Additional Lighting and Physical Characteristics of the Work Stations.

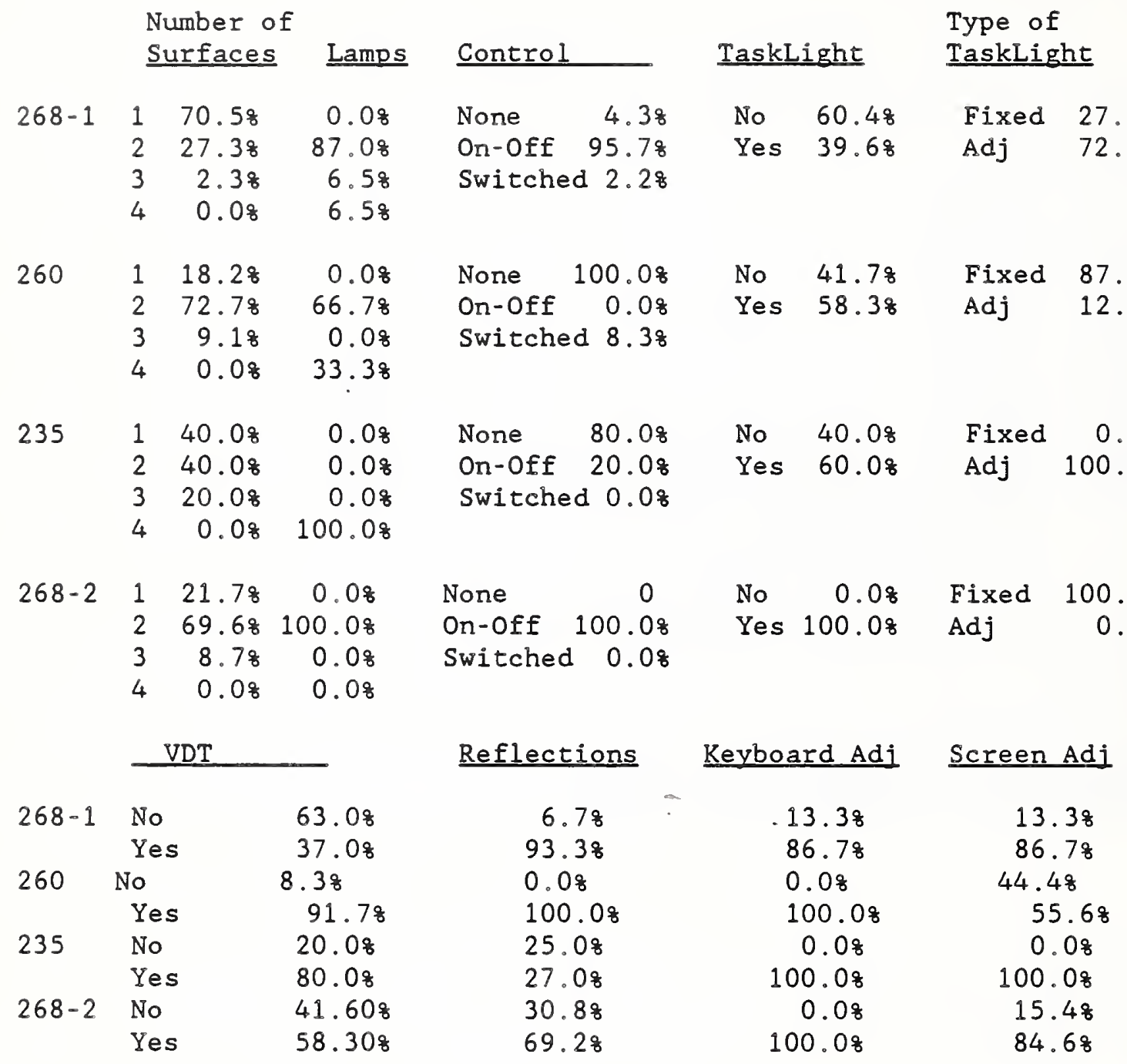

Position of the Light Source

$\begin{array}{llllllll}268-1 & \text { Percent } & \frac{\text { Above }}{40.38} & \frac{\text { Ahead }}{13.48} & \frac{\text { Right }}{14.98} & \frac{\text { Left }}{19.48} & \frac{\text { Behind }}{11.98} & \frac{\text { Total }}{67} \\ 260 & \text { Percent } & 19.48 & 19.48 & 25.88 & 22.68 & 12.98 & 31 \\ 235 & \text { Percent } & 28.68 & 28.68 & 14.38 & 21.48 & 7.18 & 14 \\ 268-2 & \text { Percent } & 51.68 & 12.98 & 12.98 & 16.18 & 6.58 & 31\end{array}$

\section{Number of Lamps}

\begin{tabular}{|c|c|c|c|c|c|}
\hline & & Two & Three & Four & Total \\
\hline 268-1 & Percent & 87.08 & 6.58 & 6.58 & 46 \\
\hline 260 & Percent & 66.78 & 0.08 & 33.38 & 12 \\
\hline 235 & Percent & 0.08 & 0.08 & $100.0 \%$ & 4 \\
\hline $268-2$ & Percent & 100.08 & 0.08 & 0.08 & 15 \\
\hline
\end{tabular}


Table 12 Continued.

Type of Work Station

\begin{tabular}{|c|c|c|c|c|c|c|c|c|}
\hline & & No & Yes & Total & & No & Yes & Total \\
\hline $268-1$ & Open & 8.38 & $\overline{91.78}$ & 48 & Shared & 27.18 & $\overline{72.9} 8$ & 48 \\
\hline 260 & Open & 8.38 & 91.78 & 12 & Shared & 16.78 & 83.38 & 12 \\
\hline 235 & Open & 20.08 & 80.08 & 5 & Shared & 0.08 & $100.0 \%$ & 5 \\
\hline $268-2$ & Open & 8.78 & 91.38 & 23 & Shared & 50.08 & 50.08 & 26 \\
\hline
\end{tabular}

Number and Height of Panels

\begin{tabular}{|c|c|c|c|c|c|c|}
\hline & & $42-54 "$ & $60-64^{\prime \prime}$ & $68-74^{\prime \prime}$ & None & Total \\
\hline $68-1$ & Panel & 20.08 & 30.08 & 7.58 & $42.5 \%$ & 40 \\
\hline 260 & Panel & 0.08 & 80.08 & $0.0 \%$ & 20.08 & 10 \\
\hline & Panel & 25.08 & 75.08 & 0.08 & 0.08 & 4 \\
\hline $8-2$ & Panel & 45.08 & 40.08 & 15.08 & $0.0 \%$ & 20 \\
\hline
\end{tabular}

Type of Wall System

$\begin{array}{llllrc}268-1 & \text { Panel Type } & \frac{\text { Wood }}{2.78} & \frac{\text { Metal }}{61.88} & \text { Fabric } & \text { Total } \\ 260 & \text { Panel Type } & 37.58 & 12.5 \% & 50.08 & 55 \\ 235 & \text { Panel Type } & 10.08 & 40.08 & 50.08 & 10 \\ 268-2 & \text { Panel Type } & 37.58 & 31.38 & 31.38 & 64\end{array}$

Type of Furniture

$\begin{array}{llrcrr}268-1 & \text { Furniture Type } & \frac{\text { Systems }}{6.78} & \text { Standard } & \text { Other } & \text { Total } \\ 260.08 & 13.38 & 30 \\ 235 & \text { Furniture Type } & 90.98 & 9.18 & 0.08 & 11 \\ 268-2 & \text { Furniture Type } & 100.08 & 0.08 & 0.08 & 4 \\ & \text { Furniture Type } & 100.08 & 0.08 & 0.08 & 23\end{array}$

\section{Type of Wall Construction}

\begin{tabular}{|c|c|c|c|c|c|c|c|}
\hline & & Wood & Metal & Fabric & Dry & Block & Total \\
\hline $268-1$ & Wall Construction & 1.78 & 0.08 & 3.38 & 40.08 & 55.08 & 60 \\
\hline 260 & Wall Construction & 0.08 & $0.0 \%$ & 14.38 & 78.68 & $7.1 \frac{8}{8}$ & 14 \\
\hline 235 & Wall Construction & 0.08 & 0.08 & 0.08 & 100.08 & 0.08 & 5 \\
\hline $268-2$ & Wall Construction & 0.08 & 0.08 & 0.08 & 75.98 & 24.18 & 29 \\
\hline
\end{tabular}

\begin{tabular}{|c|c|c|c|c|c|}
\hline & & Chai & Arms & Cha & Wheels \\
\hline & & No & Yes & No & Yes \\
\hline $268-1$ & Chair & $\overline{40.98}$ & $\overline{59.18}$ & $\overline{5.98}$ & 94.18 \\
\hline 260 & Chair & 27.38 & 72.78 & 54.58 & 45.58 \\
\hline 235 & Chair & 20.08 & 80.08 & 40.08 & 60.08 \\
\hline $268-2$ & Chair & 12.08 & 88.08 & 4.38 & 95.78 \\
\hline
\end{tabular}


Table 12 Continued.

Experimenter Rating of Chair Condition

$\begin{array}{llrrrrrr} & & \underline{1} & \underline{2} & \underline{3} & \underline{4} & \underline{5} & \underline{\text { Mean }} \\ 268-1 & \text { Rating } & 0.08 & 13.38 & 55.68 & 22.28 & 8.98 & 3.27 \\ 260 & \text { Rating } & 0.08 & 27.38 & 9.18 & 63.68 & 0.08 & 3.30 \\ 235 & \text { Rating } & 0.08 & 0.08 & 20.08 & 80.08 & 0.08 & 3.80 \\ 268-2 & \text { Rating } & 0.08 & 12.08 & 28.08 & 48.08 & 12.08 & 3.60\end{array}$

Personalization of Work Station

\begin{tabular}{|c|c|c|c|c|c|}
\hline & No & Yes & & No & Yes \\
\hline 268-1 Wall & 62.58 & $3 \overline{7.5} 8$ & Desk & 52.18 & $4 \overline{7.9} 8$ \\
\hline Wall & 63.68 & 36.48 & Desk & 63.68 & 36.48 \\
\hline Wall & 0.08 & 100.08 & Desk & 40.08 & $60.0 \%$ \\
\hline 68-2 Wall & 15.48 & 84.68 & Desk & 11.58 & 88.58 \\
\hline
\end{tabular}

\section{Supplementary Fan or Heater}

$\begin{array}{llrrrrr}268-1 & \text { Fan } & \frac{\text { No }}{63.88} & \frac{\text { Yes }}{36.28} & \text { Heater } & \frac{\text { No }}{93.38} & \frac{\text { Yes }}{6.78} \\ 260 & \text { Fan } & 100.08 & 0.08 & \text { Heater } & 100.08 & 0.08 \\ 235 & \text { Fan } & 40.08 & 60.08 & \text { Heater } & 100.08 & 0.08 \\ 268-2 & \text { Fan } & 57.78 & 42.38 & \text { Heater } & 95.78 & 4.38\end{array}$

Experimenter Ratings of Noise

$\begin{array}{llcccccc}268-1 & \text { Rating } & \frac{\text { Phone }}{1.98} & \frac{\text { Conver }}{2.69} & \frac{\text { Printer }}{1.71} & \frac{\text { Equip }}{1.27} & \frac{\text { Vent }}{2.00} & \frac{\text { Outside }}{1.13} \\ 260 & \text { Rating } & 2.08 & 3.33 & 3.00 & 2.75 & 4.00 & 1.18 \\ 235 & \text { Rating } & 1.00 & 3.20 & 3.20 & 2.80 & 3.60 & 1.60 \\ 268-2 & \text { Rating } & 2.75 & 2.96 & 1.71 & 1.25 & 1.61 & 1.00\end{array}$


There were two lamps per fixture in Buildings 260 and 268 (both before and after the renovation). There were four lamps per fixture in 235 which may have accounted for the much higher illuminances observed there. Control over the lighting was either non-existent, as in 260 , or by "on-off" switches (with virtually no lamps switched off) as in 268 and 235.

The first column of table 12 indicates that the renovation in 268 increased the amount of task lighting from $40 \%$ to 1008 of the work stations. About $60 \%$ of the work stations in 235 and 260 had task lighting. As can be seen from the next column in table 12, the percentage of those with fixed task lighting in 268 increased from 27.88 to 1008 following the renovation. About $87 \%$ of the task lighting in 260 was also fixed. Relatively few work stations at the site had adjustable task lighting. The next entries in Table 12 present data on VDT's in the work station. The first column presents the number of work stations with VDT's. As can be seen, 80-908 of those in 235 and 260 had VDT's as compared with 428 in 268 before the renovation and 58.38 after. Reflections on the screen were visible at almost all work stations, although the percentage of screen reflections in 268 declined from 93.38 to 69.28 following the renovation. Virtually all work stations had adjustable keyboards; while 55.68 of those in 260 and about 858 in 268 also had adjustable screens.

Table 12 presents further descriptive information about the work stations. The first entries describe the colors (as recorded by the experimenter) of the furnishings (primarily desks, chairs, and dividers) and the approximate frequency with which they were observed. The most frequently occurring colors in 260 were white, wood and beige, with a small amount of blue and orange. In 235, the few colors observed included white, blue, beige and red. In 268 after the renovation, frequent colors included beige, blue, cream, wood, and brown. This description is somewhat deceptive since colors in each work station had been coordinated as part of the renovation so that one office area had rose dividers, while another had brown, and another blue. The color appearance in 268 was greatly improved judging by the favorable response to questions about it on the questionnaire.

The next entries provide information on the position of the light source in the work station. Here, "above" meant the light source directly above, "ahead" meant "in front of", while "right", "left", and "behind" are self explanatory. The distribution of luminaire placement was fairly even in 235 and 260 with sources located in all the major quadrants except behind. In 268 , however, noticeably more luminaires were located directly above the work station. This number increased somewhat following the renovation. In all work stations, cool white fluorescent lamps were consistently used (with no mixture with other source types - in accordance with good design practice).

The vast majority (80-928) of the work stations were both open-plan and shared. All work stations in 235, 260 and 268 following the renovation had panels, typically 60-64 in. in height, separating them from adjacent areas. Before the renovation, 408 in 268 had no panels. Most of the original furniture in 268 was metal and wood with a shift to systems furniture following the renovation. Walls were typically drywall or block with virtually no wallpaper, wood or fiberboard. 
Inspection of table 12 indicates that most chairs at the site had arms and four legs with wheels and adjustable (reclining) seats. The condition of the chair was rated by the experimenter using a scale of 1 to 5 where "l" meant poor and "5" meant good. Using this scale, chairs in 268-1 received a mean rating of 3.27 ; those in 260 a mean rating of 3.36 ; in 235 a rating of 3.8 ; and in 268-2 a rating of 3.6 -- indicating that the experimenter rated overall chair condition as above the scale midpoint of 3.0 .

Examination of the personalization of desks and walls revealed that 37.58 in 268-1, 36.48 in 260, 1008 in 235, and 84.68 in 268-2 had some form of wall personalization such as pictures or posters. Between 36 and 888 had personal items on their desks. In both cases the number of personal items increased in 268 following the renovation -- perhaps because of the addition of cloth covered panel boards or simply due to settling in after the move.

The percentage of fans ranged from 36.28 to 608 in 235 and 268 , with none observed in 260. There were slightly more fans after the renovation in 268 . The percentage of space heaters was very low -- below 58 -- even in January after the renovation. No space heaters were observed in 235 and 260 .

The experimenter also rated the number of intrusive sounds heard in the work station. The mean ratings, presented in Table 12, for all four buildings were highest for conversations of co-workers, with an overall mean of 3.04 on a 4-point scale. At least 408 of the work stations in 235 and 260 were rated as "4" indicating many conversational intrusions, while 68.88 in $268-1$ and 95.88 in 268-2 were rated as "3". Intrusive sounds from ventilation were particularly high in 260 (with all work stations receiving the highest rating) and in 235. Ratings were much lower in 268 (with means of 2.0 and 1.61). Ringing telephones were a problem in 268 following the renovation-but not in 235. Printer noise was evident in 260 and 235 with mean ratings of 3.0 and 3.2. Equipment noise was also apparent in these buildings with mean ratings of 2.75 and 2.8 . As might be expected ratings of outside noise were very low (between 1.0 and 1.6 ) due to the absence of windows. The intrusiveness of sounds was, of course, dependent on the activities being performed when they were recorded. The experimenter ratings tend, however, to reinforce the occupant ratings, particularly the annoyance of conversations of co-workers (mean of 3.37 ).

Table 13 presents summary data for temperature, humidity, and noise. Temperature and humidity were measured with a solomat ${ }^{2}$ multi-channel modometer (2016) which uses a platinum thermohygroneter to measure temperature and humidity. These data indicate a mean temperature of about $74.7^{\circ} \mathrm{F}$ for the site, near the upper limit of the ASHRAE (1981) comfort guidelines for winter conditions $\left(68^{\circ}-74.5^{\circ} \mathrm{F}\right)$ but at the middle of the summer range $\left(73^{\circ}-79^{\circ} \mathrm{F}\right)$. Relative humidities tended to be higher in buildings 235 and 260 than in 268. (The humidity measures for 268 after the renovation are so low that they are likely to be erroneous and so are not reported.) Noise levels were measured using a Quest ${ }^{2}$ model 155 precision hand-held sound level meter with a standard $1 / 2$ in condenser microphone. Ambient sound levels were measured on the dBA scale. The average noise level ( $52.4 \mathrm{dBA}$ ) was within the OSHA guidelines for noise damage, although these guidelines do not provide any indication of perceived annoyance. 
Table 13. Average Temperature, Humidity and Noise in the Four Buildings at the Site.

\begin{tabular}{|c|c|c|c|c|}
\hline BLDG & & Temp $\left({ }^{\circ} \mathrm{F}\right)$ & Humidity & Noise ( $d B A)$ \\
\hline 235 & $\begin{array}{l}\text { Average } \\
\text { Std. Dev }\end{array}$ & $\begin{array}{r}73.6 \\
1.5\end{array}$ & $\begin{array}{r}54.8 \\
2.6\end{array}$ & $\begin{array}{r}53.0 \\
5.1\end{array}$ \\
\hline 260 & $\begin{array}{l}\text { Average } \\
\text { Std. Dev. }\end{array}$ & $\begin{array}{r}74.2 \\
1.7\end{array}$ & $\begin{array}{l}62.3 \\
10.2\end{array}$ & $\begin{array}{r}52.3 \\
6.2\end{array}$ \\
\hline $268-1$ & $\begin{array}{l}\text { Average } \\
\text { Std. Dev. }\end{array}$ & $\begin{array}{r}74.3 \\
1.6\end{array}$ & $\begin{array}{l}41.0 \\
19.2\end{array}$ & $\begin{array}{r}57.1 \\
9.4\end{array}$ \\
\hline $268-2$ & $\begin{array}{l}\text { Average } \\
\text { Std. Dev. }\end{array}$ & $\begin{array}{r}75.7 \\
2.0\end{array}$ & - & $\begin{array}{r}44.8 \\
8.1\end{array}$ \\
\hline & $\begin{array}{l}\text { Site Mean } \\
\text { Std. Dev. }\end{array}$ & $\begin{array}{r}74.7 \\
1.9\end{array}$ & $\begin{array}{l}46.2 \\
19.1\end{array}$ & $\begin{array}{l}52.4 \\
10.0\end{array}$ \\
\hline
\end{tabular}


The final measurements were of the office space including the length and width of the desk, work station, chair and files. Detailed measures of binder bins, shelves, files, and secondary desks were taken in 268 after the renovation. Summary data for these measures are presented in table 14.

Examination of the average desk area indicates a sizeable decrease in desk area in 268 following the renovation from $15.1 \mathrm{ft}^{2}\left(1.40 \mathrm{~m}^{2}\right)$ to $9.2 \mathrm{ft}^{2}$ $\left(0.85 \mathrm{~m}^{2}\right)$. This decrease was attributable primarily to reduced desk width from a mean of 34.7 in $(88.1 \mathrm{~cm})$ to 24.8 in $(63 \mathrm{~cm})$. The mean desk area was greater in $260\left(11.8 \mathrm{ft}^{2}\right.$ or $\left.1.1 \mathrm{~m}^{2}\right)$ and $235\left(12.4 \mathrm{ft}^{2}\right.$ or $\left.1.15 \mathrm{~m}^{2}\right)$. In all buildings, desk height was very similar -- 28.3 to 31.7 in $(71.9$ to $80.5 \mathrm{~cm})$.

For all work stations, the mean chair length was very similar - between 19.4 and 21.4 in $(49.3$ to $54.4 \mathrm{~cm}$ ) while the width ranged from 18.3 to 19.8 in $(46.5$ to $50.3 \mathrm{~cm})$. The mean chair area was 2.2 to $2.9 \mathrm{ft}^{2}$ ( 0.2 to $0.27 \mathrm{~m}^{2}$ ) with relatively little difference between buildings. Analysis of the additional features of the new furniture from the renovation in 268 revealed more extensive use of binder bins, shelves, and files. Where there was a secondary desk, its mean area was $7.9 \mathrm{ft}^{2}\left(0.73 \mathrm{~m}^{2}\right)$.

The total area of the individual work station was also determined. Since a work station was generally in an open area with no enclosing walls, its size was estimated by measuring the space directly available to the occupant. This typically included the desk, space for chair movement (about $3 \mathrm{ft}$ ), and distance to partitions and file cabinets (which often served to delineate the work station). Table 14 indicates that area in the work station declined following the renovation in 268 by about $10 \mathrm{ft}^{2}$ per work station. Thus, mean work station area was about $70 \mathrm{ft}^{2}\left(6.5 \mathrm{~m}^{2}\right)$ in $268-1$, but only about $63.2 \mathrm{ft}^{2}$ $\left(5.87 \mathrm{~m}^{2}\right.$ ) after the renovation. In fact, the median area was $60 \mathrm{ft}^{2}$ in 260 and 268-1 and $50 \mathrm{ft}^{2}$ in 268-2. The mean area in 260 was $71.8 \mathrm{ft}^{2}\left(6.67 \mathrm{~m}^{2}\right)$ and $52.3 \mathrm{ft}^{2}\left(4.85 \mathrm{~m}^{2}\right)$ in 235. The decline in work station area in 268 may account for the feelings of being cramped and lacking space reported in the questionnaire data. 
Table 14. Measurements of Space in the Four Buildings

\begin{tabular}{lrrrrrrrr} 
& $\begin{array}{rrrrr}268-1 \\
\text { Avg }\end{array}$ & Std & $\begin{array}{r}260 \\
\text { Avg }\end{array}$ & Std & $\begin{array}{r}235 \\
\text { Avg }\end{array}$ & Std & \multicolumn{2}{c}{$268-2$} \\
Avg & Std \\
DESKLNG & 62.6 & 9.5 & 58.9 & 3.6 & 60.0 & 0.0 & 56.4 & 21.2 \\
DESKWDT & 34.7 & 5.0 & 28.8 & 2.6 & 29.8 & 0.4 & 24.8 & 2.4 \\
DESKHGT & 31.3 & 2.8 & 28.3 & 1.1 & 30.0 & 0.0 & 31.7 & 10.9 \\
SqFt & 15.1 & 3.1 & 11.8 & 1.6 & 12.4 & 0.2 & 9.2 & 3.2 \\
Desk\#2 & & & & & & & 7.9 & 1.3 \\
& & & & & & & & \\
WSLENGH & 8.9 & 2.9 & 9.5 & 3.6 & 9.0 & 1.7 & 7.8 & 2.6 \\
WSWIDTH & 7.4 & 2.6 & 7.0 & 2.0 & 5.9 & 0.9 & 7.7 & 2.6 \\
WSarea & 70.0 & 42.0 & 71.8 & 53.7 & 52.3 & 10.3 & 63.2 & 38.9 \\
& & & & & & & & \\
CHRLNGT & 19.4 & 2.7 & 20.8 & 1.9 & 21.4 & 1.7 & 20.9 & 1.6 \\
CHRWDTH & 18.3 & 1.6 & 18.5 & 1.0 & 18.6 & 0.8 & 19.8 & 1.0 \\
ChrAT & 2.2 & 0.9 & 2.7 & 0.4 & 2.8 & 0.3 & 2.9 & 0.3 \\
FILELNG & 0.0 & 0.0 & 60.0 & 0.0 & 49.0 & 14.2 & 35.8 & 13.8 \\
FILEWDT & 0.0 & 0.0 & 5.0 & 0.0 & 23.7 & 9.0 & 28.0 & 6.0
\end{tabular}

Distribution of Dimensions in the Work Stations

Length in ft

ft $235260268-1268-2$

\section{Width in $\mathrm{ft}$}

Number

$235260268-1268-2$

Work Station area in Ft? Number

SqFt $235260268-1 \quad 268-2$

$\begin{array}{rrrrrrrrrrrrrr}1 & 0 & 0 & 0 & 0 & 0 & 0 & 0 & 0 & 10 & 0 & 0 & 1 & 0 \\ 2 & 0 & 0 & 1 & 0 & 0 & 0 & 1 & 0 & 20 & 0 & 0 & 0 & 0 \\ 3 & 0 & 0 & 0 & 0 & 0 & 0 & 0 & 0 & 30 & 0 & 1 & 0 & 2 \\ 4 & 0 & 0 & 0 & 1 & 0 & 0 & 0 & 1 & 40 & 1 & 0 & 3 & 6 \\ 5 & 0 & 0 & 2 & 0 & 2 & 2 & 6 & 0 & 50 & 2 & 2 & 6 & 9 \\ 6 & 0 & 1 & 0 & 6 & 2 & 3 & 4 & 4 & 60 & 0 & 6 & 9 & 1 \\ 7 & 1 & 1 & 3 & 11 & 0 & 4 & 6 & 13 & 70 & 2 & 1 & 1 & 0 \\ 8 & 1 & 3 & 5 & 1 & 1 & 0 & 3 & 1 & 80 & 0 & 0 & 2 & 0 \\ 9 & 1 & 3 & 9 & 1 & 0 & 2 & 1 & 3 & 90 & 0 & 0 & 1 & 1 \\ 10 & 0 & 1 & 2 & 0 & 0 & 0 & 3 & 0 & 100 & 0 & 0 & 0 & 3 \\ 11 & 2 & 1 & 3 & 4 & 0 & 0 & 2 & 1 & 110 & 0 & 1 & 0 & 0 \\ 12 & 0 & 1 & 1 & 0 & 0 & 1 & 2 & 1 & 120 & 0 & 0 & 1 & 1 \\ 13 & 0 & 0 & 0 & 0 & 0 & 0 & 0 & 0 & 130 & 0 & 0 & 1 & 0 \\ 14 & 0 & 0 & 1 & 1 & 0 & 0 & 1 & 0 & 140 & 0 & 0 & 2 & 0 \\ 15 & 0 & 0 & 0 & 1 & 0 & 0 & 0 & 0 & 150 & 0 & 0 & 0 & 0 \\ 16 & 0 & 0 & 2 & 0 & 0 & 0 & 0 & 0 & 160 & 0 & 0 & 0 & 1 \\ 17 & 0 & 0 & 0 & 0 & 0 & 0 & 0 & 0 & 170 & 0 & 0 & 0 & 0 \\ 18 & 0 & 0 & 0 & 0 & 0 & 0 & 0 & 1 & 180 & 0 & 0 & 1 & 1 \\ 19 & 0 & 0 & 0 & 0 & 0 & 0 & 0 & 0 & 190 & 0 & 0 & 1 & 0 \\ 20 & 0 & 1 & 0 & 0 & 0 & 0 & 0 & 0 & 200 & 0 & 0 & 0 & 0\end{array}$

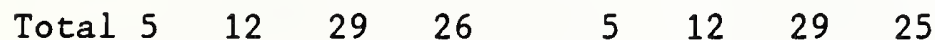

$5 \quad 12 \quad 29 \quad 25$ 


\section{Recommendations}

\subsection{Source for Suggestions}

Based on the questionnaire results, the physical measures, suggestions by the occupants, interviews with management personnel, and personal observations a number of specific recommendations for improving the buildings are presented in the following pages. Most of the recommendations apply to 260 and 268, since most of the data was obtained for these two buildings, although section 5.1.6 presents recommendations specifically for 235 .

\subsubsection{Indoor Air Quality}

Both the response to the questionnaire and conversations with personnel in the buildings indicated that indoor air quality was perceived to be a major problem. There was a high incidence of reported health problems, including respiratory diseases, headaches, allergies, and irritated eyes. People were convinced that there were major problems in the heating ducts with smells of noxious fumes and smoke appearing in offices located away from the source of the fumes or smoke. The questionnaire data reiterated strongly that the most troublesome problem for people at the site was indoor air quality, especially in buildings 260 and 268. The fact that about $70 \%$ of those questioned in these two buildings expressed dissatisfaction with their indoor air quality and air circulation is serious. Their mean rating of 1.95 for air quality and air circulation was significantly below both the Canadian rating (2.3) and the scale midpoint (3.0). In addition, the reported problems with frequent headaches and eye irritation in 260 and 268 reinforce the suggestion that the ventilation system may not perform adequarely, or that there may be sources of excessive contaminants.

As a result, the first recommendation for improving the conditions in 260 and 268 is for an engineering survey of the HVAC equipment to determine if it is performing as designed, and if the design is adequate for current conditions in the two buildings. Since the buildings have undergone extensive modifications over the years, with the addition and removal of interior walls, changes in tasking, and increases in personnel load, the original design may well be inadequate. In fact, 268 is really two buildings with separate HVAC systems joined together in what appears to be an unhappy union. Part of the problem with the ventilation may be due to the numerous configuration changes in the building over the years, in which walls were erected and removed without consideration of the placement of heating ducts and vents. The engineering survey should examine the original design, determine if all the buildings meet the original design specifications, and then evaluate whether these specifications are adequate for the current operations, particularly in building 268 and 260 . The survey would also suggest design modifications in the HVAC system to meet current needs.

At the same time, the cleanliness of the ducts and vents, as well as the condition of the filters and air exchangers, should be evaluated. The numerous comments by personnel about dust on their desks in the mornings, as well as of stuffy, stale air, indicate that the ventilating system may not be performing adequately. Similarly, the frequent complaints about temperature 
swings suggest problems with the heating and cooling part of the HVAC equipment, as well. Noticeable fluctuations occur in heating and cooling with one room being $72^{\circ} \mathrm{F}$ and another being $82^{\circ} \mathrm{F}$, and then reversing the next day for no obvious reason. Because both buildings (260 and 268) are windowless, and should be less subject to daily variations in solar load, the frequent swings in temperature are difficult to explain. As a result, the engineering survey should also assess the performance of the controls, heating, and cooling for the HVAC system.

In addition, because of the health-related symptoms and the numerous comments about poor indoor air quality, a screening analysis should be done to determine if there are any significant pollutants in the air. This is particularly necessary in 268 where chemicals and fumes from the paint and machine shops could enter the space directly or be picked up by the return air. For example, when ammonia was used to clean the shops, there were numerous complaints of eyes watering and people being dizzy. In addition, although the photolab is exhausted separately, this may not be adequate since fumes are often detected. These problems suggest that the ventilation system may malfunction and pick up exhausted fumes. As a result, the screening analysis should focus on the chemicals used in the building, as well as on $\mathrm{CO}_{2}$ concentrations (high levels of which are associated with high personnel densities).

While some respondents suggested replacing the entire HVAC system, the initial engineering survey could determine the magnitude of the problems, and evaluate whether solutions such as cleaning, modifying the HVAC controls, or changing maintenance routines would solve some problems before the major expense of complete replacement is incurred. Nonetheless, the data from the survey suggest that the complaints about indoor air quality should not be ignored. The condition of the HVAC system should be assessed and improved to ensure that the productivity and health of the occupants are not being seriously impaired.

One easily implemented recommendation is to enforce the "No Smoking" policy in the individual offices. This should remove some complaints about indoor air quality. At the same time, however, some provision should be made for a smoking break area for those who do smoke.

Recommendations

1. Perform a comprehensive engineering survey of the HVAC system including controls. Evaluate air flow rates in work spaces. Clean system thoroughly.

2. Perform limited survey of indoor air quality. Include survey of chemicals known to be used in the facility as well as $\mathrm{CO}_{2}$.

3. Develop, implement, and follow a regular maintenance program, including regular filter cleaning and changing for the HVAC systems (including ducts and vents) in all buildings. 
4. Enforce the "No Smoking" policy stringently. Make break areas available for smokers, as well as consider courses on quitting smoking.

5. Evaluate the performance of controls for temperature on the HVAC system. Determine reasons for, and correct, extreme variations in temperature.

\subsubsection{Space and Privacy}

Results from the questionnaire, including the comment data, and interviews with management personnel, indicated that space and privacy were another critical concern to people at the facility. These issues include space for storage, horizontal space to spread out papers (including blue prints and other large pieces), and space between people. Analysis of the measurements of the space indicated that most personnel were in spaces smaller than the GSA suggested guidelines of $135 \mathrm{ft}^{2}$ per person. As a result, they may feel genuinely cramped. In addition, there is no place for people to sit and think when they are faced with a difficult technical problem. An even more pressing concern from a supervisory standpoint is the lack of a place to counsel employees or hold private discussions without being overheard.

\section{Recommendations}

1. Study the existing GSA and military guidelines for space and furniture, evaluate individual tasks, and determine the desk space, file space, and personal space etc., needed to do the task. Use this information to provide a sound rationale for allocating space and furniture.

2. Provide a separate conference/counseling space for private conversations including meetings with outside contractors and employees.

3. Inventory equipment and furniture and remove any unnecessary items, while continuing to meet the needs of employees and tasks. Identify items requiring repair or replacement.

4. Involve employees in decisions about design and renovation so that the ultimate design reflects their needs and concerns.

5. Address staffing needs and space requirements for staff to avoid stress and overcrowding.

\subsubsection{Noise and Privacy}

One result of the space limitations is that any almost extra noise in the work space is a potential problem. It adds distractions and reduces privacy. For example, people commented that having their conversations overheard was extremely bothersome. On the questionnaire, the mean rating for conversational privacy was 1.9 - significantly below the scale midpoint. Furthermore, people indicated that having outside contractors overhear 
private staff conversations was a potential conflict-of-interest problem. In addition, because people tend to use speaker phones, their conversations are easily overhead and add to noise in the offices. Finally, noise from printers was a problem because printer covers are not provided with the printers. Because getting a printer cover or a laser jet printer requires a special requisition, they are not frequently obtained.

Recommendations

1. Limit conversations on the speaker phones when there are several people in the office; use more sound barriers; and provide individual offices for managers or make quiet space available.

2. Provide separate area for contractors to wait and do business in, or remind staff to monitor their conversations carefully when contractors are present.

3. Provide printer covers wherever needed. Consider adding laser printers in areas where high volume printing must be done or move printers out of occupied spaces.

\subsubsection{Windows and Break Areas}

The negative reaction to the interior environmental conditions may be intensified because of the lack of windows in the buildings. The questionnaire contained numerous comments about the need for windows for fresh air, light, and view out - not only for morale but also to improve physical conditions. For example, the front door to 268 is the only place in the building where people can see out. There is no comparable daylit entry way to 260 . In addition, because many people brown bag their lunch, they eat at their desk since neither of the two nearby eating areas allow brown bagging. As a result, they may spend their entire work day at their desks with no access to the outside. Although there are plans to build sunroom break areas in 268 , these may be subject to budget cuts.

An additional problem is the need to enforce compliance with the no smoking regulations and provide break areas for smoking. Because of problems with holes in the carpets, smoking was banned in the hallways. Yet productivity is hurt when people must go long distances from their offices to smoke. Using the same break area for smokers and non-smokers is not an appropriate solution.

Recommendations

1. Build sunroom break areas on 268 and 260 if at all possible.

2. Consider providing picnic tables outside for use during the spring, summer and fall; consider making arrangements for people to brown bag at the different eating places; and consider implementing exercise programs over the lunch hour so that people would have a break which might also reduce some of the stress of work. 
3. Provide visual interest and relief for the windowless buildings by using appropriately chosen graphics, paintings (posters), and colors. Provide sufficient space for each employee to personalize his/her own area with small photos, cartoons, etc.

4. Evaluate feasibility of adding windows or even skylights to certain offices and break areas.

5. Provide separate break areas for smokers and non-smokers. Consider providing facilities with tables and chairs suitable for eating lunch.

\subsubsection{Lighting}

Although lighting did not elicit as many complaints as did air quality and space, problems with lighting were observed at the site. Although a variety of fixtures were used in separate areas, both louvered and prismatic, the hodgepodge of fixtures and sources reported by Rubin and Collins (1988) at Army field stations did not exist. Lamps were consistently cool white (except in the warehouse area of 235) so that a checkerboard appearance was avoided. Nonetheless, there was dirt on the fixtures from the air conditioning (perhaps because the louvers were too close to the ceiling). Other fixtures had yellowed and discolored with age. In addition, there was no program for group relamping or fixture replacement; lamps are changed only when someone notices that they have burned out.

Other lighting problems involved glare, particularly on VDT screens, and lack of separate lighting for particular tasks. The addition of systems furniture during the renovation in 268 reduced the overall light levels, because the partitions blocked light from the ceiling fixtures. As the fresh paint and task lighting ages, the light levels may well drop below acceptability and should be monitored. In the shops area of 268 , the ambient lighting does not provide enough illuminance for repair of intricate equipment due to the high ceiling and dirty luminaires. In these areas, an adjustable, functioning task lamp is needed to provide high light levels at the task. In more conventional office areas, adjustable task lighting is also needed because the illuminance requirements are so different for paper and VDT tasks.

Recommendations

1. Consider the use of deep cell parabolic-type fixtures in offices where both paper and VDT tasks are performed to reduce glare from the overhead lights.

2. Orient systems furniture properly with respect to the overhead light fixtures to provide more uniform ambient lighting. Relying on the built-in lighting to light the entire work station can be inadequate since these fixtures do not provide sufficient light for the whole desk. Where possible, plan the arrangement of the furniture so that light sources do not shine in a person's eyes or directly on VDT screens. 
3. Implement the planned renovation to the lighting in the shops area. Continue to provide good adjustable task lighting for equipment repair.

4. Provide adjustable task lighting for office tasks, in which the luminaire can be moved to illuminate the task. Implement localized lighting controls (both switching and dimming) where feasible.

5. Clean fixtures regularly. Consider moving them away from diffusers to reduce dust and problems with discoloring. Develop regular maintenance and replacement program for lamps and luminaires.

6. Consider use of better color rendering light sources such as the "designer" (3200) series now available from major lighting manufacturers. Better color rendering lamps would improve the appearance of people, walls, and furnishings, and possibly alleviate some of the desire for daylight as a light source. Another alternative might be the use of light pipes to bring daylight into deep interior areas.

\subsubsection{Safety and Training}

At the time the study was initiated, there was no safety shower immediately in the shops area, although the men's rest room nearby had a conventional shower. If an accident occurred, the individual (regardless of sex) would have to use this shower. Other concerns about safety included electric cords on the floor, which present a tripping hazard, as well as ladders hanging over desks, various industrial hazards, and slippery floors near the doors during wet weather. Training deficiencies were also an issue as there appeared to be no systematic procedures for getting technical advice for hardware, software, and linkages between the two. A frequent comment on the questionnaire was the need for more training on hardware and software use, as well as for new, more functional equipment.

Recommendations

1. Provide accessible safety showers and eyewashes in any area likely to need them.

2. Remove tripping and falling hazards. Provide warning signs about slippery floors and remove standing water.

3. When new software packages are introduced, provide training on them. Also train users on hardware and operating procedures.

4. Evaluate equipment needs, including computers, software, repair and maintenance tools, phone service, and power requirements based on task needs. Institute more effective repair program. 


\subsubsection{Building 235}

In the warehouse of building 235 where packing and crating are done, there is no insulation between the roof and the people. Consequently, it is not environmentally controlled, so that temperatures are very cold in the winter and hot in the summer making it very difficult to work. Although one solution has been to use space heaters and fans, these do not work well, particularly under extreme temperatures. In addition, because the lights were placed over the storage racks in a high bay arrangement, there is little light on work or circulation areas. Another problem is that the color rendering of lighting in this space was quite poor (since high pressure sodium lighting was used). In addition, the ballasts buzz and create an annoying noise. Although personnel have suggested relamping the warehouse with mercury vapor lamps, metal halide lamps are likely to be a better, longterm solution.

Recommendations

1. Insulate the roof of 235 to decrease the extremes in heat and cold, and allow people to work without gloves in the winter and overheating in the summer.

2. Relamp the warehouse portion of 235 with metal halide rather than mercury lamps, as they are longer lived and have better color rendering. Locate fixtures so that they light work and circulation areas. Provide local task lighting where feasible.

\subsection{Conclusions}

The data analysis clearly indicated that indoor air quality was a major concern in buildings 260 and 268, even after the renovation. The numerous complaints of stuffy, stagnant air appeared to be related to air flow rates and possible contaminants. Temperature and humidity also appeared to be poorly controlled. Analysis of the data indicated that the other major problem was that of space, particularly lack of space for spreading out big documents and blueprints. The lack of space also led to many complaints about noise and lack of privacy. Although the renovation in 268 was successful in improving the appearance of the space, it decreased the satisfaction with the amount of space. Given the physical limitations on the size of the buildings and staffing requirements, quick fixes are not obvious, but clearly the problems of indoor air quality and space demand attention. 


\section{References}

American Society for Heating, Refrigerating and Air-Conditioning Engineers (ASHRAE). Atlanta, GA. 55-1981.

Collins, B.L., Fisher, W.S, Gillette, G.L., Marans, R.W. Evaluating Office Lighting Environments: Second Level Analysis. NISTIR 89-4069, April 1989.

Collins, B.L. and Rubin. A.I. Analysis of Work Environment Data from Three Army Field Stations. National Institute of Standards and Technology, NISTIR 88-3871, October 1988 .

Dillon, R., and Vischer, J.C. Derivation of the Tenant Questionnaire Survey Assessment Method: Office Building Occupant Survey Data Analysis. Ottawa, Canada: Public Works Canada, AES/SAG 1-4:87-9, November 1987 b.

Dilion, R., and Vischer, J.C. User Manual: Tenant Questionnaire Survey. Ottawa, Canada: Public Works Canada, AES/SAG 1-4:87-8, November 1987 a.

Flynn, J.E., Spencer, T.J., Martyniuk, O., and Hendrick. C. Interim Study of Procedures for Investigating the Effect of Light on Impression and Behaviour. Journal of the Illuminating Engineering Society, 1973, Pp. 87-94.

Gillette, G., and Brown, M. Occupant Evaluation of Commercial Office Lighting: Volume I., Methodology and Bibliography. ORNL/TM-10264/V1, Oak Ridge National Laboratory, November, 1986.

Gillette, G. Evaluating Office Lighting Environments: Reference Lighting Power Density Data. NBSIR 88-3691, National Bureau of Standards, January, 1988 .

Gillette, G., and Brown, M. Occupant Evaluation of Commercial Office Lighting: Volume III, Data Archive and Database Management System. ORNL/TM10264/V2, Oak Ridge National Laboratory, August, 1987.

Hawkes, R.J., Loe, D.L., and Rowlands, E. A note towards the understanding of lighting quality. Journal of the Illuminating Engineering Society, 1979, Jan, Pp. 111-120.

IES Lighting Handbook: 1987 Application Volume. Illuminating Engineering Society of North America, 345 East 47th Street, NY, NY 10017, 1987.

IES Lighting Handbook: 1984 Reference Volume. Illuminating Engineering Society of North America, 345 East 47th Street, NY, NY 10017, 1984.

Louis Harris Associates for Steelcase. The Office Environment Index: 1987 Full Report, and 1987 Summary Report. Steelcase, 1987.

Marans, R. W. Evaluating office lighting environments: A further report. Lighting Design and Application, 1987, 17, p. 32-36, 51. 
Marans, R. W., and Brown, M. Occupant Evaluation of Commercial Office Lighting: Volume II. Preliminary Data Analysis. ORNL/TM-10264/V2, Oak Ridge National Laboratory, November, 1987.

Meyer, B. Indoor Air Ouality. Reading, MA: Addison-Wesley Pub. Co., 1983.

Rea, M. Towards a model of visual performance: Foundations and data. Journal of the Illuminating Engineering Society, 1986, 15, pp. 41-57.

Rubin, A.I. and Collins, B.I. Interim Survey of Selected Military Building Environments: A Research Approach. NBSIR 87-3606, August 1987.

Rubin, A.I. and Collins, B.L. Evaluation of the working environment at selected U.S. Army field stations: Suggestions for Improvement. National Bureau of Standards, NBSIR 88-3827, August 1988.

Ulrich, R.S. View through a window may influence recovery from surgery. Science. 1984,224 , pp. 420-421. 
Appendix A. Questionaire Administered at the Site.

Room Number

Building Number

ENVIRONMENT QUESTIONNAIRE

(Including Coding for Identifiers)

1. How long have you worked in the building where you are now employed?

\begin{tabular}{ll}
$\frac{1}{2}$ & Less than 1 year \\
\hline 3 & 1-2 years \\
\hline 4 & More than 5 years
\end{tabular}

2. How long have you worked at your present job in this building?
$\frac{\frac{1}{2}}{\frac{3}{4}}$
Less than 1 year
$\mathrm{ID}=$ LONGSPAC
1-2 years
2- 5 years
More than 5 years

3. Please rate your work space on each of the following:

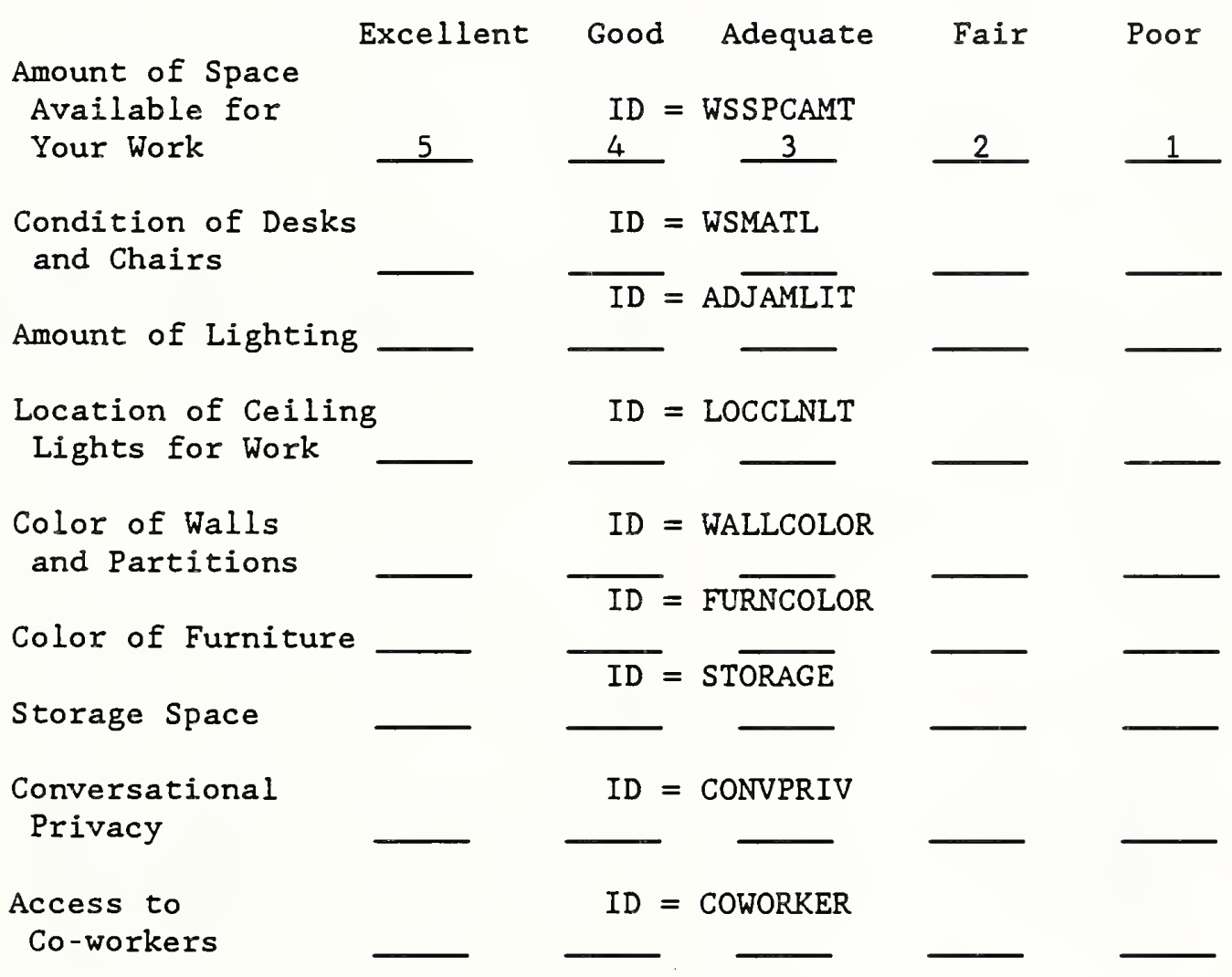


Excellent Good Adequate Fair Poor

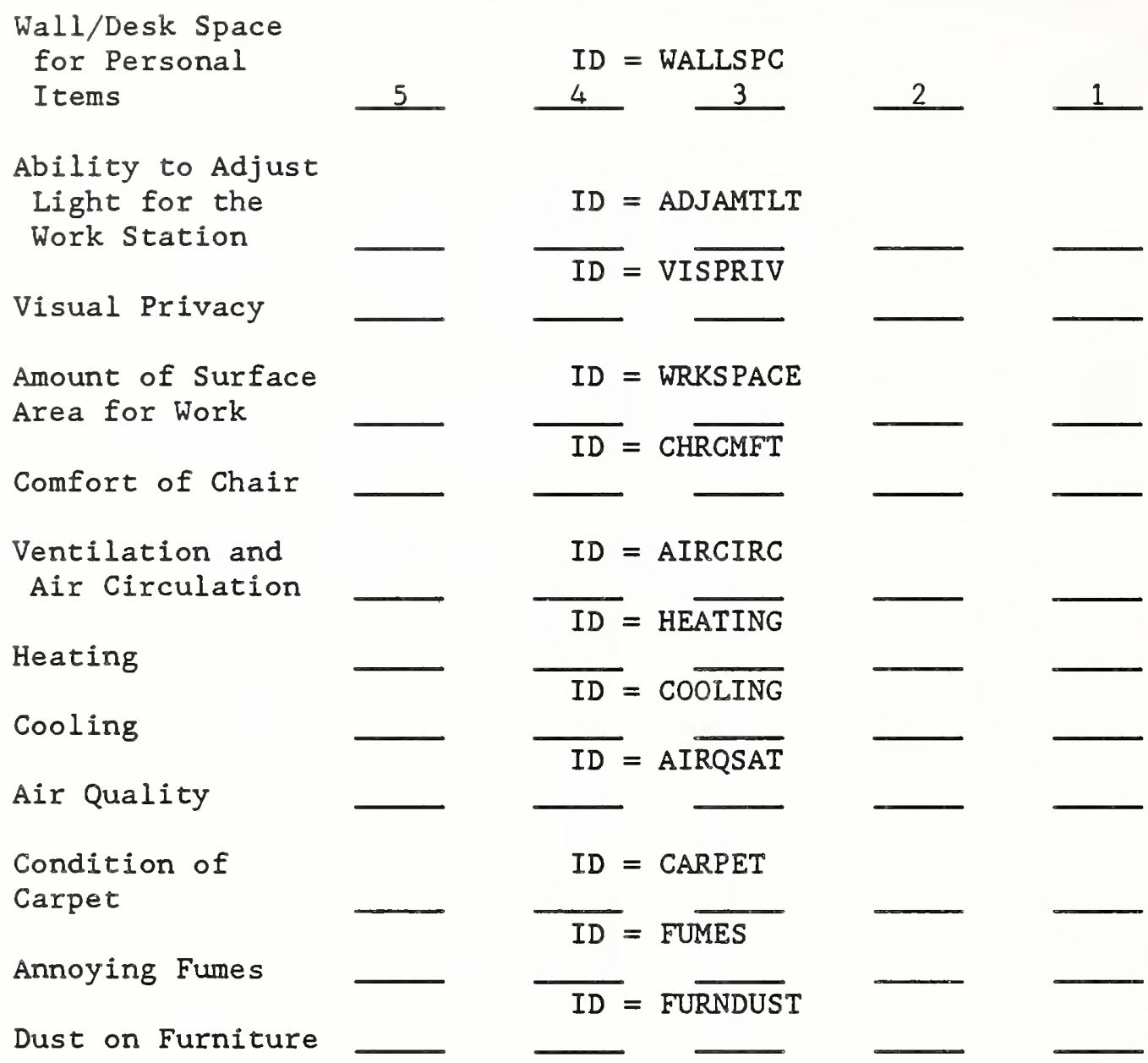

4. The way the offices and other work spaces are arranged in terms of making it easier for employees to get their jobs done is:

$\begin{array}{r}5 \\ \hline 4 \\ \hline 3 \\ \hline 2 \\ \hline 1\end{array}$

Excellent

ID $=$ ARGMTWS

Pretty Good

Neither good nor bad

Fair

Poor

5. The way the work spaces and offices look is:

$\begin{array}{r}5 \\ \hline 4 \\ \hline 3 \\ \hline 2 \\ \hline 1\end{array}$

Excellent

ID $=$ LOOKWS

Pretty Good

Neither good nor bad

Fair

Poor 
6. For each of the following spaces in your building, please rate the quality of the lighting by placing an $x$ in the appropriate column.

$\begin{array}{llll}\text { Excellent } & \begin{array}{l}\text { Pretty Neutral } \\ \text { Good }\end{array} & \begin{array}{l}\text { Not Very } \\ \text { Good }\end{array} & \text { Poor } \begin{array}{c}\text { Not } \\ \text { Applicable }\end{array}\end{array}$

\begin{tabular}{|c|c|c|}
\hline \multirow[b]{2}{*}{ Break Areas } & \multirow[b]{2}{*}{5} & \multirow{2}{*}{$\begin{array}{l}\text { ID }=\text { RTLTBREAK } \\
4\end{array}$} \\
\hline & & \\
\hline Corridors \& & & $I D=$ RTLTHALL \\
\hline & & $\overline{I D}=$ RTLTRSTM \\
\hline Restrooms & & 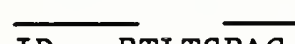 \\
\hline Work Spaces & & + \\
\hline $\begin{array}{c}\text { Conference } \\
\text { Rooms }\end{array}$ & & $\mathrm{ID}=\mathrm{RTLTCONF}$ \\
\hline
\end{tabular}

7. On the average, how many hours a day do you spend at your work space in this building?

\begin{tabular}{llllll}
$\begin{array}{ll}1-2 \\
\text { Hours }\end{array}$ & $\begin{array}{l}3-4 \\
\text { Hours }\end{array}$ & $\begin{array}{l}5-6 \\
\text { Hours }\end{array}$ & $\begin{array}{l}7-8 \\
\text { Hours }\end{array}$ & $\begin{array}{l}9-10 \\
\text { Hours }\end{array}$ & $\begin{array}{l}\text { More than } \\
10 \text { hours }\end{array}$ \\
1 & & 2 & ID $=$ HRSDYBLG & \\
\hline
\end{tabular}

8. Which of the following tasks best describes the work that you normally do. (CHECK THOSE THAT APPLY)

\begin{tabular}{|c|c|c|}
\hline 3 & Using a video display terminal (VDT) & $I D=$ VDTUSN \\
\hline 1 & Reading and writing & $I D=$ READING \\
\hline 5 & Filing & $I D=F I L I N G$ \\
\hline 8 & Repairing equipment & $I D=R E P A I I R N$ \\
\hline 2 & Reviewing manuals & $I D=$ REVIEWN \\
\hline 7 & Managing & $I D=$ MANAGING \\
\hline 6 & Meeting with contractors & $I D=$ MEETING \\
\hline 9 & Travel & $I D=$ TRAVLEN \\
\hline 4 & Review of technical drawings & $I D=$ REVTECHN \\
\hline 0 & Other. Please specify & $I D=$ OTHREN \\
\hline
\end{tabular}


9. Please estimate the number of hours that you spend at each task on a typical day.

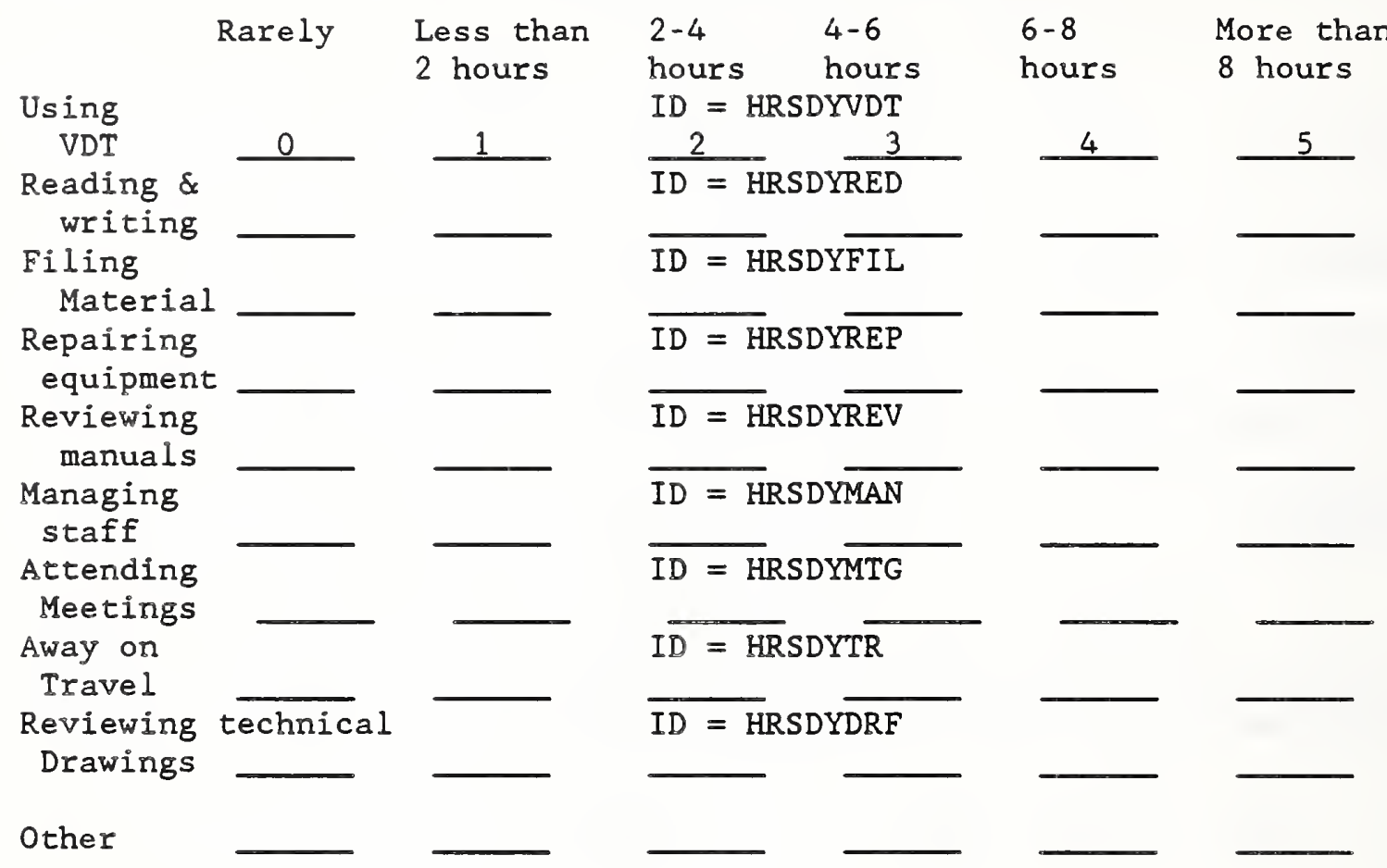

10. For each task performed, please rate the lighting available to you.

Excellent Pretty Neutral Not Very Poor $\begin{gathered}\text { Not } \\ \text { Good } \\ \text { Applicable }\end{gathered}$
Good

$\begin{array}{llll}\text { Reading } & 5 & 4 & \frac{3}{\text { ID }=\text { LTREAD }} \\ \text { Using VDT } & - & \frac{2}{\text { ID=LIDT }} \\ \text { Filing } & - & \frac{\text { ID=LTFILE }}{\text { ID }=\text { LTREPEQP }} \\ \begin{array}{l}\text { Repairing } \\ \text { Equipment } \\ \text { Reviewing } \\ \text { Drawings } \\ \text { Other }\end{array} & - & \\ \text { ID }=\text { LTDRAFT }\end{array}$

11. How would you describe the amount of light available to you now?

$\begin{array}{r}\frac{1}{2} \\ \hline 3 \\ \hline 4 \\ \hline 5\end{array}$

Much too bright

$I D=A M T L T B R T$

A bit too bright

Just about right

A bit too dim

Much too dim 
12. Overall, how satisfied are you with the lighting at your work space.

\begin{tabular}{c}
$\frac{5}{4}$ \\
\hline 3 \\
\hline 2 \\
\hline 1
\end{tabular}

Very Satisfied

ID $=$ WSLITSAT

Fairly Satisfied

Neither Satisfied nor Dissatisfied

Not Very Satisfied

Not At All Satisfied

13. Are there any changes that you would make to the lighting at your workstation?

ID $=$ CHANGES

14. If you use a Video Display Terminal (VDT), indicate how bothersome each of the following conditions is for you. If you do not use a VDT, please go to question 15 .

Not at all

Bothersome

Screen

Flicker

Distance to

Screen

Screen

Angle

Glare from

Overhead Light

Keyboard

Angle

Height of

Desk

Comfort of

Chair

Reflections

on Screen

Ease of Reading

Printed/Typed

Material

Location of Overhead Light

Inability to

Adjust Screen or

Keyboard

Space for Printed Material

Inability to

Adjust light
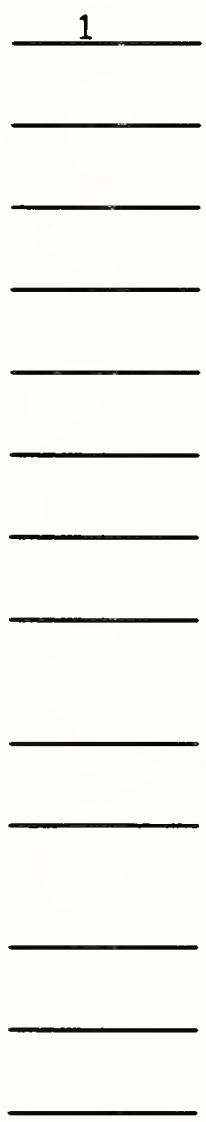

Not very

Bothersome

Fairly

Bothersome

Very

Bothersome

ID $=$ VDTFLICK

$\frac{2}{I D=V D T D S T S C}$

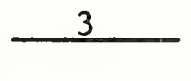

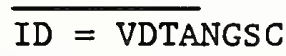

$\overline{I D}=$ VDTGLARE

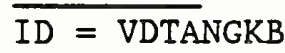

$\overline{I D}=$ VDTDSKHT

$\overline{I D}=$ VDTSEAT

ID = VDTREFSC

$I D=$ VDTREAD

$\overline{I D}=$ VDTBRTLT

$I D=$ VDTADJSC

$\overline{I D=V D T S}$ PACE

$\overline{I D}=$ VDTADJLT

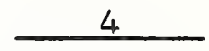

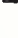

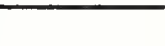

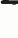

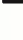

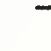<smiles>C1CC1</smiles>

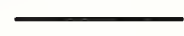

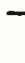

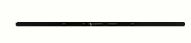


15. Sometimes the arrangements of work stations can be distracting to the people in offices. Please indicate how bothersome each of the following is to you.

$\begin{array}{llll}\text { Not at all } & \text { Not very } & \text { Fairly } & \text { Very } \\ \text { Bothersome } & \text { Bothersome } & \text { Bothersome } & \text { Bothersome }\end{array}$

\begin{tabular}{ll} 
Ringing & \\
Telephones & \\
Conversations & \\
of People & \\
Noise From & \\
Printers & \\
Noise From Other & \\
Equipment & \\
Noise From & \\
Ventilating & \\
System & \\
Noise From & \\
Corridors & \\
Reflected Glare & \\
Off Work Surfaces \\
Glare From Ceiling \\
Lights \\
Overly \\
Dim Lights \\
Absence of \\
View out \\
Too Hot \\
in Summer \\
Too Cold \\
in Winter \\
Too Many \\
Drafts \\
Air is Too \\
Stuffy \\
People Walking \\
Around \\
People Too \\
Close \\
Unpleasant \\
Smells \\
Cigarette \\
Smoke \\
Wide Swings in \\
Temperature \\
Indoor Air \\
Quality \\
Lack of Adjustable \\
Task Light \\
\hline \\
\hline \\
\\
\hline
\end{tabular}

ID $=$ NOISEPHN

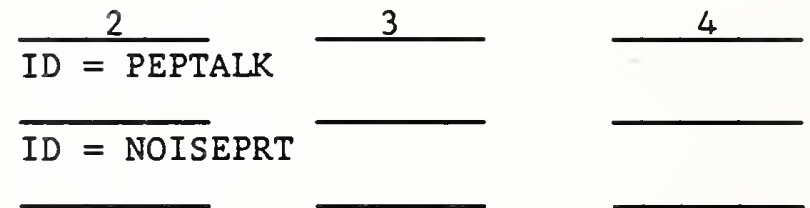

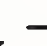
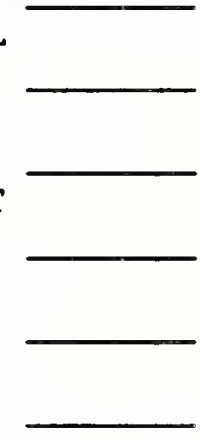

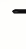

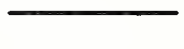

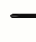

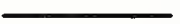$$
I D=\text { SMELLS }
$$$$
\overline{I D}=S M O K E
$$$$
\text { ID }=\text { TEMPSWN }
$$$$
\text { ID = AIRQUAL }
$$$$
\text { ID }=\text { NOTSKLT }
$$ 
16. Please rate each of the following by placing an $\underline{X}$ in the space that best describes your feelings about this building. For example, if you think the building is pleasant, put an $\underline{X}$ next to the word "pleasant"; if you think it is unpleasant, put an $\underline{x}$ next to the word "unpleasant"; and if you think it is in between, please put an $\underline{X}$ where you think it belongs.

Pleasant $\quad 5 \quad \underline{\text { ID=BLDGPLST }} \quad 3 \quad 2 \quad 1 \quad$ Unpleasant

Adequate for my job $5 \quad \underline{I D=B L D G A D Q T} \quad 3 \quad 2 \quad 1$ Not adequate for job

Well Maintained

Interiors

Confined

$5 \quad$ ID=BLDGMAIN $\quad 3 \quad 2 \quad 1$

Poorly Maintained

Interiors

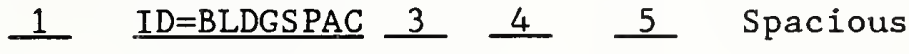

Stimulating Spaces $5 \quad \underline{I D=S T I M U L} \quad 3 \quad 2 \quad 1$

Unstimulating Spaces

Poorly Lit Spaces

$1 \quad$ ID=WELLIT $3 \quad 4 \quad 5$

Well Lit Spaces

Humid

Clean

Noisy

Colorful

Interesting

Hot

Relaxed Atmosphere

Smelly

1 ID=BLDGHUMD $3 \quad 4 \quad 5 \quad$ Dry

$5 \quad$ ID=BLDGCLEN $3 \quad 2 \quad 1 \quad$ Dirty

$5 \quad$ ID=BLDGQUIT $3 \quad 2 \quad 1 \quad$ Quiet

$5 \quad$ ID=BLDGCLR $3 \quad 2 \quad 1 \quad$ Drab

Bright

$5 \quad$ ID=BLDGINTR $3 \quad 2 \quad 1 \quad$ Boring

5 ID=BLDGTEMP $3 \quad 2 \quad 1 \quad$ Cold

$5 \quad$ ID=BLDGATMS $\quad 3 \quad 2 \quad 1 \quad$ Tense Atmosphere

1 ID=BLDGSML $3 \quad 4 \quad 5 \quad$ Not Smelly

$5 \quad \underline{\text { ID }=\text { BLDGBRT }} \quad 3 \quad 2 \quad 1 \quad$ Dim

17. How often have you experienced any of the following symptoms which you think are caused by working in this building?

Never Rarely Sometimes Frequently Most of

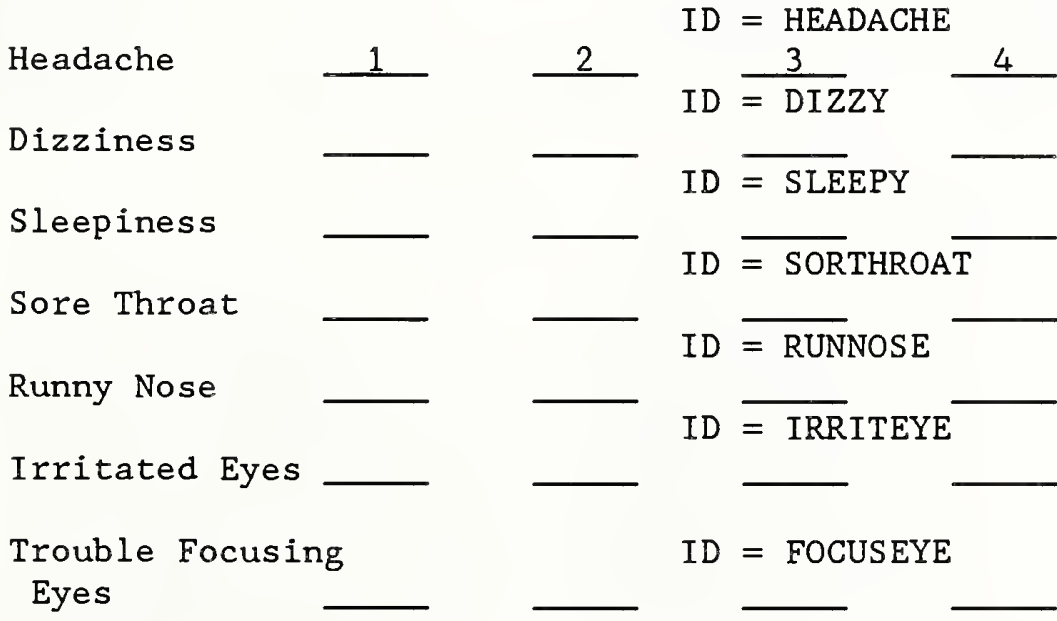

the Time

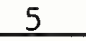


Never Rarely Sometimes Frequently Most of

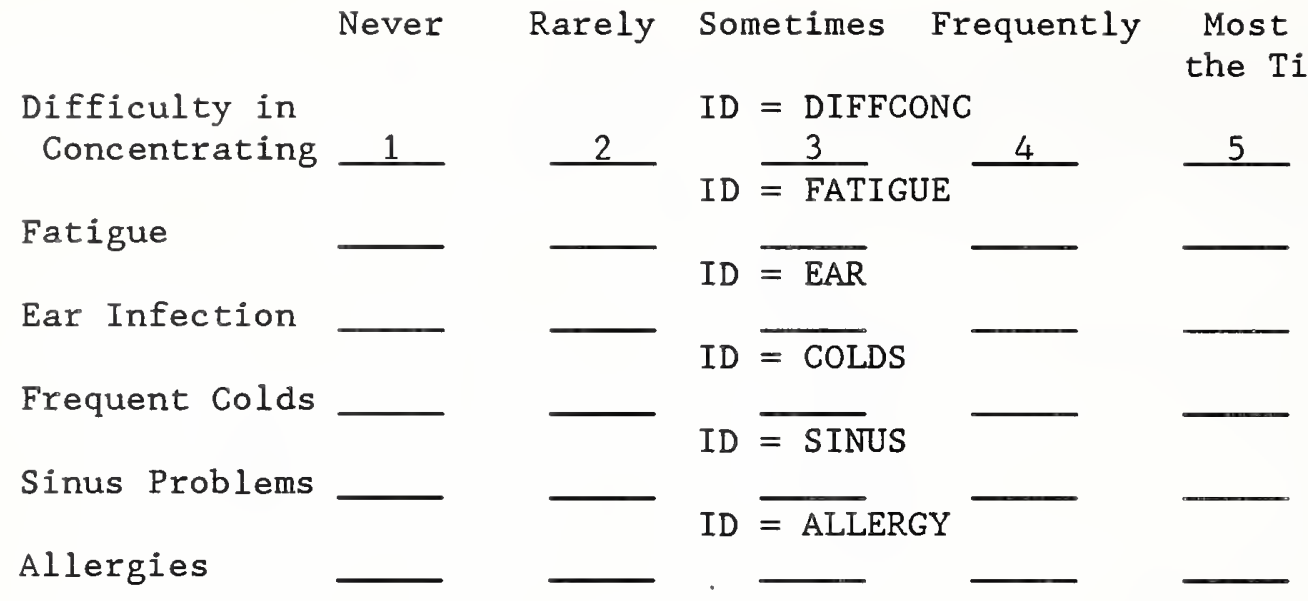

18. Suppose you could make 4 changes to your overall work environment. Using the list below, indicate the 4 changes you would make in order of preference (where 1 = most preferred).

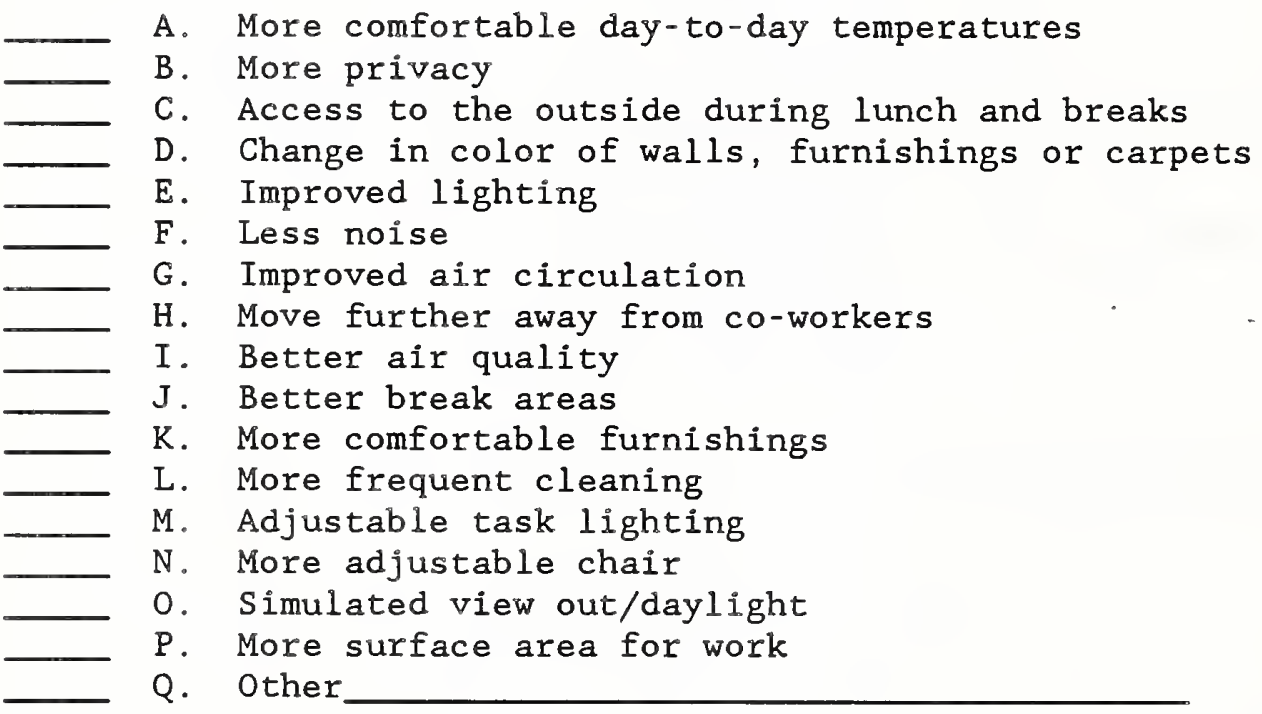

ID=WS IMTEMP ID=WSIMPRIV ID=WS IMACC ID=WSIMCLR ID=WSIMLTG ID=WSIMNOIS ID=WSIMAIRC ID=WS IMLOC ID=WS IMAIRQ ID=WSIMBKSP ID=WS IMFURN ID=WS IMCLN ID=WS IMTKLT ID =WS IMCHAR ID=WS IMDLT ID=WS IMSURF ID=WS IMOTHR

19. Please explain the reasons for your four choices. 
20. Overall, how satisfied are you with your work space and furniture?

\begin{tabular}{lll}
\hline 5 & Very Satisfied & ID $=$ FURNSAT \\
\hline 4 & Fairly Satisfied & Neither Satisfied Nor Dissatisfied \\
\hline 2 & Not Very Satisfied & \\
\hline 1 & Not at all Satisfied &
\end{tabular}

21. If you could make any changes to your work space what would you do?

$$
I D=\text { WSCG }
$$

22. Do you feel the need to have a view outside during break periods or lunch?
1 Yes
- No
$I D=$ NEEDSOUT

23. Overall, how satisfied are you with your work equipment?

$\frac{5}{\frac{5}{3}}$

Very Satisfied

ID = EQUIPSAT

Fairly Satisfied

Neither Satisfied nor Dissatisfied

Not Very Satisfied

Not At All Satisfied

24. If you could make any changes to the work equipment, what would you do?

$$
\text { ID }=\text { EQUIPCHG }
$$

25. Please rate your chair on each of the following:

\begin{tabular}{|c|c|c|}
\hline $\begin{array}{c}\text { Ease of movement } \\
\text { on carpet }\end{array}$ & 4 & $\begin{array}{l}\text { ID }=\text { CHAIRMOV } \\
3 \\
\end{array}$ \\
\hline $\begin{array}{c}\text { Ease of adjusting } \\
\text { seat height }\end{array}$ & & $\mathrm{ID}=\mathrm{CHRHGT}$ \\
\hline $\begin{array}{c}\text { Ease of adjusting } \\
\text { back height }\end{array}$ & & ID = CHRBACK \\
\hline $\begin{array}{c}\text { Back tilt or } \\
\text { tension }\end{array}$ & & ID = CHAIRADJ \\
\hline $\begin{array}{l}\text { General } \\
\text { condition }\end{array}$ & & ID = CHAIRCON \\
\hline
\end{tabular}

Excellent Good Fair Poor 
26. Please indicate how true the following statements are for your job.

$\begin{array}{lccl}\text { Very } & \text { Somewhat } & \text { Not Very } & \text { Not At } \\ \text { True } & \text { True } & \text { True } & \text { All True }\end{array}$

The work

is important

When I talk to co-workers, others can hear us

My job is satisfying

My work must be very

I have the equipment to get my job done well

My eyes get tired when I work

for more than 2 hours

My job requires me to stay

in one place all day

My job requires a great deal of concentration

I have enough time

to get my work done

Lighting at my desk keeps me from doing my job well

I have opportunities to develop my own special abilities 4

I am satisfied with the quality of my work

I miss having a view out or window

Noise keeps me from doing my job well

My job requires me to work very fast and accurately 1

I would like to know what the weather is like outside
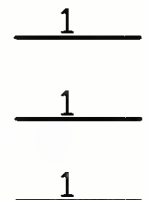

ID = WRKIMPT

$\frac{3}{\mathrm{ID}=\text { COWRKHR }}$

$\frac{2}{\mathrm{ID}=\mathrm{JOBSAT}}$

$\frac{3}{\mathrm{ID}=\text { WRKACR }}$

$\frac{2}{\mathrm{ID}=\mathrm{EQUIP}}$

$\frac{2}{\mathrm{ID}=\mathrm{TIREDEYE}}$

$\frac{2}{\mathrm{ID}=\text { NOMOVFWS }}$

$\frac{2}{I D=\text { CONCNTRT }}$

$\frac{3}{\text { ID }=\text { WORKTIME }}$

$\frac{2}{\mathrm{ID}=\mathrm{LT}}$ GHINDR

$\frac{2}{\text { ID }=\text { WRKABILIT }}$

$\frac{3}{I D=\text { WORKSAT }}$

$\frac{2}{I D=M I S S V I E W ~} \frac{3}{3}$

$\frac{2}{\mathrm{ID}=\text { WRKNOISE }}$

$\frac{2}{I D=\text { WORKFAST }}$

$\frac{2}{\text { ID }=\text { WEATHER }} \frac{3}{3}$
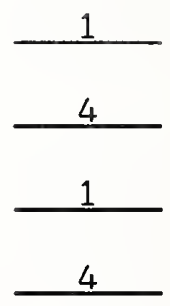

4
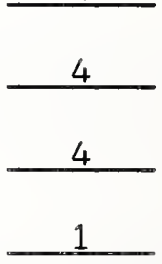

4

4

1

4

4

4

4

4

27. Which of the following best describes your job?

\begin{tabular}{ll}
$\frac{1}{2}$ & Administrative \\
Clerical & \\
\hline 3 & Equipment Repair \& Testing \\
\hline 5 & ADP Operator \\
& Other
\end{tabular}

28. Are you Military?

Civilian?

Contractor?

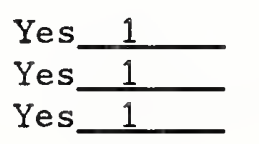

\begin{tabular}{ll} 
No & 0 \\
No & 0 \\
No & 0 \\
\hline
\end{tabular}

ID $=$ MILITARY

ID $=$ CIVILIAN

ID $=$ CONTRACT 
29. Are you a female?

Male?

$\mathrm{ID}=\mathrm{SEX}$
30. Do you wear glasses?
Are they bifocals?
contact lenses?

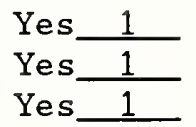
No $\frac{0}{0}$
No $\frac{0}{0}$
ID = GLASSES
ID $=$ BIFOCALS
$I D=$ CONTACTS

31. If you answered yes to question \#30, how long have you worn corrective lenses?

\begin{tabular}{|c|c|c|}
\hline 1 & Less than 6 months & $I D=$ LONGLENS \\
\hline 2 & 6-12 months & \\
\hline 3 & 1-2 years & \\
\hline 4 & 2-5 years & \\
\hline 5 & More than 5 years & \\
\hline
\end{tabular}

32. How many days have you been absent from work due to illness during the last six months?

\begin{tabular}{|c|c|}
\hline 0 & None \\
\hline 1 & 1-2 days \\
\hline 2 & 3-5 days \\
\hline 3 & 6-12 days \\
\hline 4 & More than 12 days \\
\hline
\end{tabular}

$I D=$ LONGSICK

33. How old are you?

$\begin{array}{llll}1 & \text { Under } 20 & 2 & 3 \\ 4 & 40-49 & 50-29 \quad 50-59 \quad \text { ID }=\text { AGE }\end{array}$

34. How much overtime did you routinely work before the current budget restrictions?

None
5 hours/week
$5-10$ hours/week
More than 10 hours/week $\frac{1}{3}$$\quad$ ID = OVERTIME

35. What suggestions would you make for improving the building to make your job easier?

Thank you very much for your participation. 
EMRA Environmental Measures - Direct

Time is:

Date is:

Space I.D.

Recorder:

1. Number of work surfaces or

places where tasks occur:

1

1

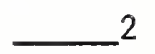

3 or more

1a. Illuminance while SEATED in chair:

PRIMARY

SECONDARY

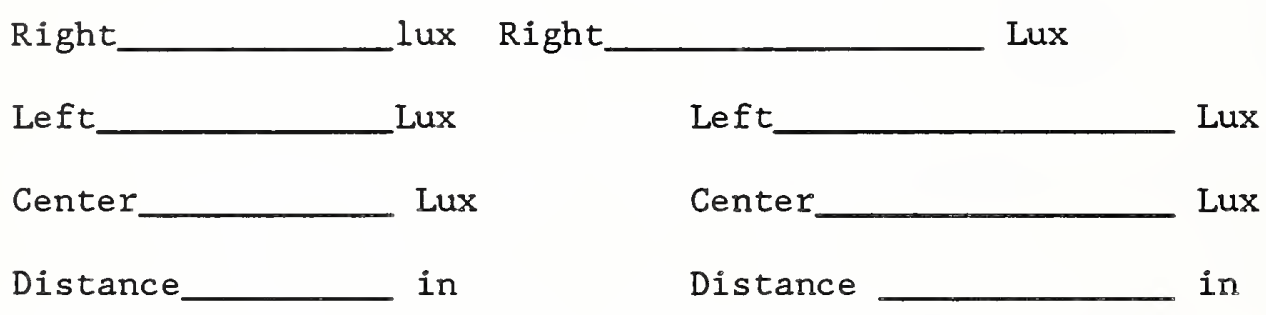

2. Luminance at PRIMARY task area:

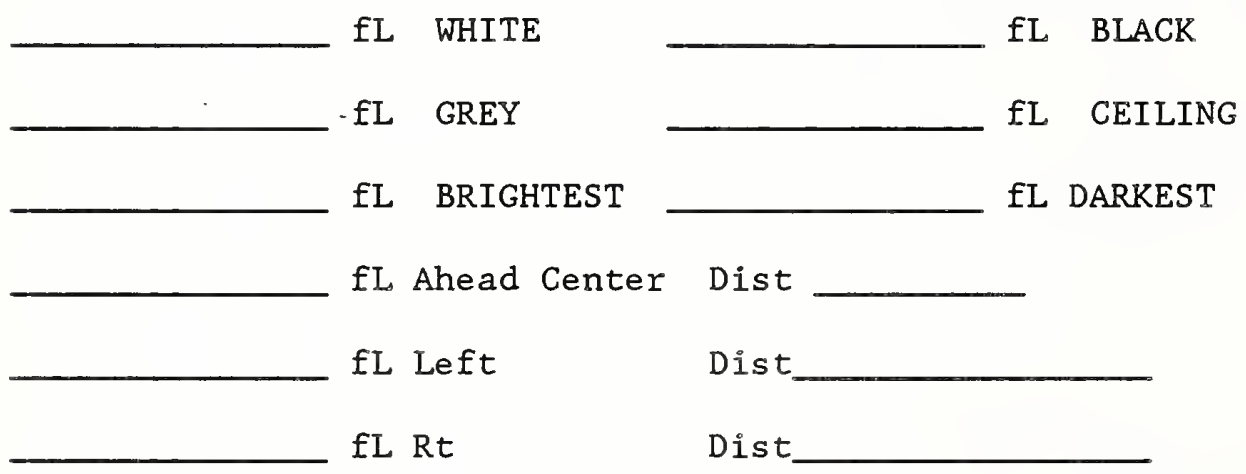

3. Overhead Luminaire Type:

Lens

Grille/Louvre

Other

4. Position with respect to work station:

Above

Right

Ahead

Behind

Left

5. Lamp type for overhead lighting:

Number of tubes 
6. Control of Switching:

None

7. Have lamps been switched off?

Yes

How Many?

No

8. Does the workstation have a VDT?

Yes No

a. Reflected light from electric light sources can be seen on screen?......

b. Keyboard can be raised and lowered?..

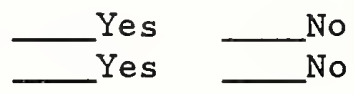

c. Screen can be raised, lowered, or tilted?.................... Yes

d. Location of screen

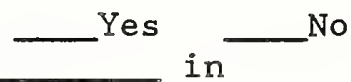

9. Luminance at VDT task area:

Keyboard $\operatorname{lux}$

Screen $\operatorname{lux}$

fL White

fL Center

fL Right

fL Bottom

fL SCREEN $\mathrm{CH}$

fL SCREEN $\mathrm{CH}$
fL on Black

fL Left

fL Upper
$\mathrm{CH}$

$\mathrm{CH}$

10. Dominant colors in workstation:

11. Workstation is in an open area: Yes No

12. Type of panels:

1. 42"-54" Panels

2. 60"-64" Panels

3. 68"-74" Panels

4. Open without Panels

6. Distance to Panel

12b. The space containing the workstation is: 
1. Private

2. Shared

13. Furnishings are predominantly (Check all that apply):

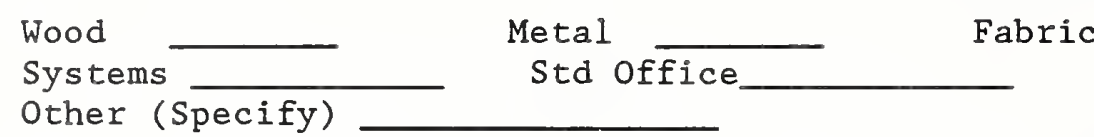

14. Walls are predominantly (Check all that apply):

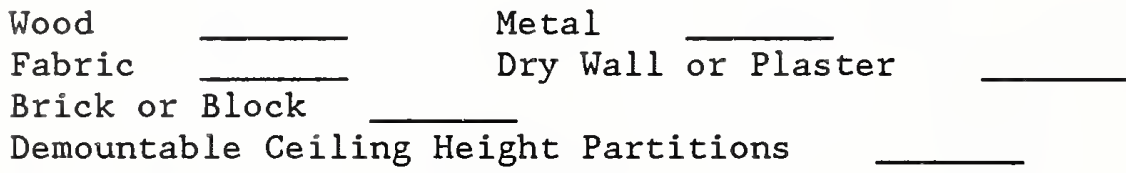

Other (Specify)

15. Type of office chair:

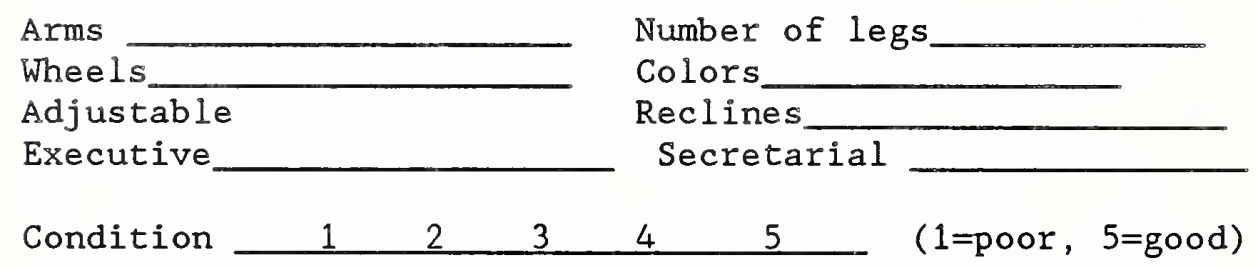

16. Does the workstation have:

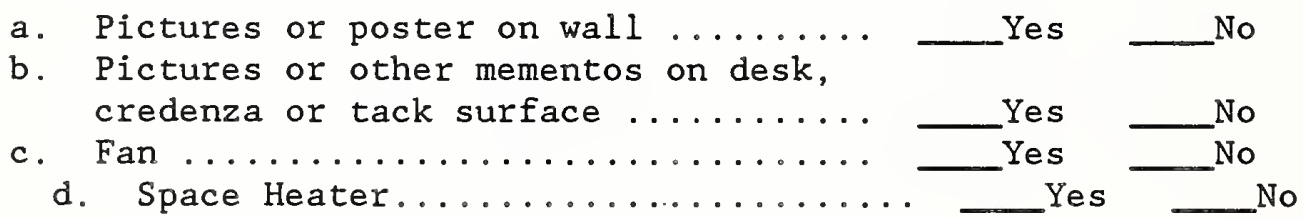

17. Is there supplemental task lighting at primary/secondary task location? Yes No

Lamp Type

Free Standing Movable

Furniture integrated

Desk mounted moveable

Other

18. Illuminance of Task Light $\operatorname{lux}$

Luminance fL White fL Black

\section{Direction of Light}


Fixed

Adjustable

Height of Task Light Above Task Surface in.

20. Instrusive Sounds

$$
\begin{aligned}
& \text { Very } \\
& \text { None Little Some A Lot }
\end{aligned}
$$

a. Ringing Telephones

b. Conversations of Co-workers

c. Printer or Computer Noise

d. Other Office Equipment Noise

e. Vent System Noise

f. Outside Noise

g. Music or Intercom

21. Temperature:

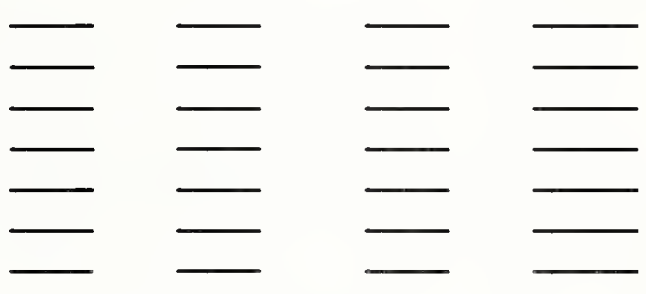
${ }^{\circ} \mathrm{F} \quad$ Dry Bulb
22. Humidity
\& Relative Humidity
23. Air Flow
CFM

24. Background Noise Level dBA Reading Source

\begin{tabular}{|c|c|c|}
\hline Desk & Length & Width_ \\
\hline Office Area & Length & Width \\
\hline Chair & Length & Width. \\
\hline File Cabinet & Length & Width \\
\hline
\end{tabular}

25. Area Occupied by Person 
Appendix B. Percentage Response Data for All Buildings

\begin{tabular}{|c|c|c|c|c|c|c|c|c|c|c|c|c|}
\hline & & $\underline{0^{\prime} s}$ & $\underline{1^{\prime} \mathrm{s}}$ & $\underline{2^{\prime} s}$ & $\underline{3^{\prime} s}$ & $4^{\prime} \mathrm{s}$ & $5^{\prime} s$ & $\mathrm{~N}$ & Avg & Std & SMean & $\underline{\mathrm{SN}}$ \\
\hline 235 & WSSPCAMT & $\overline{0.08}$ & $\overline{8.38}$ & 8.38 & $3 \overline{7.5 \%}$ & 33.38 & 12.5 웅 & 24 & 3.33 & 1.07 & 3.00 & $\overline{309}$ \\
\hline 260 & WSSPCAMT & 0.08 & 17.48 & 13.08 & 34.88 & 24.68 & 10.18 & 69 & 2.97 & 1.22 & & \\
\hline $93 / 8$ & WSSPCAMT & 0.08 & 15.88 & 15.88 & 42.18 & 21.18 & 5.38 & 19 & 2.84 & 1.09 & & \\
\hline 58-1 & WSSPCAMT & 0.08 & 18.38 & 21.78 & 27.08 & 22.68 & 10.48 & 115 & 2.85 & 1.25 & & \\
\hline $68-2$ & WSSPCAMT & 0.08 & 15.98 & 14.68 & 20.78 & 32.98 & 15.98 & 82 & 3.17 & 1.33 & & \\
\hline 35 & WSMATL & 0.08 & 8.38 & 16.78 & 12.58 & 54.28 & 8.38 & 24 & 3.38 & 1.11 & 3.46 & 307 \\
\hline 50 & WSMATL & 0.08 & 1.48 & 11.68 & 23.28 & 44.98 & 18.88 & 69 & 3.68 & 0.96 & & \\
\hline $93 / 8$ & WSMATL & $0.0 \%$ & 0.08 & 21.18 & $21.1 \%$ & 42.18 & $15.8 \%$ & 19 & 3.53 & 0.99 & & \\
\hline 88-1 & WSMATL & 0.08 & 13.28 & 20.28 & 29.88 & 31.68 & 5.38 & 114 & 2.96 & 1.12 & & \\
\hline 68-2 & WSMATL & 1.28 & 2.58 & 9.98 & 9.98 & 37.08 & 39.58 & 81 & 3.98 & 1.14 & & \\
\hline 35 & AMTLTWRK & $0.0 \%$ & 17.48 & 26.18 & 26.18 & 17.48 & 13.08 & 23 & 2.83 & 1.27 & 3.16 & 307 \\
\hline 60 & AMTLTWRK & 0.08 & $10.1 \%$ & 20.38 & 29.08 & 31.98 & 8.78 & 69 & 3.09 & 1.13 & & \\
\hline $93 / 8$ & AMTLTWRK & $0.0 \%$ & $0.0 \%$ & 5.38 & 31.68 & 42.18 & 21.18 & 19 & 3.79 & 0.83 & & \\
\hline 58-1 & AMTLTWRK & 0.08 & 12.38 & 19.38 & 31.68 & 34.28 & 2.68 & 114 & 2.96 & 1.06 & & \\
\hline $8-2$ & AMTLTWRK & 0.08 & 2.48 & 18.38 & 23.28 & 42.78 & 13.48 & 82 & 3.46 & 1.01 & & \\
\hline 35 & LOCCLNLT & 0.08 & 12.58 & 37.58 & 20.88 & 16.78 & $12.5 \%$ & 24 & 2.79 & 1.22 & 3.07 & 308 \\
\hline 0 & LOCCLNLT & $0.0 \%$ & $14.7 \%$ & 20.68 & 25.08 & 30.98 & $8.8 \%$ & 68 & 2.99 & 1.21 & & \\
\hline $3 / 8$ & LOCCLNLT & 0.08 & 5.38 & 5.38 & 31.68 & 36.88 & 21.18 & 19 & 3.63 & 1.04 & & \\
\hline $8-1$ & LOCCLNLT & 0.08 & 13.08 & 20.98 & 29.68 & 33.98 & 2.68 & 115 & 2.92 & 1.08 & & \\
\hline $8-2$ & LOCCLNLT & 0.08 & 7.38 & 15.98 & 28.08 & 35.48 & 13.48 & 82 & 3.32 & 1.11 & & \\
\hline 35 & WALLCOLR & 0.08 & 17.48 & 17.48 & 17.48 & 39.18 & 8.78 & 23 & 3.04 & 1.27 & 3.08 & 307 \\
\hline 50 & WALLCOLR & 0.08 & 24.68 & 24.68 & 31.98 & 13.08 & 5.88 & 69 & 2.51 & 1.16 & & \\
\hline $3 / 8$ & WALLCOLR & 0.08 & 5.38 & $10.5 \%$ & 15.88 & 57.98 & 10.58 & 19 & 3.58 & 0.99 & & \\
\hline $8-1$ & WALLCOLR & $0.0 \%$ & 10.58 & 17.58 & 31.68 & 36.08 & 4.48 & 114 & 3.06 & 1.06 & & \\
\hline $8-2$ & WALLCOLR & 0.08 & 11.08 & 7.38 & 22.08 & 42.78 & 17.18 & 82 & 3.48 & 1.18 & & \\
\hline 35 & FURNCOLR & 0.08 & $16.7 \%$ & $20.8 \%$ & 25.08 & 37.58 & 0.08 & 24 & 2.83 & 1.11 & 3.11 & 299 \\
\hline 60 & FURNCOLR & 0.08 & 7.68 & 21.28 & 31.88 & 27.38 & 12.18 & 66 & 3.15 & 1.12 & & \\
\hline $93 / 8$ & FURNCOLR & 0.08 & $10.5 \%$ & $15.8 \%$ & 26.38 & 42.18 & $5.3 \%$ & 19 & 3.16 & 1.09 & & \\
\hline $68-1$ & FURNCOLR & 0.08 & 17.18 & 17.18 & 44.18 & 18.98 & 2.78 & 111 & 2.73 & 1.04 & & \\
\hline $58-2$ & FURNCOLR & 0.08 & 5.18 & 7.68 & 25.38 & 38.08 & 24.18 & 79 & 3.68 & 1.07 & & \\
\hline 35 & STORAGE & 0.08 & 36.48 & 13.68 & 27.38 & 18.28 & 4.58 & 22 & 2.41 & 1.27 & 2.21 & 305 \\
\hline 60 & STORAGE & 0.08 & 46.48 & 24.68 & 14.58 & 13.08 & 1.48 & 69 & 1.99 & 1.12 & & \\
\hline $93 / 8$ & STORAGE & 0.08 & $21.1 \%$ & 47.48 & 5.38 & 26.38 & 0.08 & 19 & 2.37 & 1.09 & & \\
\hline $68-1$ & STORAGE & $0.0 \%$ & 40.78 & 28.38 & $18.6 \%$ & 12.48 & 0.08 & 113 & 2.03 & 1.04 & & \\
\hline $58-2$ & STORAGE & $0.0 \%$ & 30.58 & 20.7 웅 & $19.5 \%$ & 19.58 & 9.88 & 82 & 2.57 & 1.35 & & \\
\hline 235 & CONVPRIV & 0.08 & 58.38 & 20.88 & 8.38 & 8.38 & 4.28 & 24 & 1.79 & 1.15 & 1.90 & 307 \\
\hline 50 & CONVPRIV & 0.08 & 55.18 & 23.28 & 13.08 & 4.38 & 4.38 & 69 & 1.80 & 1.10 & & \\
\hline $93 / 8$ & CONVPRIV & 0.08 & 52.68 & $15.8 \%$ & $15.8 \%$ & 15.88 & 0.08 & 19 & 1.95 & 1.15 & & \\
\hline $58-1$ & CONVPRIV & $0.0 \%$ & 63.58 & 13.98 & 12.28 & 9.68 & 0.98 & 115 & 1.70 & 1.06 & & \\
\hline $68-2$ & CONVPRIV & 0.08 & $43.8 \%$ & 15.08 & 16.38 & 18.88 & 6.38 & 80 & 2.29 & 1.35 & & \\
\hline & COWORKER & 0.08 & 8.78 & 0.08 & 30.48 & 39.18 & 21.78 & 23 & 3.65 & 1.09 & 3.37 & 308 \\
\hline & COWORKER & 0.08 & 7.28 & 8.78 & 24.68 & 40.68 & $18.8 \%$ & 69 & 3.55 & 1.11 & & \\
\hline
\end{tabular}


293/8 COWORKER

268-1 COWORKER

268-2 COWORKER

235 WALLSPC

260 WALLSPC

293/8 WALLSPC

268-1 WALLSPC

268-2 WALLSPC

235 ADJAMTLT

260 ADJAMTLT

293/8 ADJAMTLT

268-1 ADJAMTLT

268-2 ADJAMTLT

235 VISPRIV

260 VISPRIV

$293 / 8$ VISPRIV

268-1 VISPRIV

268-2 VISPRIV

235 WRKSPACE

260 WRKSPACE

293/8 WRKSPACE

268-1 WRKSPACE

268-2 WRKSPACE

235 CHRCMFT

260 CHRCMFT

293/8 CHRCMFT

268-1 CHRCMFT

268-2 CHRCMFT

235 AIRCIRC

260 AIRCIRC

293/8 AIRCIRC

268-1 AIRCIRC

268-2 AIRCIRC

235 HEATING

260 HEATING

293/8 HEATING

268-1 HEATING

268-2 HEATING

235 COOLING

260 COOLING

293/8 COOLING

268-1 COOLING

268-2 COOLING $\begin{array}{lllllllll}0.08 & 9.68 & 13.08 & 32.28 & 33.98 & 11.38 & 115 & 3.24 & 1.12\end{array}$ $\begin{array}{llllllllll}0.08 & 7.38 & 17.18 & 32.98 & 29.38 & 13.48 & 82 & 3.24 & 1.11\end{array}$

$\begin{array}{lllllllllll}0.0 z & 20.8 z & 12.58 & 25.08 & 29.28 & 12.58 & 24 & 3.00 & 1.32 & 2.54 & 306\end{array}$ $\begin{array}{lllllllll}0.08 & 27.58 & 11.68 & 34.88 & 21.78 & 4.38 & 69 & 2.64 & 1.22\end{array}$ $\begin{array}{lllllllll}0.08 & 21.18 & 15.88 & 36.88 & 21.18 & 5.38 & 19 & 2.74 & 1.16\end{array}$ $\begin{array}{lllllllll}0.08 & 31.38 & 29.58 & 23.28 & 13.48 & 2.78 & 112 & 2.27 & 1.12\end{array}$ $\begin{array}{lllllllll}0.08 & 34.18 & 13.48 & 17.18 & 25.68 & 9.88 & 82 & 2.63 & 1.42\end{array}$

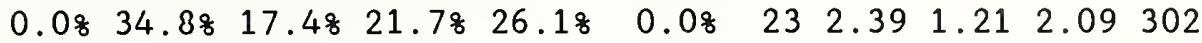
$\begin{array}{lllllllll}0.08 & 54.48 & 22.18 & 19.18 & 2.98 & 1.58 & 68 & 1.75 & 0.96\end{array}$ $\begin{array}{lllllllll}0.08 & 50.08 & 16.78 & 11.18 & 16.78 & 5.68 & 18 & 2.11 & 1.33\end{array}$ $\begin{array}{lllllllll}0.08 & 51.88 & 19.6 z & 14.38 & 14.38 & 0.08 & 112 & 1.91 & 1.11\end{array}$ $\begin{array}{lllllllll}0.08 & 37.08 & 11.18 & 22.28 & 22.28 & 7.48 & 81 & 2.52 & 1.37\end{array}$

$\begin{array}{lllllllllll}0.08 & 26.18 & 21.78 & 21.78 & 26.18 & 4.38 & 23 & 2.61 & 1.24 & 2.31 & 301\end{array}$ $\begin{array}{lllllllll}0.08 & 38.28 & 20.68 & 25.08 & 11.88 & 4.48 & 68 & 2.24 & 1.20\end{array}$ $\begin{array}{lllllllll}0.08 & 21.18 & 10.58 & 42.18 & 15.88 & 10.58 & 19 & 2.84 & 1.23\end{array}$ $\begin{array}{llllllllll}0.08 & 51.48 & 18.98 & 18.08 & 11.78 & 0.08 & 111 & 1.88 & 1.08\end{array}$ $\begin{array}{llllllllll}0.08 & 22.58 & 21.38 & 21.38 & 30.08 & 5.08 & 80 & 2.74 & 1.24\end{array}$

$0.08 \quad 17.48 \quad 17.48 \quad 39.18 \quad 21.78$ $\begin{array}{lllll}0.08 & 27.98 & 22.18 & 23.58 & 25.08\end{array}$ $\begin{array}{lllll}0.08 & 15.88 & 26.38 & 42.18 & 15.88\end{array}$ $0.08 \quad 18.68 \quad 26.58 \quad 38.18 \quad 15.08$ $0.08 \quad 23.28 \quad 17.1825 .6828 .08$

$\begin{array}{llllll}4.38 & 23 & 2.78 & 1.10 & 2.62 \quad 305\end{array}$

$\begin{array}{llll}1.58 & 68 & 2.50 & 1.18\end{array}$

$\begin{array}{llll}0.08 & 19 & 2.58 & 0.94\end{array}$

$\begin{array}{llll}1.88 & 113 & 2.55 & 1.01\end{array}$

$\begin{array}{llll}6.18 & 82 & 2.77 & 1.25\end{array}$

$\begin{array}{lllllll}0.08 & 12.58 & 20.8 \% & 20.88 & 37.58 & 8.38\end{array}$

$\begin{array}{lllllll}0.08 & 1.48 & 14.58 & 23.28 & 47.88 & 13.08\end{array}$

$\begin{array}{llllll}0.08 & 5.38 & 15.88 & 42.18 & 21.18 & 15.88\end{array}$

$\begin{array}{lllllllll}6.28 & 18.68 & 34.58 & 35.48 & 5.38 & 113 & 3.15 & 0.99\end{array}$

$\begin{array}{llllllllll}0.08 & 6.18 & 17.18 & 30.58 & 37.88 & 8.58 & 82 & 3.26 & 1.03\end{array}$

$0.08 \quad 33.38 \quad 20.88 \quad 20.88 \quad 16.78$ $\begin{array}{lllll}0.08 & 55.18 & 20.38 & 10.18 & 10.18\end{array}$ $0.08 \quad 15.8821 .18 \quad 26.38 \quad 31.68$ $\begin{array}{lllll}0.08 & 67.58 & 15.88 & 7.98 \quad 7.98\end{array}$ $0.0854 .9811 .08 \quad 18.3814 .68$

$\begin{array}{lllllll}8.38 & 24 & 2.46 & 1.32 & 1.90 & 308\end{array}$ $\begin{array}{llll}4.38 & 69 & 1.88 & 1.20\end{array}$

$\begin{array}{lllll}5.38 & 19 & 2.89 & 1.17\end{array}$

$0.98114 \quad 1.590 .99$

$\begin{array}{llll}1.28 & 82 & 1.96 & 1.19\end{array}$

$\begin{array}{lllll}0.08 & 18.28 & 18.28 & 22.78 & 36.48\end{array}$ $\begin{array}{lllll}0.08 & 35.38 & 20.68 & 27.98 & 11.88\end{array}$ $\begin{array}{lllll}0.08 & 16.78 & 27.88 & 22.28 & 27.88\end{array}$ $\begin{array}{lllll}0.08 & 34.58 & 29.18 & 20.08 & 13.68\end{array}$

4.58

$\begin{array}{lllll}22 & 2.91 & 1.20 & 2.32 & 299\end{array}$

$\begin{array}{llll}4.48 & 68 & 2.29 & 1.19\end{array}$

$\begin{array}{llll}5.68 & 18 & 2.78 & 1.18\end{array}$

$\begin{array}{lllllllll}0.08 & 35.88 & 23.58 & 25.98 & 12.38 & 2.58 & 81 & 2.22 & 1.13\end{array}$

$\begin{array}{lllllllllll}0.08 & 20.88 & 8.38 & 29.28 & 29.28 & 12.58 & 24 & 3.04 & 1.31 & 2.16 & 307\end{array}$

$\begin{array}{lllllllll}0.08 & 37.78 & 27.58 & 17.48 & 14.58 & 2.98 & 69 & 2.17 & 1.17\end{array}$

$\begin{array}{lllllllll}0.08 & 0.08 & 31.68 & 21.18 & 31.68 & 15.88 & 19 & 3.32 & 1.08\end{array}$

$\begin{array}{lllllllll}0.08 & 54.98 & 20.48 & 15.08 & 8.88 & 0.98 & 113 & 1.81 & 1.05\end{array}$

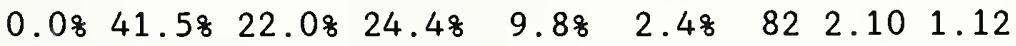




\begin{tabular}{|c|c|c|c|c|c|c|c|c|c|c|c|c|}
\hline & & $\underline{0^{\prime} s}$ & $\underline{1^{\prime} s}$ & $\underline{2^{\prime} s}$ & $3^{\prime} s$ & $4^{\prime} 5$ & $5^{\prime} s$ & $\mathrm{~N}$ & Avg & Std & SMean & $\underline{\mathrm{SN}}$ \\
\hline 35 & AIRQSAT & $\overline{0.08}$ & 17.48 & 26.18 & 30.48 & $\overline{17.48}$ & 8.78 & 23 & 2.74 & 1.19 & 2.00 & 306 \\
\hline 60 & AIRQSAT & 0.08 & 59.48 & 18.88 & 10.18 & 8.78 & $2.9 \%$ & 69 & 1.77 & 1.12 & & \\
\hline $3 / 8$ & AIRQSAT & $.0 \%$ & 10.58 & 31.68 & 31.68 & 21.18 & 5.38 & 19 & 2.79 & 1.06 & & \\
\hline $8-1$ & AIRQSAT & $0.0 \%$ & 48.78 & 28.38 & 13.38 & 9.78 & 0.08 & 113 & 1.84 & 0.99 & & \\
\hline $8-2$ & AIRQSAT & $0.0 \%$ & 45.18 & 19.58 & 23.28 & 11.08 & 1.28 & 82 & 2.04 & 1.11 & & \\
\hline & CAR & 0.08 & 17.48 & 21.78 & 13.08 & 21.78 & 4.38 & 23 & 2.65 & 1.17 & 3.17 & 21 \\
\hline & CARPET & 0.08 & 13.28 & 22.18 & $33.8 \%$ & 25.08 & 5.98 & 68 & 2.88 & 1.11 & & \\
\hline $3 / 8$ & CARPET & $0.0 \%$ & 15.88 & 26.38 & 31.68 & 26.38 & $0.0 \%$ & 19 & 2.68 & 1.03 & & \\
\hline & CARPET & 0.08 & $11.8 \%$ & $10.8 \%$ & 15.18 & 30.18 & 32.38 & 93 & 3.56 & 1.39 & & \\
\hline 2 & $\mathrm{CA}$ & .08 & 16.48 & 13.48 & 19.48 & 32.88 & 17.98 & 67 & 3.22 & 1.34 & & \\
\hline & $S$ & .08 & 22.78 & 22.78 & $31.8 \%$ & 22.78 & 4.58 & 22 & 2.55 & 1.08 & 2.67 & 28 \\
\hline & FUM & 0.08 & 25.48 & 25.48 & 17.98 & 23.98 & 7.58 & 67 & 2.63 & 1.29 & & \\
\hline $3 /$ & FUM & 0.08 & $5.6 \%$ & 27.88 & 33.38 & 27.88 & 5.68 & 18 & 3.00 & 1.00 & & \\
\hline 1 & FUMES & 0.08 & $15.5 \%$ & 30.18 & 26.28 & 24.38 & 3.98 & 103 & 2.66 & 1.16 & & \\
\hline-2 & FUM & $0.0 \%$ & 17.18 & 31.68 & 25.08 & 19.7 용 & 6.68 & 76 & 2.67 & 1.16 & & \\
\hline & UST & .08 & 8.38 & 33.38 & 29.28 & 20.88 & 8.38 & 24 & 2.88 & 1.09 & 2.70 & 29 \\
\hline 60 & UUST & 0.08 & 25.48 & 37.38 & 26.98 & $9.0 \%$ & 1.58 & 67 & 2.24 & 0.98 & & \\
\hline$/ 8$ & FURNDUST & $0.0 \%$ & $15.8 \%$ & 26.38 & 31.68 & 21.18 & 5.38 & 19 & 2.74 & 1.12 & & \\
\hline & FURNDUST & 0.08 & 17.08 & 22.68 & 31.18 & 22.68 & 6.68 & 106 & 2.77 & 1.19 & & \\
\hline & FURNDUST & 0.08 & 11.78 & 22.18 & 33.88 & 24.78 & $7.8 \%$ & 77 & 2.95 & 1.12 & & \\
\hline & & 08 & $4.3 \%$ & 21.78 & 21.78 & 43.58 & $8.7 \%$ & 23 & .30 & .04 & & Ju \\
\hline & WS & .08 & 10.38 & 19.18 & 27.98 & 41.28 & $1.5 \%$ & 68 & 3.04 & 1.04 & & \\
\hline & WS & .0 웅 & $15.8 \%$ & 15.88 & 31.68 & 36.88 & 0.08 & 19 & 2.89 & 1.07 & & \\
\hline & TWS & 0.08 & 19.68 & 17.08 & 30.48 & 27.78 & 5.48 & 112 & 2.82 & 1.19 & & \\
\hline-2 & ARGMTWS & 0.08 & 12.38 & $19.8 \%$ & $21.0 \%$ & 40.78 & 6.28 & 81 & 3.09 & 1.16 & & \\
\hline & & 0.08 & 8.78 & 34.88 & $8.7 \%$ & 43.58 & 4. & 23 & 3.00 & 1.14 & +2.84 & 30 \\
\hline & LOO & 0.08 & 18.88 & 36.28 & 17.48 & 27.58 & 0.08 & 69 & 2.54 & 1.08 & & \\
\hline $93 / 8$ & LOO & 0.08 & 10.58 & 21.18 & 31.68 & 36.88 & 0.08 & 19 & 2.95 & 1.00 & & \\
\hline $68-1$ & WS & 0.08 & 22.38 & $27.7 \%$ & 25.08 & 22.38 & 2.78 & 112 & 2.55 & 1.14 & & \\
\hline-2 & KWS & 0.08 & 7.58 & 17.58 & 11.38 & $50.0 \%$ & $13.8 \%$ & 80 & 3.45 & 1.15 & & \\
\hline & RK & .78 & 12.58 & 8.38 & 25.08 & 16.78 & 20.88 & 24 & 2.75 & 1.74 & +2.18 & 29 \\
\hline & RTI & 13.08 & $2.9 \%$ & 15.98 & 29.08 & 30.48 & $8.7 \%$ & 69 & 2.87 & 1.44 & & \\
\hline $93 / 8$ & RTLTBRK & 0.08 & 0.08 & 0.08 & 52.68 & $36.8 \%$ & 10.58 & 19 & 3.58 & 0.67 & & \\
\hline $58-1$ & RTLTBRK & 44.48 & $13.0 \%$ & $3.7 \%$ & 18.58 & 17.68 & 2.88 & 108 & 1.60 & 1.70 & & \\
\hline $68-2$ & RTLTBRK & 47.48 & 5.18 & 1.38 & 14.18 & 23.18 & 9.08 & 78 & 1.87 & 1.95 & & \\
\hline 235 & ALL & 0 웅 & 8.38 & $8.3 \%$ & 25.08 & $45.8 \%$ & 12.58 & 24 & 3.46 & 1.08 & 3.26 & 30 \\
\hline$-\infty$ & RTLTHALL & $0.0 \%$ & 2.98 & 8.78 & 43.58 & 36.28 & 8.78 & 69 & 3.39 & 0.87 & & \\
\hline $293 / 8$ & RTLTHALL & 29.48 & 0.08 & 5.98 & 35.38 & 23.58 & 5.98 & 17 & 2.41 & 1.68 & & \\
\hline $68-1$ & RTLTHALL & $2.6 \%$ & 7.98 & $8.8 \%$ & 45.68 & 29.88 & 5.38 & 114 & 3.08 & 1.07 & & \\
\hline $68-2$ & RTLTHALL & 0.08 & 3.78 & $9.8 \%$ & $31.7 \%$ & 41.58 & 13.48 & 82 & 3.51 & 0.97 & & \\
\hline & - & 00 & 16.78 & & & 25.08 & & 24 & 2.96 & 1.27 & 3.31 & 30 \\
\hline & RTLTRSTM & $0.0 \%$ & 10.18 & 18.88 & 33.38 & 26.18 & 11.68 & 69 & 3.10 & 1.14 & & \\
\hline & RTLTRSTM & 0.08 & 0.08 & 10.58 & 47.48 & 31.68 & 10.58 & 19 & 3.42 & 0.82 & & \\
\hline 8-1 & RTLTRSTM & $0.0 \%$ & 7.08 & 14.98 & 32.58 & $36.8 \%$ & $8.8 \%$ & 114 & 3.25 & 1.04 & & \\
\hline
\end{tabular}


268-2 RTLTRSTM

235 RTLTSPAC

260 RTLTSPAC

293/8 RTLTSPAC

268-2 RTLTSPAC

235 RTLTCONF

260 RTLTCONF

293/8 RTLTCONF

268-1 RTLTCONF

268-2 RTLTCONF

$\begin{array}{ll}235 & \text { LTREAD } \\ 260 & \text { LTREAD } \\ 293 / 8 & \text { LTREAD } \\ 268-1 & \text { LTREAD } \\ 268-2 & \text { LTREAD } \\ & \\ 235 & \text { LTVDT } \\ 260 & \text { LTVDT } \\ 293 / 8 & \text { LTVDT } \\ 268-1 & \text { LTVDT } \\ 268-2 & \text { LTVDT } \\ & \\ 235 & \text { LTFILE } \\ 260 & \text { LTFILE } \\ 293 / 8 & \text { LTFILE } \\ 268-1 & \text { LTFILE } \\ 268-2 & \text { LTFILE }\end{array}$

268-2 LTFILE

$\begin{array}{ll}235 & \text { LTREPEQP } \\ 260 & \text { LTREPEQP } \\ 293 / 8 & \text { LTREPEQP } \\ 268-1 & \text { LTREPEQP } \\ 268-2 & \text { LTREPEQP }\end{array}$

235 LTDRAFT

260 LTDRAFT

293/8 LTDRAFT

268-1 LTDRAFT

268-2 LTDRAFT

235 LTOTHER

260 LTOTHER

293/8 LTOTHER

268-1 LTOTHER

268-2 LTOTHER
268-1 RTLTSPAC

$\frac{0^{\prime} \mathrm{s}}{0.08} \quad \frac{1^{\prime} \mathrm{s}}{3.78} \quad \frac{2^{\prime} \mathrm{s}}{7.38} \frac{3^{\prime} \mathrm{s}}{24.48} \frac{4^{\prime} \mathrm{s}}{51.28} \frac{5^{\prime} \mathrm{s}}{13.48} \frac{\mathrm{N}}{82} \frac{\text { Avg }}{3.63} \frac{\text { Std }}{0.93} \underline{\text { SMean }} \underline{\mathrm{SN}}$

$\begin{array}{lllll}4.28 & 4.28 & 16.78 & 33.38 & 33.38\end{array}$

$\begin{array}{llllll}0.08 & 16.28 & 13.28 & 27.98 & 38.28\end{array}$

8.38

$\begin{array}{lllll}24 & 3.13 & 1.17 & 3.06 & 307\end{array}$

$\begin{array}{lllllllll}0.08 & 0.08 & 0.08 & 57.98 & 31.68 & 10.58 & 19 & 3.53 & 0.68\end{array}$

$\begin{array}{lllllllll}0.98 & 16.78 & 21.18 & 28.98 & 28.98 & 3.58 & 114 & 2.79 & 1.16\end{array}$

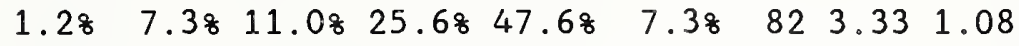

$\begin{array}{lllll}47.68 & 0.08 & 0.08 & 23.88 & 19.08\end{array}$

$\begin{array}{lllll}5.98 & 1.58 & 16.28 & 23.58 & 47.18\end{array}$

$\begin{array}{lllllll}9.58 & 21 & 1.95 & 1.94 & 3.04 & 302\end{array}$

$\begin{array}{llllll}33.38 & 0.08 & 0.08 & 44.48 & 16.78\end{array}$

$\begin{array}{llll}5.98 & 68 & 3.22 & 1.19\end{array}$

$\begin{array}{llllll}6.28 & 6.28 & 10.68 & 35.48 & 36.38\end{array}$

$\begin{array}{llll}5.68 & 18 & 2.28 & 1.69\end{array}$

$\begin{array}{lllll}5.38 & 113 & 3.05 & 1.22\end{array}$

$\begin{array}{lllllllll}6.18 & 2.48 & 7.38 & 29.38 & 46.38 & 8.58 & 82 & 3.33 & 1.19\end{array}$

$\begin{array}{lllllllllll}0.08 & 4.58 & 4.58 & 27.38 & 50.08 & 13.68 & 22 & 3.64 & 0.93 & 3.23 & 292\end{array}$

$\begin{array}{lllllllll}3.08 & 9.08 & 23.98 & 23.98 & 34.38 & 6.08 & 67 & 2.96 & 1.20\end{array}$

$\begin{array}{lllllllll}0.08 & 0.08 & 5.38 & 36.88 & 36.88 & 21.18 & 19 & 3.74 & 0.85\end{array}$

$\begin{array}{lllllllll}0.08 & 16.88 & 14.08 & 23.48 & 39.38 & 6.58 & 107 & 3.05 & 1.21\end{array}$

$\begin{array}{lllllllll}0.08 & 3.98 & 14.38 & 19.58 & 53.28 & 9.18 & 77 & 3.49 & 0.98\end{array}$

$\begin{array}{lllllllllll}0.08 & 7.18 & 14.38 & 35.78 & 42.98 & 0.08 & 14 & 3.14 & 0.91 & 2.83 & 247\end{array}$

$\begin{array}{lllllllll}4.78 & 12.58 & 23.48 & 31.38 & 23.48 & 4.78 & 64 & 2.70 & 1.22\end{array}$

$\begin{array}{lllllllll}0.08 & 0.08 & 11.88 & 35.38 & 29.48 & 23.58 & 17 & 3.65 & 0.97\end{array}$

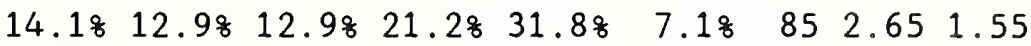

$\begin{array}{lllllllll}10.48 & 9.08 & 13.48 & 20.98 & 40.38 & 6.08 & 67 & 2.90 & 1.44\end{array}$

$\begin{array}{lllll}12.58 & 0.08 & 0.08 & 25.08 & 56.38\end{array}$

$\begin{array}{lllllll}6.38 & 16 & 3.31 & 1.36 & 3.09 & 219\end{array}$

$\begin{array}{lllllllll}6.48 & 6.48 & 17.08 & 27.78 & 36.28 & 6.48 & 47 & 3.00 & 1.27\end{array}$

$\begin{array}{lllllllll}0.08 & 0.08 & 0.08 & 31.38 & 43.88 & 25.08 & 16 & 3.94 & 0.75\end{array}$

$\begin{array}{lllllllll}12.58 & 8.88 & 6.38 & 28.88 & 35.08 & 8.88 & 80 & 2.84 & 1.54\end{array}$

$\begin{array}{lllllllll}6.78 & 5.08 & 3.38 & 36.78 & 41.78 & 6.78 & 60 & 3.22 & 1.21\end{array}$

$\begin{array}{lllllllllll}77.88 & 0.08 & 0.08 & 11.18 & 11.18 & 0.08 & 9 & 0.78 & 1.47 & 1.76 & 140\end{array}$

$\begin{array}{lllllllll}53.88 & 0.08 & 3.88 & 3.88 & 26.98 & 11.58 & 26 & 1.85 & 2.07\end{array}$

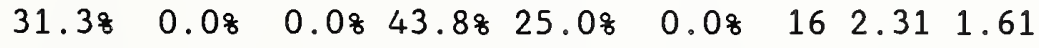

$\begin{array}{lllllllll}37.08 & 7.48 & 14.88 & 16.78 & 22.28 & 1.98 & 54 & 1.82 & 1.66\end{array}$

$\begin{array}{lllllllll}42.98 & 14.38 & 8.68 & 8.68 & 25.78 & 0.08 & 35 & 1.60 & 1.68\end{array}$

$\begin{array}{llllll}33.38 & 0.08 & 0.08 & 25.08 & 41.78 & 0.08\end{array}$

$\begin{array}{lllll}12 & 2.42 & 1.75 & 2.48 & 185\end{array}$

$\begin{array}{llllll}24.38 & 10.88 & 13.58 & 18.98 & 24.38 & 8.18\end{array}$

$\begin{array}{lll}37 & 2.32 & 1.69\end{array}$

$\begin{array}{lllllllll}25.08 & 0.08 & 6.38 & 31.38 & 25.08 & 12.58 & 16 & 2.69 & 1.72\end{array}$

$\begin{array}{lllllllll}16.28 & 12.28 & 17.68 & 23.08 & 24.38 & 6.88 & 74 & 2.47 & 1.54\end{array}$

$\begin{array}{lllllllll}21.78 & 8.78 & 10.98 & 17.48 & 32.68 & 8.78 & 46 & 2.57 & 1.70\end{array}$

$\begin{array}{llllll}20.08 & 20.08 & 0.08 & 20.08 & 20.08 & 20.08\end{array}$

$\begin{array}{lllll}5 & 2.60 & 1.85 & 2.5190\end{array}$

33.3816 .78

$\begin{array}{llll}5.68 & 22.28 & 16.78 & 5.68\end{array}$

$\begin{array}{lll}18 & 1.89 & 1.70\end{array}$

$33.38 \quad 0.08$

$0.08 \quad 44.48 \quad 11.18 \quad 11.18$

92.331 .76

$17.98 \quad 10.78$

$\begin{array}{llll}7.18 & 28.68 & 35.78 & 0.08\end{array}$

$\begin{array}{lll}28 & 2.45 & 1.54\end{array}$

10.0810 .08

0.0836 .7840 .08

3.38

$302.97 \quad 1.35$

235 AMTLTBRT

$0.08 \quad 0.08$

4.3843 .5843 .58

8.78

$\begin{array}{llllll}23 & 3.57 & 0.71 & 3.33 & 300\end{array}$

260 AMTLTBRT
0.08

3.08

$4.58 \quad 44.88 \quad 38.88$

9.08 
293/8 AMTLTBRT 268-1 AMTLTBRT 268-2 AMTLTBRT

235 WSLITSAT

260 WSLITSAT

293/8 WSLITSAT

268-1 WSLITSAT

268-2 WSLITSAT

235 VDTFLICK

260 VDTFLICK

$293 / 8$ VDTFLICK

268-1 VDTFLICK

268-2 VDTFLICK

235 VDTDSTSC

260 VDTDSTSC

$293 / 8$ VDTDSTSC

268-1 VDTDSTSC

268-2 VDTDSTSC

235 VDTANGSC

260 VDTANGSC

$293 / 8$ VDTANGSC

268-1 VDTANGSC

268-2 VDTANGSC

235 VDTGLARE

260 VDTGLARE

293/8 VDTGLARE

268-1 VDTGLARE

268-2 VDTGLARE

235 VDTANGKB

260 VDTANGKB

$293 / 8$ VDTANGKB

268-1 VDTANGKB

268-2 VDTANGKB

235 VDTDSKHT

260 VDTDSKHT

293/8 VDTDSKHT

268-1 VDTDSKHT

268-2 VDTDSKHT

235 VDTSEAT

260 VDTSEAT

293/8 VDTSEAT

268-1 VDTSEAT

268-2 VDTSEAT $\frac{0^{\prime} s}{0.08} \frac{1^{\prime} s}{0.08} \frac{2^{\prime} s}{26.38} \frac{3^{\prime} s}{63.28} \frac{4^{\prime} s}{10.58} \frac{5^{\prime} s}{0.08} \frac{\mathrm{N}}{19} \frac{\text { Avg }}{2.84}$ Std SMean SN $\begin{array}{lllllllll}0.08 & 3.78 & 5.58 & 49.58 & 34.98 & 6.48 & 109 & 3.35 & 0.83\end{array}$

$\begin{array}{lllllllll}0.08 & 2.48 & 4.98 & 59.88 & 31.78 & 1.28 & 82 & 3.24 & 0.67\end{array}$

$\begin{array}{lllllllllll}0.08 & 8.38 & 8.38 & 33.38 & 37.58 & 12.58 & 24 & 3.38 & 1.07 & 3.11 & 308\end{array}$

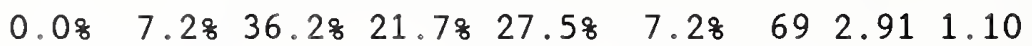

$\begin{array}{lllllllll}0.08 & 0.08 & 5.38 & 42.18 & 31.68 & 21.18 & 19 & 3.68 & 0.86\end{array}$

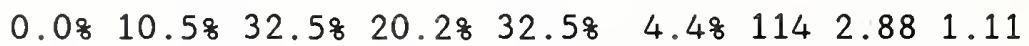

$\begin{array}{lllllllll}0.08 & 4.98 & 17.18 & 25.68 & 39.08 & 13.48 & 82 & 3.39 & 1.07\end{array}$

$\begin{array}{lllllll}0.08 & 9.18 & 63.68 & 9.18 & 18.28 & 0.08\end{array}$

$\begin{array}{lllll}11 & 2.36 & 0.88 & 2.05 \quad 210\end{array}$

$0.08 \quad 36.78 \quad 45.08$

6.7811 .78

$0.08 \quad 37.58 \quad 31.38 \quad 6.38 \quad 25.08$

$\begin{array}{llll}0.08 & 60 & 1.93 & 0.95\end{array}$

$\begin{array}{llllll}0.08 & 34.38 & 25.78 & 25.78 & 14.38\end{array}$

$\begin{array}{llll}0.08 & 16 & 2.19 & 1.18\end{array}$

$\begin{array}{llllll}0.08 & 50.98 & 18.98 & 20.88 & 9.48\end{array}$

$\begin{array}{llll}0.08 & 70 & 2.20 & 1.06\end{array}$

$\begin{array}{llll}0.08 & 53 & 1.89 & 1.04\end{array}$

$\begin{array}{lllrlllllll}0.08 & 18.28 & 72.78 & 9.18 & 0.08 & 0.08 & 11 & 1.91 & 0.51 & 1.69 & 211 \\ 0.08 & 46.78 & 40.08 & 11.78 & 1.78 & 0.08 & 60 & 1.68 & 0.74 & & \\ 0.08 & 43.88 & 56.38 & 0.08 & 0.08 & 0.08 & 16 & 1.56 & 0.50 & & \\ 0.08 & 47.88 & 34.88 & 13.08 & 4.38 & 0.08 & 69 & 1.74 & 0.85 & & \\ 0.08 & 54.58 & 32.78 & 9.18 & 3.68 & 0.08 & 55 & 1.62 & 0.80 & & \end{array}$

$\begin{array}{lllll}0.08 & 36.48 & 54.58 & 0.08 & 9.18\end{array}$

0.08

$\begin{array}{llllll}11 & 1.82 & 0.83 & 1.81 & 209\end{array}$

$\begin{array}{lllll}0.08 & 50.88 & 37.38 & 8.58 & 3.48\end{array}$

0.08

$\begin{array}{llll}59 & 1.64 & 0.78\end{array}$

$\begin{array}{llllll}0.08 & 37.58 & 62.58 & 0.08 & 0.08\end{array}$

$0.0 \frac{8}{8}$

$\begin{array}{lll}16 & 1.63 & 0.48\end{array}$

$\begin{array}{llllll}0.08 & 34.88 & 39.18 & 18.88 & 7.28\end{array}$

0.08

$\begin{array}{lll}69 & 1.99 & 0.91\end{array}$

$\begin{array}{lllll}0.08 & 46.38 & 35.28 & 9.38 & 9.38\end{array}$

0.08

$\begin{array}{lll}54 & 1.81 & 0.94\end{array}$

$\begin{array}{llllll}0.08 & 18.28 & 45.58 & 9.18 & 27.38\end{array}$

$\begin{array}{llllll}0.08 & 13.38 & 35.08 & 33.38 & 18.38\end{array}$

0.08

$\begin{array}{lllll}11 & 2.45 & 1.08 & 2.63216\end{array}$

$\begin{array}{llllll}0.08 & 31.38 & 50.08 & 12.58 & 6.38\end{array}$

0.08

$\begin{array}{lll}60 & 2.57 & 0.94\end{array}$

$0.08 \quad 15.18 \quad 21.98 \quad 20.58 \quad 42.58$

0.08

$\begin{array}{llll}16 & 1.94 & 0.83\end{array}$

$0.08 \quad 25.08 \quad 23.28 \quad 21.48 \quad 30.4 \%$

0.08

$\begin{array}{lll}73 & 2.90 & 1.11\end{array}$

$\begin{array}{lll}56 & 2.57 \quad 1.16\end{array}$

$0.08 \quad 9.18 \quad 63.68 \quad 18.28$

9.18

$0.08 \quad 42.48 \quad 32.28 \quad 16.98$

8.58

0.08

$\begin{array}{lllll}11 & 2.27 & 0.75 & 1.91 & 211\end{array}$

$\begin{array}{lllll}0.08 & 40.08 & 53.38 & 6.78\end{array}$

$0.0 \%$

0.08

$\begin{array}{lll}59 & 1.92 & 0.96\end{array}$

$\begin{array}{lllll}0.08 & 42.38 & 35.28 & 12.78\end{array}$

9.98

0.08

$151.67 \quad 0.60$

0.0 영 $38.28 \quad 38.28 \quad 16.48$

7.38

0.08

$\begin{array}{lll}71 & 1.90 & 0.97\end{array}$

$\begin{array}{lll}55 & 1.93 & 0.91\end{array}$

$\begin{array}{llll}0.08 & 9.18 & 81.88 & 0.08\end{array}$

9.18

0.08

$\begin{array}{llllll}11 & 2.09 & 0.67 & 1.91 & 211\end{array}$

$\begin{array}{lllll}0.08 & 50.88 & 32.28 & 10.28\end{array}$

$6.8 \%$

0.08

$\begin{array}{lll}59 & 1.73 & 0.90\end{array}$

$\begin{array}{llllll}0.08 & 53.38 & 33.38 & 13.38 & 0.08\end{array}$

0.08

$\begin{array}{llll}15 & 1.60 & 0.71\end{array}$

$\begin{array}{llllll}0.08 & 35.78 & 35.7 \% & 15.78 & 12.98\end{array}$

0.08

$\begin{array}{lll}70 & 2.06 & 1.01\end{array}$

$\begin{array}{llllll}0.08 & 32.18 & 44.68 & 16.18 \quad 7.18\end{array}$

0.08

$\begin{array}{llll}56 & 1.98 & 0.88\end{array}$

$\begin{array}{llllllll}0.08 & 18.28 & 45.58 & 36.48 & 0.08\end{array}$

0.08

$\begin{array}{llllll}11 & 2.18 & 0.72 & 1.86 & 211\end{array}$

$\begin{array}{lllll}0.08 & 55.98 & 32.28 & 10.28\end{array}$

1.78

0.08

$\begin{array}{lll}59 & 1.58 & 0.74\end{array}$

$\begin{array}{lllll}0.08 & 43.88 & 50.08 & 0.08 & 6.38\end{array}$

0.08

$\begin{array}{lll}16 & 1.69 & 0.77\end{array}$

$\begin{array}{lllll}0.08 & 45.78 & 30.08 & 11.48 & 12.98\end{array}$

0.08

$\begin{array}{lll}70 & 1.91 & 1.04\end{array}$

$\begin{array}{llllll}0.08 & 34.58 & 40.08 & 9.18 & 16.48\end{array}$

$0.0 \%$

$552.07 \quad 1.04$ 
235 VDTREFSC

260 VDTREFSC

293/8 VDTREFSC

268-1 VDTREFSC

268-2 VDTREFSC

235 VDTREAD

260 VDTREAD

293/8 VDTREAD

268-1 VDTREAD

268-2 VDTREAD

235 VDTBRTLT

260 VDTBRTLT

293/8 VDTBRTLT

268-1 VDTBRTLT

268-2 VDTBRTLT

235 VDTADJSC

260 VDTADJSC

293/8 VDTADJSC

268-1 VDTADJSC

268-2 VDTADJSC

235 VDTSPACE

260 VDTSPACE

293/8 VDTSPACE

268-1 VDTSPACE

268-2 VDTSPACE

235 VDTADJLT

260 VDTADJLT

293/8 VDTADJLT

268-1 VDTADJLT

268-2 VDTADJLT

235 NOISEPHN

260 NOISEPHN

$293 / 8$ NOISEPHN

268-1 NOISEPHN

268-2 NOISEPHN

235 PEPTALK

260 PEPTALK

293/8 PEPTALK

268-1 PEPTALK

268-2 PEPTALK

235 NOISEPRT

260 NOISEPRT

$293 / 8$ NOISEPRT

268-1 NOISEPRT $\frac{0^{\prime} \mathrm{s}}{0.0 \%} \frac{1^{\prime} \mathrm{s}}{9.1 \%} \frac{2^{\prime} \mathrm{s}}{54.5 \%} \frac{3^{\prime} \mathrm{s}}{9.1 \%} \frac{4^{\prime} \mathrm{s}}{27.38} \frac{5^{\prime} \mathrm{s}}{0.0 \%} \frac{\mathrm{N}}{11} \frac{\text { Avg }}{2.55} \frac{\text { Std }}{0.99} \frac{\text { SMean }}{2.55} \frac{\mathrm{SN}}{216}$

$\begin{array}{lllllllll}0.08 & 16.78 & 38.38 & 30.08 & 15.08 & 0.08 & 60 & 2.43 & 0.94\end{array}$

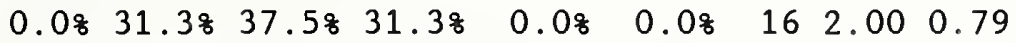

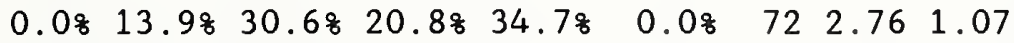

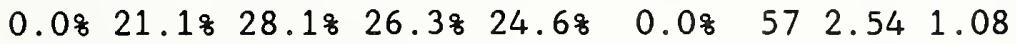

$0.08 \quad 20.08 \quad 70.08 \quad 10.08 \quad 0.08$ $\begin{array}{lllll}0.08 & 33.98 & 47.58 & 10.28 & 8.58\end{array}$ $\begin{array}{lllll}0.08 & 50.08 & 43.88 & 6.38 & 0.08\end{array}$ $0.08 \quad 32.98 \quad 35.78 \quad 24.38 \quad 7.18$ $0.0 \% \quad 24.18 \quad 48.18 \quad 18.5 \% \quad 9.3 \%$

0.08

$\begin{array}{lllll}10 & 1.90 & 0.542 .00 \quad 209\end{array}$

$0.08 \quad 591.93 \quad 0.88$

$\begin{array}{llll}0.08 & 16 & 1.56 & 0.61\end{array}$

$\begin{array}{llll}0.08 & 70 & 2.06 & 0.92\end{array}$

$\begin{array}{llll}0.08 & 54 & 2.13 & 0.88\end{array}$

$0.08 \quad 9.18 \quad 54.58 \quad 9.18 \quad 27.38$ $\begin{array}{llllll}0.08 & 25.48 & 35.68 & 32.28 & 6.88\end{array}$ $\begin{array}{llllll}0.08 & 50.08 & 42.98 & 0.08 & 7.18\end{array}$ $\begin{array}{llllll}0.08 & 22.58 & 25.48 & 25.48 & 26.88\end{array}$ $\begin{array}{llllll}0.08 & 25.98 & 35.28 & 27.8 \% & 11.1 \%\end{array}$

0.08

$\begin{array}{lllll}11 & 2.55 & 0.99 & 2.32 & 209\end{array}$

$\begin{array}{llll}0.08 & 59 & 2.20 & 0.90\end{array}$

$\begin{array}{llll}0.08 & 14 & 1.64 & 0.81\end{array}$

$\begin{array}{llll}0.08 & 71 & 2.56 & 1.11\end{array}$

$\begin{array}{llll}0.08 & 54 & 2.24 & 0.96\end{array}$

$\begin{array}{lllll}0.08 & 0.08 & 80.08 & 10.08 & 10.08\end{array}$ $\begin{array}{lllll}0.08 & 40.78 & 30.58 & 23.78 & 5.18\end{array}$ $\begin{array}{llllll}0.08 & 33.38 & 46.78 & 13.38 & 6.78\end{array}$ $\begin{array}{llllll}0.08 & 33.8 \% & 22.58 & 22.58 & 21.1 \%\end{array}$ $\begin{array}{llllll}0.08 & 40.78 & 27.88 & 18.58 & 13.08\end{array}$

0.08

$\begin{array}{lllll}10 & 2.30 & 0.64 & 2.11209\end{array}$

$\begin{array}{llll}0.08 & 59 & 1.93 & 0.92\end{array}$

$\begin{array}{llll}0.08 & 15 & 1.93 & 0.85\end{array}$

$\begin{array}{llll}0.08 & 71 & 2.31 & 1.15\end{array}$

$0.08 \quad 54 \quad 2.04 \quad 1.05$

$\begin{array}{llllll}0.08 & 0.08 & 60.08 & 20.08 & 20.08\end{array}$ $\begin{array}{llllll}0.08 & 23.78 & 27.18 & 23.78 & 25.48\end{array}$ $\begin{array}{llllll}0.08 & 46.78 & 33.38 & 0.08 & 20.08\end{array}$ $\begin{array}{lllll}0.08 & 20.38 & 29.08 & 21.78 & 29.08\end{array}$ $\begin{array}{lllllll}0.0 \% & 14.8 \% & 40.7 \% & 20.48 & 24.18\end{array}$

0.08

0.08

0.08

0.08

0.08

$\begin{array}{llllll}10 & 2.60 & 0.80 & 2.51 & 207\end{array}$

$\begin{array}{lllll}0.08 & 0.08 & 36.48 & 36.48 & 27.38\end{array}$

$\begin{array}{llllll}0.08 & 14.08 & 36.88 & 29.88 & 19.38\end{array}$

$\begin{array}{llllll}0.08 & 40.08 & 40.08 & 6.7 \% & 13.3 \%\end{array}$

$\begin{array}{lllll}0.08 & 15.58 & 23.98 & 21.18 & 39.48\end{array}$

$0.0821 .28 \quad 28.8825 .0825 .08$

$0.0 \%$

0.08

$592.51 \quad 1.11$

$0.0 \%$

$\begin{array}{lll}15 & 1.931 .12\end{array}$

$\begin{array}{lll}69 & 2.59 \quad 1.11\end{array}$

$0.0 \%$

$\begin{array}{lll}54 & 2.54 \quad 1.01\end{array}$

$\begin{array}{lllll}0.08 & 36.48 & 31.88 & 13.68 & 18.28\end{array}$ $\begin{array}{llllll}0.08 & 18.28 & 39.48 & 33.38 & 9.18\end{array}$ $\begin{array}{llllll}0.08 & 5.38 & 31.68 & 21.18 & 42.18\end{array}$ $\begin{array}{llllll}0.08 & 17.48 & 37.68 & 23.98 & 21.18\end{array}$ $\begin{array}{llllll}0.08 & 19.58 & 36.48 & 27.38 & 16.98\end{array}$

$0.08 \quad 52 \quad 2.541 .08$

0.08

0.08

0.08

$0.08 \quad 1092.49 \quad 1.01$

$\begin{array}{llll}0.08 & 77 & 2.42 & 0.98\end{array}$

$\begin{array}{lllll}0.08 & 28.68 & 42.98 & 23.88 & 4.88\end{array}$ $\begin{array}{llllll}0.08 & 13.68 & 42.48 & 33.38 & 10.68\end{array}$ $0.08 \quad 15.88 \quad 47.48 \quad 5.38 \quad 31.68$ $0.08 \quad 14.58 \quad 31.88 \quad 24.58 \quad 29.18$ $\begin{array}{llllll}0.08 & 14.18 & 30.88 & 39.78 & 15.48\end{array}$

0.08 0.08 $\begin{array}{llllll}21 & 2.05 & 0.84 & 2.53 & 294\end{array}$ $\begin{array}{llll}0.08 & 19 & 2.53 & 1.09\end{array}$ $\begin{array}{llll}0.08 & 110 & 2.68 & 1.04\end{array}$ $\begin{array}{llll}0.08 & 78 & 2.56 & 0.91\end{array}$

$0.08 \quad 27.88 \quad 50.08 \quad 11.18 \quad 11.18$ $\begin{array}{llllll}0.08 & 18.28 & 45.58 & 24.28 & 12.18\end{array}$ $\begin{array}{lllll}0.08 & 33.38 & 33.38 & 22.28 & 11.1 \%\end{array}$ $\begin{array}{llllll}0.08 & 28.28 & 30.98 & 26.48 & 14.58\end{array}$ $\begin{array}{lllllll}0.08 & 18 & 2.06 & 0.91 & 2.23 & 287\end{array}$

$\begin{array}{llll}0.08 & 66 & 2.30 & 0.90\end{array}$

$\begin{array}{llll}0.08 & 18 & 2.11 & 0.99\end{array}$

$\begin{array}{lllll}0.08 & 110 & 2.27 & 1.03\end{array}$ 
268-2 NOISEPRT

235 NOISEEQP

260 NOISEEQP

$293 / 8$ NOISEEQP

268-1 NOISEEQP

268-2 NOISEEQP

235 NOISEVNT

260 NOISEVNT

$293 / 8$ NOISEVNT

268-1 NOISEVNT

268-2 NOISEVNT

235 NOISEHAL

260 NOISEHAL

$293 / 8$ NOISEHAL

268- 1 NOISEHAL

268-2 NOISEHAL

235 GLRWKSF

260 GLRWKSF

293/8 GLRWKSF

268-1 GLRWKSF

268-2 GLRWKSF

235 GLRCLNLT

260 GLRCLNLT

293/8 GLRCLNLT

268-1 GLRCLNLT

268-2 GLRCLNLT

235 DIMLIT

260 DIMLIT

293/8 DIMLIT

268-1 DIMLIT

268-2 DIMLIT

235 NOVIEW

260 NOVIEW

293/8 NOVIEW

268-1 NOVIEW

268-2 NOVIEW

235 HOTSUMR

260 HOTSUMR

$293 / 8$ HOTSUMR

268-1 HOTSUMR

268-2 HOTSUMR

235 COLDWTR

260 COLDWTR $\underline{0^{\prime} \mathrm{s}} \quad \frac{1^{\prime} \mathrm{s}}{2^{\prime} \mathrm{s}} \quad \underline{3^{\prime} \mathrm{s}} \quad 4^{\prime} \mathrm{s} \quad 5^{\prime} \mathrm{s} \quad \mathrm{N}$ Avg Std SMean $\underline{\mathrm{SN}}$ $\begin{array}{lllllllll}0.08 & 29.38 & 37.38 & 18.78 & 14.78 & 0.08 & 75 & 2.19 & 1.02\end{array}$

$\begin{array}{lllll}0.08 & 31.88 & 50.08 & 4.58 & 13.68\end{array}$

$0.08 \quad 21.28 \quad 43.98 \quad 21.28 \quad 13.68$

$0.08 \quad 33.38 \quad 33.38 \quad 11.18 \quad 22.28$

$0.08 \quad 25.08 \quad 37.08 \quad 22.28 \quad 15.78$

$\begin{array}{llllll}0.08 & 22 & 2.00 & 0.95 & 2.19 & 291\end{array}$

$\begin{array}{llll}0.08 & 66 & 2.27 & 0.95\end{array}$

$\begin{array}{llll}0.08 & 18 & 2.22 & 1.13\end{array}$

$0.08108 \quad 2.29 \quad 1.01$

$\begin{array}{lllllllll}0.08 & 29.98 & 45.58 & 15.68 & 9.18 & 0.08 & 77 & 2.04 & 0.90\end{array}$

$\begin{array}{llllll}0.08 & 38.18 & 47.68 & 4.88 & 9.58\end{array}$

$0.08 \quad 24.68 \quad 52.38 \quad 13.88$

9.28

$0.08 \quad 38.98 \quad 44.48 \quad 11.18 \quad 5.68$

$0.08 \quad 31.88 \quad 43.08 \quad 15.98 \quad 9.38$

$\begin{array}{llllll}0.08 & 44.98 & 37.28 & 9.08 & 9.08\end{array}$

0.08

$\begin{array}{llllll}21 & 1.86 & 0.89 & 1.96 & 289\end{array}$

$\begin{array}{llll}0.08 & 65 & 2.08 & 0.86\end{array}$

$\begin{array}{llll}0.08 & 18 & 1.83 & 0.83\end{array}$

$\begin{array}{llll}0.08 & 107 & 2.03 & 0.92\end{array}$

$\begin{array}{llll}0.08 & 78 & 1.82 & 0.93\end{array}$

$\begin{array}{lllllll}0.08 & 33.38 & 47.68 & 14.38 & 4.88\end{array}$

$0.08 \quad 34.88 \quad 50.08 \quad 10.68 \quad 4.58$

$\begin{array}{llllll}0.08 & 47.18 & 35.38 & 0.08 & 17.68\end{array}$

$\begin{array}{llllll}0.08 & 36.18 & 43.58 & 13.98 & 6.58\end{array}$

$\begin{array}{llllll}0.08 & 44.78 & 35.58 & 15.88 & 3.98\end{array}$

0.08

0.08

$\begin{array}{llllll}21 & 1.90 & 0.81 & 1.86 & 288\end{array}$

$\begin{array}{lllll}0.08 & 17 & 1.88 & 1.08\end{array}$

$\begin{array}{llll}0.08 & 108 & 1.91 & 0.87\end{array}$

$\begin{array}{llll}0.08 & 76 & 1.79 & 0.85\end{array}$

$\begin{array}{llllll}0.08 & 27.38 & 36.48 & 22.78 & 13.68\end{array}$

$\begin{array}{llllll}0.08 & 26.98 & 40.38 & 20.98 & 11.98\end{array}$

$\begin{array}{llllllll}0.08 & 26.38 & 47.48 & 15.88 & 10.58\end{array}$

$0.08 \quad 25.28 \quad 33.68 \quad 22.48 \quad 18.78$

$\begin{array}{llllll}0.08 & 34.28 & 35.58 & 19.78 & 10.58\end{array}$

0.08

222.231 .00

2.21291

$\begin{array}{llll}0.08 & 67 & 2.18 & 0.96\end{array}$

$\begin{array}{llll}0.08 & 19 & 2.11 & 0.91\end{array}$

$\begin{array}{llll}0.08 & 107 & 2.35 & 1.05\end{array}$

$\begin{array}{llll}0.08 & 76 \quad 2.07 & 0.98\end{array}$

$0.08 \quad 33.38 \quad 38.18 \quad 14.38 \quad 14.38$

$\begin{array}{llllll}0.08 & 23.98 & 38.88 & 25.48 & 11.98\end{array}$

$0.08 \quad 26.38 \quad 52.68 \quad 10.58 \quad 10.58$

$\begin{array}{lllll}0.08 & 21.18 & 38.58 & 21.18 & 19.38\end{array}$

$\begin{array}{lllll}0.08 \quad 32.08 & 33.3 \% & 22.78 \quad 12.08\end{array}$

0.08

212.101 .02

2.25291

0.08

$\begin{array}{lll}67 & 2.25 & 0.95\end{array}$

$\begin{array}{llll}0.08 & 19 & 2.05 & 0.89\end{array}$

$\begin{array}{llll}0.08 & 109 & 2.39 & 1.02\end{array}$

$\begin{array}{llll}0.08 & 75 & 2.15 & 1.00\end{array}$

$\begin{array}{lllll}0.08 \quad 31.88 & 36.48 & 18.28 & 13.68\end{array}$ $\begin{array}{llllll}0.08 & 21.28 & 36.48 & 24.28 & 18.28\end{array}$ $\begin{array}{llllll}0.08 & 44.48 & 38.98 & 16.78 & 0.08\end{array}$ $\begin{array}{llllll}0.08 & 30.88 & 33.68 & 18.78 & 16.88\end{array}$ $\begin{array}{llllll}0.08 & 30.18 & 31.58 & 21.98 & 16.48\end{array}$

0.08

0.08

$22 \quad 2.14 \quad 1.012 .23 \quad 286$

$\begin{array}{llll}0.08 & 18 & 1.72 & 0.73\end{array}$

$0.08 \quad 107 \quad 2.21 \quad 1.06$

$\begin{array}{llll}0.08 & 73 & 2.25 & 1.06\end{array}$

$\begin{array}{lllll}0.08 & 27.88 & 38.98 & 5.68 & 27.88\end{array}$ $\begin{array}{lllll}0.08 & 11.58 & 19.78 & 21.38 & 47.58\end{array}$ $0.08 \quad 29.48 \quad 41.28 \quad 17.68 \quad 11.88$ $\begin{array}{lllll}0.08 & 23.18 & 26.98 & 12.58 & 37.58\end{array}$ $\begin{array}{llllll}0.08 & 27.68 & 30.38 & 18.48 & 23.78\end{array}$

$\begin{array}{lllllll}0.08 & 18 & 2.33 & 1.15 & 2.58 & 276\end{array}$

$\begin{array}{llll}0.08 & 61 & 3.05 & 1.06\end{array}$

$\begin{array}{llll}0.08 & 17 & 2.12 & 0.96\end{array}$

$\begin{array}{lllll}0.08 & 104 & 2.57 & 1.26\end{array}$

$\begin{array}{llll}0.08 & 76 & 2.38 & 1.12\end{array}$

$0.08 \quad 40.98 \quad 31.88 \quad 13.68 \quad 13.68$ $0.08 \quad 29.78 \quad 31.38 \quad 26.68 \quad 12.58$ $\begin{array}{llllll}0.08 & 26.38 & 31.68 & 15.88 & 26.38\end{array}$ $\begin{array}{llllll}0.08 & 11.78 & 16.28 & 27.08 & 45.08\end{array}$ $0.0819 .28 \quad 23.18 \quad 25.68 \quad 32.18$

0.08

0.08

$\begin{array}{llllll}22 & 2.00 & 1.04 & 2.66 \quad 294\end{array}$

$\begin{array}{llll}0.08 & 19 & 2.42 & 1.14\end{array}$

$0.081113 .05 \quad 1.04$

$\begin{array}{llll}0.08 & 78 & 2.71 & 1.11\end{array}$

$\begin{array}{lllll}0.08 & 35.08 & 35.08 & 5.08 & 25.08\end{array}$

$\begin{array}{lllllll}0.08 & 20 & 2.20 & 1.17 & 2.55 & 291\end{array}$ $0.08 \quad 20.38 \quad 35.98 \quad 28.18 \quad 15.68$

$\begin{array}{llll}0.08 & 64 & 2.39 & 0.98\end{array}$ 


\begin{tabular}{|c|c|c|c|c|c|c|c|c|c|c|c|c|}
\hline & & $\underline{0^{\prime} s}$ & $\underline{1^{\prime} s}$ & $\underline{2^{\prime} s}$ & $\underline{3^{\prime} s}$ & $4^{\prime} s$ & $5^{\prime} s$ & $\mathrm{~N}$ & $\underline{\mathrm{Avg}}$ & $\underline{\text { Std }}$ & SMean & $\underline{\mathrm{SN}}$ \\
\hline $93 / 8$ & COLDWTR & $\overline{0.08}$ & 27.88 & 27.88 & 11.18 & 33.38 & 0.08 & 18 & 2.50 & 1.21 & & \\
\hline 58-1 & COLDWTR & 0.08 & 17.08 & 25.98 & 28.68 & 28.68 & 0.08 & 112 & 2.69 & 1.06 & & \\
\hline $68-2$ & COLDWTR & 0.08 & 18.28 & 32.58 & 22.18 & 27.38 & 0.08 & 77 & 2.58 & 1.07 & & \\
\hline 35 & DRAFTS & 0.08 & 40.08 & 35.08 & 10.08 & $15.0 \%$ & $0.0 \%$ & 20 & 2.00 & 1.05 & 2.15 & 289 \\
\hline 60 & DRAFTS & 0.08 & 29.78 & 34.48 & 20.38 & 15.68 & 0.08 & 64 & 2.22 & 1.04 & & \\
\hline $293 / 8$ & DRAFTS & 0.08 & 33.38 & 33.38 & 11.18 & 22.28 & $0.0 \%$ & 18 & 2.22 & 1.13 & & \\
\hline $68-1$ & DRAFTS & 0.08 & 31.88 & 34.58 & 15.58 & 18.28 & 0.08 & 110 & 2.18 & 1.09 & & \\
\hline $68-2$ & DRAFTS & 0.08 & 36.48 & 35.18 & 14.38 & 14.38 & 0.08 & 77 & 2.06 & 1.04 & & \\
\hline 35 & STUFYAIR & $0.0 \%$ & 19.08 & 38.18 & 28.68 & 14.38 & 0.08 & 21 & 2.38 & 0.95 & 2.86 & 289 \\
\hline 0 & STUFYAIR & 0.08 & 10.98 & 23.48 & 23.48 & 42.28 & 0.08 & 64 & 2.97 & 1.05 & & \\
\hline $93 / 8$ & STUFYAIR & 0.08 & 27.88 & 33.38 & 22.28 & 16.78 & 0.08 & 18 & 2.28 & 1.04 & & \\
\hline $68-1$ & STUFYAIR & 0.08 & 11.88 & 20.98 & 27.38 & $40.0 \%$ & 0.08 & 110 & 2.95 & 1.04 & & \\
\hline $68-2$ & STUFYAIR & 0.08 & 13.28 & 23.78 & 22.48 & 40.88 & 0.08 & 76 & 2.91 & 1.08 & & \\
\hline 35 & PEPLWALK & $0.0 \%$ & 33.38 & 47.68 & $4.8 \%$ & 14.38 & 0.08 & 21 & 2.00 & 0.98 & 2.10 & 290 \\
\hline 60 & PEPLWALK & 0.08 & 34.38 & 49.38 & 9.0 웅 & 7.58 & 0.08 & 67 & 1.90 & 0.85 & & \\
\hline $93 / 8$ & PEPLWALK & 0.08 & 22.28 & 44.48 & 5.68 & 27.88 & 0.08 & 18 & 2.39 & 1.11 & & \\
\hline $3-1$ & PEPLWALK & 0.08 & 28.28 & 42.78 & 15.58 & 13.68 & 0.08 & 110 & 2.15 & 0.98 & & \\
\hline $68-2$ & PEPLWALK & 0.08 & 25.78 & 43.28 & 18.98 & 12.28 & 0.08 & 74 & 2.18 & 0.95 & & \\
\hline 35 & PEPLCLOS & 0.08 & 40.08 & 35.08 & 15.08 & 10.08 & $0.0 \%$ & 20 & 1.95 & 0.97 & 2.29 & 290 \\
\hline 60 & PEPLCLOS & $0.0 \%$ & 23.18 & 52.38 & 12.38 & 12.38 & 0.08 & 65 & 2.14 & 0.91 & & \\
\hline $293 / 8$ & PEPLCLOS & $0.0 \%$ & $27.8 \%$ & 38.98 & 5.68 & $27.8 \%$ & 0.08 & 18 & 2.33 & 1.15 & & \\
\hline $268-1$ & PEPLCLOS & 0.08 & 26.18 & 27.08 & 24.38 & 22.58 & $0.0 \%$ & 111 & 2.43 & 1.10 & & \\
\hline $68-2$ & PEPLCLOS & 0.08 & 23.78 & 36.88 & 25.08 & 14.58 & 0.08 & 76 & 2.30 & 0.99 & & \\
\hline 235 & SMELLS & 0.08 & 36.48 & 36.48 & 4.58 & 22.78 & 0.08 & 22 & 2.14 & 1.14 & 2.32 & 293 \\
\hline 260 & SMELLS & 0.08 & 22.48 & 38.88 & 23.98 & 14.98 & 0.08 & 67 & 2.31 & 0.98 & & \\
\hline $293 / 8$ & SMELLS & 0.08 & 22.28 & 44.48 & 11.18 & 22.28 & 0.08 & 18 & 2.33 & 1.05 & & \\
\hline $268-1$ & SMELLS & 0.08 & 23.48 & 29.98 & 25.28 & 21.58 & 0.08 & 107 & 2.43 & 1.09 & & \\
\hline $268-2$ & SMELLS & $0.0 \%$ & 26.68 & 39.28 & 19.08 & 15.28 & 0.08 & 79 & 2.23 & 1.01 & & \\
\hline 235 & SMOKE & $0.0 \%$ & 38.18 & 23.88 & 14.38 & 23.88 & $0.0 \%$ & 21 & 2.24 & 1.19 & 2.43 & 293 \\
\hline 260 & SMOKE & $0.0 \%$ & 35.88 & 25.48 & 14.98 & 23.98 & 0.08 & 67 & 2.27 & 1.18 & & \\
\hline $293 / 8$ & SMOKE & 0.08 & 31.68 & 36.88 & 15.88 & 15.88 & 0.08 & 19 & 2.16 & 1.04 & & \\
\hline $268-1$ & SMOKE & 0.08 & $31.8 \%$ & 20.08 & 17.38 & 30.98 & 0.08 & 110 & 2.47 & 1.23 & & \\
\hline $268-2$ & SMOKE & $0.0 \%$ & 28.98 & 14.58 & 21.18 & 35.58 & 0.08 & 76 & 2.63 & 1.23 & & \\
\hline 235 & TEMPSWN & 0.08 & 35.08 & 35.08 & 15.08 & 15.08 & 0.08 & 20 & 2.10 & 1.04 & 2.63 & 291 \\
\hline 260 & TEMPSWN & 0.08 & 16.48 & 28.48 & 23.98 & 31.38 & 0.08 & 67 & 2.70 & 1.08 & & \\
\hline $293 / 8$ & TEMPSWN & 0.08 & 26.38 & 26.38 & 21.18 & 26.38 & 0.08 & 19 & 2.47 & 1.14 & & \\
\hline $268-1$ & TEMPSWN & 0.08 & 13.88 & 32.18 & 22.98 & 31.28 & $0.0 \%$ & 109 & 2.72 & 1.05 & & \\
\hline $268-2$ & TEMPSWN & 0.08 & 18.48 & 27.68 & 26.38 & 27.68 & $0.0 \%$ & 76 & 2.63 & 1.07 & & \\
\hline 235 & AIRQUAL & 0.08 & 18.28 & 50.08 & 18.28 & 13.68 & 0.08 & 22 & 2.27 & 0.91 & 2.83 & 296 \\
\hline 260 & AIRQUAL & $0.0 \%$ & 6.08 & 26.98 & 26.98 & 40.38 & 0.08 & 67 & 3.01 & 0.95 & & \\
\hline $293 / 8$ & AIRQUAL & 0.08 & $15.8 \%$ & 52.68 & 21.18 & 10.58 & 0.08 & 19 & 2.26 & 0.85 & & \\
\hline-1 & AIRQUAL & $0.0 \%$ & 10.08 & 27.38 & 26.48 & 36.48 & $0.0 \%$ & 110 & 2.89 & 1.01 & & \\
\hline-2 & AIRQUAL & 0.08 & $12.8 \%$ & 25.68 & 20.58 & 41.08 & 0.08 & 78 & 2.90 & 1.08 & & \\
\hline
\end{tabular}




\begin{tabular}{|c|c|c|c|c|c|c|c|c|c|c|c|c|}
\hline & & $\underline{0^{\prime} s}$ & $\underline{1 ' s}$ & $\underline{2^{\prime} s}$ & $\underline{3^{\prime} s}$ & $4^{\prime} \mathrm{s}$ & $5^{\prime} s$ & $\mathrm{~N}$ & Avg & $\underline{\text { Std }} \subseteq$ & Mean & $\underline{\mathrm{SN}}$ \\
\hline 235 & NOTSKLT & 0.08 & 30.08 & 30.08 & 20.08 & 20.08 & 0.08 & 20 & 2.30 & 1.10 & 2.60 & 28 \\
\hline 60 & NOTSKLT & .08 & 9.58 & 31.78 & 33.38 & 25.48 & 0.08 & 63 & 2.75 & 0.94 & & \\
\hline $93 / 8$ & NOTSKLT & .08 & 15.88 & 63.28 & 10.58 & 10.58 & 0.08 & 19 & 2.16 & 0.81 & & \\
\hline $8-1$ & NOTSKLT & .08 & 20.28 & 22.98 & 22.98 & 33.98 & 0.08 & 109 & 2.71 & 1.14 & & \\
\hline $8-2$ & NOTSKLT & .08 & 16.48 & 35.68 & 30.18 & 17.88 & 0.08 & 73 & 2.49 & 0.97 & & \\
\hline & HEADACHE & $0 z$ & 22.78 & $50.0 \%$ & 9.18 & 13.68 & 4.58 & 22 & 2.27 & 1.09 & 82 & \\
\hline 60 & HEADACHE & .08 & $5.9 \%$ & 19.18 & 42.68 & 27.98 & 4.48 & 68 & 3.06 & 0.94 & & \\
\hline $93 / 8$ & HEADACHE & .08 & 15.88 & 26.38 & 31.68 & 15.88 & 10.58 & 19 & 2.79 & 1.20 & & \\
\hline $68-1$ & HEADACHE & .08 & 14.88 & 19.18 & 40.98 & 19.18 & $6.1 \%$ & 115 & 2.83 & 1.09 & & \\
\hline $58-2$ & HEADACHE & 0.08 & 17.18 & 12.28 & $48.8 \%$ & $19.5 \%$ & 2.48 & 82 & 2.78 & 1.02 & & \\
\hline 5 & DIZ & .08 & 54.58 & 27.38 & 13.68 & 0.08 & 4.58 & 22 & 1.73 & 1.01 & 1.78 & \\
\hline 60 & DIZZY & .08 & 50.08 & 22.18 & 17.68 & 5.98 & 4.48 & 68 & 1.93 & 1.14 & & \\
\hline $93 / 8$ & DIZZY & 0.08 & 47.48 & 36.88 & 10.58 & 0.08 & 5.38 & 19 & 1.79 & 1.00 & & \\
\hline $268-1$ & DIZZY & 0.08 & 54.98 & 20.48 & 18.68 & 4.48 & 1.88 & 113 & 1.78 & 1.01 & & \\
\hline $58-2$ & DIZZY & 0.08 & 55.68 & 29.68 & 11.18 & 1.28 & 2.58 & 81 & 1.65 & 0.90 & & \\
\hline 35 & $\mathrm{~S}$ & 8 & 36.48 & 36.48 & 22.78 & 0.08 & 4.58 & 22 & 2.00 & 1.00 & 2 & \\
\hline 60 & SLE & 08 & 13.48 & 11.98 & 47.88 & 17.98 & 9.08 & 67 & 2.97 & 1.09 & & \\
\hline$/ 8$ & SLEEPY & 08 & 31.68 & 36.88 & 21.18 & 10.58 & $0.0 \%$ & 19 & 2.11 & 0.97 & & \\
\hline $58-1$ & SLEEPY & .08 & 21.28 & 18.68 & 31.08 & 23.08 & 6.28 & 113 & 2.74 & 1.20 & & \\
\hline $68-2$ & SLEEPY & .08 & 20.78 & 22.08 & 37.88 & 17.18 & 2.48 & 82 & 2.59 & 1.07 & & \\
\hline 5 & ROT & 8 & $54.5 \%$ & 36.48 & 0.08 & 4.58 & 4.58 & 22 & 1.68 & 1.02 & 2.20 & \\
\hline 60 & IROT & 08 & 34.38 & 17.98 & 34.38 & 9.08 & 4.58 & 67 & 2.31 & 1.16 & & \\
\hline $93 / 8$ & ROT & 08 & 42.18 & 31.68 & $15.8 \%$ & 5.38 & 5.38 & 19 & 2.00 & 1.12 & & \\
\hline $68-1$ & ROT & .08 & $38.1 \%$ & 24.88 & 19.58 & 15.98 & 1.88 & 113 & 2.19 & 1.16 & & \\
\hline $68-2$ & SORTHROT & 0.08 & 28.88 & 27.58 & 31.38 & 8.88 & 3.88 & 80 & 2.31 & 1.09 & & \\
\hline 35 & $S E$ & 08 & 52.28 & 21.78 & 17.48 & 4.38 & 4.38 & 23 & 1.87 & 1.12 & 2.38 & \\
\hline 60 & RUN & .08 & 34.38 & 11.98 & 40.38 & 7.58 & 6.08 & 67 & 2.39 & 1.20 & & \\
\hline $93 / 8$ & RUNI & .08 & 31.68 & 21.18 & 26.38 & 10.58 & 10.58 & 19 & 2.47 & 1.31 & & \\
\hline $68-1$ & RUNNOSE & .08 & 33.68 & 18.68 & 29.28 & 15.08 & 3.58 & 113 & 2.36 & 1.19 & & \\
\hline $68-2$ & RUNNOSE & .08 & 24.78 & 27.28 & 25.98 & 17.38 & 4.98 & 81 & 2.51 & 1.18 & & \\
\hline 35 & I & & 39.18 & 21.78 & 21.78 & $8.7 \%$ & & 23 & 26 & 1.29 & 2.76 & \\
\hline 50 & YE & & 17.98 & 11.98 & 34.38 & 28 & 58 & 67 & 2.96 & 1.19 & & \\
\hline 18 & EYE & 8 & 26.38 & 26.38 & 26.38 & 15.88 & 5.38 & 19 & 2.47 & 1.19 & & \\
\hline-1 & TEYE & 0.08 & 25.28 & 13.08 & 30.48 & 26.18 & 5.28 & 115 & 2.73 & 1.24 & & \\
\hline $268-2$ & IRRITEYE & 0.08 & 22.28 & 9.98 & 35.88 & 24.78 & 7.48 & 81 & 2.85 & 1.23 & & \\
\hline 235 & EYE & & 27.38 & 40.98 & 9.18 & & & $2 \angle$ & 2.36 & 1.26 & 2.43 & \\
\hline 260 & FOCUSEYE & .08 & 19.48 & 25.48 & 25.48 & 26.98 & 3.08 & 67 & 2.69 & 1.15 & & \\
\hline $293 / 8$ & FOCUSEYE & .08 & 36.88 & 31.68 & 15.88 & 10.58 & 5.38 & 19 & 2.16 & 1.18 & & \\
\hline $268-1$ & FOC & .08 & 32.78 & 19.58 & 24.88 & 16.88 & 6.28 & 113 & 2.42 & 1.28 & & \\
\hline $268-2$ & FOCUSEYE & 0.08 & 27.28 & 32.18 & 25.98 & 11.18 & 3.78 & 81 & 2.32 & 1.10 & & \\
\hline 235 & DIFFCONC & 08 & 36.48 & 22.78 & 22.78 & 13.68 & 4.58 & 22 & 2.27 & 1.21 & 2.84 & 30 \\
\hline 260 & DIFFCONC & $0.0 \%$ & 4.58 & 27.38 & 54.58 & 12.18 & 1.58 & 66 & 2.79 & 0.77 & & \\
\hline $293 / 8$ & DIFFCONC & $0.0 \%$ & 15.88 & 31.68 & 36.88 & 10.58 & 5.38 & 19 & 2.58 & 1.04 & & \\
\hline $268-1$ & DIFFCONC & 0.08 & 7.88 & 19.18 & 49.68 & 19.18 & 4.38 & 115 & 2.93 & 0.93 & & \\
\hline
\end{tabular}




\begin{tabular}{|c|c|c|c|c|c|c|c|c|c|c|c|c|}
\hline $268-2$ & DIFFCONC & $\frac{0^{\prime} s}{0.08}$ & $\frac{1^{\prime} s}{8.88}$ & $\frac{2^{\prime} s}{15.08}$ & $\frac{3^{\prime} s}{50.08}$ & $\frac{4^{\prime} s}{23.88}$ & $\frac{5^{\prime} s}{2.58}$ & $\frac{\mathrm{N}}{80}$ & $\frac{\operatorname{Avg}}{2.96}$ & $\frac{\text { Std }}{0.91}$ & $\underline{\text { SMean }}$ & $\underline{\mathrm{SN}}$ \\
\hline 35 & FATIGUE & 0.08 & 36.48 & 36.48 & 13.68 & 9.18 & 4.58 & 22 & 2.09 & 1.12 & 2.69 & 297 \\
\hline 60 & FATIGUE & 0.08 & 9.18 & 15.28 & 47.08 & 27.38 & 1.58 & 66 & 2.97 & 0.92 & & \\
\hline $93 / 8$ & FATIGUE & 0.08 & 21.18 & 26.38 & 36.88 & 15.88 & 0.08 & 19 & 2.47 & 0.99 & & \\
\hline $68-1$ & FATIGUE & 0.08 & 17.48 & 18.38 & 45.08 & 15.68 & 3.78 & 109 & 2.70 & 1.04 & & \\
\hline $68-2$ & FATIGUE & 0.08 & 7.48 & 33.38 & 46.98 & 9.98 & 2.58 & 81 & 2.67 & 0.85 & & \\
\hline 35 & EAR & 0.08 & 65.28 & 26.18 & 4.38 & 0.08 & 4.38 & 23 & 1.52 & 0.93 & 1.46 & 296 \\
\hline 50 & EAR & 0.08 & 73.88 & 16.98 & 6.28 & 3.18 & 0.08 & 65 & 1.38 & 0.74 & & \\
\hline $93 / 8$ & EAR & 0.08 & 73.78 & 21.18 & 5.38 & 0.08 & 0.08 & 19 & 1.32 & 0.57 & & \\
\hline $68-1$ & EAR & 0.08 & 68.28 & 16.48 & 8.28 & 4.58 & 2.78 & 110 & 1.57 & 1.00 & & \\
\hline $68-2$ & EAR & 0.08 & 73.48 & 17.78 & 6.38 & 1.38 & 1.38 & 79 & 1.39 & 0.77 & & \\
\hline 35 & COLDS & 0.08 & 52.28 & 39.18 & 0.08 & 4.38 & 4.38 & 23 & 1.70 & 1.00 & 2.10 & 299 \\
\hline 260 & COLDS & 0.08 & 40.98 & 33.38 & 16.78 & 7.68 & 1.58 & 66 & 1.95 & 1.01 & & \\
\hline $93 / 8$ & COLDS & 0.08 & 31.68 & 26.38 & 31.68 & 10.58 & 0.08 & 19 & 2.21 & 1.00 & & \\
\hline $58-1$ & COLDS & 0.08 & 38.78 & 23.48 & 21.68 & 12.68 & 3.68 & 111 & 2.19 & 1.18 & & \\
\hline $268-2$ & COLDS & 0.08 & 30.08 & 33.88 & 25.08 & 8.88 & 2.58 & 80 & 2.20 & 1.04 & & \\
\hline 235 & SINL & 0.08 & 52.28 & 21.78 & 4.38 & 13.08 & 8.78 & 23 & 2.04 & 1.37 & 2.48 & 300 \\
\hline 260 & SINUS & 0.08 & 40.98 & 12.18 & 21.28 & 12.18 & 13.68 & 66 & 2.45 & 1.46 & & \\
\hline $293 / 8$ & SINUS & 0.08 & 31.68 & 21.18 & 31.68 & 5.38 & 10.58 & 19 & 2.42 & 1.27 & & \\
\hline $268-1$ & SINUS & 0.08 & 35.78 & 15.28 & 26.88 & 13.48 & 8.98 & 112 & 2.45 & 1.33 & & \\
\hline $268-2$ & SINUS & 0.08 & 27.58 & 15.08 & 30.08 & 16.38 & 11.38 & 80 & 2.69 & 1.33 & & \\
\hline 235 & ALLERGY & 0.08 & 52.28 & 30.48 & 4.38 & 4.38 & $8.7 \%$ & 23 & 1.87 & 1.23 & 32.14 & 295 \\
\hline 260 & ALLERGY & 0.08 & 56.18 & 15.28 & 10.68 & 9.18 & 9.18 & 66 & $2: 00$ & 1.36 & & \\
\hline $293 / 8$ & ALLERGY & 0.08 & 42.18 & 21.18 & 21.18 & 5.38 & 10.58 & 19 & 2.21 & 1.32 & & \\
\hline $268-1$ & ALLERGY & 0.08 & 45.48 & 17.68 & 19.48 & 10.28 & 7.48 & 108 & 2.17 & 1.30 & & \\
\hline $268-2$ & ALLERGY & 0.08 & 40.58 & 17.78 & 24.18 & 10.18 & 7.68 & 79 & 2.27 & 1.29 & & \\
\hline 235 & FURNSAT & 0.08 & 4.28 & 16.78 & 25.08 & 45.88 & 8.38 & 24 & 3.38 & 0.99 & 3.08 & 305 \\
\hline 260 & FURNSAT & 0.08 & 5.88 & 30.48 & 10.18 & 50.78 & 2.98 & 69 & 3.14 & 1.07 & & \\
\hline $293 / 8$ & FURNSAT & 0.08 & 5.38 & 15.88 & 36.88 & 36.88 & 5.38 & 19 & 3.21 & 0.95 & & \\
\hline $268-1$ & FURNSAT & 0.08 & 9.08 & 38.78 & 21.68 & 26.18 & 4.58 & 111 & 2.78 & 1.07 & & \\
\hline $268-2$ & FURNSAT & 0.08 & 7.38 & 20.78 & 17.18 & 42.78 & 12.28 & 82 & 3.32 & 1.15 & & \\
\hline 235 & NEDSEOUT & 34.88 & 65.28 & 0.08 & 0.08 & 0.08 & 0.08 & 23 & 0.65 & 0.48 & 80.71 & 296 \\
\hline 260 & NEDSEOUT & 9.28 & 87.78 & 1.58 & 0.08 & 1.58 & 0.08 & 65 & 0.97 & 0.50 & & \\
\hline $293 / 8$ & NEDSEOUT & 22.28 & 77.88 & 0.08 & 0.08 & 0.08 & 0.08 & 18 & 0.78 & 0.42 & & \\
\hline $268-1$ & NEDSEOUT & 34.58 & 63.68 & 0.98 & 0.08 & 0.98 & 0.08 & 110 & 0.69 & 0.58 & & \\
\hline $268-2$ & NEDSEOUT & 47.58 & 52.58 & 0.08 & 0.08 & 0.08 & 0.08 & 80 & 0.53 & 0.50 & & \\
\hline 235 & EQUIPSAT & 0.08 & 0.08 & 4.28 & 25.08 & 62.58 & 8.38 & 24 & 3.75 & 0.66 & 53.19 & 30 \\
\hline 260 & EQUIPSAT & 0.08 & 8.78 & 20.38 & $18.8 \%$ & 46.48 & $5.8 \%$ & 69 & 3.20 & 1.10 & & \\
\hline $293 / 8$ & EQUIPSAT & 0.08 & 10.58 & 31.68 & 31.68 & 26.38 & 0.08 & 19 & 2.74 & 0.96 & & \\
\hline $268-1$ & EQUIPSAT & 0.08 & 7.18 & 28.68 & 25.08 & 30.48 & 8.98 & 112 & 3.05 & 1.11 & & \\
\hline $268-2$ & EQUIPSAT & 0.08 & 7.48 & 19.88 & 21.08 & 39.58 & 12.38 & 81 & 3.30 & 1.14 & & \\
\hline 23. & CHAIRMOV & 0.08 & 9.58 & 23.88 & 52.48 & 14.38 & 0.08 & 21 & 2.71 & 0.82 & 2.72 & 277 \\
\hline 260 & CHAIRMOV & 0.08 & 4.48 & 16.28 & 61.88 & 17.68 & 0.08 & 68 & 2.93 & 0.71 & & \\
\hline
\end{tabular}


$293 / 8$ CHAIRMOV

268-1 CHAIRMOV

268-2 CHAIRMOV

\section{CHRHGT \\ 260 CHRHGT \\ 293/8 CHRHGT \\ 268-1 CHRHGT \\ 268-2 CHRHGT \\ 235 CHRBACK \\ 260 CHRBACK \\ 293/8 CHRBACK \\ 268-1 CHRBACK \\ 268-2 CHRBACK}

$\begin{array}{ll}235 & \text { CHRADJT } \\ 260 & \text { CHRADJT } \\ 293 / 8 & \text { CHRADJT } \\ 268-1 & \text { CHRADJT } \\ 268-2 & \text { CHRADJT }\end{array}$

$\begin{array}{ll}235 & \text { CHAIRCON } \\ 260 & \text { CHAIRCON } \\ 293 / 8 & \text { CHAIRCON } \\ 268-1 & \text { CHAIRCON } \\ 268-2 & \text { CHAIRCON }\end{array}$

235 COWRKHR

260 COWRKHR

293/8 COWRKHR

268-1 COWRKHR

268-2 COWRKHR

\begin{abstract}
235 TIREDEYE
260 TIREDEYE

293/8 TIREDEYE

268-1 TIREDEYE

268-2 TIREDEYE
\end{abstract}

235 NOMOVFWS

260 NOMOVFWS

293/8 NOMOVFWS

268-1 NOMOVFWS

268-2 NOMOVFWS

235 CONCNTRT

260 CONCNTRT

293/8 CONCNTRT

268-1 CONCNTRT

268-2 CONCNTRT

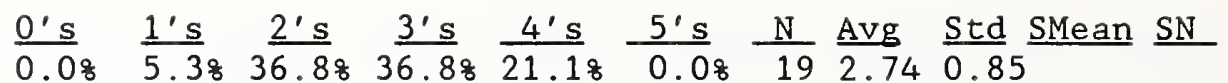

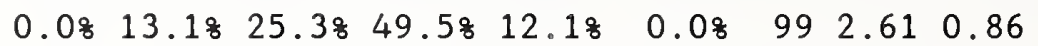

$\begin{array}{lllllllll}0.08 & 11.48 & 31.48 & 35.78 & 21.48 & 0.08 & 70 & 2.67 & 0.94\end{array}$

$\begin{array}{lllllllllll}0.08 & 17.48 & 30.48 & 43.58 & 8.78 & 0.08 & 23 & 2.43 & 0.88 & 2.50 & 299\end{array}$

$\begin{array}{lllllllll}0.08 & 7.28 & 24.68 & 52.28 & 15.98 & 0.08 & 69 & 2.77 & 0.80\end{array}$

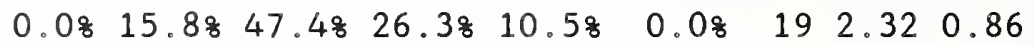

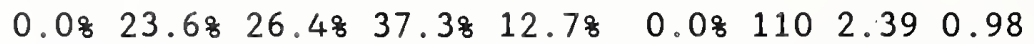

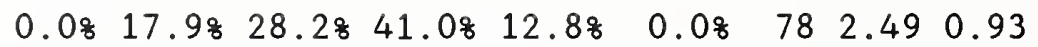

$0.0 \% \quad 21.78 \quad 30.48 \quad 39.1 \% \quad 8.78$

$0.0 \% 14.98 \quad 28.48 \quad 41.8 \% \quad 14.98$

$0.0 \% \quad 31.6 \% \quad 36.8 \% \quad 26.3 \% \quad 5.3 \%$

$0.0 \% \quad 29.2 \% \quad 21.7 \% \quad 35.8 \% 13.2 \%$

$0.08 \quad 35.68 \quad 19.28 \quad 31.58 \quad 13.78$

$\begin{array}{lllllll}0.08 & 23 & 2.35 & 0.91 & 2.34 & 288\end{array}$

$\begin{array}{llll}0.08 & 67 & 2.57 & 0.92\end{array}$

$\begin{array}{llll}0.0 \% & 19 & 2.05 & 0.89\end{array}$

$\begin{array}{llll}0.08 & 106 & 2.33 & 1.03\end{array}$

$\begin{array}{llll}0.08 & 73 & 2.23 & 1.08\end{array}$

$0.08 \quad 17.48 \quad 34.88 \quad 39.18 \quad 8.78$

$0.08 \quad 10.18 \quad 14.58 \quad 58.08 \quad 17.48$

$0.08 \quad 21.1$ 용 $26.38 \quad 31.68 \quad 21.18$

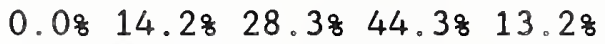

$0.08 \quad 16.78 \quad 26.98 \quad 42.38 \quad 14.18$

$\begin{array}{lllllll}0.08 & 23 & 2.39 & 0.87 & 2.60 & 295\end{array}$

$\begin{array}{llll}0.08 & 69 & 2.83 & 0.83\end{array}$

$\begin{array}{llll}0.08 & 19 & 2.53 & 1.04\end{array}$

$\begin{array}{llll}0.08 & 106 & 2.57 & 0.89\end{array}$

$\begin{array}{llll}0.08 & 78 & 2.54 & 0.93\end{array}$

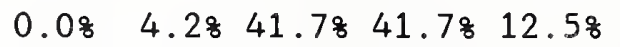

$\begin{array}{lllll}0.08 & 2.98 & 15.98 & 55.18 & 26.18\end{array}$

$\begin{array}{llllll}0.08 & 0.08 & 42.18 & 42.18 & 15.88\end{array}$

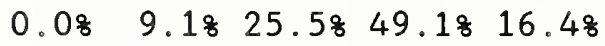

$0.08 \quad 9.9 \% \quad 23.5 \% \quad 50.6 \% \quad 16.08$

$\begin{array}{lllllll}0.08 & 24 & 2.63 & 0.75 & 2.79 & 303\end{array}$

$\begin{array}{llll}0.08 & 69 & 3.04 & 0.73\end{array}$

$\begin{array}{lllll}0.08 & 19 & 2.74 & 0.71\end{array}$

$\begin{array}{lllll}0.08 & 110 & 2.73 & 0.84\end{array}$

$\begin{array}{llll}0.08 & 81 & 2.73 & 0.85\end{array}$

$\begin{array}{lllll}0.08 & 57.18 & 33.38 & 4.88 & 4.8 \%\end{array}$

0.08

$\begin{array}{llllll}21 & 1.57 & 0.79 & 1.49 & 297\end{array}$

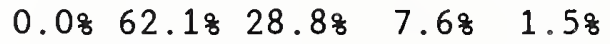

$\begin{array}{lllll}0.08 & 36.8 \% & 52.6 \% & 5.3 \% & 5.3 \%\end{array}$

$0.08 \quad 69.1 \% \quad 24.5 \% \quad 5.5$ 용 0.9 영

0.08

$\begin{array}{lll}66 & 1.48 & 0.70\end{array}$

$\begin{array}{llll}0.08 & 19 & 1.79 & 0.77\end{array}$

$\begin{array}{lllll}0.08 & 56.88 & 33.38 & 8.68 & 1.28\end{array}$

$\begin{array}{llll}0.08 & 110 & 1.38 & 0.63\end{array}$

$\begin{array}{llll}0.08 & 81 & 1.54 & 0.70\end{array}$

$\begin{array}{llllll}0.0 \% & 4.88 & 33.3 \% & 33.38 & 28.6 \%\end{array}$

$0.0 \% \quad 13.68 \quad 43.98 \quad 28.8 \% 13.68$

$0.08 \quad 21.1 \% \quad 42.1 \% \quad 26.38 \quad 10.5 \%$

0.08

$\begin{array}{llllll}21 & 2.86 & 0.89 & 2.45 & 296\end{array}$

$\begin{array}{llll}0.08 & 66 & 2.42 & 0.89\end{array}$

$\begin{array}{llll}0.08 & 19 & 2.26 & 0.91\end{array}$

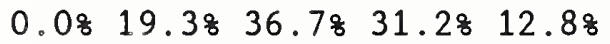

$\begin{array}{llll}0.08 & 109 & 2.38 & 0.94\end{array}$

0.0 용 12.3 용 40.7 왕 30.9 영 16.0 용

$\begin{array}{llll}0.08 & 81 & 2.51 & 0.90\end{array}$

$\begin{array}{lllll}0.08 & 4.58 & 31.88 & 45.58 & 18.28\end{array}$

0.08

$\begin{array}{lllll}22 & 2.77 & 0.79 & 2.62 & 299\end{array}$

$\begin{array}{llllll}0.08 & 9.08 & 50.78 & 26.98 & 13.48\end{array}$

0.08

$\begin{array}{lll}67 & 2.45 & 0.83\end{array}$

$0.0 \%$

$5.38 \quad 31.68 \quad 31.68 \quad 31.68$

$\begin{array}{llll}0.08 & 19 & 2.89 & 0.91\end{array}$

$\begin{array}{llllll}0.08 & 9.28 & 41.38 & 32.18 & 17.48\end{array}$

$\begin{array}{llll}0.08 & 109 & 2.58 & 0.88\end{array}$

$\begin{array}{llllll}0.08 & 9.88 & 34.18 & 31.78 & 24.48\end{array}$

$\begin{array}{llll}0.08 & 82 & 2.71 & 0.94\end{array}$

$\begin{array}{lllll}0.08 & 0.08 & 9.18 & 50.08 & 40.98\end{array}$

0.08

$\begin{array}{lllllll}22 & 3.32 & 0.63 & 3.34 & 299\end{array}$

0.08

$\begin{array}{lllll}0.08 & 6.18 & 39.48 & 54.58\end{array}$

0.08

$\begin{array}{llll}66 & 3.48 & 0.61\end{array}$

0.08

$5.38 \quad 15.8 \% \quad 21.18 \quad 57.98$

$\begin{array}{lllll}0.08 & 19 & 3.32 & 0.92\end{array}$

$0.0 \%$

$\begin{array}{llll}1.88 & 7.38 & 49.18 & 41.88\end{array}$

$\begin{array}{lllll}0.0 ㅇ ㅛ ㅇ ~ & 110 & 3.31 & 0.68\end{array}$

$\begin{array}{lllll}0.08 & 82 & 3.27 & 0.72\end{array}$ 


\begin{tabular}{|c|c|c|c|c|c|c|c|c|c|c|c|c|}
\hline & & $\underline{0^{\prime} s}$ & $1^{\prime} \mathrm{s}$ & $\underline{2} \mathrm{~s}$ & 3's & $4^{\prime} s$ & $5^{\prime} s$ & $\mathrm{~N}$ & Avg & $\underline{\mathrm{Std}}$ & SMean & $\underline{\mathrm{SN}}$ \\
\hline 235 & WORKTIME & 0.08 & $38.1 \%$ & 57.18 & $4.8 \%$ & $0.0 \%$ & $0.0 \%$ & 21 & 1.67 & 0.56 & 2.27 & 298 \\
\hline 260 & WORKTIME & 0.08 & 12.18 & 45.58 & 27.38 & 15.28 & $0.0 \%$ & 66 & 2.45 & 0.89 & & \\
\hline $293 / 8$ & WORKTIME & 0.08 & $15.8 \%$ & 31.68 & 31.68 & 21.18 & $0.0 \%$ & 19 & 2.58 & 0.99 & & \\
\hline $68-1$ & WORKT IME & 0.08 & 23.68 & 43.68 & $22.7 \%$ & $10.0 \%$ & $0.0 \%$ & 110 & 2.19 & 0.91 & & \\
\hline $68-2$ & WORKTIME & 0.08 & 17.18 & 46.38 & 26.88 & $9.8 \%$ & $0.0 \%$ & 82 & 2.29 & 0.86 & & \\
\hline 235 & LTGHINDR & 0.08 & $0.0 \%$ & 28.68 & 33.38 & $38.1 \%$ & $0.0 \%$ & 21 & 3.10 & 0.81 & 2.96 & 293 \\
\hline 260 & LTGHINDR & $0.0 \%$ & $7.7 \%$ & $10.8 \%$ & 52.38 & 29.28 & $0.0 \%$ & 65 & 3.03 & 0.84 & & \\
\hline $293 / 8$ & LTGHINDR & 0.08 & 0.08 & 10.58 & $15.8 \%$ & 73.78 & 0.08 & 19 & 3.63 & 0.67 & & \\
\hline $68-1$ & LTGHINDR & 0.08 & 8.38 & 38.08 & 31.58 & 22.28 & $0.0 \%$ & 108 & 2.68 & 0.91 & & \\
\hline $58-2$ & LTGHINDR & 0.08 & 1.38 & 25.08 & 37.58 & 36.38 & 0.08 & 80 & 3.09 & 0.81 & & \\
\hline 35 & WRKABILIT & 0.08 & 13.68 & 22.78 & 45.58 & 18.28 & 0.08 & 22 & 2.68 & 0.92 & 2.59 & 297 \\
\hline 260 & WRKABILIT & 0.08 & 12.18 & 31.88 & 43.98 & 12.18 & 0.08 & 66 & 2.56 & 0.86 & & \\
\hline $293 / 8$ & WRKABILIT & 0.08 & 21.18 & 31.68 & 31.68 & $15.8 \%$ & 0.08 & 19 & 2.42 & 0.99 & & \\
\hline $268-1$ & WRKABILIT & 0.08 & 13.98 & 29.68 & 48.18 & 8.38 & 0.08 & 108 & 2.51 & 0.83 & & \\
\hline $68-2$ & WRKABILIT & 0.08 & 6.18 & 29.38 & $48.8 \%$ & 15.98 & 0.08 & 82 & 2.74 & 0.79 & & \\
\hline 35 & WORKSAT & 0.08 & 47.68 & 47.68 & 0.08 & 4.88 & 0.08 & 21 & 1.62 & 0.72 & 1.17 & 298 \\
\hline 60 & WORKSAT & 0.08 & 43.98 & 50.08 & 3.08 & 3.08 & 0.08 & 66 & 1.65 & 0.69 & & \\
\hline $293 / 8$ & WORKSAT & 0.08 & 26.38 & 52.68 & 21.18 & 0.08 & 0.08 & 19 & 1.95 & 0.69 & & \\
\hline $268-1$ & WORKSAT & 0.08 & 28.28 & 60.98 & 10.08 & 0.98 & $0.0 \%$ & 110 & 1.84 & 0.63 & & \\
\hline $268-2$ & WORKSAT & 0.08 & 35.48 & 54.98 & 7.38 & 2.48 & 0.08 & 82 & 1.77 & 0.69 & & \\
\hline 235 & MISSVIEW & 0.08 & 38.18 & 19.08 & 23.88 & 19.08 & 0.08 & 21 & 2.24 & 1.15 & 1.9 & 296 \\
\hline 260 & MISSVIEW & 0.08 & 74.68 & 14.98 & 4.58 & 6.08 & 0.08 & 67 & 1.42 & 0.83 & & \\
\hline $293 / 8$ & MISSVIEW & 0.08 & $11.1 \%$ & 22.28 & $16.7 \%$ & 50.08 & $0.0 \%$ & 18 & 3.06 & 1.08 & & \\
\hline $268-1$ & MISSVIEW & 0.08 & 46.38 & 27.88 & 13.98 & 12.08 & 0.08 & 108 & 1.92 & 1.04 & & \\
\hline $268-2$ & MISSVIEW & 1.28 & 36.68 & $31.7 \%$ & 11.08 & $19.5 \%$ & $0.0 \%$ & 82 & 2.11 & 1.14 & & \\
\hline 235 & WRKNOISE & $0.0 \%$ & 0.08 & 9.58 & 57.18 & 33.38 & 0.08 & 21 & 3.24 & 0.61 & 2.65 & 295 \\
\hline 260 & WRKNOISE & 0.08 & 6.28 & 27.78 & 44.68 & 21.58 & 0.08 & 65 & 2.82 & 0.84 & & \\
\hline $293 / 8$ & WRKNOISE & 0.08 & 5.38 & 26.38 & 52.68 & 15.88 & $0.0 \%$ & 19 & 2.79 & 0.77 & & \\
\hline $268-1$ & WRKNOISE & $0.0 \%$ & 10.28 & 44.48 & $27.8 \%$ & 17.68 & 0.08 & 108 & 2.53 & 0.90 & & \\
\hline $268-2$ & WRKNOISE & 0.08 & 8.58 & 42.78 & 39.08 & $9.8 \%$ & 0.08 & 82 & 2.50 & 0.78 & & \\
\hline 235 & WORKFAST & 0.08 & 14.38 & 66.78 & 19.08 & 0.08 & 0.08 & 21 & 2.05 & 0.58 & 2.14 & 295 \\
\hline 260 & WORKFAST & 0.08 & 26.28 & 58.58 & 12.38 & 3.18 & 0.08 & 65 & 1.92 & 0.71 & & \\
\hline $293 / 8$ & WORKFAST & 0.08 & 31.68 & 15.88 & 42.18 & 10.58 & $0.0 \%$ & 19 & 2.32 & 1.03 & & \\
\hline $268-1$ & WORKFAST & 0.08 & $14.8 \%$ & $53.7 \%$ & 25.98 & 5.68 & 0.08 & 108 & 2.22 & 0.76 & & \\
\hline $268-2$ & WORKFAST & $0.0 \%$ & $11.0 \%$ & 59.88 & 28.08 & $1.2 \%$ & $0.0 \%$ & 82 & 2.20 & 0.63 & & \\
\hline 235 & WEATHER & 0.08 & 27.38 & 22.78 & 31.88 & 18.28 & 0.08 & 22 & 2.41 & 1.07 & 1.91 & 297 \\
\hline 260 & WEATHER & 0.08 & 67.28 & 26.98 & 3.08 & 3.08 & 0.08 & 67 & 1.42 & 0.69 & & \\
\hline $293 / 8$ & WEATHER & 0.08 & 42.18 & 31.68 & $15.8 \%$ & $10.5 \%$ & 0.08 & 19 & 1.95 & 1.00 & & \\
\hline $268-1$ & WEATHER & $0.0 \%$ & 36.48 & 40.28 & $13.1 \%$ & $10.3 \%$ & 0.08 & 107 & 1.97 & 0.95 & & \\
\hline $268-2$ & WEATHER & 0.08 & 30.58 & 41.58 & 18.38 & $9.8 \%$ & 0.08 & 82 & 2.07 & 0.93 & & \\
\hline 235 & BLDGPLST & $0.0 \%$ & $15.0 \%$ & 10.08 & 40.08 & 20.08 & 15.08 & 20 & 3.10 & 1.22 & 2.85 & 286 \\
\hline 260 & BLDGPLST & 0.08 & 21.58 & 36.98 & 30.88 & 6.28 & 4.68 & 65 & 2.35 & 1.03 & & \\
\hline $293 / 8$ & BLDGPLST & 0.08 & 5.68 & $0.0 \%$ & 38.98 & 44.48 & 11.18 & 18 & 3.56 & 0.90 & & \\
\hline $268-1$ & BLDGPLST & 0.08 & $12.0 \%$ & 21.38 & 40.78 & 22.28 & 3.78 & 108 & 2.84 & 1.02 & & \\
\hline
\end{tabular}


268-2 BLDGPLST

235 BLDGADQT

260 BLDGADQT

293/8 BLDGADQT

268-1 BLDGADQT

268-2 BLDGADQT

235 BLDGMAIN

260 BLDGMAIN

293/8 BLDGMAIN

268-1 BLDGMAIN

268-2 BLDGMAIN

235 BLDGSPAC

260 BLDGSPAC

293/8 BLDGSPAC

268-1 BLDGSPAC

268-2 BLDGSPAC

$\begin{array}{ll}235 & \text { STIMUL } \\ 260 & \text { STIMUL } \\ 293 / 8 & \text { STIMUL } \\ 268-1 & \text { STIMUL } \\ 268-2 & \text { STIMUL } \\ & \\ 235 & \text { WELLIT } \\ 260 & \text { WELLIT } \\ 293 / 8 & \text { WELLIT } \\ 268-1 & \text { WELLIT } \\ 268-2 & \text { WELLIT }\end{array}$

235 BLDGHUMD

260 BLDGHUMD

293/8 BLDGHUMD

268-1 BLDGHUMD

268-2 BLDGHUMD

235 BLDGCLEN

260 BLDGCLEN

293/8 BLDGCLEN

268-1 BLDGCLEN

268-2 BLDGCLEN

235 BLDGQUIT

260 BLDGQUIT

293/8 BLDGQUIT

268-1 BLDGQUIT

268-2 BLDGQUIT

235 BLDGCLR

260 BLDGCLR $\frac{0^{\prime} \mathrm{s}}{0.0 \%} \frac{1^{\prime} \mathrm{s}}{10.78} \frac{2^{\prime} \mathrm{s}}{18.7 \%} \frac{3^{\prime} \mathrm{s}}{38.78} \frac{4^{\prime} \mathrm{s}}{18.7 \%} \frac{5^{\prime} \mathrm{s}}{13.38} \frac{\mathrm{N}}{75} \frac{\text { Avg }}{3.05} \frac{\text { Std }}{1.15} \underline{\text { SMean }} \underline{\mathrm{SN}}$

$\begin{array}{lllllllllll}0.08 & 8.78 & 4.38 & 43.58 & 26.18 & 17.48 & 23 & 3.39 & 1.09 & 3.14 & 304\end{array}$

$\begin{array}{lllllllll}0.08 & 7.48 & 23.58 & 35.38 & 22.18 & 11.88 & 68 & 3.07 & 1.10\end{array}$

$\begin{array}{lllllllll}0.08 & 0.08 & 11.18 & 33.38 & 44.48 & 11.18 & 18 & 3.56 & 0.83\end{array}$

$\begin{array}{lllllllll}0.08 & 8.08 & 21.28 & 41.68 & 22.18 & 7.18 & 113 & 2.99 & 1.02\end{array}$

$\begin{array}{lllllllll}0.08 & 8.58 & 11.08 & 40.28 & 28.08 & 12.28 & 82 & 3.24 & 1.08\end{array}$

$\begin{array}{lllll}0.08 & 8.78 & 4.38 & 60.98 & 17.48\end{array}$

0.0 용 18.8 \% $24.6 \% \quad 36.28 \quad 13.0 \%$

$\begin{array}{llllll}8.78 & 23 & 3.13 & 0.95 & 3.08 & 303\end{array}$

$\begin{array}{lllll}0.08 & 5.68 & 5.68 & 33.38 & 55.68\end{array}$

$\begin{array}{llll}7.28 & 69 & 2.65 & 1.14\end{array}$

$0.08 \quad 5.68 \quad 5.68 \quad 33.38 \quad 55.68 \quad 0.08 \quad 183.390 .83$

$\begin{array}{lllllllll}0.08 & 9.88 & 11.68 & 46.48 & 24.18 & 8.08 & 112 & 3.09 & 1.03\end{array}$

$\begin{array}{lllllllll}0.08 & 6.28 & 14.88 & 34.68 & 27.28 & 17.38 & 81 & 3.35 & 1.11\end{array}$

$\begin{array}{lllllllllll}0.08 & 17.48 & 17.48 & 52.28 & 8.78 & 4.38 & 23 & 2.65 & 1.00 & 2.41 & 299\end{array}$

$\begin{array}{lllllllll}0.08 & 41.88 & 23.98 & 16.48 & 11.98 & 6.08 & 67 & 2.16 & 1.25\end{array}$

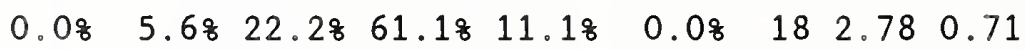

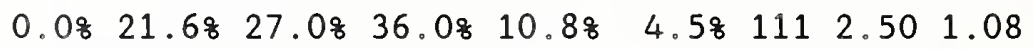

$\begin{array}{lllllllll}0.08 & 23.88 & 31.38 & 35.08 & 5.08 & 5.08 & 80 & 2.36 & 1.05\end{array}$

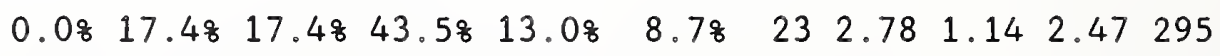

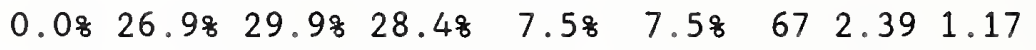

$\begin{array}{lllllllll}0.08 & 17.68 & 23.58 & 41.28 & 17.68 & 0.08 & 17 & 2.59 & 0.97\end{array}$

$\begin{array}{lllllllll}0.08 & 23.68 & 30.08 & 36.48 & 6.48 & 3.68 & 110 & 2.36 & 1.02\end{array}$

$\begin{array}{lllllllll}0.08 & 19.28 & 26.98 & 34.68 & 14.18 & 5.18 & 78 & 2.59 & 1.10\end{array}$

$\begin{array}{lllllllllll}0.08 & 4.38 & 34.88 & 34.88 & 13.08 & 13.08 & 23 & 2.96 & 1.08 & 2.83 & 301\end{array}$

$\begin{array}{lllllllll}0.08 & 15.98 & 21.78 & 43.58 & 11.68 & 7.28 & 69 & 2.72 & 1.09\end{array}$

$\begin{array}{lllllllll}0.08 & 11.18 & 5.68 & 44.48 & 22.28 & 16.78 & 18 & 3.28 & 1.15\end{array}$

$\begin{array}{lllllllll}0.08 & 16.58 & 22.08 & 34.98 & 16.58 & 10.18 & 109 & 2.79 & 1.21\end{array}$

$\begin{array}{lllllllll}0.08 & 17.18 & 18.38 & 37.88 & 18.38 & 8.58 & 82 & 2.83 & 1.17\end{array}$

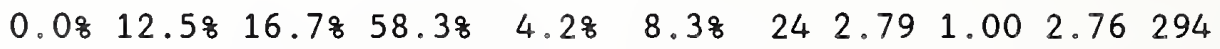

$\begin{array}{lllllllll}0.08 & 26.28 & 26.28 & 30.88 & 9.28 & 7.78 & 65 & 2.46 & 1.19\end{array}$

$\begin{array}{lllllllll}0.08 & 0.08 & 11.18 & 72.28 & 11.18 & 5.68 & 18 & 3.11 & 0.66\end{array}$

$\begin{array}{lllllllll}0.08 & 13.98 & 26.98 & 41.78 & 9.38 & 8.38 & 108 & 2.71 & 1.08\end{array}$

$\begin{array}{lllllllll}0.08 & 10.18 & 8.98 & 62.08 & 11.48 & 7.68 & 79 & 2.97 & 0.95\end{array}$

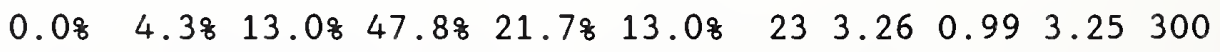

$\begin{array}{lllllllll}0.08 & 7.68 & 19.78 & 43.98 & 16.78 & 12.18 & 66 & 3.06 & 1.07\end{array}$

$\begin{array}{lllllllll}0.08 & 5.68 & 16.78 & 50.08 & 11.18 & 16.78 & 18 & 3.17 & 1.07\end{array}$

$\begin{array}{lllllllll}0.08 & 7.28 & 9.08 & 44.18 & 26.18 & 13.58 & 111 & 3.30 & 1.04\end{array}$

$\begin{array}{llllllllll}0.08 & 3.78 & 13.48 & 39.08 & 30.58 & 13.48 & 82 & 3.37 & 0.99\end{array}$

$\begin{array}{lllllllllll}0.08 & 4.58 & 27.38 & 31.88 & 27.38 & 9.18 & 22 & 3.09 & 1.04 & 3.40 & 301\end{array}$

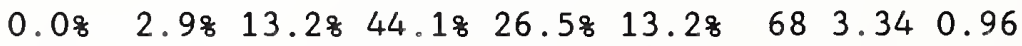

$\begin{array}{lllllllll}0.08 & 5.68 & 11.18 & 50.08 & 22.28 & 11.18 & 18 & 3.22 & 0.97\end{array}$

$\begin{array}{lllllllll}0.08 & 2.78 & 5.48 & 45.58 & 28.68 & 17.98 & 112 & 3.54 & 0.93\end{array}$

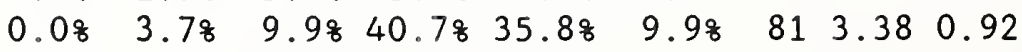

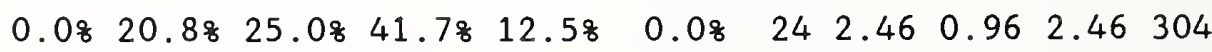
$\begin{array}{lllllllll}0.08 & 42.08 & 27.58 & 23.28 & 2.98 & 4.38 & 69 & 2.00 & 1.08\end{array}$ 
293/8 BLDGCLR

268-1 BLDGCLR

268-2 BLDGCLR

235 BLDGINTR

260 BLDGINTR

293/8 BLDGINTR

268-1 BLDGINTR

268-2 BLDGINTR

235 BLDGTEMP

260 BLDGTEMP

293/8 BLDGTEMP

268-1 BLDGTEMP

268-2 BLDGTEMP

235 BLDGATMS

260 BLDGATMS

293/8 BLDGATMS

268-1 BLDGATMS

268-2 BLDGATMS

235 BLDGSMEL

260 BLDGSMEL

293/8 BLDGSMEL

268-1 BLDGSMEL

268-2 BLDGSMEL

235 BLDGBRIT

260 BLDGBRIT

293/8 BLDGBRIT

268-1 BLDGBRIT

268-2 BLDGBRIT

235 WSIMTEMP

260 WSIMTEMP

293/8 WSIMTEMP

268-1 WSIMTEMP

268-2 WSIMTEMP

235 WSIMPRIV

260 WSIMPRIV

293/8 WSIMPRIV

268-1 WSIMPRIV

268-2 WSIMPRIV

235 WSIMACC

260 WSIMACC

$293 / 8$ WSIMACC

268-1 WSIMACC

268-2 WSIMACC $\underline{0^{\prime} \mathrm{s}} \quad \underline{1^{\prime} \mathrm{s}} \quad \underline{2^{\prime} \mathrm{s}} \quad \underline{3^{\prime} \mathrm{s}} \quad 4^{\prime} \mathrm{s} \quad 5^{\prime} \mathrm{s} \quad \mathrm{N}$ Avg Std SMean $\underline{\mathrm{SN}}$ $\begin{array}{lllllllll}0.08 & 11.18 & 11.18 & 66.78 & 11.18 & 0.08 & 18 & 2.78 & 0.79\end{array}$ $\begin{array}{lllllllll}0.08 & 30.68 & 19.88 & 35.18 & 10.88 & 3.68 & 111 & 2.37 & 1.13\end{array}$

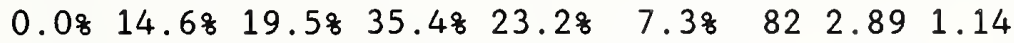

$\begin{array}{llllll}0.08 & 12.58 & 25.08 & 33.38 & 20.88\end{array}$ $0.08 \quad 34.88 \quad 26.18 \quad 27.58 \quad 7.28$ $0.08 \quad 11.18 \quad 22.28 \quad 50.08 \quad 16.78$ $0.08 \quad 21.88 \quad 23.68 \quad 40.08 \quad 8.28$ $\begin{array}{lllll}0.08 & 17.18 & 24.48 & 37.88 & 13.48\end{array}$

$\begin{array}{lllllll}8.38 & 24 & 2.88 & 1.13 & 2.54 & 303\end{array}$

$\begin{array}{llll}4.38 & 69 & 2.20 & 1.12\end{array}$

$\begin{array}{llll}0.08 & 18 & 2.72 & 0.87\end{array}$

$\begin{array}{lllll}6.48 & 110 & 2.54 & 1.11\end{array}$

$\begin{array}{llll}7.38 & 82 & 2.70 & 1.12\end{array}$

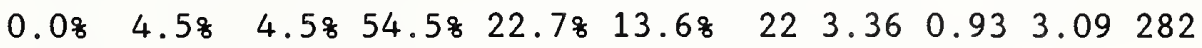

$\begin{array}{lllllllll}0.08 & 12.98 & 4.88 & 66.18 & 11.38 & 4.88 & 62 & 2.90 & 0.93\end{array}$

$\begin{array}{lllllllll}0.08 & 0.08 & 11.18 & 83.38 & 5.68 & 0.08 & 18 & 2.94 & 0.40\end{array}$

$\begin{array}{lllllllll}0.08 & 10.08 & 7.08 & 49.08 & 16.08 & 18.08 & 100 & 3.25 & 1.13\end{array}$

$\begin{array}{llllllllll}0.08 & 8.88 & 8.8 \% & 61.38 & 16.38 & 5.08 & 80 & 3.00 & 0.89\end{array}$

$\begin{array}{lllll}0.08 & 8.38 & 12.58 & 45.88 & 25.08\end{array}$

$0.08 \quad 22.48 \quad 32.8 \% \quad 29.98 \quad 6.08$

$0.08 \quad 11.18 \quad 22.28 \quad 44.48 \quad 22.28$

$\begin{array}{lllllll}8.38 & 24 & 3.13 & 1.01 & 2.74 & 302\end{array}$

$\begin{array}{llllll}0.08 & 15.38 & 23.48 & 37.88 & 18.98\end{array}$

$9.08 \quad 67 \quad 2.46 \quad 1.16$

$\begin{array}{llll}0.08 & 18 & 2.78 & 0.92\end{array}$

$\begin{array}{lllllllll}0.08 & 13.48 & 23.28 & 37.88 & 17.18 & 8.58 & 82 & 2.84 & 1.12\end{array}$

$\begin{array}{llllll}0.08 & 13.08 & 8.78 & 34.88 & 8.78 & 34.88\end{array}$

$\begin{array}{lllllll}0.08 & 15.98 & 21.78 & 34.88 & 14.58 & 13.08\end{array}$

$23 \quad 3.43 \quad 1.38 \quad 3.06 \quad 302$

$\begin{array}{lllllllll}0.08 & 5.68 & 11.18 & 44.48 & 22.28 & 16.78 & 18 & 3.33 & 1.05\end{array}$

$\begin{array}{lllllllll}0.08 & 10.08 & 12.78 & 48.28 & 12.78 & 16.48 & 110 & 3.13 & 1.14\end{array}$

$\begin{array}{lllllllll}0.08 & 8.5 \% & 15.98 & 52.48 & 15.98 & 7.38 & 82 & 2.98 & 0.97\end{array}$

$\begin{array}{llllll}0.08 & 8.78 & 13.08 & 47.88 & 8.78 & 21.78\end{array}$

$\begin{array}{llllll}23 & 3.22 & 1.18 & 2.88 & 298\end{array}$

$\begin{array}{llllll}0.08 & 14.78 & 25.08 & 41.28 & 11.88 & 7.48\end{array}$

$\begin{array}{lll}68 & 2.72 & 1.08\end{array}$

$\begin{array}{lllllllll}0.08 & 5.68 & 0.08 & 66.78 & 16.78 & 11.18 & 18 & 3.28 & 0.87\end{array}$

$\begin{array}{lllllllll}0.08 & 11.08 & 22.08 & 45.08 & 13.88 & 8.38 & 109 & 2.86 & 1.05\end{array}$

$\begin{array}{lllllllll}0.08 & 10.08 & 16.38 & 53.88 & 17.58 & 2.58 & 80 & 2.86 & 0.90\end{array}$

$\begin{array}{lllll}0.08 & 66.78 & 0.08 & 0.08 & 33.38\end{array}$

0.08

$\begin{array}{lllll}6 & 2.00 & 1.41 & 1.92 \quad 130\end{array}$

$\begin{array}{lllll}0.08 & 36.48 & 27.38 & 22.78 & 13.68\end{array}$

0.08

$22 \quad 2.14 \quad 1.06$

$\begin{array}{lllll}0.08 & 42.98 & 57.18 & 0.08 & 0.08\end{array}$

0.08

$\begin{array}{lll}7 & 1.57 & 0.49\end{array}$

$\begin{array}{lllll}0.08 & 50.08 & 20.78 & 13.88 & 15.58\end{array}$

0.08

$\begin{array}{lll}58 & 1.92 & 1.14\end{array}$

$\begin{array}{lllll}0.08 & 56.88 & 8.18 & 29.78 & 5.48\end{array}$

0.08

$\begin{array}{llll}37 & 1.84 & 1.03\end{array}$

$\begin{array}{llllll}0.08 & 37.58 & 37.58 & 0.08 & 25.08\end{array}$ $\begin{array}{llllll}0.08 & 40.08 & 16.78 & 16.78 & 26.78\end{array}$

0.08

$\begin{array}{lllll}8 & 2.13 & 1.17 & 2.27 & 116\end{array}$ $\begin{array}{lllllll}0.08 & 20.08 & 0.08 & 40.08 & 40.08\end{array}$ $\begin{array}{llllll}0.08 & 22.28 & 40.08 & 24.48 & 13.38\end{array}$

0.08

302.301 .24

$\begin{array}{llll}0.08 & 5 & 3.00 & 1.10\end{array}$ $\begin{array}{llllll}0.08 & 35.78 & 35.78 & 10.78 & 17.98\end{array}$

0.08

$\begin{array}{lll}45 & 2.29 & 0.96\end{array}$

$\begin{array}{llll}0.08 & 28 & 2.11 & 1.08\end{array}$

$\begin{array}{lllll}0.08 & 0.08 & 0.08 & 0.08 & 0.08\end{array}$

0.08

$\begin{array}{llllll}0 & 0.00 & 0.00 & 2.83 & 18\end{array}$

$\begin{array}{llllll}0.08 & 0.08 & 33.38 & 33.38 & 33.38\end{array}$

0.08

$\begin{array}{llll}6 & 3.00 & 0.82\end{array}$

$\begin{array}{llllll}0.08 & 0.08 & 0.08 & 0.08 & 0.08\end{array}$

0.08

$\begin{array}{llll}0 & 0.00 & 0.00\end{array}$

$\begin{array}{llllll}0.08 & 0.08 & 16.78 & 33.38 & 50.08\end{array}$

0.08

$\begin{array}{llll}6 & 3.33 & 0.75\end{array}$

$\begin{array}{llllll}0.08 \quad 33.38 & 33.38 & 16.78 & 16.78\end{array}$

$\begin{array}{lll}6 & 2.17 & 1.07\end{array}$ 


\begin{tabular}{|c|c|c|c|c|c|c|c|c|c|c|c|c|}
\hline & & $\underline{0^{\prime} s}$ & 1's & $\underline{2^{\prime} s}$ & $3^{\prime} s$ & $4^{\prime} s$ & $5^{\prime} s$ & $\mathrm{~N}$ & Avg & $\underline{\text { std }} \underline{\mathrm{s}}$ & SMean & SN \\
\hline 35 & WS IMCLR & 0.08 & 0.08 & 37.58 & 50.08 & 12.58 & 0.08 & 8 & 2.75 & 0.66 & 2.94 & 41 \\
\hline 60 & WS IMCLR & 0.08 & 0.08 & 18.88 & 37.58 & 43.88 & 0.08 & 16 & 3.25 & 0.75 & & \\
\hline $93 / 8$ & WS IMCLR & .08 & 0.08 & 0.081 & 100.08 & 0.08 & 0.08 & 1 & 3.00 & 0.00 & & \\
\hline & WS IMCLR & .08 & 18.28 & 18.28 & 45.58 & 18.28 & 0.08 & 11 & 2.42 & 1.19 & & \\
\hline-2 & WS IMCLR & 0.08 & 0.08 & 0.08 & 60.08 & 40.08 & 0.08 & 5 & 3.40 & 0.49 & & \\
\hline & SIMLTG & .08 & 35.78 & 0.08 & 50.08 & 14.38 & 0.08 & 14 & 2.43 & 1.12 & 2 & 85 \\
\hline & WS IMLTG & .08 & 35.38 & 23.58 & 29.48 & $11.8 \%$ & 0.08 & 17 & 2.18 & 1.04 & & \\
\hline $3 / 8$ & WS IMLTG & 0.088 & 0.08 & 0.081 & 100.08 & 0.08 & 0.08 & 2 & 3.00 & 0.00 & & \\
\hline $8-1$ & WS IMLTG & 0.08 & 17.18 & 34.38 & 20.08 & 28.68 & 0.08 & 35 & 2.60 & 1.07 & & \\
\hline $8-2$ & WS IMLTG & 0.08 & 23.58 & 47.18 & 11.88 & 17.68 & 0.08 & 17 & 2.24 & 1.00 & & \\
\hline & TOIS & 0.08 & 0.08 & 66.78 & 0.08 & 33.38 & 0.08 & 3 & 2.67 & 0.94 & 2.71 & 66 \\
\hline 60 & WS IMNOIS & 0.08 & 0.08 & 50.08 & 30.08 & 20.08 & 0.08 & 10 & 2.70 & 0.78 & & \\
\hline $93 / 8$ & WS IMNOIS & 0.08 & 37.58 & 12.58 & 25.08 & 25.08 & 0.08 & 8 & 2.38 & 1.22 & & \\
\hline $68-1$ & WS IMNOIS & 0.08 & 8.38 & 33.38 & 12.58 & 45.88 & 0.08 & 24 & 2.96 & 1.06 & & \\
\hline-2 & WSIMNOIS & 0.08 & 19.08 & 28.68 & 28.68 & 23.88 & 0.08 & 21 & 2.57 & 1.05 & & \\
\hline 35 & WS IMAIRC & 0.08 & 10.08 & 30.08 & 10.08 & 50.08 & $0.0 \%$ & 10 & 3.00 & 1.10 & 2.37 & 13 \\
\hline 60 & WS IMAIRC & 0.08 & 26.78 & 40.08 & 20.08 & 13.38 & 0.08 & 30 & 2.20 & 0.98 & & \\
\hline $293 / 8$ & WS IMAIRC & 0.08 & 25.08 & 25.08 & 0.08 & $50.0 \%$ & 0.08 & 4 & 2.75 & 1.30 & & \\
\hline $268-1$ & WSIMAIRC & 0.08 & 17.68 & 37.38 & 27.58 & 17.68 & 0.08 & 51 & 2.45 & 0.98 & & \\
\hline $268=0$ & WS I & 0.08 & 20.08 & 45.08 & 30.08 & 5.08 & 0.08 & 40 & 2.20 & 0.81 & & \\
\hline 235 & WS I & 0.08 & 0.08 & 0.08 & 100.08 & 0.08 & 0.08 & 1 & 3.00 & 0.00 & 2.80 & 23 \\
\hline 260 & WS IN & 0.08 & 0.08 & 0.08 & 50.08 & 50.08 & 0.08 & 4 & 3.50 & 0.50 & & \\
\hline $293 / 8$ & WS IMLOC & 0.08 & 50.08 & 0.08 & 0.08 & $50.0 \%$ & 0.08 & 2 & 2.50 & 1.50 & & \\
\hline $268-\cdot 1$ & WS IMLOC & 0.0 웅 & 18.28 & 9.18 & 36.48 & 36.48 & 0.08 & 11 & 2.67 & 1.31 & & \\
\hline $268-2$ & WS IMLOC & 0.08 & 20.08 & 20.08 & 40.08 & 20.08 & 0.08 & 5 & 2.60 & 1.02 & & \\
\hline 35 & WSI & 0.08 & 20.08 & 40.08 & 20.08 & 20.08 & 0.08 & 5 & 2.40 & 1.02 & 2.37 & 11 \\
\hline 260 & WS IMAIRQ & 0.08 & 26.98 & 26.98 & 23.18 & 23.18 & 0.08 & 26 & 2.42 & 1.12 & & \\
\hline $293 / 8$ & WS IMAIRQ & 0.08 & 60.08 & 40.08 & 0.08 & 0.08 & 0.08 & 5 & 1.40 & 0.49 & & \\
\hline $268-1$ & IRQ & 0.08 & 31.88 & 13.68 & 34.18 & 20.58 & 0.08 & 44 & 2.43 & 1.14 & & \\
\hline $68-2$ & WS IMAIRQ & 0.08 & 28.98 & 26.38 & 21.18 & 23.78 & 0.08 & 38 & 2.39 & 1.14 & & \\
\hline 235 & KSP & 0.08 & 0.08 & 50.08 & 50.08 & 0.08 & 0.08 & 2 & 2.50 & 0.50 & 2.76 & 54 \\
\hline 60 & KSP & 0.08 & 11.18 & 22.28 & 33.38 & 33.38 & 0.08 & 9 & 2.89 & 0.99 & & \\
\hline /8 & WSI & 0.08 & 25.08 & 0.08 & 50.08 & 25.08 & 0.08 & 4 & 2.75 & 1.09 & & \\
\hline-1 & WS II & 0.08 & 22.78 & 22.78 & 13.68 & 40.98 & 0.08 & 22 & 2.73 & 1.21 & & \\
\hline $68-2$ & WS IMBKSP & 0.08 & 23.58 & 17.68 & 17.68 & 41.28 & 0.08 & 17 & 2.76 & 1.21 & & \\
\hline 230 & URN & .08 & 0.08 & 25.08 & 25.08 & 50.08 & & 4 & 3.25 & 0.83 & 3.11 & 35 \\
\hline 60 & WS IMFURN & 0.08 & 0.08 & 16.78 & 50.08 & 33.38 & 0.08 & 6 & 3.17 & 0.69 & & \\
\hline $93 / 8$ & WS IMFURN & 0.08 & 33.38 & 0.08 & 33.38 & 33.38 & 0.08 & 3 & 2.67 & 1.25 & & \\
\hline $68-1$ & WS IN & 0.08 & 16.78 & 16.78 & 16.78 & 50.08 & 0.08 & 12 & 3.00 & 1.15 & & \\
\hline $68-2$ & WS IMFURN & 0.08 & 20.08 & 0.08 & 10.08 & 70.08 & 0.08 & 10 & 3.30 & 1.19 & & \\
\hline 32 & & - & 0.08 & 0.08 & 0.08 & 0.08 & & 0 & 0.00 & 0.00 & 3.36 & 11 \\
\hline .00 & WS IMCLEN & 0.08 & 0.08 & 0.08 & 20.08 & $80.0 \%$ & 0.08 & 5 & 3.80 & 0.40 & & \\
\hline $293 / 8$ & WS IMCLEN & 0.08 & 0.08 & 0.08 & 100.08 & 0.08 & 0.08 & 2 & 3.00 & 0.00 & & \\
\hline $68-1$ & WS IMCLEN & 0.08 & 50.08 & 0.08 & 0.08 & 50.08 & 0.08 & 2 & 2.50 & 1.50 & & \\
\hline
\end{tabular}




\begin{tabular}{|c|c|c|c|c|c|c|c|c|c|c|c|c|}
\hline $8-2$ & WS IMCLEN & $\frac{0^{\prime} \mathrm{s}}{0.08}$ & $\frac{1^{\prime} s}{0.08}$ & $\frac{2^{\prime} s}{0.08}$ & $\frac{3^{\prime} s}{50.08}$ & $\frac{4^{\prime} s}{50.08}$ & $\frac{5^{\prime} s}{0.08}$ & $\frac{\mathrm{N}}{2}$ & $\frac{\mathrm{Avg}}{3.50}$ & $\frac{\text { Std }}{0.50} s$ & SMean & $\underline{\mathrm{SN}}$ \\
\hline 235 & WS IMTKLT & 0.08 & 40.08 & 20.08 & 0.08 & 40.08 & 0.08 & 5 & 2.40 & 1.36 & 2.72 & 47 \\
\hline 260 & WS IMTKLT & 0.08 & 0.08 & 33.38 & 44.48 & 22.28 & 0.08 & 9 & 2.89 & 0.74 & & \\
\hline $293 / 8$ & WS IMTKLT & 0.08 & 66.78 & 0.08 & 0.08 & 33.38 & 0.08 & 3 & 2.00 & 1.41 & & \\
\hline $268-1$ & WS IMTKLT & 0.08 & 21.18 & 5.38 & 47.48 & 26.38 & 0.08 & 19 & 2.79 & 1.06 & & \\
\hline $268-2$ & WS IMTKLT & 0.08 & 9.18 & 27.38 & 36.48 & 27.38 & 0.08 & 11 & 2.82 & 0.94 & & \\
\hline 235 & WS IMCHAR & 0.081 & 100.08 & 0.08 & 0.08 & 0.08 & $0.0 \%$ & 2 & 1.00 & 0.00 & 2.88 & 25 \\
\hline 260 & WS IMCHAR & 0.08 & 0.08 & 100.08 & 0.08 & 0.08 & 0.08 & 1 & 2.00 & 0.00 & & \\
\hline $293 / 8$ & WS IMCHAR & 0.08 & 0.08 & 50.08 & 0.08 & 50.08 & 0.08 & 4 & 3.00 & 1.00 & & \\
\hline $268-1$ & WS IMCHAR & 0.08 & 0.08 & 22.28 & 11.18 & 66.78 & 0.08 & 9 & 3.44 & 0.83 & & \\
\hline $268-2$ & WS IMCHAR & 0.08 & 11.18 & 33.38 & 22.28 & 33.38 & 0.08 & 9 & 2.78 & 1.03 & & \\
\hline 235 & WSIMDLT & 0.08 & 16.78 & $0.0 \%$ & 33.38 & $50.0 \%$ & 0.08 & 6 & 3.17 & 1.07 & 2.58 & 79 \\
\hline 260 & WS IMDLT & 0.08 & 50.08 & 17.98 & 25.08 & 7.18 & 0.08 & 28 & 1.89 & 1.01 & & \\
\hline $293 / 8$ & WS IMDLT & 0.08 & 0.08 & 33.38 & 33.38 & 33.38 & 0.08 & 3 & 3.00 & 0.82 & & \\
\hline $268-1$ & WSIMDLT & 0.08 & 18.28 & 9.18 & $27.3 \%$ & 45.58 & $0.0 \%$ & 22 & 3.00 & 1.13 & & \\
\hline $268-2$ & WS IMDLT & 0.08 & 20.08 & 5.08 & 45.08 & 30.08 & 0.08 & 20 & 2.85 & 1.06 & & \\
\hline 235 & WS IMSURF & .08 & 0.08 & 50.08 & 16.78 & 33.38 & 0.08 & 6 & 2.83 & 0.90 & 2.87 & 90 \\
\hline 260 & WS IMSURF & 0.08 & 13.08 & 21.78 & 8.78 & 56.58 & 0.08 & 23 & 3.09 & 1.14 & & \\
\hline $293 / 8$ & WS IMSURF & 0.08 & 0.08 & 50.08 & 20.08 & 30.08 & 0.08 & 10 & 2.80 & 0.87 & & \\
\hline $268-1$ & WS IMSURF & 0.08 & 16.08 & 24.08 & 16.08 & 44.08 & 0.08 & 25 & 2.88 & 1.14 & & \\
\hline $268-2$ & WS IMSURF & 0.08 & 19.28 & 26.98 & 19.28 & 34.68 & 0.08 & 26 & 2.69 & 1.14 & & \\
\hline 235 & WSIMOTHR & 0.08 & 0.08 & 0.08 & 0.08 & 0.08 & 0.08 & 0 & 0.00 & 0.00 & 0.05 & 12 \\
\hline 260 & WSIMOTHR & 0.08 & 0.08 & 0.08 & 0.08 & 0.08 & 0.08 & 0 & 0.00 & 0.00 & & \\
\hline $293 / 8$ & WSIMOTHR & 0.08 & 0.08 & 0.08 & 0.08 & 0.08 & 0.08 & 0 & 0.00 & 0.00 & & \\
\hline $268-1$ & WS IMOTHR & 0.08 & 50.08 & 0.08 & 0.08 & 50.08 & 0.08 & 2 & 0.31 & 0.98 & & \\
\hline $268-2$ & WSIMOTHR & 100.08 & 0.08 & 0.08 & 0.08 & 0.08 & 0.08 & 10 & 0.00 & 0.00 & & \\
\hline 235 & LONGWORK & 0.08 & 45.88 & 45.88 & 4.28 & 8.38 & 0.08 & 24 & 1.79 & 0.87 & 2.40 & 309 \\
\hline 260 & LONGWORK & 0.08 & 26.18 & 11.68 & 39.18 & 21.78 & 1.48 & 69 & 2.61 & 1.13 & & \\
\hline $293 / 8$ & LONGWORK & 0.08 & 52.68 & 21.18 & 26.38 & 0.08 & $0.0 \%$ & 19 & 1.74 & 2.36 & & \\
\hline $268-1$ & LONGWORK & 0.08 & 25.28 & 27.08 & 27.08 & 20.98 & 0.08 & 115 & 2.43 & 1.08 & & \\
\hline $268-2$ & LONGWORK & 0.08 & 26.88 & 25.68 & 17.18 & 30.58 & 0.08 & 82 & 2.51 & 1.18 & & \\
\hline 235 & LONGSPAC & 0.08 & 43.58 & 47.88 & 0.08 & 8.78 & 0.08 & 23 & 1.74 & 0.85 & 2.14 & 307 \\
\hline 260 & LONGSPAC & 0.08 & 33.38 & 13.08 & 39.18 & 13.08 & 1.48 & 69 & 2.36 & 1.12 & & \\
\hline $293 / 8$ & LONGSPAC & 0.08 & 52.68 & 21.18 & 26.38 & 0.08 & 0.08 & 19 & 1.74 & 0.85 & & \\
\hline $268-1$ & LONGSPAC & 0.08 & 35.78 & 28.78 & 24.38 & 11.38 & 0.08 & 115 & 2.11 & 1.02 & & \\
\hline $268-2$ & LONGSPAC & 0.08 & 34.68 & 28.48 & 19.88 & 17.38 & 0.08 & 81 & 2.20 & 1.09 & & \\
\hline 235 & WRKIMPT & 0.08 & 0.08 & $4.8 \%$ & 4.88 & 90.58 & 0.08 & 21 & 3.86 & 0.47 & 3.61 & 296 \\
\hline 260 & WRKIMPT & 0.08 & 1.58 & 3.08 & 18.28 & 77.38 & 0.08 & 66 & 3.71 & 0.60 & & \\
\hline $293 / 8$ & WRKIMPT & 0.08 & 10.58 & 15.88 & 21.18 & 52.68 & 0.08 & 19 & 3.16 & 1.04 & & \\
\hline $268-1$ & WRKIMPT & 0.08 & 2.88 & 5.68 & 24.18 & 67.68 & 0.08 & 108 & 3.56 & 0.72 & & \\
\hline $268-2$ & WRKIMPT & 0.08 & 0.08 & 8.58 & 20.78 & 70.78 & 0.08 & 82 & 3.62 & 0.64 & & \\
\hline 23 & JOBSAT & 0.08 & 4.88 & 9.58 & 66.78 & 19.08 & 0.08 & 21 & 3.00 & 0.69 & 3.04 & 295 \\
\hline & JOBSAT & 0.08 & 4.68 & 13.88 & 46.28 & 35.48 & 0.08 & 65 & 3.12 & 0.81 & & \\
\hline
\end{tabular}




\begin{tabular}{|c|c|c|c|c|c|c|c|c|c|c|c|c|}
\hline & & & & & & & & & Avg & $\underline{\text { std }}=$ & Nite at & $\underline{21}$ \\
\hline $3 / 8$ & JOBSAT & 0.08 & 22.28 & 33.38 & 27.88 & 16.78 & 0.08 & 18 & 2.39 & 1.01 & & \\
\hline $8-1$ & JOBSAT & 0.08 & 6.48 & 11.98 & 52.38 & 29.48 & 0.08 & 109 & 3.05 & 0.82 & & \\
\hline $8-2$ & JOBSAT & 0.08 & 6.18 & 13.48 & 42.78 & 37.88 & 0.08 & 82 & 3.12 & 0.86 & & \\
\hline & WRKACR & 0.08 & 76.28 & 19.08 & 4.88 & 0.08 & 0.08 & 21 & 1.29 & 0.55 & 1.38 & 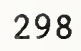 \\
\hline & WRKACR & 0.08 & 70.18 & 28.48 & 1.58 & 0.08 & 0.08 & 67 & 1.31 & 0.50 & & \\
\hline $3 / 8$ & WRKACR & 0.08 & 47.48 & 36.88 & 5.38 & 10.58 & 0.08 & 19 & 1.79 & 0.95 & & \\
\hline $8-1$ & WRKACR & 0.08 & $68.8 \%$ & 29.48 & $1.8 \%$ & 0.08 & 0.08 & 109 & 1.33 & 0.51 & & \\
\hline $8-2$ & WRKACR & 0.08 & 62.28 & 32.98 & 4.98 & 0.08 & 0.08 & 82 & 1.43 & 0.58 & & \\
\hline & EQUIP & 0.08 & 52.48 & 33.38 & 14.38 & 0.08 & 0.08 & 21 & 1.62 & 0.72 & 19 & \\
\hline & EQUIP & 0.08 & 22.78 & 48.58 & 22.78 & 6.18 & $0.0 \%$ & 66 & 2.12 & 0.83 & & \\
\hline $3 / 8$ & EQUIP & 0.08 & 5.38 & 52.68 & 31.68 & 10.58 & 0.08 & 19 & 2.47 & 0.75 & & \\
\hline $3-1$ & EQUIP & 0.08 & 18.28 & 54.58 & 17.38 & 10.08 & 0.08 & 110 & 2.19 & 0.85 & & \\
\hline $3-2$ & EQUIP & 0.08 & 21.08 & 38.38 & 29.68 & 11.18 & 0.08 & 81 & 2.31 & 0.92 & & \\
\hline & JOBTYPE & 9.18 & $31.8 \%$ & 9.18 & 4.58 & 0.08 & 45.58 & 22 & 2.91 & 0.85 & 2.67 & \\
\hline & JOBTYPE & 1.68 & 39.18 & 14.18 & 0.08 & 6.38 & 39.18 & 64 & 2.88 & 0.70 & & \\
\hline $3 / 8$ & JOBTYPE & $0.0 \%$ & 52.38 & 4.88 & 19.08 & 0.08 & 23.88 & 21 & 2.38 & 0.42 & & \\
\hline $8-1$ & JOBTYPE & 0.08 & 44.88 & 9.38 & 16.88 & $1.0 \%$ & 28.08 & 107 & 2.58 & 0.47 & & \\
\hline & JOBTYPE & 0.08 & 45.68 & 10.18 & 10.18 & 2.58 & 31.68 & 79 & 2.64 & 0.54 & & \\
\hline & MILITARY & 68.28 & 31.88 & 0.08 & 0.08 & 0.08 & 0.08 & 22 & 0.32 & 0.47 & 0.33 & \\
\hline 16 & MILITARY & 72.78 & 27.38 & 0.08 & 0.08 & 0.08 & 0.08 & 66 & 0.27 & 0.45 & & \\
\hline$/ 8$ & MILITARY & 73.78 & 26.38 & 0.08 & 0.08 & 0.08 & 0.08 & 19 & 0.26 & 0.44 & & \\
\hline-1 & MILITARY & 62.08 & 36.08 & 0.08 & 0.08 & $2.08 \%$ & 0.08 & 100 & 0.44 & 0.70 & & \\
\hline $2=2$ & MILITARY & 74.48 & 25.68 & 0.08 & 0.08 & $0.0 \%$ & 0.08 & 82 & 0.26 & 0.44 & & \\
\hline & CIVILIAN & 31.88 & 68.28 & 0.08 & 0.08 & 0.08 & 0.08 & 22 & 0.68 & 0.47 & 0.75 & \\
\hline 60 & CIVILIAN & 27.38 & 72.78 & 0.08 & 0.08 & 0.08 & 0.08 & 66 & 0.73 & 0.45 & & \\
\hline $93 / 8$ & CIVILIAN & 22.28 & $77.8 \%$ & 0.08 & 0.08 & 0.08 & 0.08 & 18 & 0.78 & 0.42 & & \\
\hline-1 & CIVILIAN & 26.08 & 74.08 & 0.08 & 0.08 & 0.08 & 0.08 & 96 & 0.73 & 0.44 & & \\
\hline-2 & CIVILIAN & 24.48 & 74.48 & 0.08 & 0.08 & 1.28 & 0.08 & 82 & 0.79 & 0.56 & & \\
\hline & CONTRACT & 100.08 & 0.08 & 0.08 & 0.08 & 0.08 & 0.08 & 22 & 0.00 & 0.00 & 0 . & \\
\hline 60 & CONTRACT & $100.0 \%$ & 0.08 & 0.08 & 0.08 & 0.08 & 0.08 & 66 & 0.00 & 0.00 & & \\
\hline $93 / 8$ & CONTRACT & 100.08 & 0.08 & 0.08 & 0.08 & 0.08 & 0.08 & 18 & 0.00 & 0.00 & & \\
\hline $68-1$ & CONTRACT & 96.68 & 3.48 & 0.08 & 0.08 & 0.08 & 0.08 & 89 & 0.03 & 0.18 & & \\
\hline $8-2$ & CONTRACT & 100.08 & 0.08 & 0.08 & 0.08 & 0.08 & 0.08 & 82 & 0.00 & 0.00 & & \\
\hline 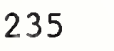 & SEX & 0.08 & 18.28 & 81.88 & 0.08 & 0.08 & 0.08 & 22 & 1.82 & 0.39 & 1.72 & \\
\hline 60 & SEX & $0.08 \%$ & 43.98 & 56.18 & 0.08 & $0.0 \%$ & 0.08 & 66 & 1.56 & 0.50 & & \\
\hline $93 / 8$ & SEX & 0.08 & 26.38 & 73.78 & 0.08 & 0.08 & 0.08 & 19 & 1.74 & 0.44 & & \\
\hline $68-1$ & SEX & 0.08 & 25.28 & 74.88 & 0.08 & 0.08 & 0.08 & 107 & 1.73 & 0.46 & & \\
\hline 60 & SEX & 0.08 & 20.78 & 79.38 & 0.08 & 0.08 & 0.08 & 82 & 1.79 & 0.41 & & \\
\hline 35 & GLASSES & .28 & $45.8 \%$ & $0.0 \%$ & 0.08 & & 0 . & 24 & 0.46 & 0.50 & 0.60 & \\
\hline 260 & GLASSES & 50.78 & 49.38 & 0.08 & 0.08 & 0.08 & 0.08 & 69 & 0.49 & 0.50 & & \\
\hline $93 / 8$ & GLASSES & 47.48 & 52.68 & 0.08 & 0.08 & 0.08 & 0.08 & 19 & 0.53 & 0.50 & & \\
\hline 68-1 & GLASSES & 33.68 & 66.48 & 0.08 & 0.08 & 0.08 & 0.08 & 110 & 0.66 & 0.47 & & \\
\hline $68-2$ & GLASSES & 32.98 & 67.18 & 0.08 & 0.08 & 0.08 & 0.08 & 82 & 0.67 & 0.47 & & \\
\hline
\end{tabular}




\begin{tabular}{|c|c|c|c|c|c|c|c|c|c|c|c|c|}
\hline & & $\underline{0^{\prime} s}$ & $\underline{1 ' s}$ & $\underline{2^{\prime} s}$ & $\underline{3^{\prime} s}$ & $4^{\prime} s$ & $5^{\prime} s$ & $\mathrm{~N}$ & Avg & $\underline{\text { Std }} \leqq$ & SMean & $\underline{\mathrm{SN}}$ \\
\hline 235 & BIFOCALS & $9 \overline{5.78}$ & $\overline{4.38}$ & $\overline{0.08}$ & $\overline{0.08}$ & 0.08 & 0.08 & 23 & $\overline{0.04}$ & $\overline{0.20}$ & 0.21 & $\overline{290}$ \\
\hline 260 & BIFOCALS & 95.78 & 4.38 & 0.08 & 0.08 & $0.0 \%$ & 0.08 & 69 & 0.04 & 0.20 & & \\
\hline $293 / 8$ & BIFOCALS & 84.28 & 15.88 & 0.08 & 0.08 & 0.08 & 0.08 & 19 & 0.16 & 0.36 & & \\
\hline $268-1$ & BIFOCALS & 63.98 & 36.18 & 0.08 & 0.08 & 0.08 & 0.08 & 97 & 0.35 & 0.48 & & \\
\hline $68-2$ & BIFOCALS & 74.48 & 25.68 & $0.0 \%$ & $0.0 \%$ & 0.08 & 0.08 & 82 & 0.26 & 0.44 & & \\
\hline 35 & CONTACTS & 91.38 & $8.7 \%$ & 0.08 & 0.08 & 0.08 & 0.08 & 23 & 0.09 & 0.28 & 0.14 & 287 \\
\hline 60 & CONTACTS & 82.68 & 17.48 & 0.08 & 0.08 & 0.08 & 0.08 & 69 & 0.17 & 0.38 & & \\
\hline $293 / 8$ & CONTACTS & 78.98 & 21.18 & 0.08 & 0.08 & 0.08 & 0.08 & 19 & 0.21 & 0.41 & & \\
\hline $268-1$ & CONTACTS & 87.28 & 12.88 & 0.08 & 0.08 & 0.08 & 0.08 & 94 & 0.13 & 0.33 & & \\
\hline $58-2$ & CONTACTS & 90.28 & 8.58 & 0.08 & 0.08 & 1.28 & 0.08 & 82 & 0.13 & 0.51 & & \\
\hline 35 & LONGLENS & 0.08 & 16.78 & 8.38 & 0.08 & 25.08 & 50.08 & 12 & 3.83 & 1.52 & 4.47 & 201 \\
\hline 60 & LONGLENS & $0.0 \%$ & 5.08 & 2.58 & 7.58 & 7.58 & 77.58 & 40 & 4.50 & 1.07 & & \\
\hline $93 / 8$ & LONGLENS & 0.08 & 7.78 & 0.08 & 0.08 & $7.7 \%$ & 84.68 & 13 & 4.62 & 1.08 & & \\
\hline $8-1$ & LONGLENS & 2.68 & 2.68 & 5.18 & 5.18 & 11.58 & 73.18 & 78 & 4.40 & 1.21 & & \\
\hline $8-2$ & LONGLENS & 0.08 & 1.78 & 1.78 & 5.28 & 12.18 & 79.38 & 58 & 4.66 & 0.80 & & \\
\hline 235 & LONGSICK & 47.88 & 47.88 & 0.08 & 4.38 & 0.08 & 0.08 & 23 & 0.61 & 0.71 & 1.19 & 303 \\
\hline 260 & LONGSICK & 33.38 & 34.88 & 15.98 & 11.68 & 4.38 & 0.08 & 69 & 1.19 & 1.15 & & \\
\hline $293 / 8$ & LONGSICK & 36.88 & 15.88 & 21.18 & 26.38 & 0.08 & 0.08 & 19 & 1.37 & 1.22 & & \\
\hline $268-1$ & LONGSICK & 40.08 & 26.48 & 17.38 & 10.08 & 6.48 & 0.08 & 110 & 1.16 & 1.23 & & \\
\hline $268-2$ & LONGSICK & $26.8 \%$ & 30.58 & 30.58 & 6.18 & 4.98 & 1.28 & 82 & 1.35 & 1.15 & & \\
\hline 235 & AGE & 0.08 & 0.0 용 & 31.88 & $31.8 \%$ & 22.78 & 13.68 & 22 & 3.30 & 1.16 & 3.39 & 296 \\
\hline 260 & AGE & 0.08 & 1.58 & $36.8 \%$ & 29.48 & $23.5 \%$ & $8.8 \%$ & 68 & 3.01 & 1.01 & & \\
\hline $293 / 8$ & AGE & 0.08 & 0.08 & 36.88 & 26.38 & 21.18 & 15.88 & 19 & 3.16 & 1.09 & & \\
\hline $268-1$ & AGE & 0.08 & 0.08 & 22.98 & 29.48 & 28.48 & 19.38 & 109 & 3.46 & 1.07 & & \\
\hline $268-2$ & AGE & $0.0 \%$ & 0.08 & 16.78 & $30.8 \%$ & $30.8 \%$ & 21.88 & 78 & 3.70 & 1.11 & & \\
\hline 235 & OVERTIME & 91.38 & 4.38 & 0.08 & 4.38 & 0.08 & 0.08 & 23 & 0.17 & 0.64 & 0.5 & 284 \\
\hline 260 & OVERTIME & 61.78 & 20.08 & 10.08 & 8.38 & 0.08 & 0.08 & 60 & 0.65 & 0.96 & & \\
\hline $293 / 8$ & OVERTIME & 84.28 & 5.38 & 5.38 & 5.38 & 0.08 & 0.08 & 19 & 0.32 & 0.80 & & \\
\hline $268-1$ & OVERTIME & 66.38 & 16.38 & 12.58 & 4.88 & 0.08 & 0.08 & 104 & 0.55 & 0.88 & & \\
\hline $268-2$ & OVERTIME & 67.98 & 14.18 & 11.58 & 6.48 & 0.08 & 0.08 & 78 & 0.56 & 0.93 & & \\
\hline
\end{tabular}


Appendix C. Suggestions for Changes to the Buildings

Table C1. Reasons for Choice Selection

Air Circulation and Air Quality Comments

$\underline{B L D G} \underline{A i r C i r c} \underline{A Q}$

2351

235

235

235

235

235

2352

2353

260

260

260

260

260

260

260

260

260

260

260

260

$260 \quad 4$

260

260

260

260

\section{Reasons for Choice}

\section{Building 235}

Parts of building has very bad air circulation. Air gets stuffy in the winter time. Because of poor ventilation and circulation smoking can cause problems to those people who are allergic to smoke

2 Recirculation of same old air.

Sometimes air becomes stuffy because there are no windows in area.

So I can be at ease when I do my job.

No ceiling fans or wall fans.

Need more fans.

3 Better breathing.

Better breathing.

Warehouse air circ poor/storage A/C often broke.

\section{Building 260}

Air circulation poor/vent above head/cold or stuffy. Clean or replace the air vents in the ceiling. better air quality should not include being able to smell cigarette smoke

It smelis like an old shoe in here.

1 Air quality very poor; trash comes out of vents. Air not properly filtered; not enough outside air. Air circulation poor; too strong or too weak. temperature and air quality are very poor Stale air.

Too cold in summer; walls added, vents remained. Poor circulation with poor quality \& less filtering. Headaches, etc from stale, smoky, dead air. Air circulation is poor.

2 Air qual terrible; headaches, sore throats/asbestos.

3 Too stuffy. Air quality terrible.

Work demands concentration/less noise/air quality/private.

Improved air circulation fosters concentration on work as opposed to attempts to breathe and long-term health worries. Sus

Would help maintain constant temperature.

smoke hangs in our area

Vents noisy and dirty/lack of air circulation. Much more needed things ie: air and lighting to daily supplies

Poor circulation:air stuffy, headaches, nausea, dizzy. 


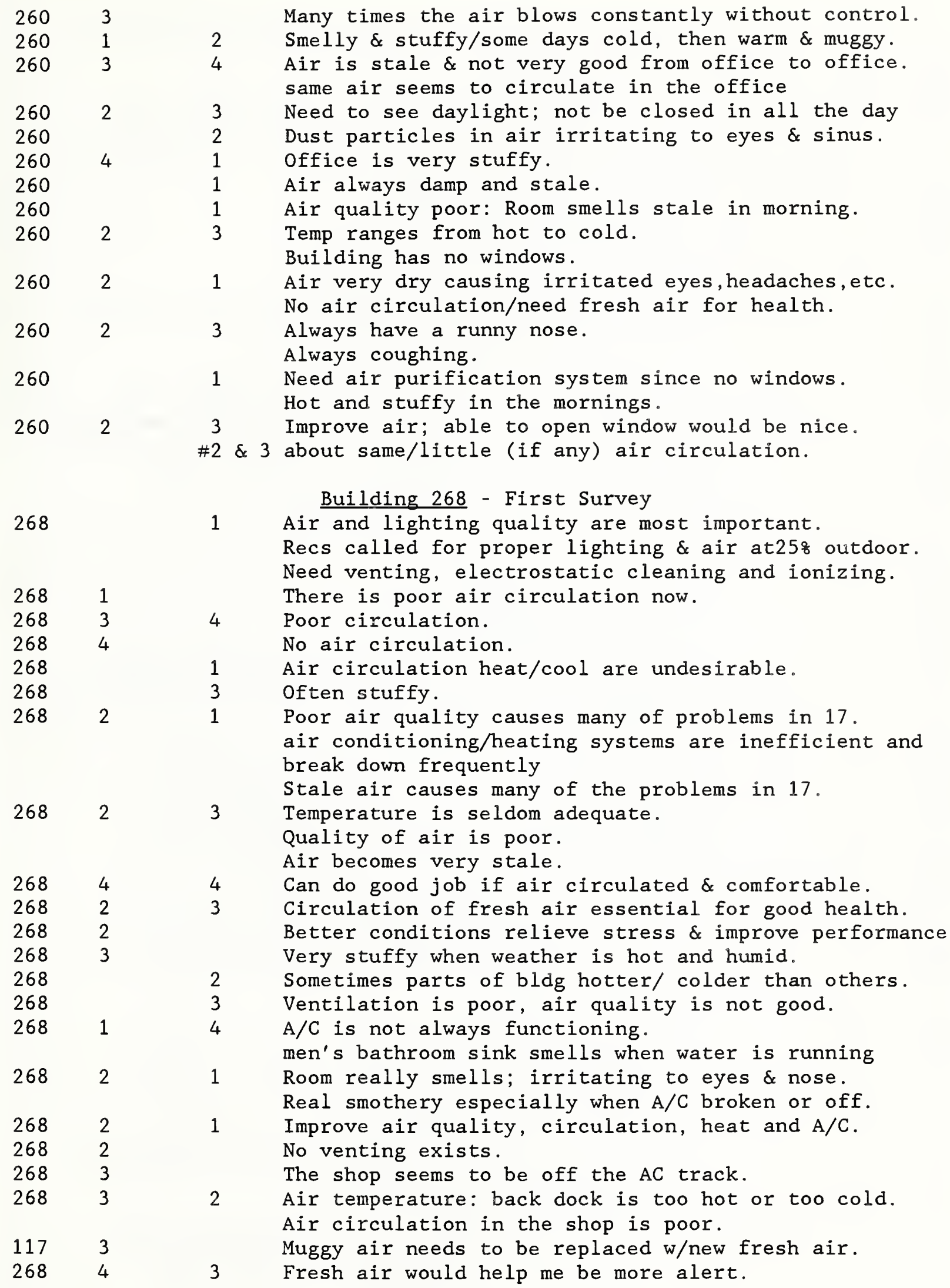


Pollutants such as cigarette smoke can irritate my eyes.

What quality?

$268 \quad 4 \quad 1$

My health.

Ventilation not very good for a maintenance shop. The ventilation is not very good for a maintenance shop.

2681

2682

Too much smoke from smokers.

Chairs are uncomfortable.

Very stuffy at times.

Air is stagnant.

Air is humid causes drowsiness.

Dislike smoking/people smoke in non-smoking areas.

Better the air because of the smoke.

No circulation in room now.

The air is real stuffy and that is uncomfortable.

Air circulation is very poor in this area.

Because of poor circulation we have poor air quality

Provide more fresh air/air is pretty stagnant.

No ventilation in my office.

We need air vents in my office.

I would like better air circulation.

Poor air, often stale.

Air smells stale, cold or hot.

Not allowed to comment.

We need a break area.

Air recirculated/lack of fresh air causes iliness.

The A/C needs cleaning, germs spread in abundance.

Poor air circulation, current ventilating system was designed for the smaller room

Nice to get stale smoke out of the office.

Air stale \& recirculated/ high disease risk.

Would make it easier to tolerate smokers.

Air quality poorest I've ever experienced.

Cold in winter; hot/humid in summer.

No air circulation; hot in summer/cold in winter.

Improve air circulation.

Improve air circulation would lower sick leave.

Need air circulation when 20 people are soldering.

Air is recirculated without adding fresh air.

Smoking.

smoking is obnoxious

Air has been bad for years.

Fans have to be used to properly circulate air.

Air quality needs upgrading.

Air is stale, poor quality.

Stagnant filters need changing.

Stuffy, no windows. No break area exist, therefore smokers tempted to pollute air.

Self explanatory.

Air/temp problems known for years \& nobody acts!

Buildings 293 and 298 


\begin{tabular}{|c|c|c|c|}
\hline 293 & 2 & 1 & $\begin{array}{l}\text { Air seems moldy during summer; aggravates allergy. } \\
\text { Air seems moldy during summer; aggravates allergy. }\end{array}$ \\
\hline 293 & & 1 & Air quality is bad. \\
\hline 298 & & 2 & More comfortable and healthy. \\
\hline $\begin{array}{l}298 \\
\text { area }\end{array}$ & & 2 & $\begin{array}{l}\text { Frequent headaches, fatigue - cigarette smoke. Break } \\
\text { is also smoking area. Not really separate from rest of } \\
\text { building - smoke filters to rest of building. }\end{array}$ \\
\hline 298 & 1 & & Cold in winter/stuffy in summer. \\
\hline 298 & & 1 & $\begin{array}{l}\text { Smoke bothers me and is a health hazard. } \\
\text { Vents are dirty. }\end{array}$ \\
\hline 298 & 4 & & $\begin{array}{l}\text { Ringing of phones, vents, etc. } \\
\text { At times it's a little warm. }\end{array}$ \\
\hline
\end{tabular}

BLDG TEMP $\quad$ REASON

Building 235

2351 Either very hot in summer or is just plain hot.

2351 Poor air circulation/temperatures not maintained.

2351 It's hot in summer and cold in winter.

2351 No exhaust fans.

2351 Need air-conditioning.

2354 Warehouse air circ poor/storage A/C often broke.

2601 Sometimes too warm in building when hot outside.

2603 Adjust temperature to the outside temperature.

2601 Some days it is freezing, others too warm.

2602 Never know what to expect by day or season.

2601 Vents blow air much cooler than needed in summer.

260

260

260

260

260

260

260

260

260

260

260

260 Too cold in summer/walls added, vents remained.

2 Most important.

2 Even temperature/now have drastic change in temp.

4 Temperature fluctuates daily (sometimes hour to hour) - either too hot or too cold - very seldom is there a happy medium.

1 Too cold all the time.

2602 Hot and stuffy in the mornings.

\section{Building 268 Fixst Survey}

2683 Need venting, electrostatic cleaning and ionizing.

2681 Temperature fluctuates. 
1 Temperature is too warm in winter and summer.

1 Temperature in our room is never constant.

1 Temperature is seldom adequate.

4 Can do good job if air circulated \& comfortable.

4 Better conditions relieve stress \& improve performance.

1 Uncomfortable to work when hot and sticky.

2 Temperatures too uneven.

$\mathrm{A} / \mathrm{C}$ is not always functioning.

$3 \mathrm{~A} / \mathrm{C}$ does not reset after power outage.

A/C not effective on hot days.

3 Temp. varies too much between out/indoor \& windows.

3 Improve air quality, circulation, heat and $\mathrm{A} / \mathrm{C}$.

1 Aids concentration.

1 No control: too hot in winter and in summer.

1 The temp makes work impossible.

1 The shop seems to be off the AC track.

1 Air temperature: back dock is too hot or too cold.

$1 \mathrm{~A} / \mathrm{C}$.

3 Fluctuation Terrible.

1 A/C not adequate during summer with all equipment.

1 Much too hot in summer.

2 No circulation in room now.

2 Winter too cold and in the summer too hot.

1 Sometimes it gets very warm or cold in this room.

1 Wide temperature range.

2 Not allowed to comment.

4 We need a break area.

2 Some days are hot and cold days get really warm.

3 Large temperature difference office to office.

2 Never sure about temperature. 85 one day 60 the next.

1 Too hot in summer, too cold in winter.

1 Unpleasant temperatures, both hot/cold.

1 Temperature control is poor.

1 Heater and $\mathrm{A} / \mathrm{C}$ don't work.

1 At desk all day, so temps. critical to comfort.

4 Sometimes you freeze, sometimes you roast. There is no consistency with temperatures

4 Room 316 is very cold in the winter.

1 Air conditioning does not work well.

2 Cold in winter; hot/humid in summer.

No air circulation; hot in summer/cold in winter.

1 Must I be sweaty or be frozen stiff to do my job?

1 Temperature in shop can go from 65 to 95.

1 No temperature controls (too cold year round).

3 One day hot, one day not; need consistent temps.

3 Air/temp problems known for years \& nobody acts!

$$
\text { Buildings } 293 \text { and } 298
$$

$2 \mathrm{~A} / \mathrm{C}$ in summer, heat in winter \& insulation in bldg.

2 Have outside temperature not change so much.

2 The day to day temperatures are not comfortable. 
1 Always cold; need wear sweater when 95 outside.

2 Cold in winter/stuffy in summer.

1 Hot in summer and winter.

Comments About Lighting and Task lighting

$\begin{array}{lll}\text { BLDG } & \text { Lite } & \text { Task L } \\ 235 & 2 & \\ 235 & 3 & 1 \\ 235 & & 2 \\ 235 & 1 & \\ 235 & 3 & \\ 235 & 1 & \\ 235 & 3 & \\ 235 & 4 & \\ 235 & 3 & \\ 235 & 1 & \\ 235 & 1 & \\ 235 & 3 & \\ 235 & & 4\end{array}$

\section{REASON \\ Building 235}

Better lighting, not bright enough.

Proper lighting is essential for reading.

1 Light too bright some tasks/not enough others.

2 To help inside the warehouse.

Lights need rearrangement in some areas.

So I can see to do my job better.

Need more light to see better.

Put lights over work area.

Back corner needs light.

See better.

lighting is poor in a large portion of work area.

Lighting is too bright.

4 need more intense light for review of drawings

260

260

260

260

260

260

260

260

260

260

260

260

260

260

260

260

260

\section{Building 260}

Light is not spread out enough.

Lighting could be improved at our work station; the bulbs aren't replaced as they blow out. Lights are inadequate.

2 Too dim.

Cannot place lighting were needed.

3 Need adjustable light/fixed in wrong place.

Most import.

too dim in some places

2 Task light is a fixed desk lamp.

The overhead lights are in line.

3 You can see better - cause less shadows.

Would better light your immediate work area.

Glare, bright in some places, too dull in others.

3 I don't like dimly lit areas.

I find the lighting very poor.

3 Glare on desk and terminal from overhead lighting.

4 being able to adjust the lighting is a comforting

Lights are old and need to be replaced.

4 My eyes are always irritated.

Would like to adjust glare on screen.

12 Bright fluorescent lights create glare.

Do not have adjustable task lighting.

Building 268

Air and lighting quality are most important.

Recs called for proper lighting \& air at $25 \%$ outdoor

Poor lighting.

3 Lighting produces glare in wrong places.

light hard to focus on work area. 
need brighter lights

3 glare on VDT could be avoided, more light to read. Glare is annoying

Get headache from glare on word processor screen.

1 Adjustable lighting is needed.

So I can read the papers on the desk.

3 Sounds good: I don't have a problem w/ desk lamp. Too much glare - lighting needs to be softer and $c$ Light location is not situated over work areas. I use my eyes constantly. More individual lighting made available. Lighting is poor.

1 My health. It is too dim to do close work on circuit cards.

3 Would like to have a desk light attached to desk.

3 Adjustable to meet the varied work sessions/types. Eyes hurt from lack of lighting/gives headaches.

1 Decrease eyestrain and glare.

Partition work area or provide built-in lighting. Not allowed to comment.

3 Glare on CRT's needs to be eliminated.

3 Proper lighting would help job performance. Bad lighting.

3 Lights too dim and glaring.

Eye strain major production loss when reading/writ I feel the lighting is a bit dim for working.

1 Glare from overhead lights makes VDT work difficult. Glare is tremendous. glare, reflections, printer noise, etc. Lighting does not seem to be adequate.

4 One would think that if one could see what one was one could work faster and accomplish more.

4 good lighting is a must when doing new soldering Lighting is horrible, the glare is very bothersome

4 Lighting directed to area.

2 VDTs need less light/equipment work needs more.

4 No light adjustments.

1 Lights are too far away from work areas.

1 Glare on computer screen.

4 No direct light over desks.

Lighting is good, but not if one has bad vision.

Comments Related to Noise and Space

BLDG Noise Loc Surf REASON

235

2 Reviewing drawings requires more work surface area.

34 So when I'm busy I don't have to listen to them. So I can perform my job easily, in my controlled and organized work space.

2 Very little space. Transformer outside office is very noisy.

3 Can always hear conversations in other areas. 
Only have a desk for reviewing technical drawings. Noise high w/ no real partitions between areas. Building 260

4 More privacy/control conversations. need more desk space

1 Each employee needs his/her own space. To get your work done w/o so many interruptions.

2 Need more room to work/ sometimes use the floors. I work out in full view of everyone in my section keep from people walking around and too close Need own office for more privacy.

3 Phone conversations easily overheard. No space to look at computer printouts. work positions are too crowded

2 There is less than $80 \mathrm{sq}$ ft per person. Hard to concentrate with all the noise/no privacy.

4 Much paperwork is generated through normal work tasks, No desk or table area provided to support this.

2 Job requires spreading out quite a bit of data. Can hear conversations from the entire work area.

1 Most import.

4 intrusion from others distracting while on phone. this would help greatly as everything has to be jam-packed on top of each other and no place to use when using terminal.

4 need more surface area Work demands concentration/less noise/air qual/private. No attempt to lower voices in large area $\mathrm{w} /$ partitions.

4 would help in organizing work

2 No room to review drawings, etc.

1 Not enough area around PC for data input. Impossible to talk w/o entire office hearing.

4 I don't like being interrupted. just not enough room for work

4 bigger table for video display terminal Space the way I need/don't like others around. Too many people coming through disrupting work.

A lot of noise from printers \& humming from terminals. Building 268

2 Desperately need room to lay out trend papers. My particular division is spread out.

4 No room for access to printer or keyboard for PC. Quieter would be better.

4 I am confined in my area and need more working area with the furniture.

3 Need room for ease of looking at drawings.

1 I move table because it's easier to work on.

2 Important for improved work/quality. Could improve work quality. Will be able to concentrate better. Too much outside interference. My health. 


\begin{tabular}{|c|c|c|c|c|}
\hline 268 & 3 & & & 35 people in area w/concrete floors, walls. \\
\hline 268 & 1 & & & Noise from machine shop, phones, conversations, etc. \\
\hline 268 & 2 & & & Cannot concentrate with music playing. \\
\hline 268 & 2 & & & Not sure due to type of work environment. \\
\hline 68 & & & 4 & $\begin{array}{l}\text { to hold drawings, books, and note-pads - } \\
\text { all at the same time }\end{array}$ \\
\hline 268 & & 4 & 3 & $\begin{array}{l}\text { For soldering I need much more room. } \\
\text { I like to work alone without being interrupted }\end{array}$ \\
\hline 268 & & 1 & & Not allowed to comment. \\
\hline 68 & 2 & 3 & 4 & $\begin{array}{l}\text { Tech work easily distracted by noisy environment. } \\
\text { I could use } 1.5 \text { times my alloted work space } \\
\text { and function more effectively. }\end{array}$ \\
\hline 268 & & 4 & & $\begin{array}{l}\text { Area cluttered because of lack of storage area. } \\
\text { So we are stumbling over each other. }\end{array}$ \\
\hline 368 & 3 & & & Plenty of loud noises. \\
\hline 268 & & & 4 & $\begin{array}{l}\text { Restricted work area is cumbersome and a major } \\
\text { hindrance to productivity. }\end{array}$ \\
\hline 268 & & & 3 & Need large surface for viewing prints, manuals. \\
\hline 268 & & & 4 & Area too open (Bull Pen Atmosphere). \\
\hline 268 & & & 4 & benches do not provide enough space \\
\hline 268 & & & 4 & $\begin{array}{l}\text { My office is very crowded and not enough } \\
\text { room for all the paperwork. }\end{array}$ \\
\hline 268 & 2 & & & $\begin{array}{l}\text { Work area much too small. } \\
\text { Too many people in space provided. }\end{array}$ \\
\hline 268 & 2 & 4 & 3 & $\begin{array}{l}\text { People talking can be heard, too small area. } \\
\text { To eliminate noise. } \\
\text { No space for technical drawings for review. }\end{array}$ \\
\hline 268 & 4 & 3 & 2 & $\begin{array}{l}\text { Work area is crowded. } \\
\text { More concentration. } \\
\text { More concentration. }\end{array}$ \\
\hline 268 & 4 & 3 & 2 & $\begin{array}{l}\text { No surface area for work that's required. } \\
\text { with people so close and normal business conducted, } \\
\text { every conversation can be heard which results } \\
\text { in loss of concentration } \\
\text { Everyone is jammed together desk against desk. }\end{array}$ \\
\hline 268 & 2 & & & $\begin{array}{l}\text { Equipment and } A / C \text { noise cuts hearing ability. } \\
\text { Distracted by hall traffic and conversations. }\end{array}$ \\
\hline 268 & & & 1 & $\begin{array}{l}\text { Technical work demands equipment, manuals, etc } \\
\text { together. }\end{array}$ \\
\hline 268 & & 2 & & Jammed in, distracting. \\
\hline 268 & 4 & & & It is too noisy. \\
\hline & & & & Buildings 293 and 298 \\
\hline 293 & 1 & & 4 & $\begin{array}{l}\text { Do less noisy work. } \\
\text { Need more room. }\end{array}$ \\
\hline 293 & 4 & & 2 & Too cluttered. \\
\hline 293 & 3 & & & Noise hurts my ears. \\
\hline 298 & & & 2 & Room between files \& to spread computer listings. \\
\hline 298 & 1 & & & Less distracting. \\
\hline 298 & 4 & 1 & 4 & Too many people - not enough space. \\
\hline 298 & & & 4 & Office is crowded. \\
\hline 298 & & & 3 & \\
\hline 298 & 1 & & 2 & of phones, vents, $\epsilon$ \\
\hline
\end{tabular}




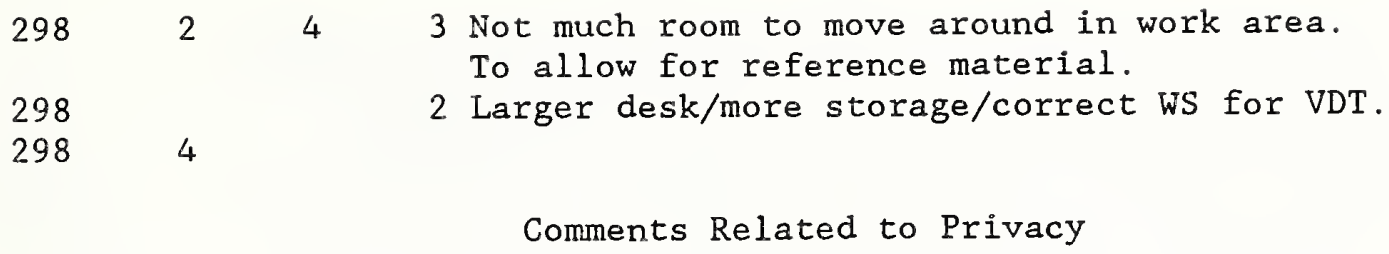

$\underline{B L D G} \underline{\text { Pxivacy }} \quad \underline{\text { REASON }}$

Building 235

$\begin{array}{lll}235 & 1 & \text { Unable to counsel employees effectively. } \\ 235 & 1 & \text { Sometimes it is very noisy in the work area. } \\ 235 & 2 & \text { Partition off work area. } \\ 235 & 4 & \text { Move to an office area. } \\ 235 & 2 & \text { You can hear each others conversation. } \\ 235 & 1 & \text { Can always hear conversations in other areas. } \\ 260 & 1 & \text { More privacy/control conversations. } \\ 260 & 3 & \text { To get your work done w/o so many interruptions. } \\ 260 & 4 & \text { I work out in full view of everyone in my section } \\ 260 & 2 & \text { Need own office for more privacy. } \\ 260 & 2 & \text { Phone conversations easily overheard. } \\ 260 & 4 & \text { There is less than } 80 \text { sq ft per person. } \\ 260 & 1 & \text { Can't concentrate w/conversations going on. } \\ 260 & 1 & \text { Need private area for discussions. } \\ 260 & 2 & \text { Area now occupying lacks adequate privacy/quietness. } \\ 260 & 3 & \text { Intrusion from others distracting while on phone. } \\ 260 & 1 & \text { We need more privacy, there is none. } \\ 260 & 3 & \text { Could be more efficient if we had private area. } \\ 260 & 1 & \text { Work demands concentration/less noise/air qual/private. } \\ 260 & 3 & \text { Impossible to talk w/o entire office hearing. } \\ 260 & 1 & \text { I don't like being interrupted. } \\ 260 & 4 & \text { need to be treated more like adults and be trusted } \\ 260 & 3 & \text { Space between desks, but find little privacy. } \\ 260 & 1 & \text { Open area. } \\ 260 & 2 & \text { Too many people coming through disrupting work. } \\ 260 & 1 & \text { Work in hectic office. } \\ 260 & 4 & \text { everybody likes privacy } \\ 260 & 4 & \text { we need more partitions for better concentration and privacy } \\ 260 & 4 & \text { there is no conference room } \\ 260 & 4 & \text { partitions are old and not tall enough } \\ 260 & 2 & \text { Branch chiefs require some privacy. } \\ & \end{array}$

Building 268

2682 sometimes hard to concentrate in open space.

2683 Quieter would be bettex.

2683 Better working conditions, relieve stress.

$268 \cdot 2$ Partitions do not isolate outside noise.

2681 Most important for improved work/quality.

2682 Open office space - too much distraction.

2682 Aids concentration.

2682 Too wide open for privacy. 
4 Distracted by people walking pass desk, no place in shop to hold private conversation (counseling) with coworkers.

3 Open area/everything is subject to anyone's eyes.

3 Partition work area or provide built-in lighting.

4 While I am on the phone and in general

2 Personnel walking around.

1 Tech work easily distracted by noisy environment.

3 Too confined.

2 Lack of privacy makes the job difficult for supervisors.

2 No privacy.

2 Privacy for better concentration \& productivity.

3 Work area near a door, so constant interruptions.

1 Area to open (Bull Pen Atmosphere).

2 Too many nosy people.

2 Can't talk on the phone without being interrupted.

1 Work area much too small.

1 Everybody hears each other's conversations.

1 No place to have private conversation.

1 More concentration. Work Area is crowded

1 Office is too small for the number of people.

3 Distracted by hall traffic and conversations.

3 Contractors can at various times overhear discussions.

2 Too many people in one room.

3 There is no privacy currently.

4 No conversation/written material personal. Everyone hears $\&$ sees everybody's business. Too close/no divided workspace Buildings 293 and 298

\section{Too cluttered.}

4 There is very little privacy.

4 Less distracting.

3 A problem only when 2 /more conversations at once.

1 For better concentration.

\section{Comments on Windows and Access to Outside}

\section{$\underline{B L D G} \underline{A C C}$ Day $\underline{R E A S O N}$}

\section{Building 235}

235

Never had a job without windows; feel closed in.

4 good views from one's workplace stimulates productivity and can increase thinking ability.

3 It would be nice to have windows.

4 Sometimes air becomes stuffy because there are no windows in

4 Let sun shine in.

1 We need windows.

\section{Building 260}

3 Put window in.

1 Add windows: sunshine healthy/see weather.

2 Would like to know weather via window.

3 Building feels like a prison:there are no windows!

1 No windows cause jail-like feeling while working.

41 Reassure myself that the world is still out there. 
it is important to get outdoors and exercise in order to get a break from the routine and compensate for a relatively sedentary job.

3 Windows beneficial to morale, quality of life.

1 Building has no windows.

3 Outside covered area for lunch/no time go to club.

4 I think a view of the outside will be stimulating and will alleviate some of the gloom inside.

41 Need to see daylight \& not closed in all day.

1 Feel boxed in: would like view outside \& sunlight.

1 Office is like a cave.

2 Self-explanatory.

2 Would like windows. Closed in all the time.

Building has no windows.

1 Don't like to be cooped up with no outside view.

3 Attitudes would be different if we could see out.

2 Would like see out/like being buried 8 hrs a day.

1 No windows.

3 Need air purification system since no windows. There are not windows.

1 Improve air; able to open window would be nice.

1 No windows.

\section{Building 268}

4 There is poor air circulation now.

3 No windows to look out.

Need windows or plant lights - plants give the office a comfy/homey look.

32 There are no windows in the building.

no break areas at the moment

4 No sunlight is depressing \& detrimental to health.

Circulation of fresh air essential for good health.

2 Personal feeling.

4 Isolation is not stimulating to the work area.

34 Variety.

3 Anything better than off-white cinder blocks.

3 Would be nice to have.

2

Building has no windows.

4 Would be nice

Building is drab \& boring, especially since there are no outside windows.

4 I know that time is passing with the changing of outside.

1 A view from a window is very relaxing/stimulating.

4 I've got to see the sunshine

4 Sometimes it gets very warm or cold in this room.

4

We need a break area.

1 Would be nice to see outside w/daylight.

4 There is none on this side of building

4 I sometimes feel I am in a prison.

3 Would be relaxing, nice to see. There are no windows at all.

3 In building w/o daylight gives low morale, fatigue.

3 more reliable 

4 Need windows in back wall - view of fields outside.
3 A break from the routine.
2 Need more windows.
1 It is good to be able to get away for lunch.
More professional looking rooms/improves attitude.

Comments about Color, Break areas, Cleaning

\section{$\underline{B L D G}$ Colr Break Clean $\underline{\text { REASON }}$}

\section{Building 235}

235

235

235

235

260

260

260

260

260

260

260

260

260

260

260

260

260

260

$260 \quad 2 \quad 3$

260

$260 \quad 4$

Don't have a break area.

The walls in the work area are in need of painting. Need all.

Change yellow to bright blue.

Building 260

With no windows, picnic table w/ shade desirable. The work area looks drab/ paint on walls looks old. Need lobby for break areas.

Break area poor/Would like room without smoke.

Colors are glaring white/hospital green, \& peeling.

One break area, but too far for some offices.

Blocked in feeling due to cubicle arrangement.

4 not more frequent, more complete cleaning

Replace furnishings w/modular styles \& imp colors.

4 very dusty/dirty area

The break area is not good.

the walls are white and gray, prefer warm soft colors

Hallways and offices haven't been painted in years. there is little room for lunch and breaks.

The carpet has never been cleaned - it is stained and ugly.

it's been a while

carpet is old and worn

Lights are old and need to be replaced.

More colorful walls would be pleasant to look at.

It would be nice to have a non-smoking break area.

4 Cafeteria should at least be upgraded.

Management doesn't care how it looks until high

ranking people come through.

3 Floors and walls are very dirty.

drab colors/ no carpet/ old furnishings

Building 268

The walls are dirty and area made of concrete.

No break areas at the moment.

No break areas or places to eat lunch.

Better conditions relieve stress \& improve performance. need a break area so if we bring our lunch we have somewhere other than our desk to eat it at.

We don't have a specific break area. 


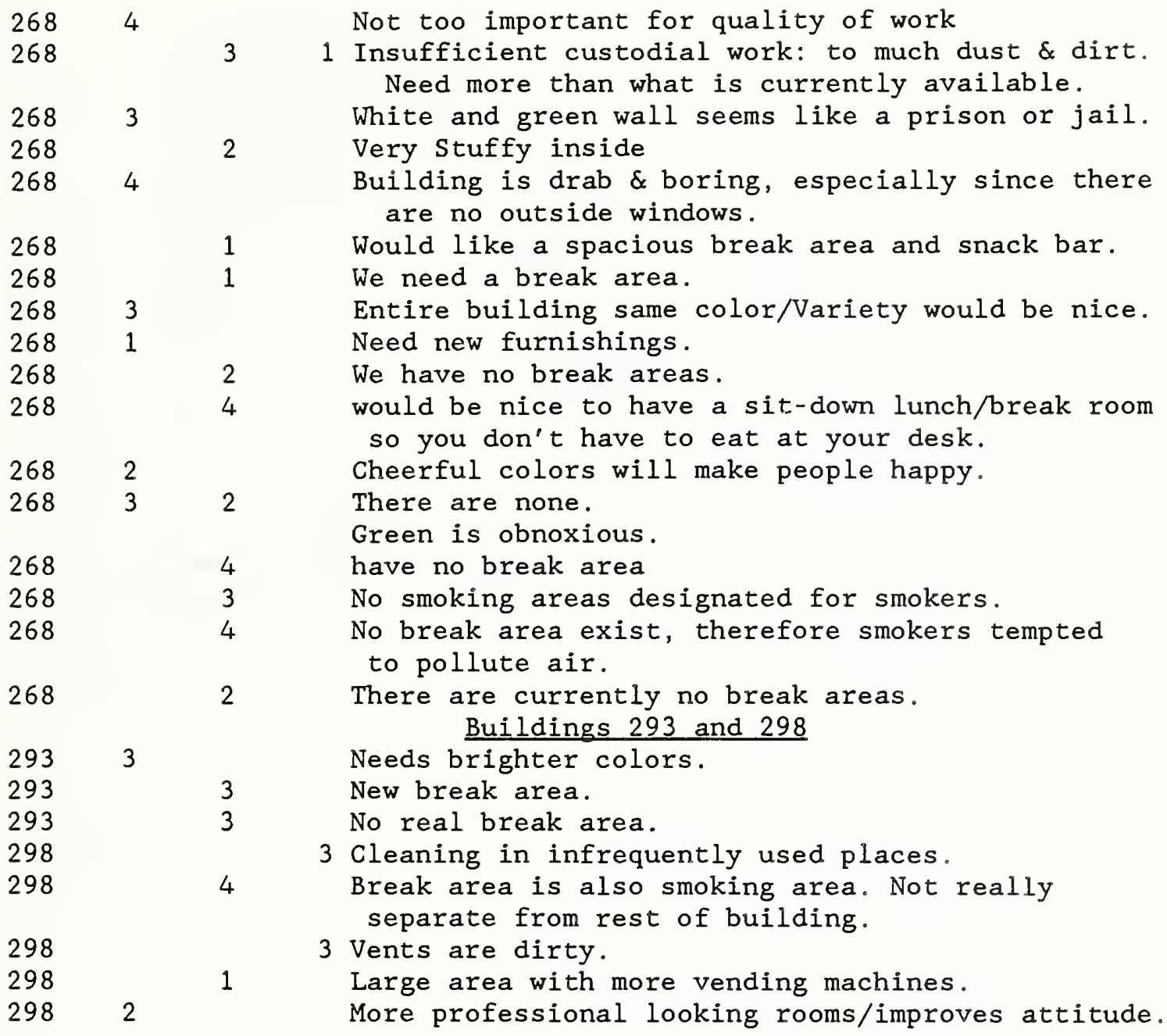

Comments Related to Chairs and Furnishings

BLDG Furn Chair Reason for Choice

\section{Building 235}

2353 To help inside the warehouse.

2351 Need more chairs.

2604 furnishings are old and almost worn out

2604 furniture is old but adequate

2602 Temperature varies too much.

26032 Chairs too old.

partitions are old and not tall enough

2682 The chairs do not adjust.

2684 Chairs either too high or too low,

Not enough back support, not well cushioned

2684 the items we have are fairly old

2681 Furniture is old - does not match. 


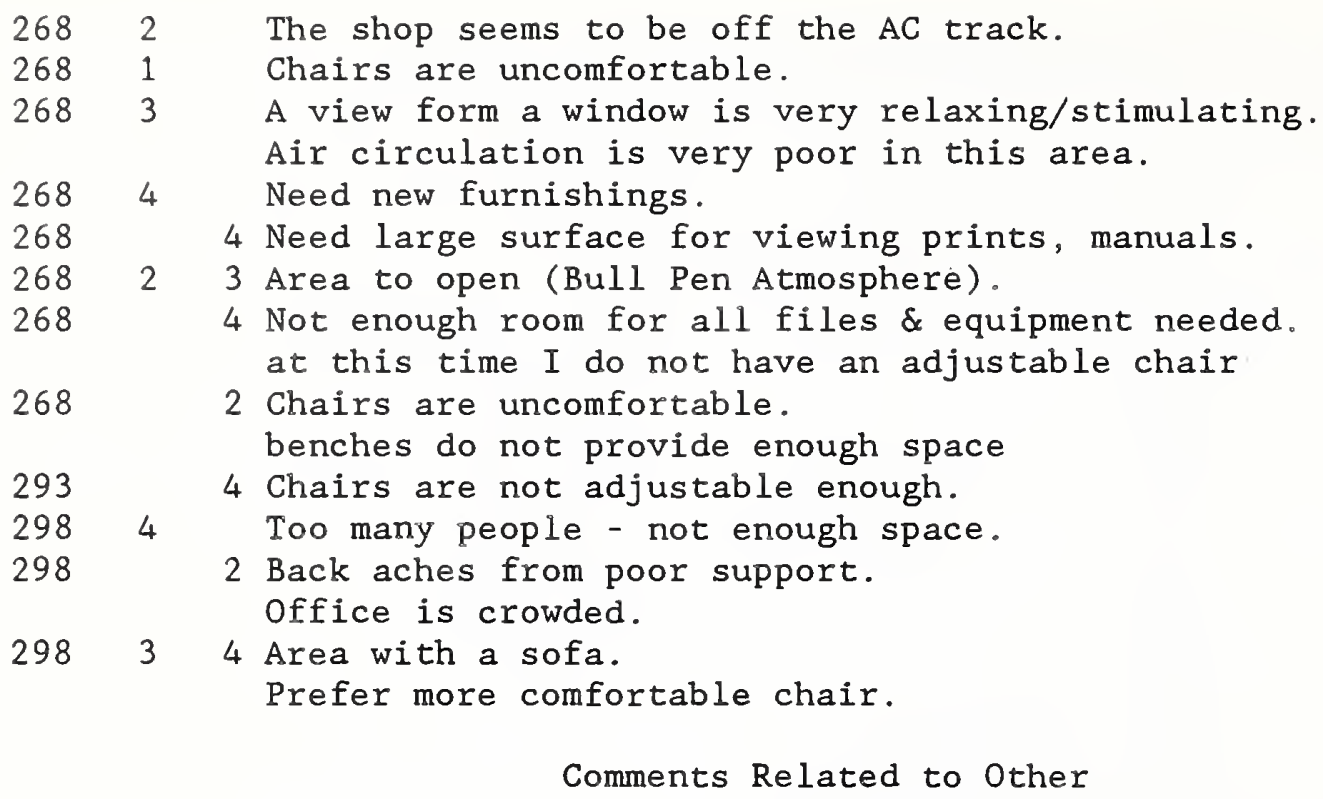

Building Comments and Reasons

$235 \quad$ Smoking

\section{Building 235} cause

because of poor ventilation and circulation, smoking can

problems to those that are allergic to cigarette smoke Classes on teamwork. No smoking

I don't like smoke; it stinks, irritates my eyes, and gets on my clothes Better work condition.

Air qual terrible/headaches, sore throats/asbestos. Could be more efficient if we had private area. Building 260

Less crisis management.

Cafeteria should at least be upgraded.

management doesn't care how it looks until

high ranking people come through

260 More room for expansion.

Branch chiefs require some privacy.

Concern about utility of modular furniture

\section{Building 268}

268 Location between staff. My particular division is spread out.

Have 4 blank walls with command (Post Commander)

not letting us put up pictures or drapes. Windows. Circulation of fresh air essential for good health. No smoking anywhere. Smoking policy is flawed. Storage area. So we are stumbling over each other. Healthier work environment. The A/C needs cleaning, germs spread in 
abundance. The building has a high mold/mildew problem; new carpet and painting without proper ventilation causes more illness. More room. Too confined.

More phones. Only 2 lines available for 12 people, who must coordinate with contractors around the U.S. Access to Autovon is almost non-existent.

268 Place for VDT/printers. Glare, reflections, printer noise, etc. Increased professional attitudes. Too many nosy people. More file space.

268 Telephones. more reliable

298 More telephone lines.

298 Improvements in atmosphere. To relax; greater space for more frequent meetings to discuss procedures and problems weekly 298 New management.

298 Uneven hallway floors; Very dangerous to have uneven floors. Paved parking lot.

268 Storage area. Not enough room for all files \& equipment needed.

268 Improved management technique by supervisors

298 Get rid of unnecessary correspondence. 
Data Collected in January 1989 for Building 268

After the Rennovation

Choices Related to Air Quality and Air Circulation

\section{AirC AQ Reason for Choice}

Rank Rank

$2 \frac{1}{1}$ No way to get away from smoke.

2 Better control for $\mathrm{A} / \mathrm{C}$.

32 Bad air; not enough fresh air added. Drafts.

3 Need window for fresh air, cigarette smoke bothers.

12 Fumes (electronic/maintenance shop) enter air vents.

Fumes (electronic/maintenance shop) enter air vents.

34 No air circulation. Poor air quality.

34 Circulation not very good. Sinuses act up halfway through the day.

34 New furniture restricts air circulation even more.

1 Reduction of allergies/related problems.

3 Poor air quality.

1 Stuffy air causes fatigue and eye irritation. Feel overly ill because too warm ( $\&$ stuffy air).

23 No air condition; hot in summer. Heat drawn out of building in winter.

4 Secondary air ventilation poor, esp in paint mixing.

1 Air quality. extremely poor.

14 Eliminates need for fans; too hot in summer, too cold in winter. Very stuffy.

12 Employees less productive. Funds used poorly; even less ventilated than before.

$4 \quad$ Old system needs replacement.

1 Air stale; ducts contain bacteria.

34 Frequent changes in heat (winter) A/C (summer). Air circulation poor; causes dry throat.

21 Very little/no fresh air. No circulation of air.

32 Air stuffy; room does not get much air. Need air circulation to alleviate stuffy feeling.

12 Air forced directly on person and work. System picks up outside odors.

2 Uncontrollable.

1 Air quality cause of colds/flus; multiple systems not good.

3 Partitions should be arranged according to A/C.

2 Smoke gets into shop.

32 Air stale in the morning. A/C \& heat regulation very poor.

1 Air is stuffy and very dusty. Place is very drafty.

1 Too many people in room at times; office totally open.

21 Air quality poor due to concentration of cigarette smokers; an effective air filtration/circulation system should be installed to minimize irritation \& obnoxious smells from cigarettes.

4 Air makes one tired; no fresh air.

$\begin{array}{lll} & 2 & \text { Air quality has direct effect on ability to perform. } \\ 2 & 1 & \text { Too many common illnesses (flu)/complaints (stuffy). }\end{array}$ Irritated eyes/headaches. 
21 Air quality terrible. Air circulation terrible.

3 Air stuffy.

2 Recommend air cleaners/smoke grabbers be provided.

23 No air circulation right now. Horrible air quality; cigarette smoke lingers.

21 No windows, fresh air would be great. Always stuffy.

2 Room hot \& humid in summer, hot \& dry in winter.

2 No air circulation.

4 No smoking policy not enforced. Smoke makes air quality poor.

24 Same air circulated all day; easy to get sick. Stale air due to closed room.

1. Too many people sick - bad air.

32 Vent/ducts never cleaned - poor air quality. Room air stale or air blasts too hard; causes colds. Too many smokers; non-smoking areas not enforced.

Choices related to Temperature

\section{Temp Reason for Choice}

Rank

3 Too hot in summex, too cold in winter.

3 Large differences in temperature.

1 Poorly controlled temperatures.

2 Temperature either too cold or too hot.

1 Room temperature fluctuates.

1 Office freezing in winter.

2 Feel overly ill because too warm (and stuffy air).

3 Too hot.

1 No air conditioning; hot in summer. Heat drawn out of building in winter.

1 Maintenance work demanding \& too hot.

3 Too hot in summer, too cold in winter.

1. Frequent changes in heat (wintex) $\mathrm{A} / \mathrm{C}$ (summer). Heat and $\mathrm{A} / \mathrm{C}$ should be sane temperature year-round.

3 Temperature fluctuates; too hot/too cold.

1 Uncontrollable.

4 System unable to balance itself in spring/fall.

3 Too hot in summer/too cold in winter.

2 Usually too cold in winter.

1 Heat in summer oppressive, not well regulated.

3 Place is very drafty.

3 People sluggish if too warm.

1 Never know temperature in advance.

1 Should have consistent temperatures.

3 Too hot/too cold.

1 Room hot \& humid in summer, hot \& dry in winter.

1 Either too cold or too hot.

3 No heat in office.

3 Room at about 65 degrees, 428 humidity, with drafts.

1 Temperatures never comfortable - too hot or cold.

Choices related to Lighting and Task Lighting 


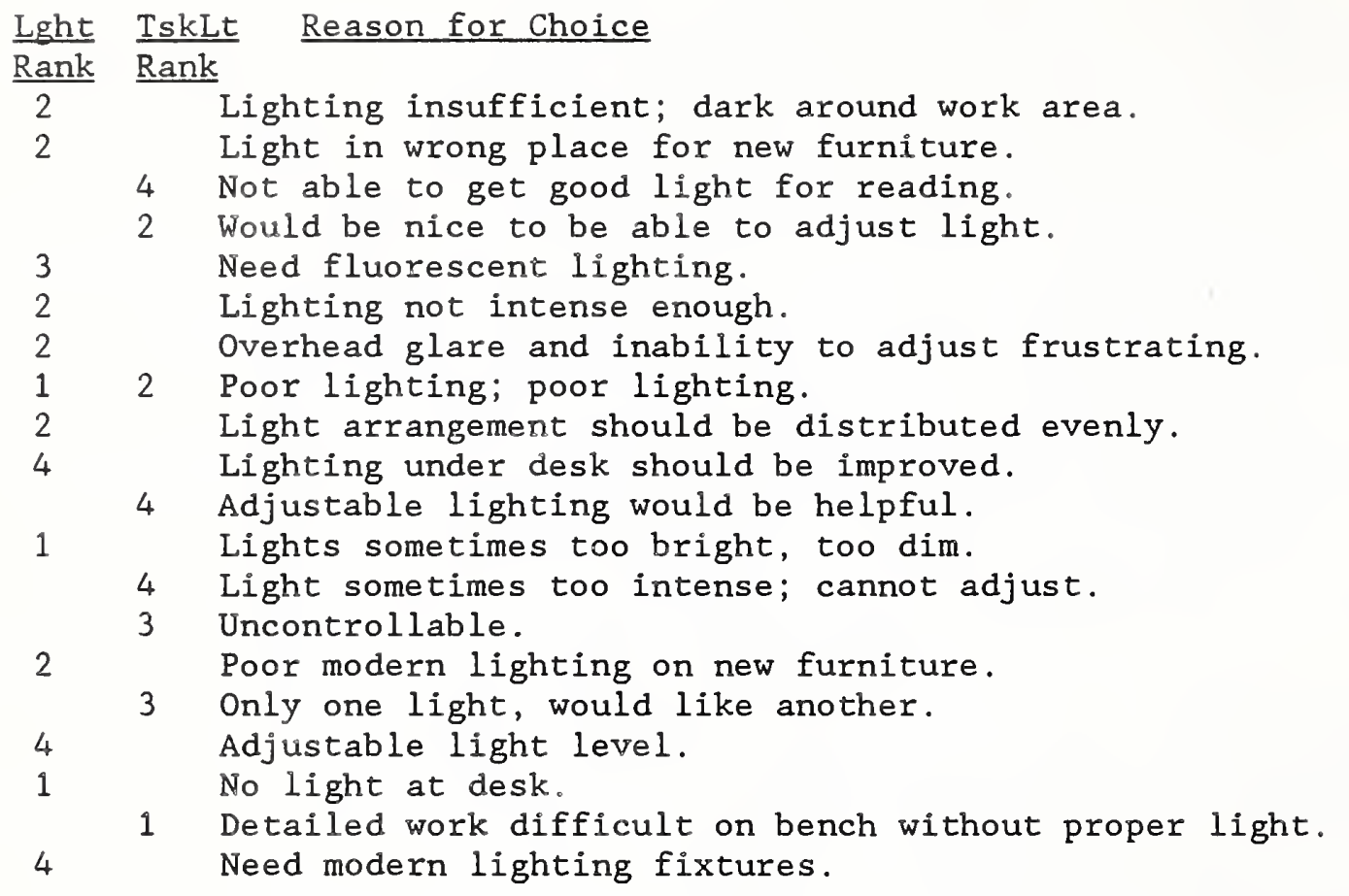

Choices related to Noise, Location of Others and Surface Area

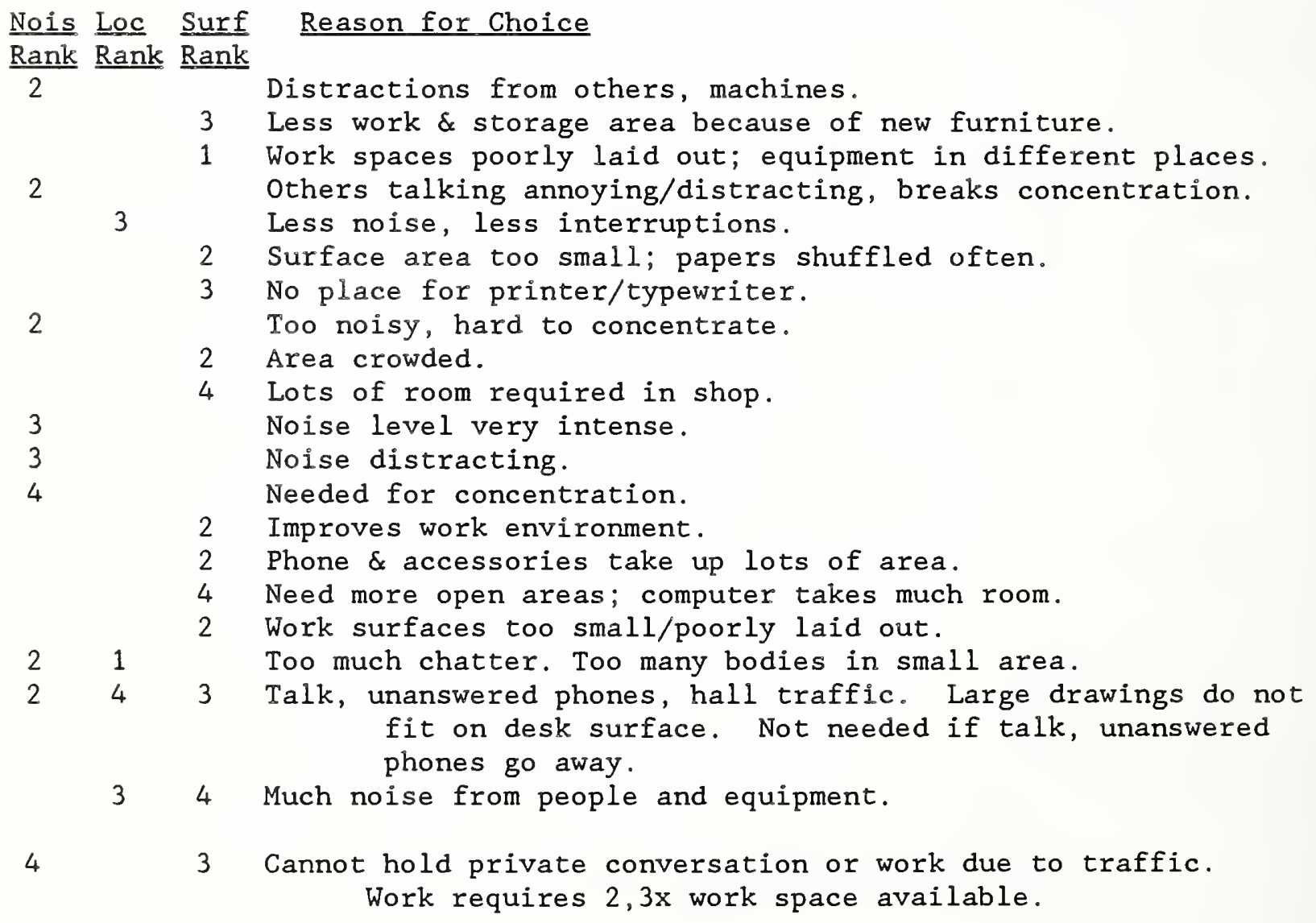


4 Too crowded at workbench.

1 Equipment takes up too much space.

Many people waste time by talking at bench. Too much noise from telephones/conversation, etc.

2 Need more space for terminals \& spreadsheet analysis. Conversation heard through walls, many people in office.

4 Obnoxious smells from cigarettes.

1 Need more space to spread out work. Driven nuts by printer in cubicle. Noise level is obnoxious.

4 More privacy $=$ less distractions. Not enough storage space.

1 No room on desk to do work. Nowhere to store work/equipment. Better concentration. Nothing to cut noise from other people.

2 Very poor work area.

Choices Related to Privacy

\section{Priv Reasons for Choice}

$\underline{\text { Rank }}$

Better concentration in seclusion. Distractions from others, machines.

Very crowded - no privacy.

More privacy to work.

Others talking annoying/distracting, breaks concentration.

High traffic area.

Often distracted.

Too many distractions; encourages b.s. sessions.

Needed for concentration.

Some stations too open.

Too many bodies in small area. Too much chatter.

Talk, unanswered phones, hall traffic.

Cannot hold private conversation or work - traffic.

Sometimes privacy needed to talk with employee.

No privacy exists.

Work better in confined area. Many people waste time by talking at bench.

2 Too many people in room at times. Office totally open.

1 Isolation necessary sometimes.

4 Too many bozos running around the area.

2 People in other cubicles can hear all.

3 More privacy = less distractions.

4 No privacy to talk.

4 Better concentration.

Choice

Choices Related to Daylight and Access Outside

Acc Dylt Reason for Choice

Rank $\underline{\text { Rank }}$

1 Cannot see outside - feel bored, confined,irritable.

4 No windows.

2 No place to go (outside).

3 Absence of sunlight depressing.

1 Would like to see daylight. 
Makes work are seem more spacious.

Employees less productive.

Need better view.

No outside view throughout day.

4 Uncontrollable.

3

No windows cause depression; need access.

3 No windows.

3 Office too confining.

3 No view.

1 Outside view helps morale.

2 Eyes need to rest; want to see outside.

1 Need break area with exposure to outside and place to relax/break.

4 Improves work attitude to see outside.

3 Personal preference.

3 Need outside light and view.

$4 \quad$ No windows, fresh air would be great.

3 Would be nice to be able to see outside.

Choices related to Color, Break Areas, and Maintenance

\section{Colr Brk Clean Reason for Choice}

4 Office too drab, no carpet.

1 No break area because not funded.

4 No break area.

$4 \quad$ Need break area.

1 No break area other than coffee pot area.

3 Drab.

3

Makes work area seem more spacious.

3 Dusty - cleaned during work hours.

3 Must use designated smoking areas.

2 No break areas available.

4 Smokers should get own area.

1 Don't like to leave building when too hot/cold.

4 Break area just part of shop.

4 Cleaning done by self.

3 No break area now; want to see view.

2 Need break area with exposure to outside and place to relax.

4 No break area for civilians.

4 More colorful workplace contributes to productivity.

3 No break areas presently.

Choices Related to Furnishings and Chair

\section{Furn Chair Reason for Choice}

\section{Rank Rank}

\begin{tabular}{|c|c|c|}
\hline & 4 & Must sit most of day. \\
\hline 3 & 4 & Chairs/accessories do not match new furniture \\
\hline & 3 & Back aches due to poor design. \\
\hline & & Need new chairs; present ones 8 yrs old. \\
\hline & & Chairs uncomfortable. \\
\hline & 1 & Chair uncomfortable. \\
\hline & & Makes work are seem more spacious. \\
\hline & & Chairs uncomfortable. \\
\hline
\end{tabular}


43 Need ergonomic chair.

Desks and storage too confusing.

4 Adjustments to desk tops should be easier.

12 Chair and desk are uncomfortable.

Chair is stiff.

2 Height of workbench chairs should move up \& down.

Other Choices

Rest are about equal.

More employee space, work area, etc.

Less tense atmosphere/more cooperation.

Less interruptions, rearrange workstations.

Larger rooms to work in.

Prohibit smoking and enforce it!

Printer space for computer.

More storage area.

Limit smokers.

Smoke-free environment. 
Changes to Lighting

\section{Bldg. $\quad$ Comment}

First Survey

A little brighter.

235 Yes, in the warehouse.

235 Put in more lights as needed.

235 Add more lights.

Put lights over work equipment in shop and office. Back corner needs lights. Dim the lighting. Need more even light/not all the light in one spot No, lighting is excellent. I would put another bulb in (blown since Dec). Something done about replacing lamps at work station. I could use a light at my desk. Add additional lights. Adjustable task lighting/less overhead lights. Arrange work stations to meet lighting arrangement Double amount of ceiling fixtures. Several areas need better lighting. Replace light covers. More suitable lighting fixtures attached to work station. I'd like to have my work station light repaired. Would be nice to be able to get lights for work station. More concerned about air quality. Distribute the light more evenly. Have the lamps that come with workstation fixed. Better availability of replacement "desk" lights. Fix the desk lights/get desk lamps.

Bulbs burned out or nowhere to plug them in. Move VDT: glare from overhead lights. Brighter bulbs. Brighter. Lights are always breaking (old \& need replacing). Cut out shadows. Cut out the glare. Repair light on desk (requested six months ago). Glare on terminals, screens. Too much glare on the terminal, irritates eyes. Install soft fluorescent bulbs. Ceiling "day" fluor w/better orientation; desk lights. Reduce glare. Need additional lights. Indirect lighting for VDT; more light for reading. Desk lamp, glare guard over computer screen. Reduce glare.

Increase slightly.

268 Change lighting to get rid of glare on screen. 
Light directly over the desk; VDT glare guard.

Table lights - reduce ceiling light glare.

Relocation of ceiling lighting/desk lamp.

BLDG Changes to Lighting - Building 268 - Jan 89 
Place lights such that no shadow falls on desk. Add light diffuser, change to non-fluorescent lights. More ceiling \& work area light. Direct light towards work space. More lighting needed.

268 Put light under counter top.

\section{Comments about Equipment}

BLDG Equipment Change

235 Modernize.

235 Update with newer state of the art equip.

235 Larger work surface area, more computer software, redesign lighting.

235 Get programs so we can use our computers at each location instead of very few locations.

260 Better access to VDT. 
Get better equipment so that each employee has his/her own. Newer equipment.

260 Computer gives me trouble; breaks down all the time, I need to do my work.

260 I would update the equipment; it's too old and out of date.

260

260

260

260

260

260 Get a more modern machine that operated more than half the time. Get new computer terminals and desks for them. PC at every work station.

Replace phone system. Replace air handling equipment. Upgrade phone system/equipment, modularize desks and work areas. Make equipment more available.

Update phone switchboard and trunk lines, new phones (merlins) are terrifc, trunk lines generate a lot of cross talk especially when raining.

260 We need more room for our computer terminal.

260 Improve computer system.

260 Better automation and more training.

260 More dependable ADP system.

260 Get new computers and workable telephones, more lights and more comfortable chairs.

260 Get more up to date equipment.

260 I'd like to have my own VDT instead of having to share.

260 Need more desk area to work on.

260 Install reliable PC in place of terminal and improve reliability of all software.

260 Obtain the proper furniture for my PC equipment.

260 Would have training on equipment - instead of whatever you can pick up.

260

260

260

260

260

260

260

260

260

260

260

260

260

260

260

260

260

260 Buy more PC's etc., new work stations, better phones.

Get updated to at least 1960.

Faster, more efficient.

Update and improve computer terminals and system.

I would prefer to have a personal computer instead of terminal.

Get better more efficient equipment.

More speed on the VDT.

Updated computer system and better lighting system.

Task station is large enough but not the design I need for work I do. More handy.

Improve computers.

New furniture.

Change computer system.

Chairs should have clear padding to roll on to protect carpeting.

Get an optical character reader.

Upgrade computer system.

Screen glare.

Improve response time on the main computer.

268 Provide materials to meet the needs. Never enough pens, pencils, paper, copy machines out of order \& limited reference material (technical/other) non-existent or out of date; and archaic telephone capability; needs changed.

268 Reduce glare, change lighting; Need space for safes, etc.

268 My own PC. 
268 New/acquire ADP Equipment \& Software. Need to do a massive overhaul in replacing \& acquiring $A D P$ equipment due to requirements of statistics and extreme shortage of manpower.

268 Have furniture that matched in design. More modern software for my PC. Better brand PC.

268 Proper software for VDTs and adequate general office supplies, rearrange furniture for more efficient use of it.

268 Change typewriter from Olivetti to IBM.

268 Find the intermittent fault in my PC.

268 Buy more software.

268 Replace older PCs with newer ones with higher resolution screens

268 Need new printer.

268 Install vacuum tubes for distribution.

268 Better choice of ADP equipment and software.

268 Update if possible.

268 Get same new equipment for the welders.

268 Update old machines.

117 Buy better and more modern equipment.

268 I think the modular furniture will be an improvement.

268 Have the rules on procurement of Pc's eased so it would be easier to get good automation.

268 Have the wp in more light area.

268 Get new test equipment and cables.

268 Replace it with new equipment.

268 Make it from this decade.

268 Newer equipment.

268 Get better soldering stations. Get some up to date test equipment.

268 Update the antique equipment.

268 Have the basic supplies we need to do our work.

268 Get a letter quality printer.

268 Bring up to current standards/technology.

268 Update it with equipment that the market uses today or as close as possible. Our antique stuff just doesn't cut it.

268 Better desk and computer stand, book shelves.

268 Update the equipment that work with in supply.

268 Provide equipment that work properly.

268 Move moderate and increase quantity of reference storage equipment.

268 Scrap the 1800 stuff and get 1900.

268 Keyboards should be located on office furniture designed for such use.

268 Telephones need a lot of work.

268 Get more up to date equipment.

268 We have PC's. However, every time we order software the request is canned.

268 Junk it.

268 A computer terminal with printer and EGA monitor, access to a good program library.

268 Have a steady supply of ribbons and paper. You can't depend on self-service supply.

268 Update computer.

268 Get more equipment.

268 Desks - not work stations.

268 More VDT/automation capability.

268 Upgrade furniture-expected in next week. 
Bigger desk, lamp.

Update with new state of the art user friendly equipment.

Get modern "state of the art" equip. or at least something from this decade

Get some.

Need much more space.

268

268

268

More desk space and files.

Add ADP equipment.

Get files.

Bring in up to date equipment that performs technical and managerial duties of job.

268

268

268

New desks and lamps, more file space.

Need personal PC and printer at each persons desk.

Improve and develop procedures for obtaining equipment/materials required to perform the job.

293

293

293

Need forklift.

Need forklift.

Buy a forklift.

We need our own fork lift \& better air \& power tools and better safety equipment to use with them.

293 Buy a forklift.

298 Better computer.

298

298

298

Go back to speedy IBM terminal.

Change software, update software and hardware, more phones.

More CRT's available. Better computer tables. Better quality copiers and microfiche machines.

298

298

298

298

298

298

298

Office automation to speed document preparation.

Better/faster computers.

Additional phone lines.

Add L-unit to desk for more work space, have own VDT with work space, more phone extensions and autovon lines.

Improve computer terminals.

Correct workstation for VDT.

Upgrade system -- all terminals need to be linked to one mainframe.

\section{Changes to Equipment Jan 89}

268 New equipment.

268 New equipment, more equipment.

268 Workable printer.

268 Microfiche reader that works.

268 Add PC, filing space.

268 Correct software.

268 Improve repair service.

268 Software for computers.

268 More space-storage, equipment, etc.

268 More software for ADP equipment.

268 Better phone system.

268 More efficient equipment.

268 Upgrade, modernize.

268 Safety equipment, upgrade.

268 Better ADP equipment. 
Replace Intel PC.

268 Desk.

268 Better supply, tools, equipment, hood.

268 Move phone, have computer.

268 Space for PC \& printer, etc.

268 More work equipment.

268 More computers, printers.

268 Larger space near computer area.

268 Own PC at desk, reliable copier.

268 Trade terminal for PC.

268 Different, better equipment.

268 Add drawer onto desk.

268 Update equipment.

268 Need internal communication.

268 Adjustable equipment.

268 Better access to parts.

268 Upgrade equipment.

268 Newer equipment.

268 Better access to PC.

268 Better equipment.

268 Better computer/software.

268 More PC's, work area larger.

268 Faster computer.

268 Better work equipment.

268 Better PC's or computers for all.

268 Get printers or remove VDT.

268 Climate control/air quality, window, privacy.

268 Better telephone service.

268 More PC's.

268 New furniture.

268 Up-grade test equipment.

268 Modern furniture horrible.

268 More files.

Suggested Changes to Work Space - First Survey

\section{Bldg Work Station Change}

235 Repaint, more privacy for employees

235 Variable lighting, more work space, more storage space

235 Paint walls and area.

235 I could spend my time doing my job rather than filling out paper work like this.

235 Build another building with more space.

235 Put in carpet, new chairs, light recess, file cabinets, central air-conditioning.

235 Move to an office area.

235 Get more space.

235 Modernize.

235 Painting of office.

235 I would make more space available for myself

235 Increase size and privacy.

260 Bigger desk and extra tables. 
A little more work area. More comfortable.

If I could make any changes I would have more lighting at my desk. Have more storage space (filing cabinets, etc.)

Check out air coming in through old ducts and check air return to see if hooked up and working.

260 Create a bit of privacy for everyone.

260 More private space, reduce lighting glare, more privacy between employees, reduce noise.

260 Remove partitions that cause cubicle style and make more room for desk and table area.

260 Add lighting, fixed and adjustable.

260 Have a window and fresh air.

260 More work space.

260 More space for working or better arrangement.

260 Take partitions down and give us a little more work space and put in some real walls for privacy.

260 Need more space and privacy.

260 Confine it too a more private area where I could work by myself in peace and quiet. Additional work space would be nice.

260 I'd like to see some of the bays opened.

260 Spread out to create more room between workers. Replace hardrock radio station with low volume easy listening station. Institute a campaign for quietness and professionalism.

260 Enlarge.

260 Change the wall colors and change the overhead lighting.

260

260 More work surface - better light.

260

Tables to review drawings and work space for material using terminal. Put in windows/improve AC/heat ducts, new work station designed around PC's; not just provide more privacy.

260 Call a contractor.

260 Work stations help to organize work area and make office have a greater appearance of professionalism.

260 More room, more up to date office furniture and modern surroundings.

260 Get more.

260 Better lighting, more privacy, more room and would be nice to have window.

260 Add windows.

260 Move to area that has access to a window for sunshine and fresh air

260 Bigger table for video display terminal and better lighting system, one with no glare.

260 Tear it down and then rebuild it with windows - install a modern heating and air conditioning system; have cubicles instead of open bays; have secretary/receptionist for screening visitors and calls.

260 Add more.

260 More lighting and better air quality.

260 Better supplies and furniture.

260 Better lighting.

260 Add more shelves. 
Better positioning on VDT with space for printouts and other documents.

268 Task/Modular Furniture would help. A new building for maintenance Dir. only would be better.

268 Improve lighting, air temperature and circulation, provide more space.

268 Paint, carpet, plants.

268 Have more comfortable workspace so I don't have to move far from my desk to my PC.

268 Change lighting, air quality, make furniture arrangement easier/ more efficient to use.

268 Put in a skylight or windows.

268 Knock hole in the wall and put in a window.

268 Better air and quieter.

268 Add a privacy screen, arrange furniture so everything would be more accessible; have more storage space.

268 Have things better arranged, controlled lighting.

268 See question 18. Also, give adequate space to workers.

268 More surface area.

268 Replace furniture, improve lighting.

268 Privacy.

268 Privacy

268 Install one-way windows, air conditioning and cover music.

268 AC

268 A window.

268 Add a door for privacy.

268 Better lighting and more privacy for concentrating.

268 Increase lighting and install sound insulation and make the area non-smoking.

268 Make it in another state.

268 Make it $100 \%$ no smoking. Block off my area.

268 New chairs, paint, enclose celling.

268 Nothing really can be done.

268 Stop the smokers and music.

268 Locate my desk in a quieter place.

268 Air, circulation and cleanliness - lighting - desk type.

268 Better lighting, more bench/drawer space, put up a partition between the benches.

268 Put in windows and improve air circulation.

268 Partition for privacy and utilize work station with built-in work surface lighting.

268 Put functions that work together in same office.

268 More room for cabinets and reference materials. 
Scrap it and re-do.

268 More space, more storage area, more classroom space.

268 Have more storage area.

268 Move my position station.

268 More work space - table tops; more book cases; areas to hang personal items.

268 Doesn't matter; We asked for what we needed and we're getting something unusable.

268 More room, privacy, and better/adjustable lighting.

368 Install picture window.

268 Better lighting and better telephone service.

Cooler and less humid, more privacy, better lighting, and more room. Have a better work station.

Install modular furniture.

Better furniture, more privacy - windows.

Move it beside a wall, away from the door--less disturbing.

I would not change furniture from desks to work stations.

More privacy.

Add computer terminal.

Need more work area for area, modular/system furniture, lighting/sound design, air quality.

Put paper in the trash.

More comfortable chairs, more table space \& better lighting.

Enlarge it.

Increase work space.

Move terminal tables closer to task stations.

Burn it.

Torch it.

Move people to a larger work area.

Need more work space.

More area space.

Need larger space with privacy.

More room.

Have rack for storage of reqs, drawings, and provisioning parts lists, table for spread out of drawings, etc. A little more elbow room.

Buy myself more files to clear off desk top.

Open 323 and 322 into one computer area.

New furniture.

Get a bigger room with adjustable temperature.

Better, fresher air. Not so crowded.

Increase.

The changes indicated in question 18 .

Expand office and work area to allow for more space.

Make workspace private and roomier.

Make each work station independent in itself.

Move

More space.

Leave

Enlarge.

Extend space for getting into filing cabinets.

Spread out,

298 Change layout in certain areas so that coworkers' chairs are not always 
in the aisle.

More filing cabinets.

298 Ventilate smokers area to outside; clean ducts; provide better chairs; provide more work space per person.

298 Enlarge and enclose.

298 More storage place for supplies; correct work station for VDT.

298 Furniture is functional, but ugly -- and very old. Needs to be upgraded.

Changes to Work Station Jan 89

268 More work area.

268 Enlarge working/surface area two-fold.

268 More room, privacy.

268 Reorganize!

268 Drawer space.

268 Enlarge, more flexible.

268 Bigger area.

268 Larger space for equipment.

268 More private, quiet.

268 More space.

268 Expand areas.

268 Better ventilation in shop.

268 No partitions.

268 More storage.

268 A DESK!

268 More work area.

268 Better sandblasting room.

268 Larger.

268 More room per employee.

268 Integrate computers with other offices.

268 Better chair, more lighting.

268 Larger work surfaces.

268 Move people.

268 More storage, improve lighting.

268 Larger working/desk area.

268 Larger surface, file space, quieter.

268 Bigger space, rearrange space.

268 Lighting, more space.

268 More privacy - a door.

268 Better phone service.

268 Widen desk.

268 Better lighting, color, privacy.

268 More bench space, light.

268 Less noise.

268 Rearrange workstations.

268 Adjustable bench chairs.

268 Windows, A/C \& heat.

268 One person per office.

268 Enlarge.

268 Leave building altogether.

268 Larger, more storage, space for printer.

268 Larger/more organized work station. 
Move printer.

268 Individual/adjustable lighting.

Larger, more privacy.

268 Enlarge.

268 Better lighting, more privacy.

268 More work area, better lighting.

268 Room for printer, light over desk.

268 L or U shaped desk, wider too.

268 Larger, better lit.

268 More work/storage area.

268 Larger/more private area.

268 Bigger office, heat.

268 Light.

268 More room.

268 Better air quality, room.

BLDG

General Comments First Survey

235

235

235

235

235

235

235

235

235

235

235

235

260

260

260

260

260

260

260

260

260

260

260

260

260

260

260

260

260

See question 18 and install windows.

Better air circulation - better color tones on walls and ceilings.

None - everything is perfect and conducive to getting the job done!

More moderate equipment, painting, redecorating.

Better lighting and temperature control.

Completely remodel building, or build a new one.

An office for individual work area.

More forklifts.

Update office equipment.

Build new building.

New roof, improved lighting, new emergency exit doors, better HVAC. Move it closer to building 268 .

Put some windows in improve the lighting. Put some walls around the desk and have a shuttle to work.

View out of a window, more work area and a better phone, my phone doesn't work well.

In own office will be best work.

Tear it down and rebuild a new one.

More storage space, windows and better ventilation.

More space and better or cleaner air.

There is not much that can be done based on the type of building and mission.

Air handling equipment refurbishment; include ability to bring in

fresh air; more functional office furnishings and space; desks,

shelves, partitions, tables, phones and PC's.

Privacy/quiet.

Put in windows.

Need windows in building.

Increase lighting, update phone lines.

Less crowding.

Improve air.

Dismantle and start anew.

More privacy; there is no privacy.

I'd like to move out of this building to one with windows and one with 
good air quality and ventilation.

260 Tear it down and start over again.

260 Install windows and insure excellent air quality. Temperature generally good.

260 Have an office setting.

260 Lights, different color schemes and artificial view to outside

260 Add on to make more storage, office space; add filing cabinets; add windows on outside walls.

260 Smoke eaters, one at or over my cube. Would like to be able to hear the music or be allowed to use my own radio; Main hallway is slippery when wet (rain or snow).

260 Call in contractor.

260 Improve all of the problems throughout this questionnaire.

260 More space per person, printer covers, better and more equipment/office supplies; better phone system; more phones, more phone lines.

260 Some other color in the offices.

260 Better air, better lighting, windows, better arrangements of furniture and let people have a voice in it.

260 Install windows, and improve air quality and lighting.

260 Bulldoze it and start over with a modern set of blueprints and multimillion dollar cost plus contract; we deserve it, the economy needs it and the taxpayers are stuck with it.

260 Replace it!

260 Add windows, closer parking.

260 Better ventilation and air quality. Improve lighting and appearance. Windows would be nice, but impossible.

260 Lighting, even temperatures.

260 Larger bathroom door.

260 Improve air quality.

260 Better air quality; more circulation, and windows to let a little sun in

260 Need storage area to store ADP paper and other equipment.

268 Stop the micro-management and management indifference to workers/ families when it comes to their resultant impact(s) from decisions or changes to/for mission performance; cut out cosmetic moral boosting for these/similar things; fix building.

268 Better lighting - break area - more eating places closer.

268 Better lighting, improve air circulation, and temp. control.

268 Windows in building; break area.

268 Fix air quality, air conditioning, heating, make adjustable lighting.

268 Put in windows, improve circulation of fresh air, replace heater/AC

268 Improved air temp, break areas.

268 Windows for fresh air, improve lighting, a better heating/cooling system

268 Install new work stations.

268 Get better means of keeping the AC working and a light directly over desk.

268 More storage space.

268 Privacy.

268 Lights, air quality.

268 Office area rearranged for quietness/privacy.

268 Complete renovation of the air and circulating systems.

268 Put all divisions in one building. 
Improve $A C$ and circulation.

268 Increase floor space for shop, improve heating and $A C$.

268 Window space.

268 Improve machine shop location and cooler break area.

268 Fix light \& air.

268 Better working conditions overall.

268 Better lighting, newer test equipment, better air circulation.

268 Less noise/no smoking in shop area.

268 Up grade the electric power and air conditioning

268 A better ventilation system.

268 Cut out the smoke and noise.

268 Get power capabilities and courses up to meet requirements. Fix air handling system. Give me direct access to my area of control - room 319; Fix the phone system.

268 Lighting, stable electrical. system, better workspace.

268 Provide better work station lighting at each work surface.

268 Increase size.

268 Improve air circ., better lighting, more individual room.

268 Tear it down and start it over.

268 More storage and work area.

268 Renovation of air system and insulation, install one large A/C unit.

268 Install a break area, improve air circulation.

268 Add classrooms. More heating/air conditioning, ventilation. Add another building.

268 Outside views, better heating/air conditioning, improved lighting, privacy.

268 Better temperature control, better lighting.

268 Better climate control and the air circulation, better lighting.

268 Bring more people on board - - too much work, not enough people.

268 The building needs a break room, so we don't have to eat at our desks.

268 Better temperature/atmospheric control.

268 Make all areas accessible without going all the way around the building.

268 More people.

268 It's not so much the building as it is the people, and budget restraints.

268 New building.

268 Better electrical system, a V.P.S. uninterruptable power supply for all computers and systems.

268 Provide good training to management.

268 Remodel.

268 Move us out.

268

268

268

268

268

268

268

268

268

268

Get more people on board, larger work area, better working conditions. Need break area, conference area, more space.

Allocate space in building according to function.

Room too small for the number of people assigned.

More room with more privacy to be able to concentrate more.

Partition office area from equipment area to confine noise.

More space, individual climate control.

Heating/cooling need fixing, additional space for work, smoking area. Enforce smoking prohibition.

268 Organize functions to eliminate time spent going to another building. 
Enlarge/ increase space.

Improve air movement/temp/quality.

Insulate roof \& walls/better lighting/better $\mathrm{A} / \mathrm{C}$, heat.

Get forklift for our use.

It should be more organized \& not considered a storage area for the rest of the post.

More room for storage or less equipment to store. Clean or install air circulation system.

Get a new air system.

More telephone lines.

Everything is wonderful except as stated. (only minor things) More automation/computer assistance.

Smoke at work stations -- separate smokers from non-smokers. Better temperature control, more confined smoking area.

Get rid of smoke from smokers.

Additional phone lines.

Enlarge it.

\section{General Comments - Jan 89}

268 Privacy, carpet, less noise.

268 More space.

268 Add break rooms, add "healthy food" vending machines; enlarge, add-on space.

268 New break area, more work area.

268 Better laid-out work spaces; put microfiche, safe, files in same building.

268 Window, four walls for sound proofing.

268 Move electronic maintenance shop to separate building (fumes from shop often get into air vents.

268 Better air quality, windows, less fumes/smells.

268 Paint, new carpet.

268 Air quality.

268 Lights, air.

268 Better cooling and heating.

268 Clean air ducts, allow windows where practical.

268 Better air circulation, storage space.

268 Privacy, quiet, better phones.

268 Windows.

268 Relocate people who complain about shop smells.

268 Secondary ventilation, larger side entrance to paint spray booth area.

268 A/C, suspended ceilings, better lighting system.

268 Modular buildings.

268 Improve/replace heating \& cooling, fix telephone system.

268 Improve heating/cooling, more space.

268 Different \& consistent color scheme.

268 Ventilation, windows, space.

Improve lighting and air control system. Move people.

Better air circulation/temperature control/lights in work area; break area with outside windows,

Move light fixtures; paint halls; install bulletin boards.

268 Change workstation layout, hallway paint job, fresh air circulation. 
More space/privacy, better lighting/temperature/air control.

Better heating and cooling system.

268 Better air quality/break areas too.

268 Better chair.

268 Less noise, better heating/cooling.

268 Better heating system, add cafeteria to building.

268 Temperature control, better ventilation.

268 Give repair facility its own building.

268 Improve air quality and circulation.

268 Break area; yellow lights instead of "white"; more space; better air circulation.

268 Replace management because they do not care.

268 Break area.

268 Improved air quality and flow with accompanying climate control; windows.

268 Improve air quality and circulation.

268 Lock it up and throw away the key.

268 Temperature control, better phone system, more phone.

268 Break area, cafeteria, smoking areas, better music/chairs, more concerned upper management.

268 Outside view.

268 Suggestions don't count.

268 Lighting, newer \& better equipment.

268 Build - more room needed.

268 Break area. 
NBS-114A (REV. 2.8C)

\begin{tabular}{|c|c|c|c|}
\hline $\begin{array}{l}\text { U.S. DEPT. OF COMM. } \\
\text { BIBLIOGRAPHIC DATA } \\
\text { SHEET (See instructions) }\end{array}$ & $\begin{array}{l}\text { 1. PUBLICATION OR } \\
\text { REPORT NO. } \\
\text { NISTIR 89-4175 }\end{array}$ & 2. Performing Organ. Repore No. & $\begin{array}{l}\text { 3. Publication Date } \\
\text { SEPTEMBER } 1989\end{array}$ \\
\hline
\end{tabular}

Post-Occupancy Evaluation of Several U.S. Government Buildings

5. AUTHOR(S)

Belinda L. Collins, Gary L. Gillette, Mubarak S. Dahir, Peter S. Goodin

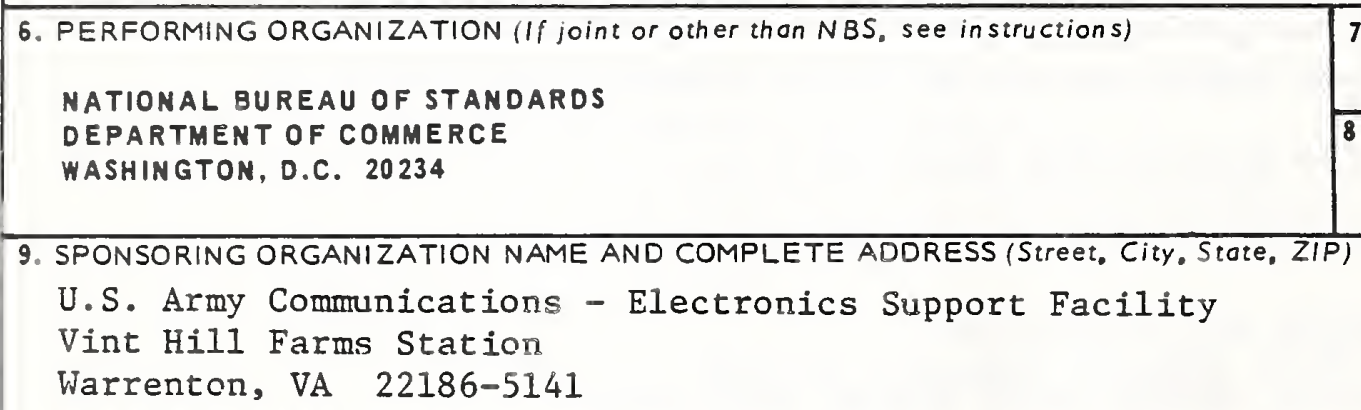

A post-occupancy evaluation was performed on five small, low-rise U.S. government buildings at a site south of Washington, D.C. The purpose of the study was to evaluate environmental conditions including lighting, space, noise, and indoor air quality, and provide recommendations for change. In addition, a comparison was made of environmental conditions before and after renovation of one of the buildings. The study employed a questionnaire about the environmental conditions, physical measures of the space (1ighting, space, noise, temperature, etc.) and interviews with personnel at the site. A total of 308 people participated (including measures before and after the renovation) and physical measures were taken at 92 work stations. Analysis of the physical measurement data indicated problems with limited space, lack of adjustable task lighting, and perceptions of poor indoor air quality in two of the buildings. The renovation was perceived to have improved the appearance of one building substantially, however. Suggestions for improvements to the buildings at the site were also made.

12. KEY WOROS (Six to iwelve entries: alphabetical order: copitalize only proper names; and seporate key words by semicolons) automation; contrast, environmental assessment; indoor air quality; lighting; luminance; noise; post-occupancy evaluation; temperature; VDT's

13. AVAILABILITY

X Unlimited

- For Official Distribution. Do Not Release to NTIS

- Order From Suderintendent of Documents, U.S. Government Printing Office, Washington. D.C. 20402.

X- Order From National Technical information Service (NTIS), Springfield, VA. 22161

14. NO. OF PRINTED PAGES 158 15. Price A08 




(6) 
